\title{
Distributed Network in Concave Operating Environment
}

\author{
Kam Mun Loong (Corresponding author) \\ Cooperative System Lab, Dept. of Mechanical Engineering, National University of Singapore \\ 21 Lower Kent Ridge Road, Singapore 119077 \\ Tel: 65-6874-002-4615 E-mail: g0500314@nus.edu.sg \\ Gerard Leng \\ Cooperative System Lab, Dept. of Mechanical Engineering, National University of Singapore \\ 21 Lower Kent Ridge Road, Singapore 119077 \\ Tel: 65-6516-6548Ｅ-mail: mpelsb@nus.edu.sg
}

This work was supported in part by the Temasek Defense Science Institute under grant TDSI/03-001/1A.

\begin{abstract}
The connectivity of distributed network within buildings depends critically on the shape of the operating environment. We propose the mean blockage as a new measure for concave shapes. The formal definition and an analytical evaluation of this measure will be shown. An algorithm has been developed to facilitate the evaluation of this measure for complicated concave polygons. The inadequacies of a couple of existing shape measures will be discussed and contrasted with the mean blockage measure for a variety of concave polygons. A possible general relationship between the blockage measure and the number of distributed sensors required to maintain high connectivity probability in concave regions will be presented.
\end{abstract}

Keywords: Distributed networks, Blockage, Concave polygons, Concavity measure, Connectivity

\section{Introduction}

Distributed network [7] is concerned with deploying multiple sensors to operate and gather information in an unknown, cluttered and possibly hazardous environment to achieve a common goal. One of the key decisions to be made in implementing a distributed network for a particular application is deciding on the optimal number of sensors that should be deployed. Besides being an important issue to the sensor network research community, it is also central to the research of cooperative systems. For cooperative systems, teams of multiple robots (which can be treated as sensors) are deployed to complete a certain task. Researchers have proposed different solutions to the problem of determining the optimal number of nodes by considering different constraints. In [11], Mei et al looked at this problem from the perspectives of energy constraints, i.e. they examined the relationships between the optimal number of nodes required to serve random requests under energy constraints. Hayes [1] defined a cost function which relates the number of robots (sensors), time taken to complete the search task and the moving speed of each robot. After that, he optimized the number of robots required for a search task by determining the minimum point of the cost function.

We argue that for distributed networks, the number of nodes required for a particular application should be optimized by ensuring the network is formed with high connectivity probability within the operating environment, thus allowing the exchange of information among individual sensors of the network. The rationale is that the network can maximize the utilization of the information gathered by every node through information sharing. This optimization problem is central to the ad-hoc networks [3] research community. In the ad-hoc network connectivity problem domain, the interest is in finding out how easily connections can be established among the individual nodes of an ad-hoc network. On the other hand, for our problem, the array of sensor nodes with Random Direction model mobility [9], can be treated as an ad-hoc network operating within a given operating environment and we are interested in the optimal number of nodes required to maintain high connectivity probability.

While the potential applications of distributed sensor networks are vast, we are interested in small scale distributed networks which are deployed inside buildings to carry out surveillance or search. The sparse deployment of sensor 
network in constrained area is one of the applications of distributed sensor network, as noted in [5]. Operating inside buildings poses another challenge for distributed networks: the concave boundary. A distributed sensor networks will find it harder to maintain connectivity operating inside concave boundaries than convex ones, as shown in Figure 1.1.

Figure 1.1 demonstrates the definition of connectivity. Two randomly moving sensors are connected if and only if the distance between them, $D$, is smaller than their communication range (transmitting/receiving range), $R$. For simplicity, we shall assume that the communication range of each sensor is the same and the communication can only be established if the two sensors are within line-of-sight (LOS) of each other and that communication in a multi-hop manner (pass information to one or more intermediate sensors and have the information routed to the target) is assumed to be possible. This assumption will hold reasonably well for operation within an enclosed area (e.g. a housing unit of typical size $10 \mathrm{~m}$ by $10 \mathrm{~m}$ ) and the technology which can support these types of communication will be the commercially available IEEE 802.11b wireless network and Bluetooth. The LOS of a sensor is the unobstructed view which the sensor can see/detect. A fully connected network is one in which there exists at least a path between any two sensors such that they can communicate to each other. The connectivity probability is the probability that the array of sensors can form a fully connected network given that each sensor is at a different position at any given time.

It is apparent that determining the optimal number of sensors to be deployed for a given search task is similar to the connectivity problem of an ad-hoc network. The connectivity probability of an ad-hoc network subjected to environment and sensory constraints is an active research field. Each node of the network is moving randomly inside an area and can either have a fixed transmitting range (connectivity probability is a function of distances between nodes) or that the connection between two nodes is fixed (determined by a probability function). The main research interest in the ad-hoc network domain is the conditions which ensure high network connectivity probability [2, 4, 8]. Bettstetter and Zangl [2] included the border effects in their study on ad-hoc networks inside a circular area. Ferrari and Tonguz [4] approached the connectivity problem from the viewpoint of the minimum number of neighbors required for each node. In [8], Santi studied the critical transmitting range for each node in an ad-hoc network under certain node mobility models. Despite the different approaches, the ad-hoc networks discussed in the literatures are concerned with convex areas (circle or rectangle) and the results are not directly applicable to our problem. Contrary to the focus on convex areas, for connectivity of distributed ad-hoc sensor networks within buildings, we are interested in concave regions.

In this paper, we will define a new measure of the concavity of a shape - the blockage. We argue that this new measure is a more natural choice in the study of connectivity probability for a distributed sensor network operating in a concave region (polygon). We will show how to evaluate the blockage analytically for a simple concave shape. Then, an algorithm will be provided to facilitate the computation of the blockage of a concave polygon. Results relating the blockage values and number of sensors required for high connectivity probability for various concave polygons will be shown. Comparisons with other shape measures will also be made to show the relationship of blockage measure with the connectivity probability of sensors inside concave areas.

\section{Blockage - a new measure of concavity}

Currently, there are many different shape measures studied in the literature [6]. However, for the connectivity problem inside a concave region, there is a more natural measure of concavity which has an intuitive physical meaning. Consider a mission in which sensors are deployed to search for a target inside a convex area. If the communication range $R$ is larger than the maximum chord joining any two points of the boundary, the distributed sensor network will be connected at all time, i.e. connectivity probability is equal to 1 . Thus, any number of sensors in the convex area will be able to maintain a fully connected network. On the other hand, if the same number of sensors are required to maintain connectivity in a concave area with exactly the same maximum chord length, the connectivity probability will be less than 1 (see Figure 2.1).

The effect of the concave corner is shown in Figure 2.1b. Node A and B cannot establish connection because their line of sights are blocked by the concave corner. By now, one can see that the problem of connecting multiple randomly moving sensors in a concave area is essentially related to how large an area each sensor can cover within its line of sight (LOS). This close relation between the connectivity probability and the field of view of the points within a particular operational area is the main motivation for the new measure defined presently.

Consider a two dimensional operational space $\mathrm{A}$ (of total area $A_{T}$ ). Suppose a sensor is located at $\left(\mathrm{x}_{\mathrm{o}}, \mathrm{y}_{\mathrm{o}}\right)$ and is within A. The field of view for the sensor is:

$$
L\left(x_{o}, y_{o}\right)=\frac{\text { the area within the line of sight of the node at }\left(x_{o}, y_{o}\right)}{\text { total area }}
$$

The blockage is simply: 


$$
\begin{aligned}
B\left(x_{o}, y_{o}\right) & =\frac{\text { the area unobserved by the node at }\left(x_{o}, y_{o}\right)}{\text { total area }} \\
& =1-L\left(x_{o}, y_{o}\right)
\end{aligned}
$$

The mean blockage is defined as "the mean of the blockage values for every location of the sensor inside the concave shape", normalized by the total area enclosed by the boundary, $A_{T}$.

$$
\begin{aligned}
\text { Mean Blockage, } \bar{B}=\frac{\int_{x \in A} \int_{y \in A} B(x, y) d x d y}{A_{T}} \\
=1-\frac{\int_{x \in A} \int L(x, y) d x d y}{A_{T}} \\
\text { Variance of Blockage, } \operatorname{Var}(B)=\frac{\int_{x \in A} \int_{y \in A}[B(x, y)-\bar{B}]^{2} d x d y}{A_{T}}
\end{aligned}
$$

(Eq.2.3)

\section{Analytical calculation of blockage for a simple concave shape}

Before we discuss the algorithm to compute the mean blockage value of an arbitrary polygon, we shall calculate the mean blockage values for a simple concave shape, namely "L-shape", analytically (see Figure 3.1a). To evaluate the mean blockage of the L-shape boundary as shown in Figure 3.1, we first notice that the line connecting the concave corner and the vertex joining two sides of length 2 is the line of symmetry of this shape. Due to this symmetry, we need only to evaluate blockage for half the area.

In Figure 3.1b, we further divide the lower half of the L-shape into three sub-regions, namely a, b and c. a', b' and c' are the mirror images of $\mathbf{a}, \mathbf{b}$ and $\mathbf{c}$ respectively. We will need to evaluate blockage for points in $\mathbf{a}, \mathbf{b}$ and $\mathbf{c}$ only. We start by evaluating blockage for points inside sub-region a and $\mathbf{b}$. As depicted in Figure 3.2, we use polar coordinate system with the origin $(O)$ at the concave corner. The axes of the polar coordinates $(\theta=0)$, which are used for evaluating the blockage for region a and $b$, are assigned to be 90 degrees apart. For a point $(r, \theta)$ within region $\mathbf{a}$ and $\mathbf{b}$, the area that this point can not see will be equal to:

$$
\begin{aligned}
& A_{a}(r, \theta)=\text { area of }\left(O Q_{1} V_{3} V_{4}\right) \\
& =1-\frac{1}{2} L \square \llbracket \sin \theta \\
& \text { and } \\
& =1-\frac{1}{2} \tan \theta, \text { since } L=\frac{1}{\cos \theta} \\
& A_{b}(r, \theta)=\text { area of }\left(O Q_{1} V_{3}\right) \\
& =\frac{1}{2} L \square \square \sin \theta \\
& =\frac{1}{2} \tan \theta, \text { since } L=\frac{1}{\cos \theta}
\end{aligned}
$$

The sums of blockage values of all the points within region $\mathbf{a}$ and $\mathbf{b}$ are:

$$
\begin{aligned}
B_{a} & =\frac{1}{A_{T}} \int_{0}^{\frac{\pi}{4}} \int_{0}^{\frac{1}{\cos \theta}} A_{a}(r, \theta) r d r d \theta \\
& =\frac{1}{3} \int_{0}^{\frac{\pi}{4}} \frac{1}{\cos \theta}\left(1-\frac{1}{2} \tan \theta\right) r d r d \theta \\
& =\frac{1}{8}
\end{aligned}
$$

and

$$
\begin{aligned}
B_{b} & =\frac{1}{A_{T}} \int_{0}^{\frac{\pi}{4}} \int_{0}^{\frac{1}{\cos \theta}} A_{b}(r, \theta) r d r d \theta \\
& =\frac{1}{3} \int_{0}^{\frac{\pi}{4}} \int_{0}^{\frac{1}{\cos \theta}}\left(\frac{1}{2} \tan \theta\right) r d r d \theta \\
& =\frac{1}{24}
\end{aligned}
$$

For points in region c, the whole area is within their field of view, thus, the blockage values for these points are 0 , i.e. $B_{c}=0$. The mean blockage values of L-shape can now be evaluated:

$$
\bar{B}=\frac{\text { Total blocked area }}{(\text { Total area })^{2}}=\frac{\left(\frac{1}{8}+\frac{1}{24}\right) \times 2}{3}=\frac{1}{9}
$$

\section{Algorithms to compute blockage for a point inside a concave polygon}

As seen from the definition of the blockage term, we need to determine the area which is within (or not within) the LOS of all the points inside the operational area. This is highly complicated, if not impossible, to be computed analytically. An algorithm to compute the blockage measure for a point inside a concave polygon is described in this section (see Algorithm 4.1 for pseudo-code). The mean blockage measure can be computed by applying this algorithm (Algorithm 4.1) to $k$ (depending on the resolution) points covering the concave area. The inputs to the algorithm are the vertices of the concave polygon and the point $P$ for which the blockage measure is to be computed. Without loss of generality, 
we assume the vertices of the boundary are given in the "correct sequence" and in the "anti-clockwise direction". This means that given a list of $n$ vertices, $V=\left\{V_{1}, V_{2} \ldots, V_{n}\right\}=\left\{\left(x_{1}, y_{1}\right), \ldots,\left(x_{i}, y_{i}\right), \ldots,\left(x_{n}, y_{n}\right)\right\}$, one can redraw the concave polygons simply by connecting the consecutive vertices together, i.e. connecting $V_{i}$ and $V_{i+1}$ for all $1 \leq i \leq n$. The "anti-clockwise direction" way of listing the vertices means that when the vertices are connected in sequence to form the edges of the polygon, the area of interest is always on the left of the edges. Equivalently, it means that the cross-product of the vectors $\vec{E}_{i}$ (a vector connecting vertex $(\mathrm{i}+1)$ from vertex $\mathrm{i}, E_{i}=\overline{V_{i} V_{i+1}}$ ) and $\overline{E_{i+1}}$ will be positive if $V_{i+1}$ is a convex corner.

Input: Vertices of Polygon, $V$, Coordinates of a point, $P=(\mathrm{x}, \mathrm{y})$.

Output: Blockage of $(\mathrm{x}, \mathrm{y})$ in the polygon, $B(\mathrm{x}, \mathrm{y})$.

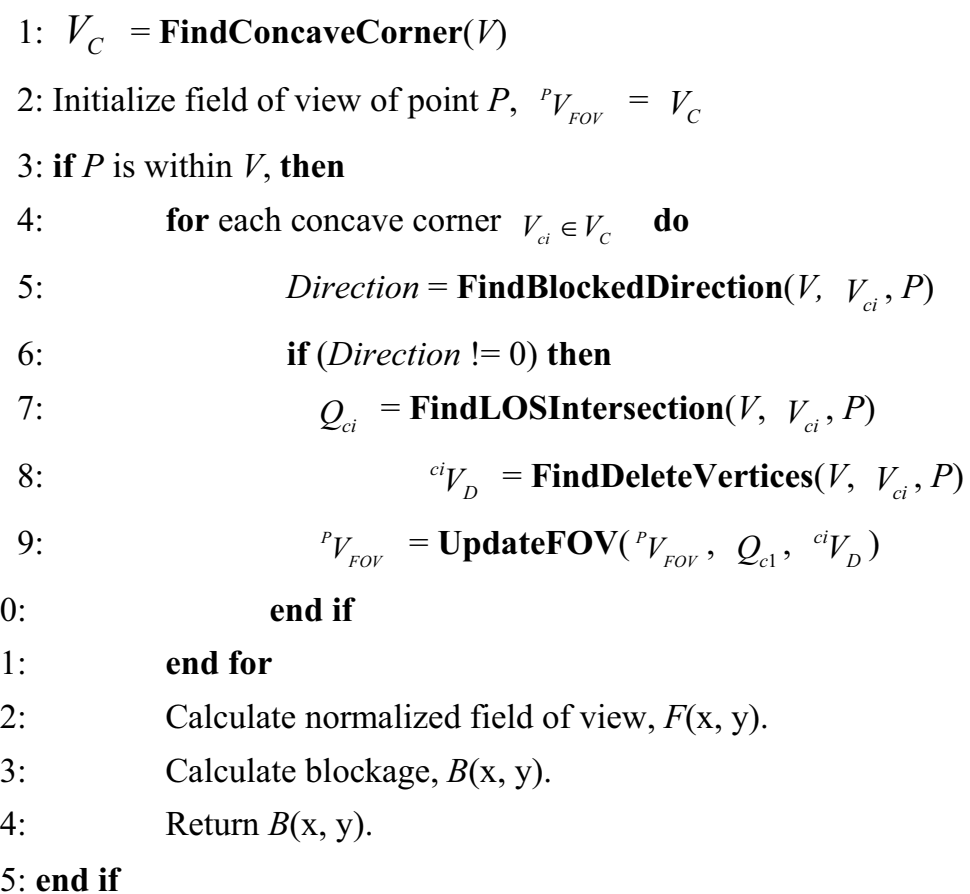

Algorithm 4.1 Overview of algorithm to compute blockage of a point.

The algorithm starts by determining which of the vertices are "concave" (Algorithm 4.2). A concave vertex is one with an internal angle greater than $180^{\circ}$. As mentioned above, this can be done by checking the sign of the cross product of $\overline{E_{i-1}} \times \bar{E}_{i}$. This step is essential because the LOS of any point within a concave polygon will only be blocked by edges connecting to concave vertices. After this step, the set of $m$ concave vertices $V_{C}=\left\{V_{c 1}, V_{c 2} \ldots, V_{c m}\right\}$ will have been determined (see Figure 4.1a).

Input: Vertices of Polygon, $V$.

Output: Vertices of all concave corners, $V_{C}$, and number of concave corners, $m$.

1: Initialize $\mathrm{m}=0, V_{C}=\varnothing, \mathrm{n}=$ number of vertices

2: for $1 \leq \mathrm{i} \leq$ n do

3: $\quad$ Find the vector of linking vertices $V_{i-1}$ and $V_{i}\left(\overline{E_{i-1}}\right)$.

4: $\quad$ Find the vector of linking vertices $V_{i}$ and $V_{i+1}\left(\bar{E}_{i}\right)$.

5: if cross product of $\overline{E_{i-1}} \times \overline{E_{i}}>0$ then

6: $\quad V_{C}=V_{C} \cup\left\{V_{i}\right\}, \mathrm{m}=\mathrm{m}+1$

7: $\quad$ end if

8: end for

9: Return $V_{C}$ and $m$.

Algorithm 4.2 FindConcaveCorner $(V)$.

Input: Vertices of Polygon, $V$, a concave vertex, $V_{c i}$, and a point $P$. 
Output: Direction of blocking of $V_{c i}$ on point $P$.

1: if $V_{c i}$ is within LOS then

2: if $V_{c i-1}$ and $V_{c i-1}$ are visible to point $\mathrm{P}$ then

3: return not blocking

4: $\quad$ else if $V_{c i-1}$ is not visible to point $\mathrm{P}$ then

5: return clockwise_blocking

6: $\quad$ else

7: $\quad$ return anti-clockwise_blocking

8: $\quad$ end if

9: else return not_blocking

Algorithm 4.3 FindBlockedDirection $\left(V, V_{c i}, P\right)$.

The second step of the algorithm (Algorithm 4.3) determines which of the edges of those concave vertices determined in step one are blocking the LOS of point $P$. Depending on the position of $P$ relative to each concave vertex, say $V_{c 1}$, the concave vertex can either 1) have no blocking effect 2) block certain area from the LOS of $\mathrm{P}$ with the edge linking $V_{c 1-1}$ and $V_{c 1}$ 3) block certain area with edge connecting $V_{c 1}$ and $V_{c 1+1}$. If the concave vertex $V_{c 1}$ is within the LOS of $P$, the algorithm will determine which type of blocking effect $V_{c 1}$ has on $P$. The algorithm will also then check which of the vertices, $V_{c 1-1}$ or $V_{c 1+1}$, is not within LOS of point $P$. If both $V_{c 1-1}$ and $V_{c 1+1}$ are within LOS of $P$, then the concave vertex does not have blocking effect on $P$ (case 1). If $V_{c 1+1}$ is not visible to $P$, then it can be concluded that edge $V_{c 1-1} V_{c 1}$ is blocking the view of $P$ (case 2). Vice versa, if $V_{c 1-1}$ is not visible, it can be concluded that $V_{c 1} V_{c 1+1}$ is blocking the view of $P$ (case 3). To facilitate our discussion, we shall refer to case 2 as "anti-clockwise" blocking and case 3 as "clockwise" blocking (see Figure 4.1b). On the other hand, if $V_{c 1}$ is not within LOS of $P$, we conclude that there is no blocking effect due to $V_{c 1}$.

The next step is to determine which of the vertices from $V$ need to be deleted as a result of the blockings by all the concave vertices $V_{C}$. In order to achieve this, connect $P$ and $V_{c 1}$ to form a straight line $P V_{c 1}$. Extend this line in the direction of $\overrightarrow{P V_{c 1}}$ to a large enough extent, say to point $T$, such that the length of $P T$ is larger than the maximum chord length of the concave polygon. Next, we find the intersection point(s) of $P T$ with the edges of the boundary $\left(V_{1} V_{2}, V_{2} V_{3}, \ldots, V_{n} V_{1}\right)$. Depending on the concave polygon, there can be many intersections. If this is the case, take the intersection point, say $Q_{c 1}$, which is farthest away from $P$ and is within LOS of $P$. Through this process, we will gain both the knowledge of point $Q_{c 1}$ and the boundary edge that $P Q_{c 1}$ intersects, say edge $V_{k} V_{k+1}$ (see Figure 4.2a).

The previous two steps will be repeated for all the concave vertices in $V_{C}$. We can now figure out which vertices are not within LOS of $P$ by using the results from the previous steps. For example, concave corner $V_{c 1}$ has "anti-clockwise" blocking effect and the intersection point $Q_{c 1}$ is found to be on edge $V_{k} V_{k+1}$. From these two pieces of information, we know that the vertices which are not within LOS are ${ }^{c 1} V_{D}=\left\{V_{c 1+1}, V_{c 1+2}, \ldots, V_{k}\right\}$. Thus, if a concave vertex, say $V_{c i}$, has no blocking effect on $\mathrm{P},{ }^{c i} V_{D}=\varnothing$. To compute the field of view (FOV) of point $\mathrm{P}$, we start by assuming that the FOV of $P$ is the entire area enclosed by the concave polygon and denote it as a list of vertices (the same way as we described a concave polygon), ${ }^{P} V_{F O V^{\prime}}=\left\{V_{1}, V_{2}, \ldots, V_{n}\right\}$. Then, vertices in ${ }^{c i} V_{D}, 1 \leq c i \leq c m$, are deleted away and all the intersection points $Q_{c i}$ are inserted (see Figure 4.2b). The blockage value is then computed using the Eq.2.2 of Section 2 .

\section{Blockage values and connectivity probability (random search)}

The algorithm has been tested on several concave shapes (Figure 5.1) and the blockage values are tabulated in Table 5.1. To determine the mean blockage value of a concave shape, the algorithm discussed in Section 4 is applied together with some standard algorithms which are used to solve this type of double integral problem [10]. Showing also in Table 5.1 are the compactness and bending energy measures of the various concave shapes. The definitions of compactness and bending energy [6] are:

$$
\text { Compactness }=\frac{4 \pi \llbracket \text { Area }}{(\text { Perimeter })^{2}}, \quad \text { Bending energy }=\frac{1}{n} \sum_{i=0}^{n} k^{2}(i)
$$


, where $k(i)$ is the discrete curvature. The chain codes for all of the concave shapes are given in the Appendix, together with the coordinates of the vertices for the "3-room house floor plan", which is an actual floor plan for a typical housing unit in Singapore. The mean blockage value for the "L1 shape" is very close to the analytical value, 0.111 , we have determined in section 3. Also, the analytical blockage value for T-shape $(0.125)$ is very close to the simulated result (0.123). The results listed in Table 5.1 are in ascending order of the mean blockage values and are plotted in Figure 5.2.

Recall that the motivation of inventing blockage measure is to come out with an efficient measure to describe the connectivity probability of the concave operational area. In other words, it is desirable that by evaluating the blockage values of a concave shape, we will know roughly how difficult (or easy) it is for an array of sensors to maintain connection with each other. Thus, we investigate the number of sensors required $(N)$ to achieve connectivity probability of greater than $90 \%$ and $95 \%$ when they are deployed to carry out a purely random search task. The purely random search task is one in which all the sensors' movements are random and are independent to the movements of all the other sensors (except for collision avoidance). This is a well established way of searching and works well when there is little prior information about the search task or the reliabilities of the sensors are low.

Input: Vertices of Polygon, $V$, a concave vertex, $V_{c i}$.

Output: $N_{95 \%} N_{95 \%}$.

1: Initialize $\mathrm{N}=2$, flag $=$ FALSE.

2: Do

3: $\quad$ for sample $=1$ to NSAMPLE

4: $\quad$ Generate $\mathrm{N}$ points randomly (with uniform distribution) inside polygon $V$.

5: $\quad$ if $(\mathrm{N}$ points are connected)

6: $\quad$ Count $=$ Count +1

7: $\quad$ end if

8: $\quad$ end for

9: $\quad$ if (Count $>0.95 *$ NSAMPLE)

10: $\quad \mathrm{N}_{95 \%}=\mathrm{N}$

11: $\quad$ flag $=$ TRUE

12: $\quad$ end if

13: $\quad \mathrm{N}=\mathrm{N}+1$

14: while $($ flag $=$ FALSE)

Algorithm 5.1 ComputeN ${ }_{95 \%}\left(V, V_{c i}\right.$, NSAMPLE).

The random movements of the sensor nodes are simulated as a random point process [5]. In a single trial, a set of $\mathrm{N}$ points are generated uniformly and randomly inside a concave environment of interest and the connectivity of these $\mathrm{N}$ points is determined. If the $\mathrm{N}$ points are connected, the trial is considered to be "successful". The connectivity probability of $\mathrm{N}$ sensor nodes moving randomly inside a concave environment is approximated by running NSAMPLE trials and counting the number of trials which are "successful". For a particular concave shape, this set of simulation is run for $2 \leq N \leq N_{95 \%}$, where $N_{95 \%}$ is the number of sensor nodes required to maintain a fully connected network with $95 \%$ probability inside the concave shape. Depending on the complexity of the concave shapes, $N_{95 \%}$ varies and one can only discover it by increasing $\mathrm{N}$ until the connectivity probability is close to $95 \%$. The pseudo code for this iterative process is summarized in Algorithm 5.1 and the results are shown in Table 5.1.

Figure 5.2 shows the relationship between $N$ and the blockage values for various concave polygons. The behaviors of the relationships between $N$ and blockage are expected. As blockage tends to zero, which corresponds to a convex shape, $N$ should tend to 2 ( 1 will be meaningless for connectivity). On the other extreme, as blockage tends to 1, which corresponds to a concave shape so complex that it is equivalent to the case where all sensors have zero communication range, the $N$ value will tend to infinity.

Having shown the usefulness of blockage, a rule of thumb can be inferred on the number of sensors required to maintain high connectivity probability $(90 \%$ or $95 \%)$ when carrying out random search task. Figure 5.3 is the plot of the same data as in Figure 5.2, but in natural-logarithm scale, i.e. $\ln (N)$ vs $-\ln (1-B)$. As seen from Figure 5.3, there exists a similar third order polynomial relationship for both $90 \%$ and $95 \%$ connectivity. In addition, this polynomial relationship between $\ln (N)$ and $-\ln (1-B)$ has the desired behavior that $\mathrm{N}$ tends to infinity when mean blockage 
value tends to 1 . For the $95 \%$ connectivity curve, the model also passes through $N=2$ when mean blockage value tends to 0 . This relationship should provide a fast and good estimate for real operation considerations.

Another observation which can be made from this study is the limitation of random search strategy for distributed sensor networks operating in concave regions. The number of sensors required to maintain high connectivity inside a 3-room housing unit is around 75 (Table 5.1), which, in real operation, may not be as feasible. Thus, as a rule of thumb, if the mean blockage value of a particular concave region of interest is higher than 0.5 (which requires more than 20 sensors to maintain $95 \%$ connectivity), it is generally not feasible to employ the random search strategy.

On the other hand, compactness and bending energy fail to capture this elegant and simple relationship (see Figure 5.4). For example, "Z1", "Z2" and "+" have the same compactness values measures but the number of sensors required for full connectivity in these boundaries are different. Similarly, bending energy does not perform well if one is to relate it to the distributed sensor network connectivity (check shape "L2", "Z1", "Z2"). In short, mean blockage has been shown to be more appropriate in the study of network connectivity for concave shapes.

\section{References}

Adam T. Hayes (2002), "How Many Robots? Group Size and Efficiency in Collective Search Task", Proceedings of the 6th International Symposium on Distributed Autonomous Sensoric Systems. 289.

C. Bettstetter, J. Zangl (2002), "How to Achieve a Connected Ad Hoc Network with Homogeneous Range Assignment: An Analytical Study with Consideration of Border Effects". Mobile and Wireless Communications Network. 125 - 129.

E. Royer, and C. K. Toh (1999), "A review of current routing protocols for ad hoc mobile wireless networks", IEEE Personal Communications. 6(2), 46-55.

G. Ferrari, O. K. Tonguz (2004), "Minimum Number of Neighbors for Fully Connected Uniform Ad Hoc Wireless Networks". IEEE International Conference on Communications.

K. Rőmer, F. Mattern (2004), “The Design Space of Wireless Sensor Networks”. IEEE Wireless Communications, Dec.

L. Fontoura Costa, \& R. M. Cesar Junior, "Shape Analysis and Classification: Theory and Practice".

Neha Jain and Dharma P. Agrawal (2005), “Current Trends in Wireless Sensor Network Design”, International Journal of Distributed Sensor Networks, 1: 101-122.

P. Santi (2005), "The Critical Transmitting Range for Connectivity in Mobile Ad Hoc Networks". IEEE Transactions on Mobile Computing. Vol 4, 310-317.

T. K. Madsen, Frank H. P. Fitzek and Ramjee Prasad (2005), "Connectivity Probability of Wireless Ad Hoc Networks: Definition, Evaluation, Comparison". Special Issue of the International Journal on Wireless Personal Communications.

W. H. Press, B. P. Flannery, S. A. Teukolsky, \& W. T. Vetterling, "Numerical Recipes in C", Cambridge University Press.

Yongguo Mei, Yung-Hsiang Lu, Y. Charlie Hu, and C.S. George Lee (2004), "Determining the Fleet Size of Mobile Robots with Energy Limitations". Proceedings of Intelligent Sensors \& Systems 1420. 
Table 5.1 Compactness, bending energy, blockage measure of the concave shapes in Figure 5.1.

\begin{tabular}{|c|c|c|c|c|c|}
\hline Shape & Compactness & Bending Energy & Mean Blockage & $\mathrm{N}($ for $90 \%$ ) & $\mathrm{N}($ for $95 \%$ ) \\
\hline L1 & 0.5890 & 3.000 & 0.110 & 3 & 4 \\
\hline $\mathrm{L} 2$ & 0.5236 & 2.667 & 0.111 & 3 & 4 \\
\hline $\mathrm{T}$ & 0.5026 & 3.200 & 0.123 & 3 & 4 \\
\hline+ & 0.4363 & 4.000 & 0.161 & 4 & 5 \\
\hline $\mathrm{X} 1$ & 0.4363 & 3.333 & 0.215 & 5 & 6 \\
\hline $\mathrm{Z1}$ & 0.4363 & 2.667 & 0.219 & 5 & 6 \\
\hline $\mathrm{Z} 2$ & 0.4363 & 2.667 & 0.278 & 7 & 9 \\
\hline $\mathrm{U}$ & 0.4363 & 2.667 & 0.287 & 7 & 9 \\
\hline $\mathrm{F} 1$ & 0.3847 & 2.857 & 0.319 & 8 & 10 \\
\hline $\mathrm{F} 2$ & 0.2827 & 2.800 & 0.367 & 11 & 14 \\
\hline $\mathrm{X} 2$ & 0.2827 & 2.800 & 0.404 & 12 & 14 \\
\hline $\mathrm{X} 3$ & 0.3436 & 2.500 & 0.432 & 12 & 15 \\
\hline $\mathrm{X} 4$ & 0.3699 & 4.400 & 0.462 & 14 & 16 \\
\hline $\mathrm{E}$ & 0.2400 & 2.000 & 0.534 & 20 & 23 \\
\hline $\mathrm{C}$ & 0.1841 & 1.500 & 0.611 & 31 & 37 \\
\hline G & 0.1739 & 1.412 & 0.641 & 34 & 40 \\
\hline 3-Room & 0.1758 & 0.1729 & 0.679 & 62 & 75 \\
\hline
\end{tabular}

The last two columns show the minimum number of sensors required to get connectivity probability of $90 \%$ and $95 \%$. 


\section{Appendix: Chain codes of concave shapes studied}

The details about chain codes can be found in [11]. The chain codes of all the concave shapes are listed in Table A. The $\mathrm{x}-\mathrm{y}$ coordinates of the vertices for the 3-room flat are included in Table A as well.

\begin{tabular}{|c|c|c|c|c|c|c|c|c|c|}
\hline Shape & \multicolumn{9}{|c|}{ Absolute Chain Codes } \\
\hline L1 & \multicolumn{9}{|c|}{$0,0,2,4,6,6$} \\
\hline $\mathrm{L} 2$ & \multicolumn{9}{|c|}{$0,0,0,2,4,2,4,2,4,6,6,6$} \\
\hline $\mathrm{Z1}$ & \multicolumn{9}{|c|}{$0,0,2,4,2,2,4,4,6,0,6,6$} \\
\hline $\mathrm{Z} 2$ & \multicolumn{9}{|c|}{$0,0,0,2,4,4,2,4,4,6,0,6$} \\
\hline F1 & \multicolumn{9}{|c|}{$0,2,2,0,2,4,2,0,2,4,4,6,6,4,4,6,0,0,6,6$} \\
\hline $\mathrm{F} 2$ & \multicolumn{9}{|c|}{$0,0,0,2,4,2,0,2,4,4,6,6,4,6$} \\
\hline $\mathrm{T}$ & \multicolumn{9}{|c|}{$0,2,0,2,4,4,4,6,0,6$} \\
\hline $\mathrm{U}$ & \multicolumn{9}{|c|}{$0,0,0,2,2,4,6,4,6,4,6,6$} \\
\hline+ & \multicolumn{9}{|c|}{$0,2,0,2,4,2,4,6,4,6,0,6$} \\
\hline $\mathrm{C}$ & \multicolumn{9}{|c|}{$0,0,0,0,0,2,2,4,6,4,4,4,2,2,2,0,0,0,6,0,2,2,4,4,4,4,4,6,6,6,6,6$} \\
\hline $\mathrm{X} 1$ & \multicolumn{9}{|c|}{$0,2,0,2,4,2,4,4,6,0,6,6$} \\
\hline $\mathrm{X} 2$ & \multicolumn{9}{|c|}{$0,2,4,1,3,4,6,0,5,7$} \\
\hline $\mathrm{X} 3$ & \multicolumn{9}{|c|}{$0,2,2,0,2,4,4,4,2,2,4,6,6,4,6,0,0,0,6,6$} \\
\hline $\mathrm{X} 4$ & \multicolumn{9}{|c|}{$0,0,0,2,2,0,2,4,4,6,6,4,2,4,6,6$} \\
\hline $\mathrm{E}$ & \multicolumn{9}{|c|}{$0,0,0,2,4,4,2,0,0,2,4,4,2,0,0,2,4,4,4,6,6,6,6,6$} \\
\hline $\mathrm{G}$ & \multicolumn{9}{|c|}{$0,0,0,0,0,2,2,2,4,4,6,0,6,4,4,4,2,2,2,0,0,0,0,2,4,4,4,4,4,6,6,6,6,6$} \\
\hline \multirow{12}{*}{ 3-Room } & Vert. & $\mathrm{x}$ & $\mathrm{y}$ & Vert. & $\mathrm{x}$ & $\mathrm{y}$ & Vert. & $\mathrm{x}$ & $\mathrm{y}$ \\
\hline & 1 & 0 & 0 & 12 & 9.1 & 17.1 & 23 & 7.2 & 11.8 \\
\hline & 2 & 7 & 0 & 13 & 9.1 & 17.3 & 24 & 7 & 11.8 \\
\hline & 3 & 7 & 6.4 & 14 & 11.6 & 17.3 & 25 & 7 & 19.6 \\
\hline & 4 & 7.2 & 6.4 & 15 & 11.6 & 17.1 & 26 & 0 & 19.6 \\
\hline & 5 & 7.2 & 0 & 16 & 11.1 & 17.1 & 27 & 0 & 9.8 \\
\hline & 6 & 13.6 & 0 & 17 & 11.1 & 12.1 & 28 & 7.2 & 9.8 \\
\hline & 7 & 13.6 & 11.9 & 18 & 13.6 & 12.1 & 29 & 7.2 & 8.2 \\
\hline & 8 & 9.1 & 11.9 & 19 & 13.6 & 19.6 & 30 & 7 & 8.2 \\
\hline & 9 & 9.1 & 12.1 & 20 & 12.7 & 19.6 & 31 & 7 & 9.6 \\
\hline & 10 & 10.7 & 12.1 & 21 & 12.7 & 21.6 & 32 & 0 & 9.6 \\
\hline & 11 & 10.7 & 17.1 & 22 & 7.2 & 21.6 & & & \\
\hline
\end{tabular}




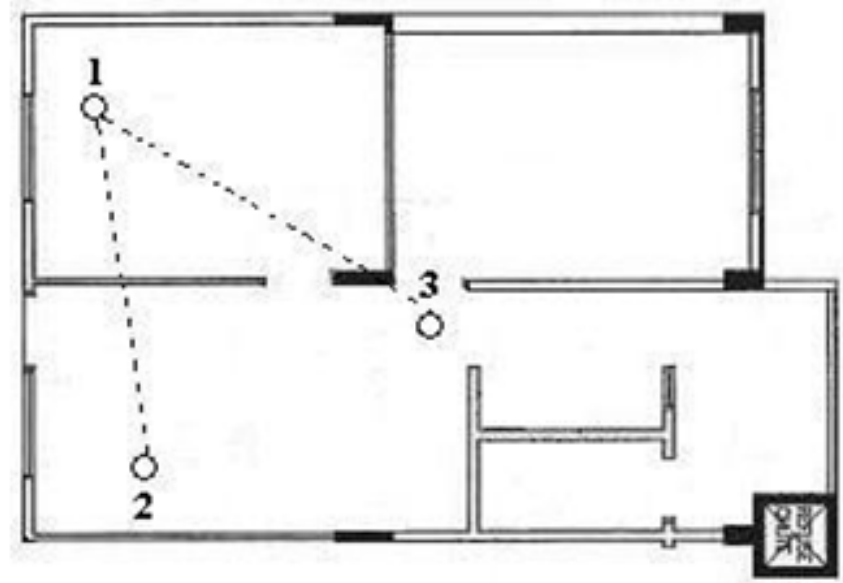

Three-sensor operation in a house

Figure 1.1 The line-of-sight of sensor 1 is blocked by the walls of a bedroom, thus rendering it unable to communicate with sensor 2 and sensor 3 .

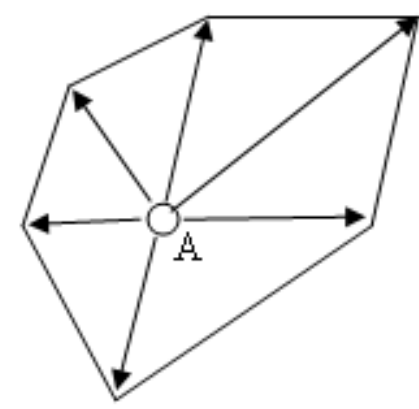

a. Convex polygon

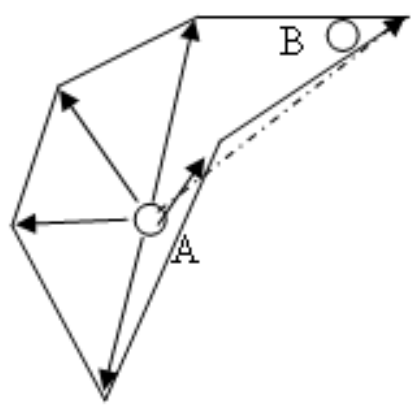

b. Concave polygon

Figure 2.1 a) The field of view of a sensor inside a convex region will be the whole convex area if the sensing range is at least the maximum chord. b) The field of view of a sensor can be less than the whole concave area even if its sensing range is larger than the maximum chord of the boundary (sensor $A$ and $B$ are not within line of sight of each other).
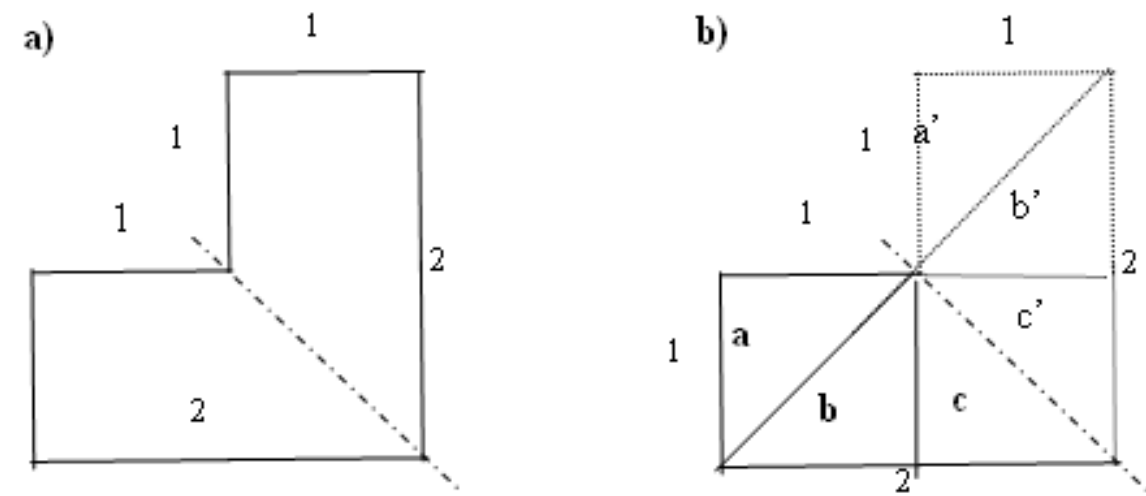

Figure 3.1 a) The simple concave shapes: L-shape. The edge lengths and symmetry lines (dotted lines) are shown in the figure as well. b) Sub-regions defined for points having similar FOV, to facilitate the evaluation of blockage values. 

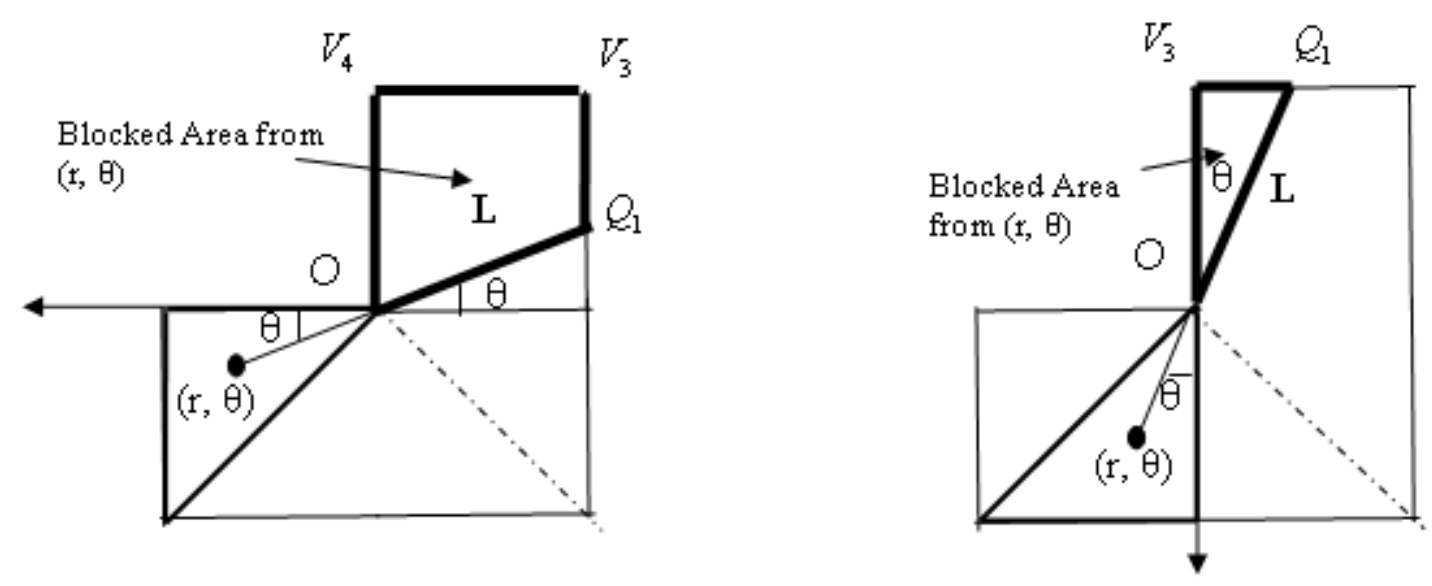

Figure 3.2 Evaluation of blockage for points in regions $a$ and $b$ (of $L$ shape).

The arrows show the $\theta=0$ axes of the polar coordinates.

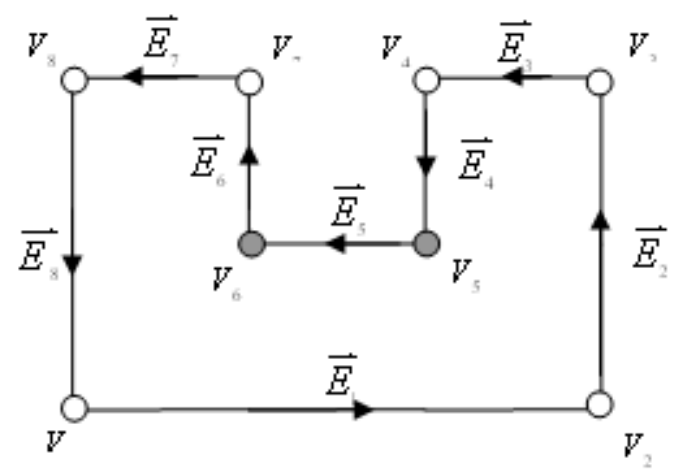

a) Determining concave vertices

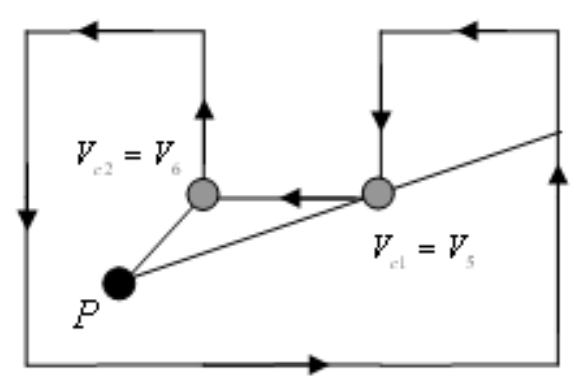

b) Determining blocking direction

Figure $4.1 \ldots$ a) The "anti-clockwise" order of listing the vertices of a concave "U" shape, $V=\left\{V_{1}, V_{2}, V_{3}, V_{4}, V_{5}, V_{6}, V_{7}, V_{s}\right\}$. The grey dots are concave vertices determined by checking the signs of the cross-products of $\overrightarrow{\vec{E}_{-1}} \times \overrightarrow{E_{j}}$ for all vertices and $V_{C}$ is found to be $V_{C}=\left\{V_{5}, V_{6}\right\}$. b) Concave vertex $V_{5}$ has a "clockwise" blocking effect on point $P\left(V_{4}\right.$ is not visible to $P$ ) while concave vertex $V_{6}$ has no blocking effect on $P$ (both $V$, and $V$, are visible to $P$ ).

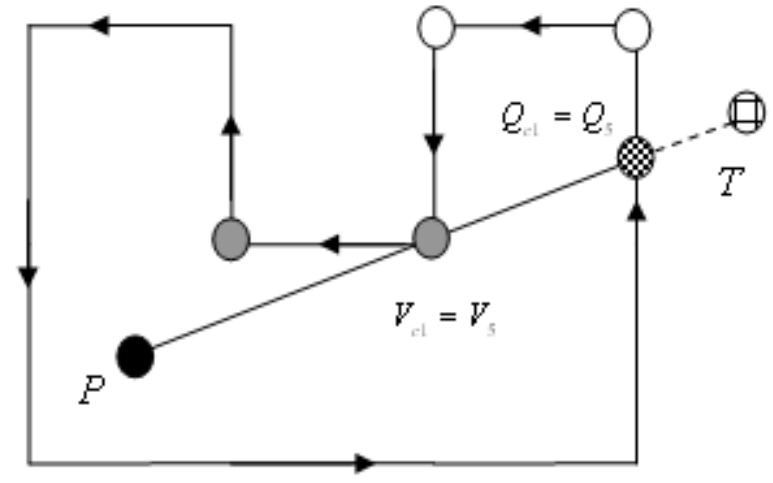

a) Determining $Q$ and vertices not within line of sight

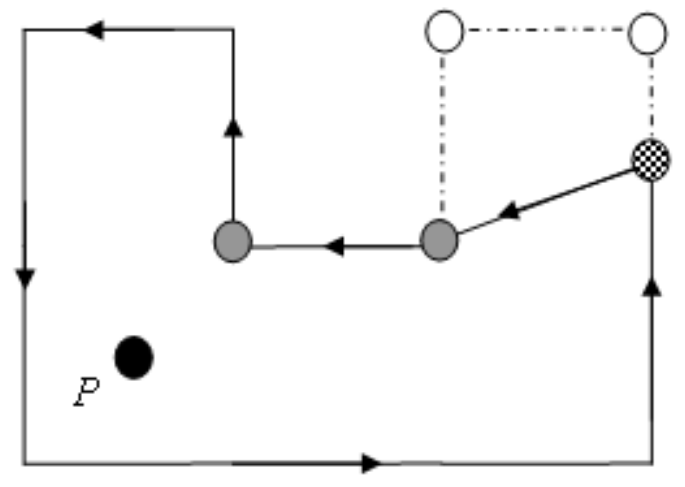

b) Field of view of $P$

Figure $4.2 \mathrm{a}$ ) Point $Q$, is found to be intersecting edge $V V$. Thus, vertices which are not visible to $\mathrm{P}$ are ${ }^{5} V_{D}=\left\{V_{3}, V_{4}\right\}$. b) The field of view of $\mathrm{P}$ is determined by deleting vertices in ${ }^{5} V_{D}$ from $\mathrm{V}$ and insert $Q$, after vertex $V_{2}$. 


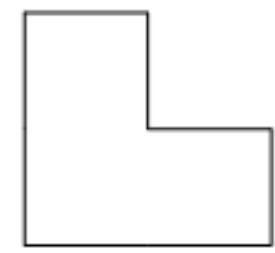

L1-shape

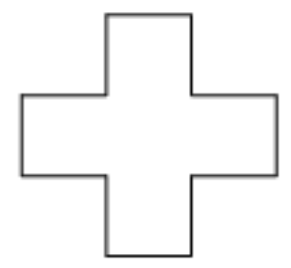

"+"- shape

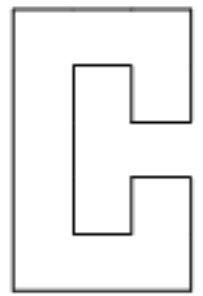

C-shape

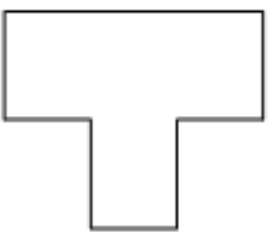

T-shape

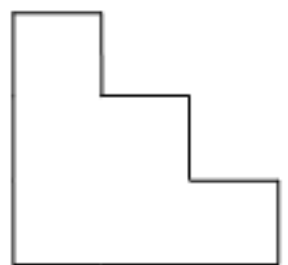

L2-shape

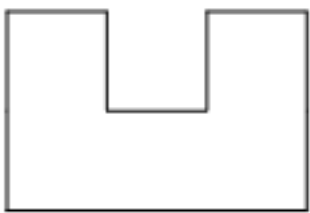

U-shape

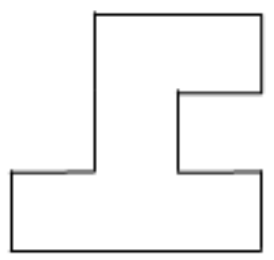

F1-shape

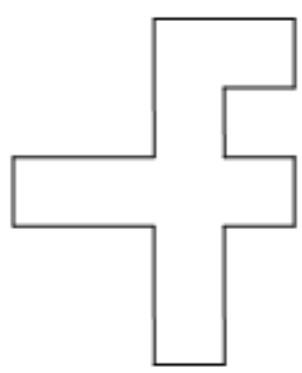

F2-shape

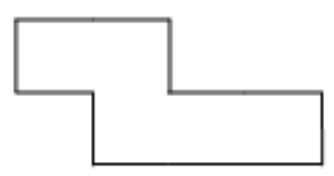

Z1-shape

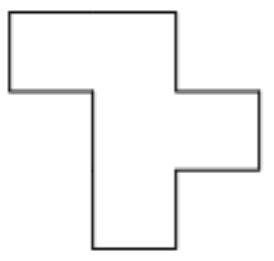

X1-shape

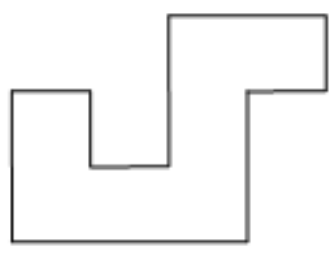

X3-shape

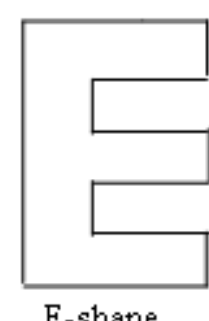

E-shape

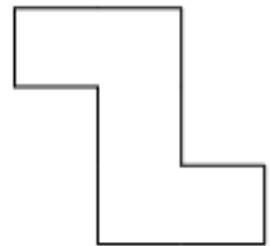

Z2-shape

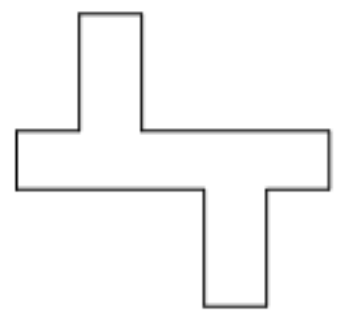

X2-shape

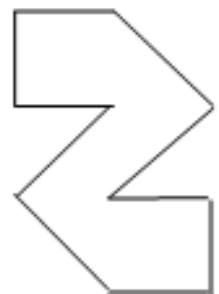

X4-shape

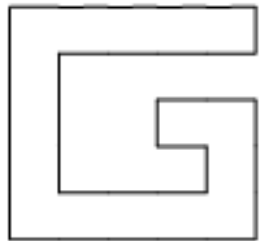

G-shape

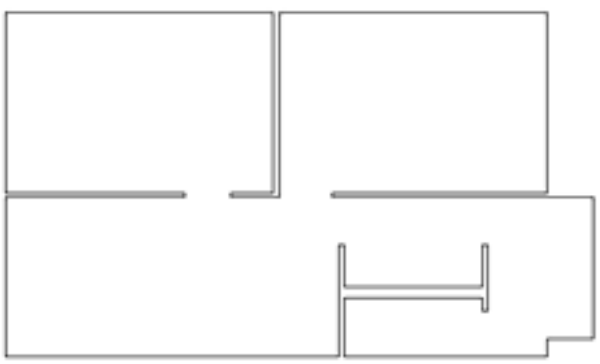

3-Room

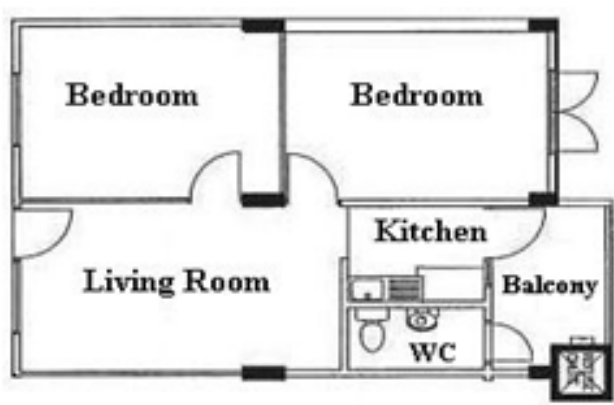

Typical 3-Room House Floor Plan

Figure 5.1 Concave shapes whose mean blockage values were computed by using the algorithm introduced in Section 4. The chain codes for all the shapes (vertices are given for 3-room house floor plan) are provided in the Appendix. Note that the polygon "3-Room" is modeled using the floor plan of a typical housing unit in Singapore. 


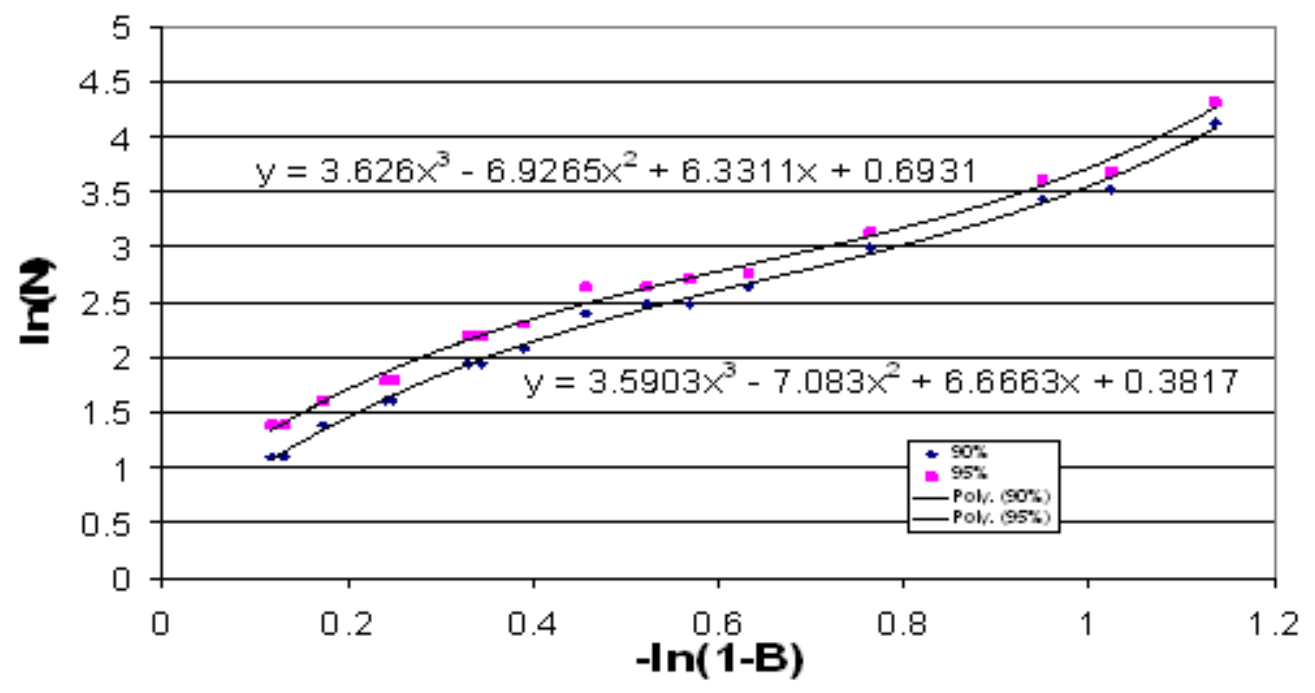

Figure 5.3 The plot of $\ln (N)$ against $-\ln (1-B)$, where $B$ is the mean blockage measure.
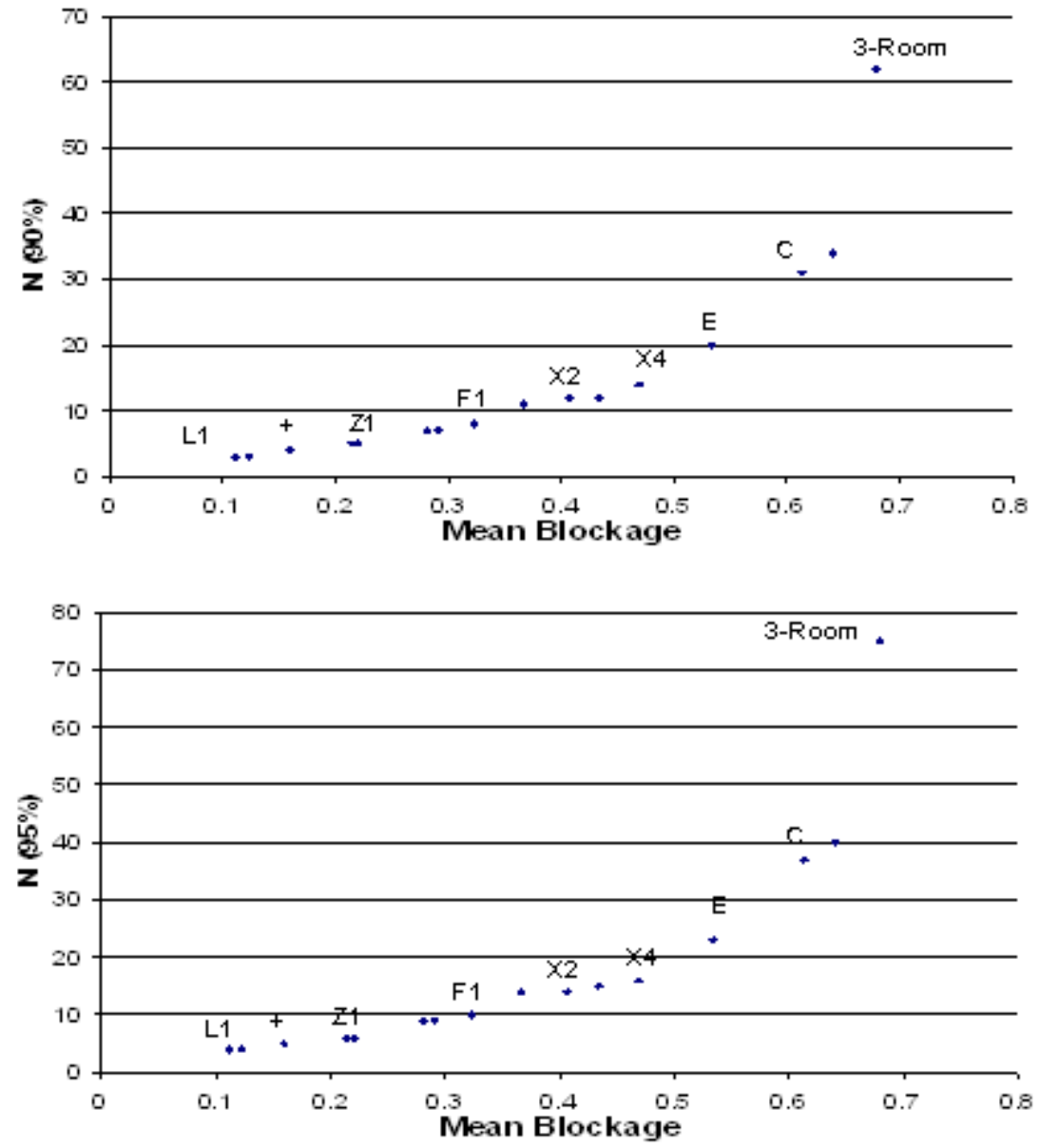

Figure 5.2 The plots of $\mathrm{N}$ against the blockage measure (for $90 \%$ and $95 \%$ connectivity probability). 

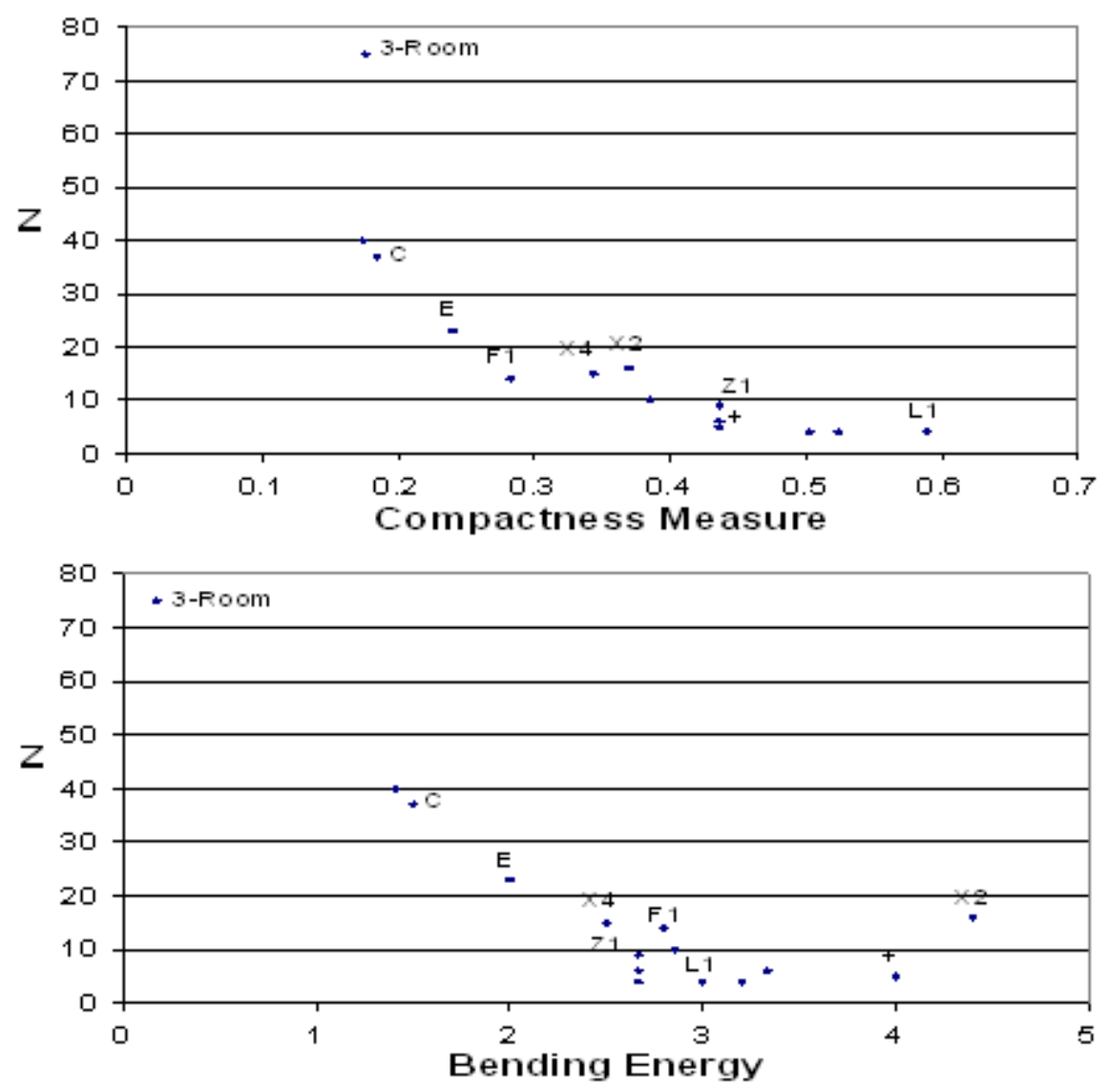

Figure 5.4 The plots of $\mathrm{N}$ versus compactness measure and bending energy. 


\title{
Robust Tracking Control of Robot Manipulator Using Dissipativity Theory
}

\author{
Hongrui Wang \\ Key Lab of Industrial Computer Control Engineering of Hebei Province \\ Yanshan University, Qinhuangdao 066004, China \\ Department of Electronic and Informational Engineering \\ Hebei University, Baoding 071002, China \\ Zhanfang Feng (Corresponding author) \\ Key Lab of Industrial Computer Control Engineering of Hebei Province \\ Yanshan University, Qinhuangdao 066004, China \\ E-mail: 98zkfzf@163.com \\ Xiuling Liu \\ Department of Electronic and Informational Engineering \\ Hebei University, Baoding 071002, China
}

\begin{abstract}
The robust $H_{\infty}$ controller is designed for the problem of rigid robot tracking, which based on the dissipativity theory. The quadratic form dissipative feedback control law was given for interference suppression under the condition of existing model error and external disturbance. The scheme improved the robustness of the system. The simulation results show that the algorithm can achieve rapid tracking of the robot system.
\end{abstract}

Keywords: Robot, Passivity, Dissipativity, Robustness

\section{Introduction}

Robot system is a very complex multi-input multi-output nonlinear system with time-varying, and the strong coupling of nonlinear dynamics. dissipativity theory has been put forward by the people's concern and reached a wide range of research results (Van der Schaft A.J., 1999; Feng, 1998) in the 1970s. Its substance is that the internal energy system loss is always less than the external energy supply rate. $H_{\infty}$ control (Mei,2003)and passive control are a special cases of dissipative control. The $H_{\infty}$ control is a kind of interference suppression control, which can not only guarantee the stability of the system, but also achieve smallest degree requested by the interference to system output. If the supply rate is the product of input and output, the state will be passivity problem. Passivity theory has been widely used in many engineering problems, such as electrical systems and thermal power systems. A strict passive dynamic system generally has excellent dynamic characteristics and satisfactory robustness. (Feng, 1999,pp. 577-582)

Stabilization controller is designed by using passivity theory on the definite part of the robot system, and then uses the dissipativity theory for interference suppression under the condition of existing model error and external disturbance. The scheme enhances the robustness of the robot tracking, at the same time, and improves the tracking accuracy and speed.

\section{Dissipative Control for Robot}

2.1 Model Control Law Design

Considering the following n-degree of robot, the dynamic equation is as follows

$$
M(q) \ddot{q}+C(q, \dot{q}) \dot{q}+G(q)=\tau
$$


Where the vector $q(t)$ is the $n \times 1$ joint angle; $M(q)$ is the $n \times n$ symmetric positive definite inertia matrix; $C(q, \dot{q}) \dot{q}$ is the $n \times 1$ vector of coriolis and centrifugal torques; $G(q)$ is the $n \times 1$ vector of gravitational torques; $\tau$ is the $n \times 1$ vector of actuator joint torques.

The description of robot systems in Eq (1), has the following characteristics:

Property $1: M(q)$ is a bounded, symmetric positive definite matrix, its inverse matrix is a bounded. There are positive number $\lambda_{1}$ and $\lambda_{2}, 0<\lambda_{1} I \leq M \leq \lambda_{2} I$.

Property 2: $\dot{M}(q)-2 C(q, \dot{q})$ is skew symmetric matrix, both $\mathrm{M}$ an $\mathrm{C}$ in $\mathrm{Eq}(1)$ satisfy the following equations

$$
\begin{gathered}
x^{T}[\dot{M}(q)-2 C(q, \dot{q})] x=0 \\
\dot{M}=C(q, \dot{q})+C(q, \dot{q})^{T}
\end{gathered}
$$

Suppose that the desired trajectory of system is described by $q_{d}, \dot{q}_{d}$ and $\ddot{q}_{d}$, then the corresponding error is defined as $e=q-q_{d}, \dot{e}=\dot{q}-\dot{q}_{d}, \ddot{e}=\ddot{q}-\ddot{q}_{d}$

The $\tau$ can be given as

$u$ is a control input signal.

$$
\tau=u+M(q) \ddot{q}_{d}+C(q, \dot{q}) \dot{q}_{d}+G(q)
$$

For system in $\mathrm{Eq}(1)$, we can give non-linear compensation in $\mathrm{Eq}(2)$, receive error dynamic equation:

$$
M \ddot{e}+C \dot{e}=u
$$

The state vector is defined:

$$
x_{1}=e, x_{2}=\dot{e}+e
$$

Obviously, when $\lim _{t \rightarrow \infty} e=0, \lim _{t \rightarrow \infty} \dot{e}=0$, if and only if

$$
\lim _{t \rightarrow \infty} x(t)=0
$$

In the new coordinates, and $\mathrm{Eq}(3)$ can be translated into the following equation of state:

The output signal is defined:

$$
\left\{\begin{array}{l}
\dot{x}_{1}=-x_{1}+x_{2} \\
M \dot{x}_{2}=-(M-C) x_{1}+(M-C) x_{2}+u
\end{array}\right.
$$

$$
y=x_{2}
$$

Choose the form of Lyapunov function as follows:

$$
V(t, x)=\frac{1}{2} x_{1}^{T} x_{1}+\frac{1}{2} x_{2}^{T} M(q) x_{2}
$$

Along the state trajectory, and its time derivative is as follows:

$$
\begin{aligned}
& \dot{V}(t, x)=x_{1}^{T} \dot{x}_{1}+\dot{x}_{2}^{T} M(q) x_{2}+\frac{1}{2} x_{2}{ }^{T} \dot{M}(q) x_{2} \\
& =x_{1}^{T} \dot{x}_{1}+x_{2}^{T}\left\{M\left(x_{2}-x_{1}\right)+C x_{1}+u\right\}+\frac{1}{2} x_{2}^{T}\{\dot{M}(q)-2 C\} x_{2} \\
& =-x_{1}^{T} x_{1}+x_{2}^{T}\left\{M\left(x_{2}-x_{1}\right)+C x_{1}+x_{1}+u\right\}
\end{aligned}
$$

The feedback control law is as follows

$$
u=\beta(x)+v
$$

With

$$
\beta(x)=-M\left(x_{2}-x_{1}\right)-C x_{1}-x_{1}
$$


So $\dot{V}(t, x)=-x_{1}^{T} x_{1}+y^{T} v \leq y^{T} v \quad \forall v$

This shows that the closed-loop system is passive from the input, viz. $v$, to the output, viz. $y$. According to relations of passivity and asymptotic stability, let $v=-y=-x_{2}$, the closed-loop system is gradual and stable.

The equation of state (6) is replaced by:

$$
\left\{\begin{array}{l}
\dot{x}_{1}=-x_{1}+x_{2} \\
\dot{x}_{2}=-M^{-1}\left(x_{1}+C x_{2}\right)+M^{-1} v \\
y=x_{2}
\end{array}\right.
$$

If formula (10) is passive, which can be written for the general form:

$$
\left\{\begin{array}{l}
\dot{x}=f(x)+g(x) v \\
y=h(x)
\end{array}\right.
$$

According to a KYP lemma, then:

$$
\left\{\begin{array}{l}
\frac{\partial V}{\partial x} f(x) \leq 0 \\
\frac{\partial V}{\partial x} g(x)=h^{T}(x)
\end{array}\right.
$$

\subsection{Robust Controller Design}

Consider the model error and external disturbances, the robot model:

$$
M(q) \ddot{q}+C(q, \dot{q}) \dot{q}+G(q)=\tau+\omega
$$

The equation of state:

$$
\left\{\begin{array}{l}
\dot{x}_{1}=-x_{1}+x_{2} \\
M \dot{x}_{2}=-(M-C) x_{1}+(M-C) x_{2}+u+\omega
\end{array}\right.
$$

Combining (9) and (14), we have

$$
\left\{\begin{array}{l}
\dot{x}_{1}=-x_{1}+x_{2} \\
\dot{x}_{2}=-M^{-1}\left(x_{1}+C x_{2}\right)+M^{-1}(v+\omega) \\
y=x_{2}
\end{array}\right.
$$

Theorem: If the definite part (10) of system (15) is the passive, for any positive number $\gamma$, system (15) is the dissipative for the supply rate $s(\omega, y)=\gamma^{2}\|\omega\|^{2}-\|y\|^{2}$, under the condition of the negative feedback:

$$
v=-y-\frac{1}{4 \gamma^{2}} y
$$

where $V(x)$ is that the energy storage function.

Proof: give a general form for system (15)

$$
\left\{\begin{array}{l}
\dot{x}=f(x)+g(x)(v+\omega) \\
y=h(x)
\end{array}\right.
$$

For any positive number $\gamma$, combining formula (16), hence

$$
\begin{aligned}
& \dot{V}=L_{f} V+L_{g} V(v+\omega)=L_{f} V-y^{T} y-\frac{1}{4 \gamma^{2}} y^{T} y+y^{T} \omega \\
& \leq L_{f} V-\|y\|^{2}-\frac{1}{4 \gamma^{2}} y^{T} y+\gamma^{2}\|\omega\|^{2}+\frac{1}{4 \gamma^{2}} y^{T} y \\
& =L_{f} V-\|y\|^{2}+\gamma^{2}\|\omega\|^{2} \leq-\|y\|^{2}+\gamma^{2}\|\omega\|^{2}
\end{aligned}
$$

So the closed-loop system is dissipative on supply rate $s(w, y)=\gamma^{2}\|\omega\|^{2}-\|y\|^{2} . V(x)$ is the storage function. 
The closed-loop system is dissipative on $s(w, y)=\gamma^{2}\|\omega\|^{2}-\|y\|^{2}$ supply rate. That is to say, the $\gamma$ is rejection ratio of closed-loop system from interference $\omega$ to output $y$, that is $H_{\infty}$ control.

\section{Simulation Research}

In order to verify the control strategy, the objects are simulated, based on the MIMO dynamics model of two-DOF robot manipulator (Liu, 2005).

The dynamics model is given by

$$
M(q) \ddot{q}+C(q, \dot{q}) \dot{q}+G(q)=u(t)+\omega
$$

where

$M(q)=\left[\begin{array}{cc}m_{1} l_{1}^{2}+m_{2}\left(l_{1}^{2}+l_{2}^{2}\right)+2 m_{2} l_{1} l_{2} \cos \left(q_{2}\right) & m_{2} l_{2}^{2}+m_{2} l_{1} l_{2} \cos \left(q_{2}\right) \\ m_{2} l_{2}^{2}+m_{2} l_{1} l_{2} \cos \left(q_{2}\right) & m_{2} l_{2}^{2}\end{array}\right], C(q, \dot{q})=\left[\begin{array}{cc}-m_{2} l_{1} l_{2} \dot{q}_{2} \sin \left(q_{2}\right) & -m_{2} l_{1} l_{2}\left(\dot{q}_{1}+\dot{q}_{2}\right) \sin \left(q_{2}\right) \\ m_{2} l_{1} l_{2} \dot{q}_{1} \sin \left(q_{2}\right) & 0\end{array}\right]$,

$g(q)=\left[\begin{array}{c}\left(m_{1}+m_{2}\right) l_{1} g \cos \left(q_{1}\right)+m_{2} l_{2} g \cos \left(q_{1}+q_{2}\right) \\ m_{2} l_{2} g \cos \left(q_{1}+q_{2}\right)\end{array}\right]$,

$m_{1}=4 \mathrm{~kg}, m_{2}=2 \mathrm{~kg}, l_{1}=1 \mathrm{~m}, l_{2}=1 \mathrm{~m}, g=9.8$ is acceleration of gravity

The model error and external disturbance: $\omega(t)=\left[\begin{array}{ll}q_{1} \dot{q}_{1} \sin (t) & q_{2} \dot{q}_{2} \cos (t)\end{array}\right]^{T}$

The position orders of joint 1 and joint 2: $q_{1 d}=\sin (\mathrm{t}) ; q_{2 d}=\cos (\mathrm{t})$

The initial joint angle position: $\left[q_{1}(0), \quad q_{2}(0)\right]^{T}=\left[\begin{array}{ll}0.1 & 0.9\end{array}\right]^{T}$

The initial angular speed: $\left[\dot{q}_{1}(0), \dot{q}_{2}(0)\right]^{T}=\left[\begin{array}{ll}0 & 0\end{array}\right]^{T}$

The rejection ratio from interference $\omega$ to output $y: \gamma=0.03$

Simulation results show that the application of dissipative control algorithm can ensure the smooth controller and gradual convergence of the tracking error.

\section{Conclusion}

In this paper, considering this robot system in model error and external disturbances conditions, robust $H_{\infty}$ tracking controller is designed by using disposition theory. The $H_{\infty}$ tracking controller can effectively inhibit interference, and the robot system can achieve quickly and accurately tracking.

\section{References}

Feng, Chunbo and Fei, Shumin. (2004). Robust control of nonlinear systems. Beijing:Science Press.

Feng, Chunbo,Zhang, Kanjian and Fei, Shumin. (1999). Passivity-based design of robust control systems. ACTA AUTOMATICA SINICA, 25(5), 577-582

Liu, Jinkun, (2005). MATLAB Simulation for Sliding Mode Control. Beijing: Tsinghua University Press.

Mei, Shengwei, Shen, Tielong and Liu, Kangzhi. (2003). Modern Robust Control Theory and Application. Beijing: Tsinghua University Press.

Van der Schaft A.J. (1999). L2 -gain and Passivity Techniques in Nonlinear Control. London: Springer-Ver-lag. 


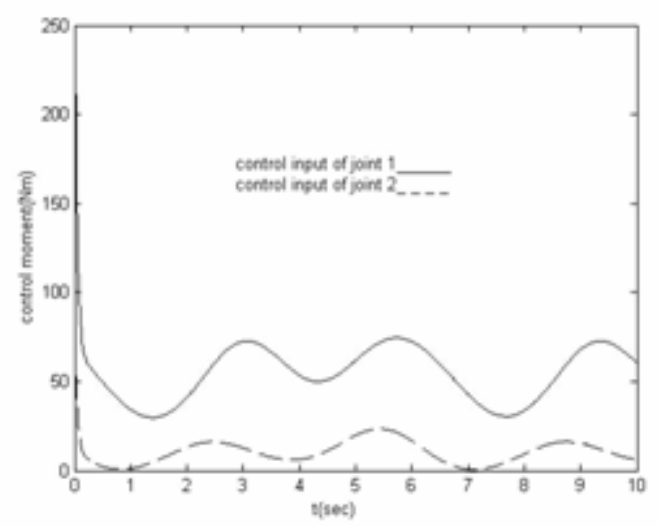

Figure 1. The control input of joint 1 and joint 2

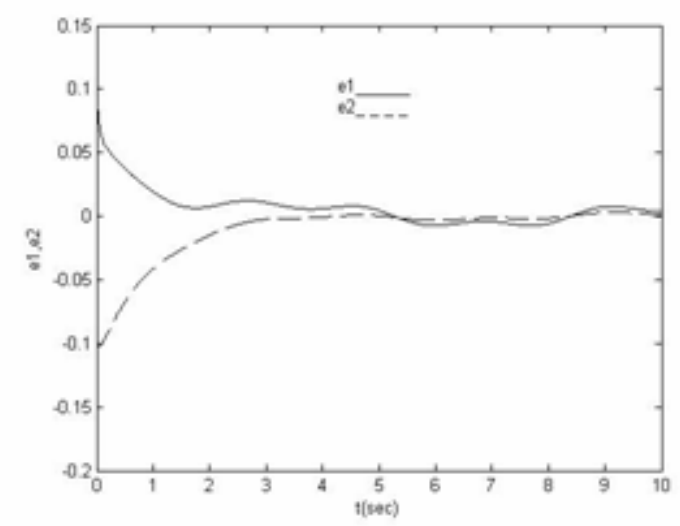

Figure 2. The tracking error of joint 1 and joint 2

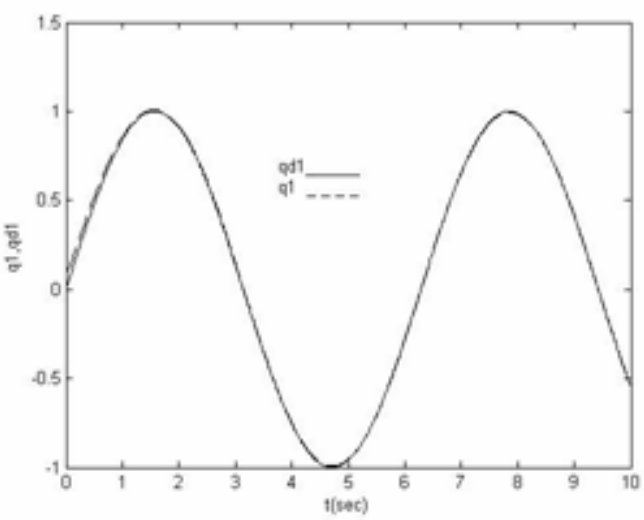

Figure 3. The tracking of joint 1

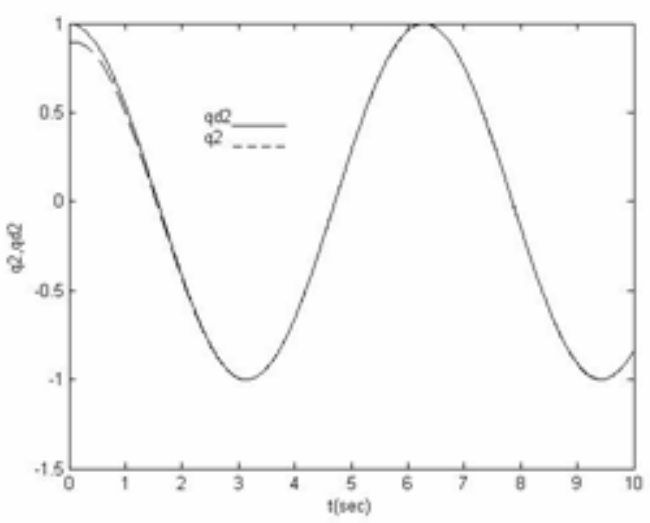

Figure 4 . The tracking of joint 2 


\title{
Forest Road Assessment in Ulu Muda
}

\section{Forest Reserve, Kedah, Malaysia}

\author{
Mohd Hasmadi, I, and Kamaruzaman, J. (Corresponding author) \\ Department of Forest Production, Faculty of Forestry \\ Universiti Putra Malaysia \\ 43400 UPM, Serdang, Selangor, Malaysia \\ Tel: 60-3-8946-7176 E-mail: kamaruz@putra.upm.edu.my \\ Muhamad Azizon, J \\ Forestry Training Unit, Forestry Department Peninsular Malaysia \\ Kepong, 52100 Kuala Lumpur, Malaysia
}

The research is financed by Peninsular Malaysia Forestry Department Headquarters and Universiti Putra Malaysia (Sponsoring information)

\begin{abstract}
For the last few decades, forest road construction for forest harvesting in the tropical forest has been shown to cause considerable damage to the soil physical properties, forest environment and watershed areas. These effects can be minimized through implementation of proper harvesting procedure in the use of harvesting machines and forest road specification guideline. Forest road specification is important as technical guideline that must be comply by any loggers in order to construct forest roads. The road constructions that meet the outlined specification were potential to minimize the damage of forest roads and increase the efficiency in forest product output, while reducing harvesting cost. The purpose of the study is to evaluate the effectiveness of feeder road construction in compliance to the Forest Road Specifications 1999 as outlined by the Forest Department of Peninsular Malaysia. Systematic samplings were conducted along $14.5 \mathrm{~km}$ of feeder road where an observation and measurements has been taken at every $500 \mathrm{~m}$ points visited. A total of 30 samples were taken which incorporate dimensions of road specification elements for each point such as road cross section, vertical alignment, horizontal alignment, road failure and earth work. The comparison data was collected to determine whether the failure is due or not to the specification. Result presented that the total length of the road failure in the study area was $551.4 \mathrm{~m}$ or $3.8 \%$ out of $14.5 \mathrm{~km}$. The types of the road failure were classified into five categories that were surface failure, surface run-off, wheel track, drainage failure and landslide. The major failure occurred on the feeder roads was surface failure, which represent about $38.2 \%$. Reasons of non-compliance are ascertained and several recommendations were given to reduce the damage of feeder road.
\end{abstract}

Keywords: Forest engineering, Timber harvesting, Assesment, Road failure, Cost

\section{Introduction}

Forest roads are built to provide an access to the forest area for logging operation, general purposes and for the transports of timber to the mills. Forest road is an engineering structure; therefore compliance to technical specification is essential to ensure its safety and reliability. Proper construction according to specific guideline could help in reducing adverse impact to the forest environment. If the guideline does not meet to the specification it would cause a major impact such as soil degradation, vegetation loss, affect water and the environment quality. Forest road should be designed to minimize the soil disturbance and avoid stream crossing where possible. According to Kamaruzaman (1995), forest road construction in tropical forest have the most significant influence on water yield, water quality, soil erosion and nutrient loss. Meanwhile, the forest road construction within a few meters of streams or river edges are a common practice in harvesting operation and undoubtedly cause the large supply of sediment to streams Kamaruzaman et al. (1986). FAO (1977) reported that road damage also can occurs from the combined impact by heavily traffic and heavy rain. The road is thus vulnerable to being damage by the traffic on the surface and sometimes the underlying 
layers have become softened by the rain and than when it is dry. Proper planning is essential in order to avoid any adverse consequences to the forest ecosystem. As a result, forest road can contribute to the important of reduced impact logging, and therefore the key element towards sustainable forest management (Mohd Hasmadi, 2005).

For instance, harvesting guideline (1997) and forest road specification guidelines (1999) have been outlined by the Forestry Department of Peninsular Malaysia to ensure that the forest road operations are commencing accordance to high standard and consistent. Forest road specifications are a basic principal to guide the loggers in forest road construction, where specification for the road design should minimize negative impacts and improves safety of all employees involved in harvesting operations. The guideline must be used by all concessionaires or loggers as a principle and standard during constructing forest roads which is comply to engineering aspect such as road specification and geometric of the road. Forest engineering involves the specification of the standard design of forest road according to actual engineering design, field layout, construction and maintenance and subsidiary structures such as bridges and culverts.

Forest road are complex engineering structures, which transport efficiency and reliable access to the forest both depend. The building of forest road involves high capital expenditure and in addition, there is continuing cost for road maintenance. Road construction and maintenance are important to be considered, especially in tropical forest with a low yield of merchantable logs per unit area, hilly area and weather conditions such as rainfall density. Therefore, construction of the road should be carried out with close observation to economic aspect and consideration of the topographic difficulty such as forest terrain (Dykstra and Heinrich, 1996). On the other hand, the design of forest road not only should permit safety for the transportation traffic but should be comply with the specification or guideline. Thus, this study was carried out to evaluate the effectiveness of feeder road construction in compliance to the Forest Road Specifications 1999 as outlined by the Forest Department of Peninsular Malaysia.

\section{Methodology}

Description of study area

The selected study area is located at Ulu Muda Forest Reserve, Baling in the Kedah State, Peninsular Malaysia. The site covers an area about 1,948 hectare, situated in Mukim Siong, where the main entrance starts from Kg. Weng. The actual study site encompasses three forest compartments; 9, 25 and 26. The distance of main road from Kg. Weng to compartment 25 is $17.3 \mathrm{~km}$. The location of the study area and feeder road is shown in Figure 1.

The forest road was built in 1960's for timber harvesting from compartment 7 . The road was used for main access to study site called Waduk, which is part of compartment 25 . The construction cost of $2.5 \mathrm{~km}$ in compartment 25 is about RM 105,000.00 at that time and the road maintenance was financed by the Department of Irrigation Malaysia and Muda Agriculture Development Authority (MADA). The maintenances includes installation of culverts, repairing side drain, road surface and bridge upgrade. The area experiences two dry seasons from January to February and June to July annually.

[Figure 1: A map of Peninsular Malaysia showing a feeder road in the study area]

\section{Data collection}

This study involved measurement of forest road specification element along $14.5 \mathrm{~km}$ of the feeder road under surveyed. Figure 2 showed the actual feeder road under studied in Ulu Muda Forest Reserve. A systematic sampling was done where the data were collected at every $500 \mathrm{~m}(0.5 \mathrm{~km})$ distance. Hundred percent sampling was done at the places or point visited, where damage occurred in order to study the cause of failure. The data were recorded to the specification designs which include:

i. Road Cross Section

- The components measured are the right of way width, carriageway width, carriage way material, road camber and pavement material.

ii. Drainage structure

- The data collected were the type and size of culvert, bridge and side drain that was divided into three parts which are depth, width at the top and bottom.

iii. Vertical alignment

- This includes the measurement of the road gradient and length of gradient.

iv. Horizontal alignment - Super elevation and radius of curve measurement. 
v. Road failure

vi. Earth work
- The data measured on failure which occurs and thus covered the length of failure, causes failure, type of failure, failure position and type of soil.

- Observation of excess earth that was disposed to approved dumpsite and the present of silt tarps to erosion prone areas.

The process of data collection involved the use of basic equipment to measure the geometric design of feeder road specification. The equipments used were compass, measuring tape $(50 \mathrm{~m})$, Suunto Clinometer, and stick pole.

[Figure 2: Feeder road in compartment 25, Ulu Muda Forest Reserve]

Types of roads failure were classified into five categories. They were:

1. Surface failure

2. Landslides

3. Wheel track

4. Drainage failure

5. Surface run-off
- Occur on running surface between 0-10 cm depths.

- Initiate on side slopes with gradients ranging from 35-140\%. Majority of the landslides started on slope between $70-90 \%$. The soils on very steep slopes were typically very shallow and it is not well developed

- Occurs on running surface when the soil could not support the weight of vehicles through tire pressure to sub grade.

- Drainage systems are not well-developed and caused water flow off road surface and disturbance to the water flow.

- The destruction or removal of the soil surface contributes to storm flow by decreasing the potential for water storage in the soil.

\section{Data analysiss}

The data was analyzed into two parts, which are the roads failure and roads specification. The road failures were presented by percentage and number of failures occurs, meanwhile roads specification were covered the minimum and maximum value, average, percentage of differential in order to compare it to the forest road specification. All measured values were keyed in SPSS software to produce the result. Forest Road Specification 1999 manual by Forestry Department of Peninsular Malaysia was used as reference and standard for comparison to the geometric design of feeder road construction.

\section{Results and Discussion}

\section{Road failure}

The total length of feeder road failure at compartments 9, 25 and 26 in Ulu Muda Forest Reserve, Kedah is 551.4m or $3.8 \%$. A total of 25 sites along the $14.5 \mathrm{~km}$ stretch of road were evaluated as road failure. The major types of failure were surface failure, surface run off and wheel track. The main reason was caused by the soil factor, where occurring sites was categorized as clay type, which can less capability for water absorption. The smallest gaps between the fine particles were led to the formation of pond track or waterlogged on the running surface. This is also affected by the climate of the area that received a high volume rain during the time of the study.

The road failures were classified into five types of failures, namely surface failure, surface run off, wheel track, drainage failure and landslide that as shown in Figure 3. The major failure occurred on the feeder road was surface 
failure with $38 \%$ or $465 \mathrm{~m}$ of road length. This was followed by drainage failure $(30 \%)$, wheel track $(23 \%)$, surface run off (5\%) and landslide (4\%), respectively. The failure such as wet or soft soil and pond occurrence caused by the damaged of the side drain and right of way built with too small construction design. All the causes influenced the road failures by influences the soil which has low water absorption in soil.

[Figure 3: Percentage of road failure by categories of failure type]

Road failure occurred by drainage was $367.9 \mathrm{~m}$, this due to the absence of improper side drain, road chamber and damaged culvert. It occurred when the water flow-off and side ditch plugged by the sediment. Drainage failure has a very close relationship to surface failure and wheel track because it happened after the traffic allowed passage through the road and the capability of soil to absorb the surface water. Meanwhile, wheel track failure type recorded of $274.9 \mathrm{~m}$ of road length. This occurred mainly because of the soil cannot support the weight of vehicles. The heavy traffic operation during the raining season affected the road damage and more slippery on the road surface. The drying process was very slow due to a small gap opening with less of light intensity and low water evaporation. Surface run-off and landslides are the minor failures occurred. Surface run-off occurred in the range of $64 \mathrm{~m}$ caused by the too high of road gradient. Soil particles removed together which water flowed to a lower area. It also occurred by the pavement material type which has a sandy surface and not well compacted. Landslide with the value of $46 \mathrm{~m}$ or occurred due to the side slope which was too steep and shallow with non-cohesive soils coupled with a side casting of excess material, probably occurs during raining season.

Road failures occur by several causes. The major causes of road failure were categorized to six factors which were shown in Figure 4. The failure caused by the small crown opening is $32 \%$ or 21 sections of the road failure. The minimum value of crown opening is $7.5 \mathrm{~m}$ and the average is $14 \mathrm{~m}$. The minimum width of crown opening was blocked light intensity to reach ground that enable drying the road surface. A higher humidity is needed to allow evaporation process which air velocity is limited in contributing to the drying process on the road surface. Figure 5 showed the example of the failure caused by insufficient crown opening.

[Figure 4: Percentage causes of road failure]

Absence of road chamber was noted at 20 places out of 25 or $31 \%$ of the road failure. The maximum value of the road chamber was $10 \%$ or 1:10 that contribute to surface run off for sandy surface. Absence of road camber contributes to improper flow of water into the side drain, and finally damaged the road surface. In addition, heavy traffic density also contributes to the removal of existing chamber at every time traffic passed through.

[Figure 5: Road failure caused by insufficient crown opening]

Side ditch is the main component in controlling water direction to avoid damages on the road surface. The absence of side ditch was observed at 8 places out of 25 sections, represented about $12 \%$. The total of side ditches that complies with the specification is $68 \%$. This revealed that the side ditch was constructed according to the specification but the rate of $68 \%$ was still lower because sometimes damaged can occurs by a high rate of water flow and erosion. Surface flow from several sources collected into small natural drainage, were not capable in handling the increased volumes of water. Figure 5 showed consequences of improper maintenance of the side ditch that caused high rate of water flow on the road surface.

The total number of unstable sub-grade or not compacted soil was 13 sections or $20 \%$ in the study area. Unstable sub grade has a low moist condition in order to support the weight of vehicle pressure. It encourages damage by wheel track because there were wide gaps exist between the fine particles. The absence or damaged culvert with the value $3 \%$ on stream crossing also caused the road failure. The lack of culvert or spaced too far apart forced the ditches to collect too large amount of water. Sometimes the culvert inlets were stuck with sediment and debris.

[Figure 6: Consequences of improper maintenance of the side ditch caused water flow on road surface]

Factors contributing to the failure are caused by geometric specifications that were not properly applied during the construction of the forest road. The measurement of different forest road components compared to specification on failure points was shown in Table 1. Meanwhile, the measurement of compliance to geometric specification on failure point was shown in Table 2.

[Table 1: Measurement of differential of forest road components compared to the specification on the road failure]

\section{Forest road specification}

The main components that have been measured in the forest specification 1999 were carriage way, right of way, side ditch, road chamber, pavement material, road gradient and length of gradient. Table 3 shows the different of each component compared to the standard design, and Table 4 showing the percentage of compliance and non-compliance of the road constructed to specification. 
The minimum limit of carriageway width is $3.5 \mathrm{~m}$ and maximum limit is $5.5 \mathrm{~m}$. The standard width for road design of feeder road must be $\leq 5 \mathrm{~m}$. It was noted that 29 out of 30 samples measured were met to standard or specification with the percentage of $96 \%$, and only one sample or $3 \%$ did not meet the specification. The minimum figure of $3.5 \mathrm{~m}$ width is too small to be counted and do not influence the log transportation due to the low traffic density except at passing sight distance. Mostly 30 samples of the road surface are in good condition and suitable for the traffic usage.

[Table 2: Measurement of compliance to geometric specification on the road failure]

[Table 3: Road construction practices compared to Forest Road Specification]

[Table 4: Percentage of compliance and non-compliance of road constructed to specification]

The percentage right of way meet the standard specification was $73.3 \%$ (22 samples) and about $26.7 \%$ ( 8 samples) did not meet to specification. Most of the rights of way widths were sufficient for road condition and traffic ( $96.7 \%)$. Forest road requires a high level of light intensity and air circulation to keep it dry. There are few things which are detrimental to the road than overhanging trees, which produce a moist surface and an eventual reduction of the bearing power. Right of way constructed does not related to the specification that contributes to the road damage and mainly it does not affect the environment.

The components of side ditch were divided into two sections, namely width at the top and depth. The percentage widths at the top constructed meet to specification was $60 \%$ and $40 \%$ does not follow the specification. There were 18 samples totally constructed which met the specification with an average level of $0.5 \mathrm{~m}$. The depth of side ditch is $56.7 \%$ compliance to specification and the minimum value is $0.2 \mathrm{~m}$. This does not contribute to a consistent depth because some of particle soils running with water flow onto the side ditch. The absence or damaged of the side ditches occurred mostly along steep terrain contributed to a surface failure. Surface flows occurred when the water flows-off onto the running surface because the soil moisture content is higher and the strength of the road will drop very fast, thus the bearing capacity of the road may change radically.

There were only $30 \%$ or 9 existed cambers met the specification with maximum values was $1: 10(10 \%)$ and the minimum value was 1:25 (4\%). There are $70 \%$ absences of the road chamber, which contributed to the road failure caused by the water, which could not flow onto the side ditch very well. The existence of road camber however is very important to avoid the formation of ponds and damages to the road surface. Road chamber more than 1:20 (5\%) is suitable since it has less affect to the road failure. Absence of the road camber contributed to surface erosion and formation of pond on the road surface. The slope of road camber must be steep enough to ensure rapid water run off and gentle enough to prevent gulling.

There are $86.7 \%$ of the road gradients that were constructed meet the specification and $13.3 \%$ constructed do not meet the specification. The maximum value of road gradient is 220 and the minimum is 10 with an average of 2.10. All the samples of gradient length are less than $200 \mathrm{~m}$ or presented $100 \%$ constructed meet to the specification. The function of the road gradient is to provide a smooth movement for all transportation and user safety in harvesting operation. The higher road gradients with unsuitable gradient length causes surface run-off and contributes to surface cracking that affect the log transportation, maintenances cost and high risk to the user.

Pavement material is the total forest floor which is removed using excavator or bulldozer with no compaction process. Gravel is very suitable in usage as material in order to avoid slippery and surface failure; however the construction cost is too high. Therefore it was observed that natural material in the forest was used to reduce the construction cost.

\section{Conclusion}

It can be concluded that most of the road constructed is in compliance to the Malaysian forest harvesting road construction specifications. However, lack of the road maintenance results in the occurrence of damages during harvesting. The roads should be maintained to ensure a stable running surface and to keep the drainage system operating. Therefore, it is necessary to maintain the road according to the specification. On the other hand, the success of the road construction was largely dependent on the raining season. The wet running surface was unable to support a vehicle load that was transferred to the ground (sub-grade) through the pressure and encourages wheel track. In all phases of road construction, adequate drainage should be provided to achieve stability of road structure. Wherever practicable, permanent drainage should be installed in advance from other construction in order to keep the roads as dry as possible. In addition, the insufficient crown opening resulted in the inability of the running surface to dry as fast as possible. The implementation and enforcement of a forest road specification guideline outlined by Forestry Department of Peninsular Malaysia before the commencement logging operation can reduce the ecological effect. In order to overcome the problem current research activities has to be put forward for formulating research with problems affecting the forest road activities. It is concluded that a wide variety of problems occur pertaining to forest road failure in forest operation can be solved through science and applied research. 


\section{References}

Dykstra, D. P. and Heinrich, R. (1996). FAO Model Code of Forest Harvesting Practice. Rome, FAO. 85p.

F.A.O. (1977). Planning of Forest Road and Harvesting System. Forestry Paper 2. Food and Agriculture Organization of the United Nation, Rome, Italy. 106p.

Forestry Department Peninsular Malaysia (1997). Harvesting Guidelines. Forestry Department Peninsular Malaysia Press. 45p.

Forestry Department Peninsular Malaysia. (1999). Specification for Forest Road in P. Malaysia. Forestry Department Peninsular Malaysia Press. 47p.

Kamaruzaman Jusoff, Nik Muhamad Majid and Desa Ahmad. (1986). Effects of Logging Roads on Erosion and Sedimentation. Paper presented at the ASEAN-US Watershed workshop on Roading and Development Activities in Relation to Soil Erosion and Sedimentation Control in Watershed, July 20-26 July 1986, Jakarta, Indonesia. 21p.

Kamaruzaman Jusoff. (1995). Instrumentation in R\&D in Forest Road Construction in Malaysia. Paper presented at the IUFRO XX World Congress, Caring for the Forest: Research in a Changing World, 6-12 August 1995, Tempere, Finland.

Mohd. Hasmadi Ismail. (2005). Application of Geoinformatics to Forest Harvesting in Malaysia. Ph.D (Thesis), Cranfield University, Silsoe, United Kingdom. 330p.

Table 1. Measurement of differential of forest road components compared to the specification on the road failure.

\begin{tabular}{|c|c|c|c|c|c|c|c|c|}
\hline & \multirow{2}{*}{$\begin{array}{l}\text { Carriageway } \\
\text { width (m) }\end{array}$} & \multirow{2}{*}{$\begin{array}{l}\text { Right } \\
\text { of way } \\
\text { (m) }\end{array}$} & \multicolumn{3}{|c|}{ Side ditch (m) } & \multirow{2}{*}{$\begin{array}{l}\text { Road } \\
\text { camber } \\
(\%)\end{array}$} & \multirow{2}{*}{$\begin{array}{l}\text { Road } \\
\text { gradient } \\
\left({ }^{0}\right)\end{array}$} & \multirow{2}{*}{$\begin{array}{l}\text { Length of } \\
\text { gradient } \\
\text { (m) }\end{array}$} \\
\hline & & & $\begin{array}{l}\text { Top } \\
\text { width }\end{array}$ & $\begin{array}{l}\text { Bottom } \\
\text { width }\end{array}$ & Depth & & & \\
\hline $\begin{array}{l}\text { Feeder road } \\
\text { specification }\end{array}$ & $\leq 5$ & $\leq 12$ & $\geq 0.5$ & 0.2 & $\geq 0.3$ & $\begin{array}{l}\geq \quad 1: 20 \\
(5 \%)\end{array}$ & $\leq 11.3$ & $\leq 200$ \\
\hline Total & 115.6 & 251.5 & 17.9 & 5.9 & 11.3 & 26 & 158 & 940 \\
\hline Average & 4.6 & 10.1 & 0.7 & 0.2 & 0.5 & 5.2 & 5.3 & 31.3 \\
\hline $\begin{array}{l}\text { Maximum } \\
\text { value }\end{array}$ & 6.8 & 14.0 & 1.9 & 0.8 & 1.2 & 10 & 14 & 70 \\
\hline $\begin{array}{l}\text { Minimum } \\
\text { value }\end{array}$ & 3.0 & 7.5 & 0.6 & 0.2 & 0.4 & 3.3 & 1 & 20 \\
\hline
\end{tabular}

Table 2. Measurement of compliance to geometric specification on the road failure

\begin{tabular}{|c|c|c|c|c|c|c|c|c|c|}
\hline & \multirow{2}{*}{$\begin{array}{l}\text { Carriage } \\
\text { Way Width }\end{array}$} & \multirow{2}{*}{$\begin{array}{l}\text { Right } \\
\text { of } \\
\text { Way }\end{array}$} & \multicolumn{3}{|c|}{ Side Ditch } & \multirow{2}{*}{$\begin{array}{l}\text { Road } \\
\text { Camber }\end{array}$} & \multirow{2}{*}{$\begin{array}{l}\text { Road } \\
\text { Gradient }\end{array}$} & \multirow{2}{*}{$\begin{array}{l}\text { Length of } \\
\text { Gradient }\end{array}$} & \multirow{2}{*}{$\begin{array}{l}\text { Pavement } \\
\text { Material }\end{array}$} \\
\hline & & & $\begin{array}{l}\text { Top } \\
\text { width }\end{array}$ & $\begin{array}{l}\text { Bottom } \\
\text { width }\end{array}$ & Depth & & & & \\
\hline $\begin{array}{l}\text { Number of } \\
\text { road } \\
\text { constructed } \\
\text { to } \\
\text { specification }\end{array}$ & 21 & 24 & 17 & & & 2 & 23 & 25 & 25 \\
\hline $\begin{array}{l}\text { Percentage } \\
(\%)\end{array}$ & 84 & 96 & 68 & & & 8 & 92 & 100 & 100 \\
\hline $\begin{array}{l}\text { Number of } \\
\text { road } \\
\text { constructed } \\
\text { not to } \\
\text { specification }\end{array}$ & 4 & 1 & 8 & & & 23 & 2 & - & - \\
\hline $\begin{array}{l}\text { Percentage } \\
(\%)\end{array}$ & 16 & 4 & 32 & & & 92 & 8 & - & - \\
\hline
\end{tabular}


Table 3. Road construction practices compared to Forest Road Specification

\begin{tabular}{|c|c|c|c|c|c|c|c|c|}
\hline & \multirow{2}{*}{$\begin{array}{l}\text { Carriageway } \\
\text { width }(\mathrm{m})\end{array}$} & \multirow{2}{*}{$\begin{array}{l}\text { Right } \\
\text { of way } \\
\text { (m) }\end{array}$} & \multicolumn{3}{|c|}{ Side ditch (m) } & \multirow{2}{*}{$\begin{array}{l}\text { Road } \\
\text { chamber } \\
(\%)\end{array}$} & \multirow{2}{*}{$\begin{array}{l}\text { Road } \\
\text { gradient } \\
\left({ }^{0}\right)\end{array}$} & \multirow{2}{*}{$\begin{array}{l}\text { Length of } \\
\text { gradient } \\
\text { (m) }\end{array}$} \\
\hline & & & $\begin{array}{l}\text { Top } \\
\text { width }\end{array}$ & $\begin{array}{l}\text { Bottom } \\
\text { width }\end{array}$ & Depth & & & \\
\hline $\begin{array}{l}\text { Feeder road } \\
\text { specification }\end{array}$ & $\leq 5$ & $\leq 12$ & $\geq 0.5$ & 0.2 & $\geq 0.3$ & $\geq 1: 20$ & $\leq 11.3$ & $\leq 200$ \\
\hline Total & 120.8 & 414.2 & 17.4 & 6.6 & 9.3 & 64.2 & 196.5 & 1385 \\
\hline Average & 4.0 & 13.8 & 0.5 & 0.2 & 0.3 & 2.1 & 6.6 & 46.2 \\
\hline $\begin{array}{l}\text { Maximum } \\
\text { value }\end{array}$ & 5.5 & 21.0 & 2.3 & 0.7 & 1.4 & 10 & 22 & 150 \\
\hline $\begin{array}{l}\text { Minimum } \\
\text { value }\end{array}$ & 3.5 & 9.0 & 0.5 & 0.3 & 0.2 & 4 & 1 & 20 \\
\hline
\end{tabular}

Table 4. Percentage of compliance and non-compliance of road constructed to specification

\begin{tabular}{|l|l|l|l|l|l|l|l|l|l|}
\hline & \multirow{2}{*}{$\begin{array}{l}\text { Carriage } \\
\text { way } \\
\text { width }\end{array}$} & $\begin{array}{l}\text { Right } \\
\text { of } \\
\text { way }\end{array}$ & $\begin{array}{l}\text { Sop } \\
\text { width }\end{array}$ & $\begin{array}{l}\text { Sottom } \\
\text { width }\end{array}$ & Depth & $\begin{array}{l}\text { Road } \\
\text { chamber }\end{array}$ & $\begin{array}{l}\text { Road } \\
\text { gradient }\end{array}$ & $\begin{array}{l}\text { Length } \\
\text { of } \\
\text { gradient }\end{array}$ & $\begin{array}{l}\text { Pavement } \\
\text { material }\end{array}$ \\
\hline $\begin{array}{l}\text { Number of } \\
\text { road } \\
\text { constructed } \\
\text { to } \\
\text { specification }\end{array}$ & 29 & 22 & 18 & 18 & 17 & 9 & 26 & 30 & 25 \\
\hline $\begin{array}{l}\text { Percentage } \\
\text { (\%) }\end{array}$ & 96.7 & 73.3 & 60 & 60 & 56.7 & 30 & 86.7 & 100 & 100 \\
\hline $\begin{array}{l}\text { Number of } \\
\text { road } \\
\text { constructed } \\
\text { not } \\
\text { specification }\end{array}$ & 1 & 8 & 12 & 12 & 13 & 21 & 4 & - & - \\
\hline $\begin{array}{l}\text { Percentage } \\
\text { (\%) }\end{array}$ & 3.3 & 26.7 & 40 & 40 & 43.3 & 70 & 13.3 & - & \\
\hline
\end{tabular}

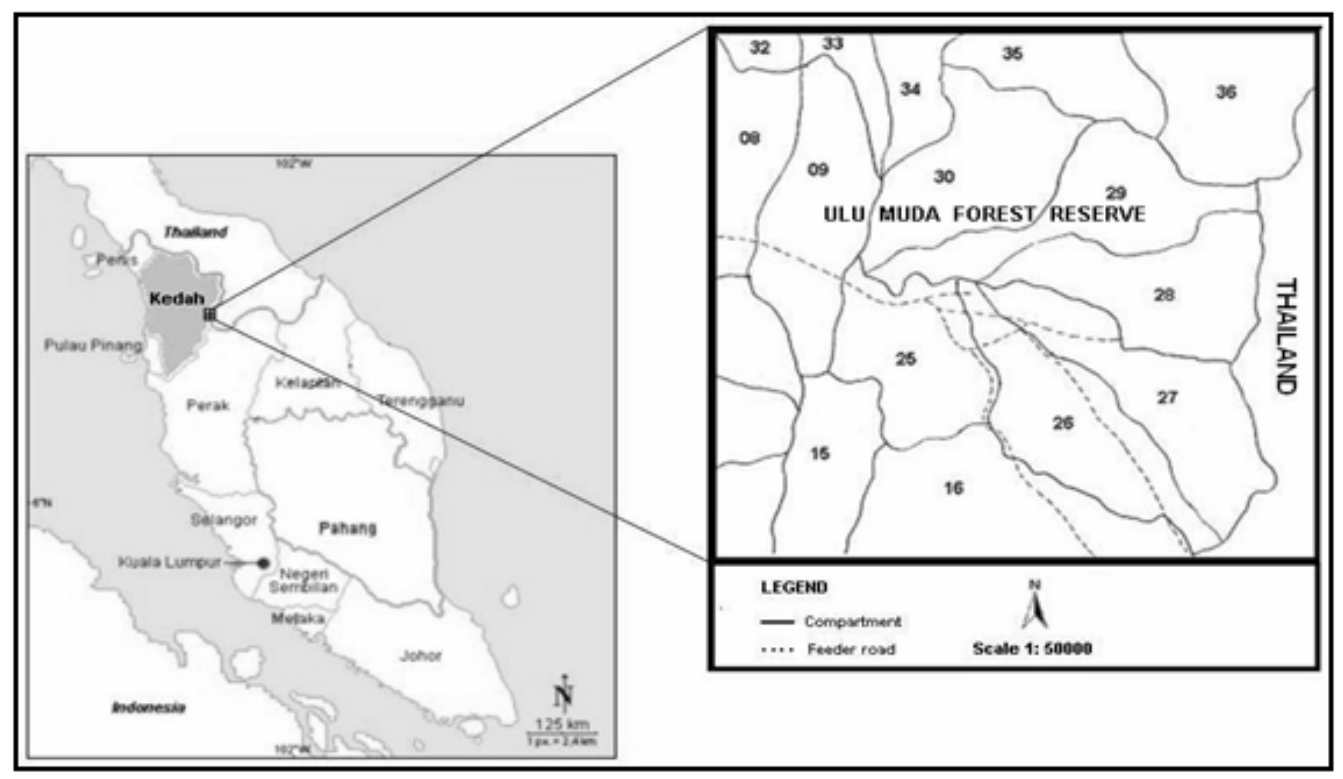

Figure 1. A Peninsular Malaysia map showing a feeder road in the study area 


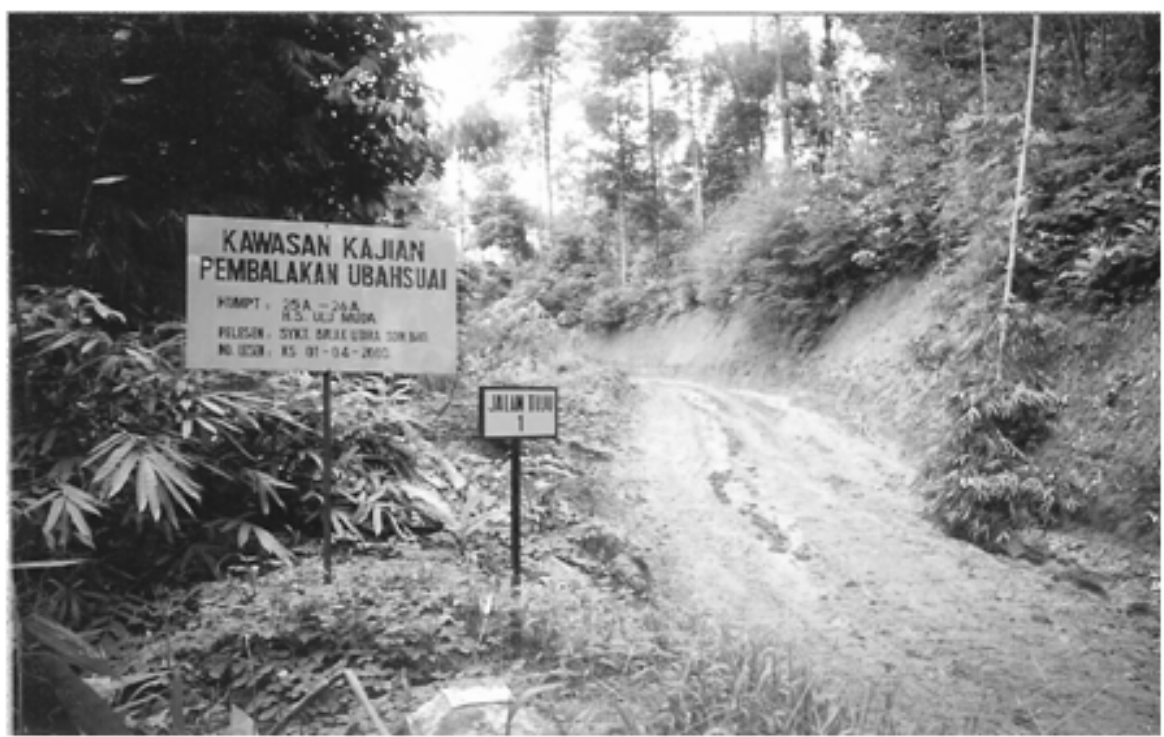

Figure 2. Feeder road in compartment 25, Ulu Muda Forest Reserve

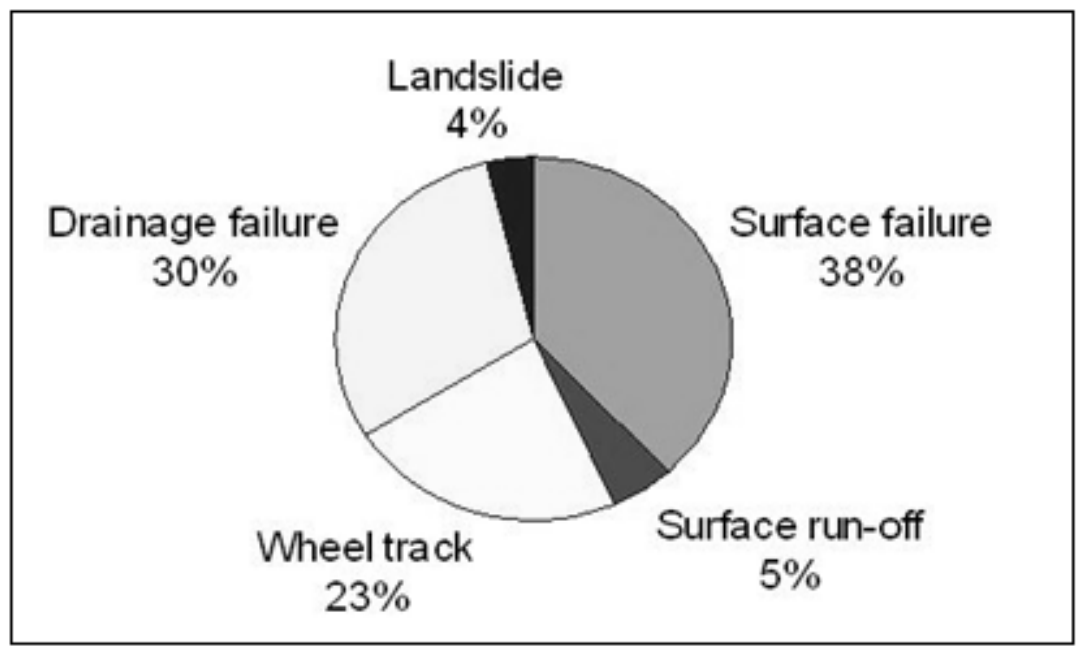

Figure 3. Percentage of road failure by categories of failure type.

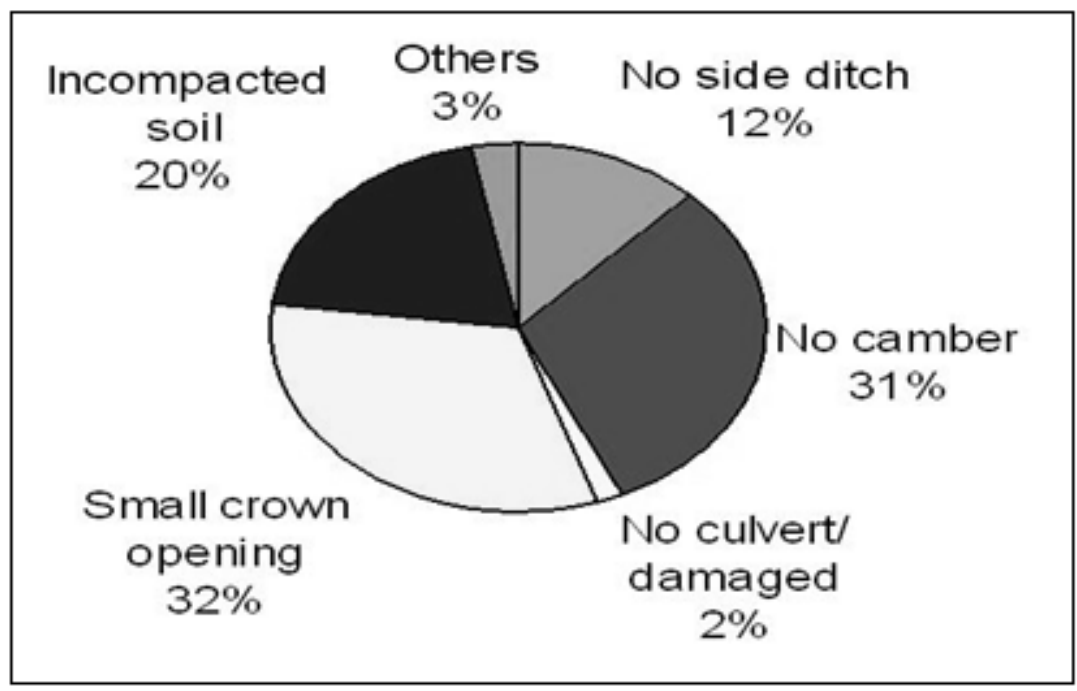

Figure 4. Percentage causes of road failure 


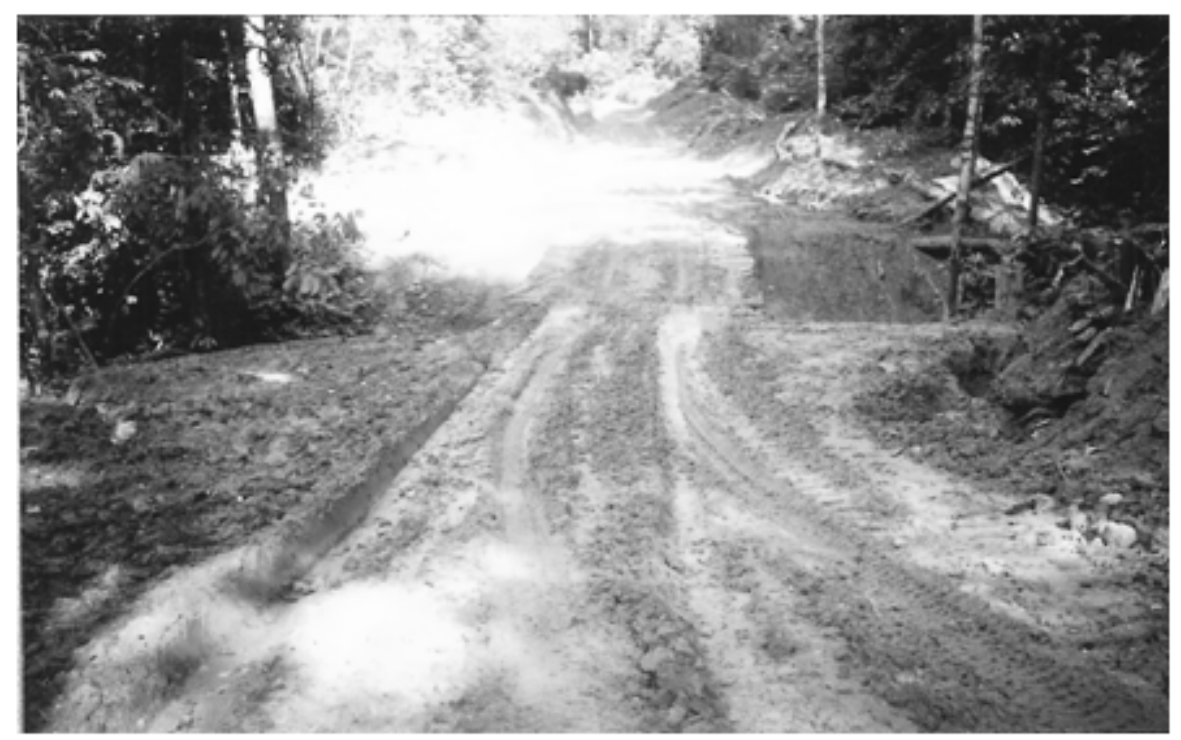

Figure 5. Road failure caused by insufficient crown opening

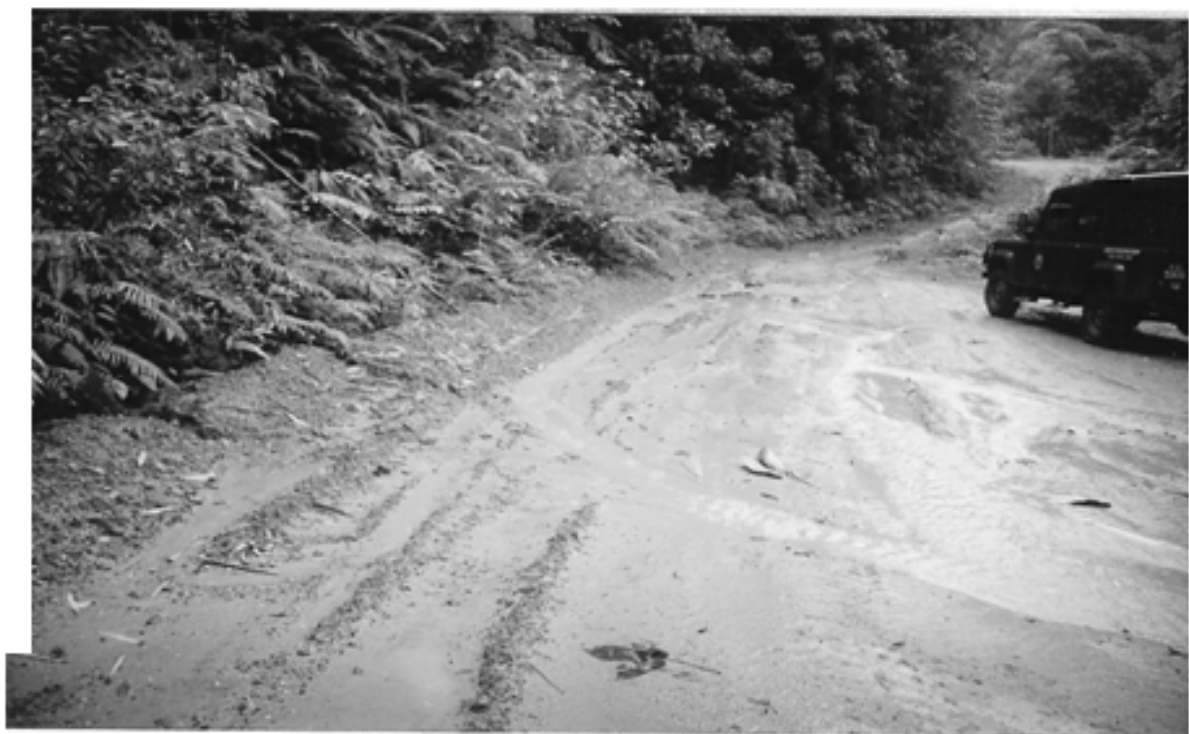

Figure 6. Consequences of improper maintenance of the side ditch caused water flow on road surface. 


\title{
Discussion on Computation of Prestressed Concrete
}

\section{Beam's Bearing Capacity}

\author{
Yingge Wang \\ Department of Civil Engineering \\ Jiaying University \\ Meizhou, Guangdong, China 514015 \\ E-mail: summerc29@126.com
}

\begin{abstract}
Based on the producing mechanism of prestressed equivalent load, the prestressed effect of the frame structure is analyzed. This paper focuses on the functional characteristics of presstressed steel bars and classifies the contribution of prestressed steel bars at two aspects. Accordingly, the ultimate normal section load-bending capacity of prstressed beam is derived; the restriction effect which will counteract prestressed frame beam caused by secondary beam is presented, and the deficiency of prevail plane rigid frame method is pointed out.
\end{abstract}

Keywords: Prestressed concrete beam, Bearing capacity, Lateral confinement

\section{Analysis of pre-stressed steel bars' operational mechanism}

The use of pre-stressed concrete is now common in structures design. And with the increasing use of new construction, there is a need for a closer look at its design and analysis. Many experimental and analytical studies have been carried out in the past five decades.

Introducing concepts of primary moment, secondary moment \& comprehensive moment into computation of statically indeterminate prestressed concrete structures brings difficulty to those structures' design. In order to profoundly reveal the essence of prestressed force, this paper analyses the role of prestressed steel bars from two aspects.

The first function of prestressed steel bars arises from the beginning of stretching prestressed bars to the establishment of effective stress $\sigma_{p e}$; at that time, the preformed holes weren't filled with grout, the prestressed reinforcements weren't bonded with concrete, either. After the stretching finished, the system comprised of prestressed reinforcement \& anchor device acts on the segregate body including concrete \& non-prestressed reinforcement, which can be identified as equivalent load. Prestressed reinforcement plays an active role, so prestressed force and internodes equivalent loads evoked by the action are recognized as exterior loads. By now, the effect of prestressed bar-anchor system on segregate body has fully developed in the form of equivalent resultant force. Despite no cementation between prestressed reinforcement \& concrete, prestressed force still applies on the segregate body consisting of concrete \& non-prestressed reinforcements after prestressed bars being stretched.

Grouting materials are injected into prepared holes after prestressed reinforcements being stretched. When the grouts condensate and get rigidity, prestressed reinforcements adhere to surrounding concrete, shaping the whole, resisting force and deforming together. As prestressed reinforcement reaches ultimate strength, the redundant tensile strength $\left(f_{p y}-\sigma_{p e}\right)$, the surplus part of construct tensile strength value $f_{p y}$ exceeding effective prestressed force $\sigma_{p e}$, passively provides resisting force like ordinary reinforcement. This is the second function of prestressed reinforcement. The trend lines of prestressed reinforcement's stress are shown in Figure1.a.

In Figure1.a, point $o^{\prime}$ is related to $\sigma_{p e}$. During the process of the surrounding concrete's being strained, the stress of prestressed reinforcement moves along the stress-path 1 until reaching yield stress $f_{p y}$. However, if the stress-strain relationship is idealized as double fold lines, the stress of prestressed reinforcement can be considered yielding at $f_{p y}$, and still keeping $f_{p y}$ despite increment of the strain. When the surrounding concrete bears more compression force, the stress in prestressed reinforcement will change along path 2. Increase $\&$ decrease of stress-strain in bonded bar is shown in Figure 1.b, where origin of coordinate is located on point $o$ '. Unlike stage 1, the change of stress on certain section will not expand to the whole bar, and the increment of stress on this section is only determined by its section internal force. Therefore, the effect of prestressed reinforcement equals to the homalographic common bar whose tensile yield 
stress is $\left(f_{p y}-\sigma_{p e}\right)$.

Generally, $\sigma_{p e}$ is a demarcation point: prestressed steel bar is an agent which acts on the structure in the form of equivalent load on one hand; on the other hand, it is a receiver supplying redundant load bigger than $\sigma_{p e}$.

What more we need to declare here is how to choose the prestressed bars' ultimate strength. Since prestressed bar has no visible yield step, which presents difficulty to accurate calculation of prestressed beam. In China Code for Design of Concrete Structures (GB 50010-2002), constrained yield stress $f_{0.2}$ is used as nominal yield stress on the base of material stress-strain curve. Prestressed reinforcement usually can reach nominal yield stress to the damage of beam with appropriately reinforcement, so it is simple and safe to replace the yield stress of high-strength material $f_{p y}$ by $f_{0.2}$, ignoring the part of stress exceeding $f_{p y}$.

\section{The equation of bearing capacity on cross-section}

In the formula of PRC (prestressed reinforcement concrete) structure's cross-section bearing capacity calculation, the problem why and how to take the secondary moment into account puzzled people in a long term, which also hindered the development of PRC structure. This paper analyses PRC structure cross-section bearing capacity on the base of exploring the prestressed reinforcement's mechanism of action.

$M_{D}$ represents design bending moment; $M_{p}$ represents the control section moment under the load of end prestressed force and its secondary internode load; $N_{p}$ expresses axial load(compression force is positive). Both design load and equivalent load are applied on structure; accordingly the bending moment on this section is $M_{D}=M_{D}+M_{p}$. By now, the first function has been considered. And then, the bearing capacity of section can be calculated by substituting common steel bar for prestressed reinforcement with same area and at the same location. We can select a differential segment as the free body, shown in Fig. 2.

Those are the equations of bearing capacity on cross-section acquired from the balanced equations for the select free body.

$\left\{\begin{array}{l}M_{D}+M_{p}=A_{s} f_{y}\left(h_{s}-\frac{x}{2}\right)+A_{p}\left(f_{p y}-\sigma_{p e}\right)\left(h_{p}-\frac{x}{2}\right)+N_{p}\left(h_{p}-e_{p}-\frac{x}{2}\right) \\ f_{c m} b x=N_{p}+A_{s} f_{y}+A_{p}\left(f_{p y}-\sigma_{p e}\right)\end{array}\right.$

\section{The influence of lateral confinement action on the bearing capacity of PRC beam's cross-section}

The structure that we choose in deducing process has not any lateral confinement. That is to say, neither connected member nor pedestal influences compression deformation of beam and constrains axial deformation. Therefore, the axial force in beam section always equals to the arithmetic product of effective prestressed force and area of pre-stressed reinforcement, $N_{p}=A_{p} \sigma_{p e}$. It is acceptable to continuous beam and frame beam connecting columns whose rigidity is smaller. The bearing capacity equation of those structures fit with the China Code for Design of Concrete Structures (GB 50010-2002). However, in practical structure, vertical construction member functions as lateral confinement more or less, which hampers the transmission of axial force in horizontal bending member. The bigger \& harder the vertical member is, the more visible the effect is. There is $N_{p}<A_{p} \sigma_{p e}$, so it is incorrect to adopt this method into calculation of beam with lateral confinement.

As to frame construction, its top \& bottom layers' prestressed beam's final axle force effect is smaller than polar pre-applied force, i.e. there is axial loss of prestress. Main reason of this loss is that pillar has lateral rigidity, and pillar's lateral limitation restricts horizontal prestress's transmission to middle part of beam. In prestressed frame construction, the equivalent load of inter-segment and polar concentrated moment affect little to beam's axial force. Moreover, the influence to beam's axial prestress is also small when in frame construction pillar's rigidity is low and stride few. But as to pillars of frame constructions with numerous layers (for example, high-level frame construction), because prestressed beam span is large, large distance between pillars causes pillars' larger load area, and the large number of layers, the result is the pillars' axial force is quite great. Size of pillars' sections are decided by axial pressing ratio, such sections are often big. The component section's rigidity is proportional with its height's cubic powers; the larger the section's height, the greater the components' rigidity. Size of frame beam's section is generally determined by the span, the section' height is usually $1 / 15 \sim 1 / 20$ of the span. The pillars' rigidity here is possibly much larger than the beam's. Because rigidity of the pillars' section is great, the axial loss of pre-stressed force is great. The more rigid the pillars are and the more the continual spans are, the more the loss is.

Under action of axial pre-applied force, beam does not counter-arch, thus there won't be spatial effect caused by secondary beam's connection. Therefore, analysis of axial pre-applied force could adopt the plane frame. When analyzing pillars' influence, the pre-applied force's vertical influencing scope should first be made clear, i.e. how many 
layers of pillars the beam's polar pre-applied force transmits through. Scope and degree of axial pre-applied force's influence are related with pillars' rigidity. As to prestressed beam, there's a lid on its top when it's pulled by pre-stressed force. Under polar funneling effect, the beam makes axial translation, thus produces pre-stressed force in middle of the beam, simultaneously drives the connected top and bottom pillars' displacement; pillars hinder beam's axial deformation by its anti-side rigidity and participate axial pre-stressed force's distribution through form of anti-cutting. The pre-applied forces assigned by top pillars completely transmit to upper pillars through upper nodes, so the upper prestressed force's range of influence is definite. As to pillars, the pre-applied force they assigned transmits to lower pillars. Shearing force of farther pillars could be neglected. When beam of certain layer is pulled, its nearest upper \& lower pillars' shearing forces are greater; shearing forces of pillars one layer farther are small; axial pressure in the neighboring layer's beams are large while axial forces in beams one layer farther are very small (and they are pulling force). Therefore, it could be demonstrated that the pre-stressed effect transmitted through pillars only need to take the neighboring upper \& lower pillars into account, i.e. pillars' rigidity's influencing area is mainly at upper \& lower layers while transmits through shearing force of beams' \& pillars' nodes when influencing.

Due to the effect of column lateral confinement, the axial force in beam is less than the effective prestressed force, that is $N_{p}<A_{p} \sigma_{p e}$. The main axial force in section of beam can be expressed as $N_{M}=A_{p} \sigma_{p e}$. Then the secondary axial force is obtained $N_{S}=N_{p}-N_{M}<0$. Obviously it is tension. Taking $N_{p}=N_{S}+N_{M}$ into the equation 1 and assuming $M_{p}=-A_{p} \sigma_{p e} e_{p}, N_{M}=A_{p} \sigma_{p e}$, we can get the equation 2.

$$
\left\{\begin{array}{l}
M_{D}+M_{p}=A_{s} f_{y}\left(h_{s}-\frac{x}{2}\right)+A_{p}\left(f_{p y}-\sigma_{p e}\left(h_{p}-\frac{x}{2}\right)+N_{S}\left(h_{p}-e_{p}-\frac{x}{2}\right)\right. \\
f_{c m} b x=N_{p}+A_{s} f_{y}+A_{p}\left(f_{p y}-\sigma_{p e}\right)
\end{array}\right.
$$

Because the secondary axial force is tension, what the section of prestressed frame beam bears is stretch bending force. Equation 2 accords with the rule in China Code for Design of Concrete Structures (GB 50010-2002). As a result, the section bearing capacity of stretch bending member is lower than that of pure bending member. The secondary axial force in beam originates from the secondary shear force in column, and its value increases with the resistance rigidity to lateral bending of column and the prestressed force absorbed by it. It is unsafe to bearing capacity and unpractical to crack resistance to directly apply the equation induced from the structure of continuous beam to the frame beam.

\section{References}

Lu, Shusheng. (2000). The modern pre-stressed concrete theory with applies. Beijing: Chinese Railroad Publishing house. pp. 238-246.

People's Republic of China Ministry of Construction. (2002). Concrete structure Design Standard (GB50010-2002). Beijing: China Building industry Publishing house.

Ranzo G. (2000). Experimental and numerical studies on the seismic performance of beam-column RC structural members subjected to high shear. Ph.D. thesis. University of Roma "La Sapienza".

Saritas A, Filippou FC. (2006). A beam finite element for shear critical RC beams, 19. ACI Special Publication SP 237, pp. 295-310.

Xiong, Xueyu, Huang, Dingye. (1998). Prestressed concrete structure load effect combination and right section supporting capacity design calculation suggestion Industrial architecture, 2, 1 5. 


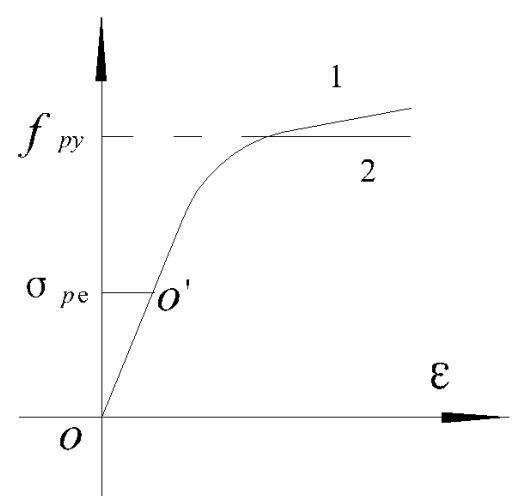

Figure 1. a Stress-strain curve of prestressed reinforcement

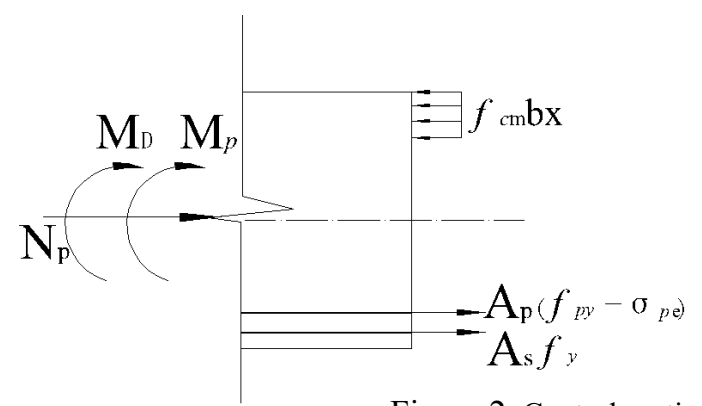

Figure 2. Control section

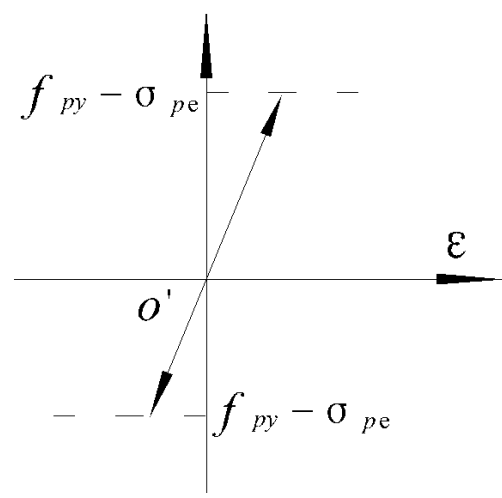

Figure 1. b Ideal stress-strain curve of prestressed reinforcement

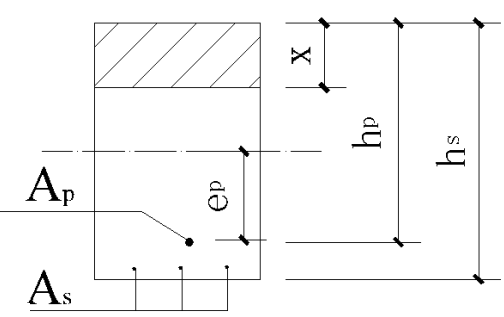




\title{
Study of pH System in Common Effluent Treatment Plant
}

\author{
B. Meenakshipriya (Corresponding author) \\ Department of Mechatronics Engineering, Kongu Engineering College \\ Perundurai, Erode - 638052, Tamilnadu, India
}

Tel: 91-098-4279-9990Ｅ-mail: devameena@rediffmail.com

Dr.K.Saravanan

Department of Chemical Engineering, Kongu Engineering College

Perundurai, Erode - 638052, Tamilnadu, India

Tel: 91-098-4270-5656 E-mail: rumisivaesh@yahoo.com

R.Shanmugam

Perundurai Common Effluent Treatment Plant

Perundurai, Erode - 638052, Tamilnadu, India

Tel: 91-098-4324-1123

S.Sathiyavathi

P.G Scholar, Department of Mechatronics Engineering, Kongu Engineering College

Perundurai, Erode - 638052, Tamilnadu, India

Tel: 91-098-4339-9667Ｅ-mail: sathiyavathisasikumar@yahoo.co.in

\begin{abstract}
This investigation considers the study of $\mathrm{pH}$ system in Common effluent treatment plant (CETP). For this purpose, Perundurai Common Effluent Treatment (PCETP) is taken for study. Waste from textile industries is rarely neutral. Certain processes such as reactive dyeing require large quantities of alkali but pre-treatments and some washes can be acidic. It is therefore necessary to adjust the $\mathrm{pH}$ in the treatment process to make the wastewater neutral. This is particularly important if biological treatment is being used, as the microbes used in biological treatment require a $\mathrm{pH}$ in the range of 6-8 and will be killed by highly acidic or alkali wastewater. In PCETP, the wastewater is mostly alkali wastes (high $\mathrm{pH})$. For this purpose, hydrochloric acid $(\mathrm{HCl})$ is added to maintain the $\mathrm{pH}$ value from 7.5 to 7.8 to save the microbes used in biological treatment as well as to reduce the wastage of chemicals.
\end{abstract}

Keywords: pH system, CETP, PCETP, Alkali wastes, $\mathrm{HCl}$

\section{Introduction}

The textile industry occupies an important place in the economy of India and other developing countries. Textile processing consumes enormous quantity of water and chemicals for various operations like washing, dyeing, etc. The low efficiency of chemical operations and spillage of chemical cause, a significant pollution hazard and make the treatment of discharged wastewater a complex problem. Most of the wastewater treatment plants recently adopt methods of chemical precipitation and subsequent clarification. Group of textile industries are joined together to form common effluent treatment plant to economize the process.

In CETPs, raw wash effluents from various textile units are collected homogenized and then pumped to flash mixer where flocculants and lime solution are added. The flocculants addition leads to particles destabilization and it very effective in removing the dyes. Since the addition of flocculants decrease alkalinity, lime is dosed to prevent abnormal decrease in $\mathrm{pH}$ value, which may affect the flocculation. The effluent from the flash mixer flows to the clariflocculator 
where the polyelectrolytes is dosed which assist in particle bridging and compaction of the sludge. The overflow from the clarilflocculator is transferred to the sand filter to a static mixer where sodium hypochlorite is added to remove any remaining organic and residual color. The sludge thus formed is transferred to the thickener for concentration of solids and dewatered in a centrifuge. The dewatered sludge from the centrifuge is allowed to stabilize and allowed to dry in sludge drying beds (Baskar, R., 2006).

The industrial pollution control regime in India is based on the standards and regulation approach. Source specific concentration based standard have been laid down for polluting units and penalties for non compliance, disconnection of electricity/water supply and closure of the units. The standards are same for large and medium units as well as for small units. While most of the large and medium polluting units have been able to erect and operate effluent treatment plants, this option does not appear to be viable for many small units because of their small size, and technical, financial and managerial constraints. Common effluent treatment plants are being suggested as a cost-effective option for compliance with the standards for small polluting units in industrial clusters (Shankar, U., 2003).

Most process plants generate a wastewater effluent that must be neutralized prior to discharge or reuse. Consequently, $\mathrm{pH}$ control is needed in just about every process plant, and yet a large percentage of $\mathrm{pH}$ loops perform poorly. Results are inferior product quality, environmental pollution, and material waste. With ever increasing pressure to improve plant efficiency and tighter regulations in environmental protection, effective and continuous $\mathrm{pH}$ control is highly desirable. However, implementing a $\mathrm{pH}$ system is like putting a puzzle together. It will only work when all the components are in place. The $\mathrm{pH}$ puzzle includes effective $\mathrm{pH}$ probes, actuators, and controllers. The challenge is to provide a controller that is able to deal with large nonlinear gain changes in the $\mathrm{pH}$ loop. It will be useful for not only wastewater neutralization, but also chemical concentration control, since concentration is a key quality variable. Various chemicals are used for $\mathrm{pH}$ control. For acidic wastes (low $\mathrm{pH}$ ) sodium hydroxide, sodium carbonate, calcium carbonate or calcium hydroxide, may be added among other things. For alkali wastes (high $\mathrm{pH}$ ), sulphuric acid or hydrochloric acid may be added. Acids can cause corrosion of equipment and care must be taken in choosing which acid to use. Hydrochloric acid is probably better from an environmental view point but can corrode stainless steel therefore plastic or appropriately coated pumps and pipes must be used (OMEGA Engineering, 2006).

A rough indication of $\mathrm{pH}$ can be obtained using $\mathrm{pH}$ papers or indicators, which change color as the $\mathrm{pH}$ level raises. These indicators have limitations on their accuracy. Most accurate $\mathrm{pH}$ measurements are obtained with a $\mathrm{pH}$ meter. A $\mathrm{pH}$ measurement system consists of three parts: a $\mathrm{pH}$ measuring electrode, a reference electrode and a high input impedance meter. Temperature compensation is contained within the instrument, because $\mathrm{pH}$ electrodes and measurement are temperature sensitive (Samiya Ahmed, 2006). Titration is the popular method for determining total acidity on basicity of a solution. An acid/base titration curve is a plot of $\mathrm{pH} \mathrm{Vs}$ reagent addition and graphically shows how $\mathrm{pH}$ changes per unit addition of reagent. Basically, a $\mathrm{pH}$ control system measures the $\mathrm{pH}$ of the solution and controls the addition of a neutralizing agent to maintain the solution at the $\mathrm{pH}$ of neutrality or within certain acceptable limits. It is, in effect, a continuous titration. These $\mathrm{pH}$ control systems are highly varied and design depends on such factors as flow, acid or base strength or variability of strength, method of adding neutralizing agent, accuracy of control (Emerson Process Management, 2004).

\section{Overview of Common Effluent Treatment Plant (CETP, SIPCOT - Perundurai)}

Textile is a major source of income and of great importance for India's economy. At the same time textile processing has major environmental impact. A large proportion of the environmental issues are related to the use and discharge of water. Textile manufacturing is among the major industrial water users. To produce one $\mathrm{kg}$ of textile fabrication about 200 liters of water is used.

A lot of chemicals are added to the process for cleaning and dyeing purposes. Obviously the wastewater effluent from this unit contains considerable amounts of hazardous pollutants, and where heavy metals are very common. In India most of the effluent from the textile industry is discharged untreated into rivers. Today $70 \%$ of available water in India is polluted and two thirds of illness in India is related to water-borne diseases.

Water treatment is a very important step to change these conditions and to achieve a sustainable situation. India's government has an awareness of this and limits for water effluent quality exist. Unfortunately, this regulation is not closely supervised and a lot of places do not follow the regulation. In newly developed industrial areas advanced wastewater treatment is used for textile effluent, as the one in this study area SIPCOT in Perundurai.

\subsection{SIPCOT}

The government is promoting industrial growth in backward and hitherto underdeveloped areas that have potential to grow. SIPCOT is an organization arranging this in the state of Tamil Nadu. Companies, willing to start up industries in that area, lease the land for 99 years and are guaranteed good infrastructure, electricity, sewage and water supply 24 hours a day. 


\subsubsection{SIPCOT Perundurai}

SIPCOT Perundurai was started in the year 2000 and it is divided into two parts, the east and the west part, totally 1240 ha. SIPCOT only leases 732 ha of the total area and today 288 ha of the area is licensed. Currently 210 industries are located in the area within the fields of chemicals, textiles industries, food manufacturing, tanning and engineering products. SIPCOT has a common sewage plant, where black water from all industries is treated. The water comes by gravity in stone-laid drainage pipes and is then taken care of by oxidization ponds.

SIPCOT Perundurai industrial plan is an area designed for 54 different units within textile processing. The processes run at the textile industries are dyeing, bleaching and yarning. The industries in SIPCOT are mainly working with cotton. The cotton contributes with much organic matter in the water effluent. Each of the industries has two different pipe systems for wastewater. One system is taking care of the water from the first washing after dying, called the dye bath effluent. This water has always very high TDS, over $2100 \mathrm{mg} / \mathrm{l}$ and is therefore not measured. The other system is for the remaining effluents from acid wash, water washing, soap washing and softening water. All this is called wash water. The industries have a sensor that measures the TDS value from the wash water, ensuring that it does not exceed $2100 \mathrm{mg} / \mathrm{l}$. If the value is higher a valve will close and direct the water back to the receiving tank to dilute with the other wash water. The textile has two different effluent wastewater streams. The dye bath has a high TDS, above $2100 \mathrm{mg} / \mathrm{l}$, and the wash water has a lower TDS, below $2100 \mathrm{mg} / \mathrm{l}$. Each industry will also measure the flow in both effluent pipes. All effluent from the industries is sent to Perundurai Common Effluent Treatment Plant, PCETP.

\subsubsection{Perundurai Common Effluent Treatment Plant}

Each industry bears the responsibility for dealing with the effluent water from their processing. Therefore the 14 textile units together formed PCETP. Each of the units has different shares in the treatment plant and consequently they are allowed different maximum flows that they can discharge to the treatment plant. The treatment plant only handles industrial effluent from those 14 textile industries. PCETP can operate $3600 \mathrm{~m} 3 / \mathrm{d}$ wash water and $450 \mathrm{~m} 3 / \mathrm{d}$ dye bath.

\subsubsection{Dye bath treatment plant}

The dye bath treatment uses an evaporator for cleaning the water. Before the evaporator the water is pre-treated in the form of sedimentation and fine screening. The evaporation unit is a high technology system that vaporizes the water in five different evaporation tanks, three falling and two forced circulation (vacuum) tanks. They reduce the power input by using two heat exchangers and by doing so recover heat from the outgoing water to the incoming water. The outcomes from the evaporation tanks are two different waters, distilled water that goes back to the industries and the second water that goes to solar dryer ponds. The water in the solar dryer ponds evaporates to the atmosphere in 10 days. The rest consists to $95 \%$ of sodium chloride, $\mathrm{NaCl}$. The salt is collected from the bottom of the ponds and stored in sacks under roof. They produce 3.6 tons of salt each day and the space for storage is limited so this soon becomes a big and critical issue. At the time of writing an investigation is being made about purifying the salt so it can be reused in the textile industries.

\subsubsection{Wash water treatment plant}

The wash water treatment plant was opened in July 2002 and reduces COD and BOD by $40-60 \%$. They regularly measure $\mathrm{pH}, \mathrm{TSS}, \mathrm{BOD}, \mathrm{COD}$ and TDS. The plant has no seasonal variation as the textile industry produces the same quantity the throughout the year. However, the hourly inflow varies widely in both quality and quantity. The receiving tank and the bar screens are designed for the peak flow, but the units down stream of the equalization tank are designed for an average flow and an average quality. The energy consumption is approximately $0.9 \mathrm{kWh} / \mathrm{m} 3$ water treated and the cost is $12-20$ Rupees $/ \mathrm{m} 3(2-4 \mathrm{SEK} / \mathrm{m} 3)$ treated water.

\subsection{Flowchart for PCETP}

The flowchart for Wash water treatment plant in PCETP is shown in the Figure 1. A number is connected to every unit.

The bar screen (1) is where the wastewater first passes through and is situated in the influent of the Receiving sump (2). It is used to take care of rags and large objects in the wastewater, so that these objects do not destroy the forthcoming units, for example pumps. PCETP has two screens that are located inside the receiving sump. The shapes are rectangular, size $1.5 \times 2.5 \mathrm{~m}^{2}$. The clear openings (spaces between bars) of the first screen are 10-15 mm and clear openings of the second screen are $20 \mathrm{~mm}$. The screen is hand-cleaned once a day and this is sufficient because the character of the water is good.

The purpose of the receiving sump is to attain the same flow into the treatment plant. The diameter of the receiving sump is 8.0 meters and it has a depth of 2.3 meters. The flow into the treatment plant is about $132-150 \mathrm{~m}^{3} / \mathrm{h}$ and TDS is less then $2100 \mathrm{mg} / \mathrm{l}$. In general, TDS is around $1800 \mathrm{mg} / \mathrm{l}, \mathrm{pH}$ is about $8-9$ and the retention time in the tank is approximately 45 minutes. 
Afterwards the water is pumped to the equalization tank (3). The water is spread over three floating aerators, which distribute the water on to the surface of the equalization tank. The water is mixed with air so that an anaerobic process does not occur and settling of suspended solids is avoided. The equalization tank is there to equalize the temperature, quality and flow rate of the water. In other words, minimizing the fluctuation in those parameters for the downstream units. The equalization tank in PCETP has a diameter of 32 meters and a depth of 4 meters. The retention time in the tank is about 24 hours with a flow of $150 \mathrm{~m}^{3} / \mathrm{h}$.

The water is then again pumped to the flash mixing tank (4). The first goal for the mixing tank is to raise the wastewater $\mathrm{pH}$ to form metal hydroxide particles, by the addition of lime. The next step is to add iron sulphate and polyelectrolyte into the wastewater. Iron sulphate destabilizes the colloids so they are able to flocculate. The polyelectrolyte attaches to the metal solid particles and small metal hydroxide particles become entangled in the polyelectrolyte. This increases the particle size, which promotes settling. The mixing tank has a volume of $1.5 \times 1.5 \times 1.8 \mathrm{~m}^{3}$ and the mixer is mechanical. In PCETP they add lime to raise the $\mathrm{pH}$ to 11 . Water samples are collected about every two hours from the equalization tank so the dose of the chemicals can be regulated to the quality of the water. On average, the chemicals added in 1 liter wash water are $80-90 \mathrm{ml}$ Lime, $\mathrm{Ca}(\mathrm{OH}) 5 \%$ and $20 \mathrm{ml}$ iron sulphate, FeSO4 5\%. The water retention time in the flash mixing tank is about two minutes.

After that the water goes into the clariflocculator (5), where the particles coagulate and sink to the bottom as sludge. The deposited sludge is scratched off from the bottom of the tank and pumped into the sludge sump. The cleaner water reaches the top; it flows out through the outfall, which extends all around the settling tank.

The outlet water from the clariflocculator goes to the clarified effluent sump (6). The sump is used to provide a constant flow into the next unit, the AVG filter (7). The clarified effluent sump in PCETP has a retention time of 30 minutes. The dimension of the tank is $10.0 \times 6.0 \times 2.5 \mathrm{~m}^{3}$. The water is pumped by means of the automatic valves gravity filter feed pumps to the Automatic Valves Gravity Filter, AVGF. The purpose of the filtering is to remove suspended solids, which did not settle in the sedimentation basin. The reason the particles do not settle could be that they are too small and do not have sufficient time to settle. The particles instead follow the water out. The wastewater passes through the filter bed composed of granular material. The removed particles are accumulated in the voids in the sand therefore the head increases. When the pressure gets too high, automatic backwashing starts to remove the suspended solids. In PCETP, the sand filter is used because it is effective and made of cheap material. They have three different sand stones of a different density to increase the flow. The coarse material is on the bottom and the fine material on the top. The driving force in the sand filter is the capillary drainage system in the bottom. The flow in the filters is $7 \mathrm{~m}^{3} / \mathrm{h}$. This gives a retention time of approximately 10 minutes. The filter is backwashed for about 15 minutes with a flow of $50 \mathrm{~m}^{3} / \mathrm{h}$, in general twice a day. The backwash water from the sand filter goes back to the receiving sump.

After the AVGF, $\mathrm{HCl}$ is added and mixed into the water with a static mixer (8) to reduce the $\mathrm{pH}$ to 7.5-7.8. A static mixer is placed on the pipe to the stability tank and is designed with baffles. This mixes the water hydraulically with $\mathrm{HCl}$.

The water then goes to the stabilization sump (9), where the $\mathrm{pH}$ in the water stabilizes, resulting in fixed $\mathrm{pH}$ at 7.5-7.8 before the water goes to the carbon filter.

The water is pumped into an Automatic Carbon Filter, ACF (10). The most effective method to take away unwanted materials such as odour, heavy metals organic and inorganic pollutants is to use an ACF. Activated carbon can be prepared from anything consisting of carbon, for example hardwood or nut shell. The materials are heated to $200-1000^{\circ} \mathrm{C}$ without oxygen and are activated by reheating to a high temperature whilst providing steam. This will give a fine capillary structure with a surface area of $1000-2000 \mathrm{~m}^{2} / \mathrm{g}$. The carbon will adsorb the pollution and in that way remove the substance. PCETP has two granular carbon filters, one in each system. The volume of the tanks is $10 \mathrm{~m}^{3}$ and each tank is under a pressure of 2.5-3.5 $\mathrm{kPa}$. The retention time in ACF is eight minutes. The thickness of the carbon bed is 0.5-0.75 meter and it is made of coconut shells. The coconut shells are used for two years before they are replaced. The filter is backwashed every eight hours for 15 minutes. The back washing and the first filtrate go to the receiving sump.

After the ACF, the clean water goes through a magnetic flow meter (11), which registers TDS and pH. This unit forms the last control of the water before it goes to the field for irrigation. The effluent water has a flow of about $139 \mathrm{~m} / \mathrm{h}, \mathrm{pH}$ around 7.5 and a TDS of $1700 \mathrm{mg} / \mathrm{l}$. Finally the water is pumped with a booster pump out to the field for irrigation.

The sludge from the bottom of the clariflocculator goes to the sludge sump (12) and then further to the sludge thickener (13). The sludge sump is a tank where the sludge is collected before it goes to the sludge thickener. This tank is essential to achieve a constant flow into the next unit. The sludge sump in the treatment plant has a diameter of 1.5 meters and a depth of 3.0 meters.

The purpose of the thickener (15) is to increase the solids content of the sludge by removing a portion of the liquid fraction. The thickener has a slow speed mixer. The mixer has the function of making air channels in the sludge, which 
makes it easy for the water to escape. Another function of the mixer is to scratch the sludge into the middle of the tank where the sludge is taken out. In PCETP the sludge thickener has a diameter of 6.0 meters and a depth of 2.0 meters.

After the sludge thickener the sludge can go two different ways. The centrifugation(14) separates liquids from solids by considerably increasing the gravity power. Due to different density between the solids and the liquid the solids go immediately to the periphery and the water stays closer to the centre and can than be separated. PCETP has two centrifuges but only uses one at a time. The centrifuge extracts the water so the outlet DS is $25 \%$. Each day $10-15$ tons of sludge is produced.

The rest of the sludge goes to the drying beds (16). Sludge-drying beds are used to dewater digested sludge. The bed is similar to slow filtration through sand. The bed is filled up with one meter of sludge and it stays untouched for 20 days. Under the sand layer there are drainpipes to collect the separated water. After drying, the sludge is removed and packed into bags and stored under a roof. The sand has three different fractions to increase the flow speed through the bed. The five drying beds are a complement to the centrifuge. They are used instead of the centrifuge when capacity is not sufficient. The dimensions of each bed are $11 \times 5.0 \times 1.0 \mathrm{~m}^{3}$.

As a final point the sludge is packed in sacks and stored under a roof until further notice. PCETP has made an investigation regarding the use of sludge for brick production. The result was very positive (Charlotta Leissner, 2005).

\section{3. pH System Description in PCETP}

After the AVGF, $\mathrm{HCl}$ is added and mixed into the water with a static mixer to reduce the $\mathrm{pH}$ to $7.5-7.8$. The alkalinity of the solution leaving the $\mathrm{AVGF}$ is measured by a digital $\mathrm{pH}$ meter, whose output is used to regulate the $\mathrm{HCl}$ dosing pump to maintain the $\mathrm{pH}$ value ( 7.5 to 7.8$)$ in the static mixer, then goes to the stabilization sump as shown in the Figure.2.

\section{Results and Discussion}

The Figure. 3 shows the behavior of the output $\mathrm{pH}$ value with respect to $\mathrm{HCl}$ dosing. The $\mathrm{pH}$ value is maintained between $7.5-7.8$ by regulating the HCL dosing. Results are summarized in the Table.1, where the pH value observed before the dosage of $\mathrm{HCl}$ varies from 10.41 to 9.06 and after dosage of $\mathrm{HCl}, \mathrm{pH}$ value is controlled between 7.5 - 7.8.

\section{Conclusion}

Perundurai Common Effluent Treatment Plant, PCETP uses new technology and units to simplify operations. The plant is well operated and it has a constant effluent water quality. PCETP treats effluent water from 14 textile industries in the area. Tamil Nadu Pollution Control Board, TNPCB, regulates the limits for industries to dispose water. The 14 textile units in SIPCOT have started PCETP to achieve a good quality of the wastewater, so now it is the treatment plant's responsibility to follow the regulation. The limits TNCPB set up for disposal of wastewater on land is achieved with good margin at PCETP. $\mathrm{pH}$ is one of the important parameter because microbes used in biological treatment can only survive in a narrow $\mathrm{pH}$ range between roughly $\mathrm{pH}$ 6-8. The result shows that the $\mathrm{pH}$ value of the treated water is maintained between $7.5-7.8$ to save the microbes used in biological treatment as well as to reduce the wastage of chemicals.

\begin{tabular}{lll}
\multicolumn{2}{l}{ Nomenclature } \\
CETP & - & Common Effluent Treatment Plant \\
PCETP & - & Perundurai Common Effluent Treatment Plant \\
AVGF & - & Automatic Valves Gravity Filter \\
$\mathrm{ACF}$ & - & Automatic Carbon Filter \\
$\mathrm{TDS}$ & - & Total Dissolved Solids \\
$\mathrm{TSS}$ & - & Total Suspended Solids \\
$\mathrm{COD}$ & - & Chemical Oxygen Demand \\
$\mathrm{BOD}$ & - & Biological Oxygen Demand \\
$\mathrm{NaCl}$ & - & Sodium Chloride \\
$\mathrm{Ca}(\mathrm{OH})$ & - & Lime \\
$\mathrm{FeSO}_{4}$ & - & Iron Sulphate \\
$\mathrm{References}$ & &
\end{tabular}

Baskar, R., Meera Sheriffa Begum.K. M., \& Sundaram.S. (2006). Characterization and reuse of textile effluent treatment plant waste sludge in clay bricks. Journal of the university of chemical technology and metallurgy, 41, 473-478. 
Charlotta Leissner, Elisebeth Wegen (2005). Industrial waste water treatment at PCETP, INDIA-A primary investigation of heavy metal content. Master's Thesis 2005:28, Department of Civil and Environmental Engineering, Water Environment Technology, Chalmers University of Technology, 20-26.

Emerson Process Management, (2004). Basics of $\mathrm{pH}$ control, [Online] Available: http://www.emersonprocess.com/raihome/documents/Liq_AppData_43-001.pdf. (August, 2004).

OMEGA Engineering, (2006). Introduction to pH, [Online] Available: http://www.omega.com/techref/ph.html.

Shankar, U., (2003). Common effluent treatment plants: An institutional arrangement for pollution control for small scale tanneries in India. [Online] Available: http://www.elaw.org/assets/pdf/India2000.pdf.

Samiya Ahmed, Alexandra Clenett, Matthew Clark and Kelvin Tapley. (2006). Choosing an Effluent

Treatment Plant. [Online] Available: http://www.sei.se/water/beel/ETP.pdf. 
Table 1. Observation of $\mathrm{pH}$ system

\begin{tabular}{|c|c|c|}
\hline Before Dosage pH VALUE & HCI DOSING (ml) & After Dosage pH value \\
\hline 10.41 & 0.70 & 7.79 \\
\hline 10.26 & 0.60 & 7.56 \\
\hline 10.23 & 0.65 & 7.64 \\
\hline 10.16 & 0.60 & 7.51 \\
\hline 10.15 & 0.55 & 7.63 \\
\hline 10.03 & 0.50 & 7.66 \\
\hline 9.93 & 0.50 & 7.63 \\
\hline 9.89 & 0.50 & 7.62 \\
\hline 9.84 & 0.50 & 7.51 \\
\hline 9.84 & 0.40 & 7.78 \\
\hline 9.83 & 0.50 & 7.62 \\
\hline 9.83 & 0.50 & 7.54 \\
\hline 9.83 & 0.40 & 7.67 \\
\hline 9.82 & 0.40 & 7.75 \\
\hline 9.82 & 0.40 & 7.67 \\
\hline 9.81 & 0.40 & 7.77 \\
\hline 9.78 & 0.40 & 7.70 \\
\hline 9.75 & 0.50 & 7.59 \\
\hline 9.72 & 0.5 & 7.67 \\
\hline 9.67 & 0.4 & 7.58 \\
\hline 9.61 & 0.4 & 7.72 \\
\hline 9.55 & 0.3 & 7.62 \\
\hline 9.54 & 0.35 & 7.52 \\
\hline 9.48 & 0.35 & 7.62 \\
\hline 9.47 & 0.35 & 7.68 \\
\hline 9.43 & 0.35 & 7.79 \\
\hline 9.43 & 0.3 & 7.64 \\
\hline 9.42 & 0.28 & 7.74 \\
\hline 9.41 & 0.55 & 7.54 \\
\hline 9.40 & 0.28 & 7.68 \\
\hline 9.37 & 0.28 & 7.61 \\
\hline 9.35 & 0.27 & 7.73 \\
\hline 9.33 & 0.5 & 7.77 \\
\hline 9.33 & 0.35 & 7.59 \\
\hline 9.31 & 0.5 & 7.71 \\
\hline 9.21 & 0.27 & 7.69 \\
\hline 9.19 & 0.27 & 7.55 \\
\hline 9.16 & 0.4 & 7.64 \\
\hline 9.10 & 0.35 & 7.50 \\
\hline 9.06 & 0.30 & 7.53 \\
\hline
\end{tabular}




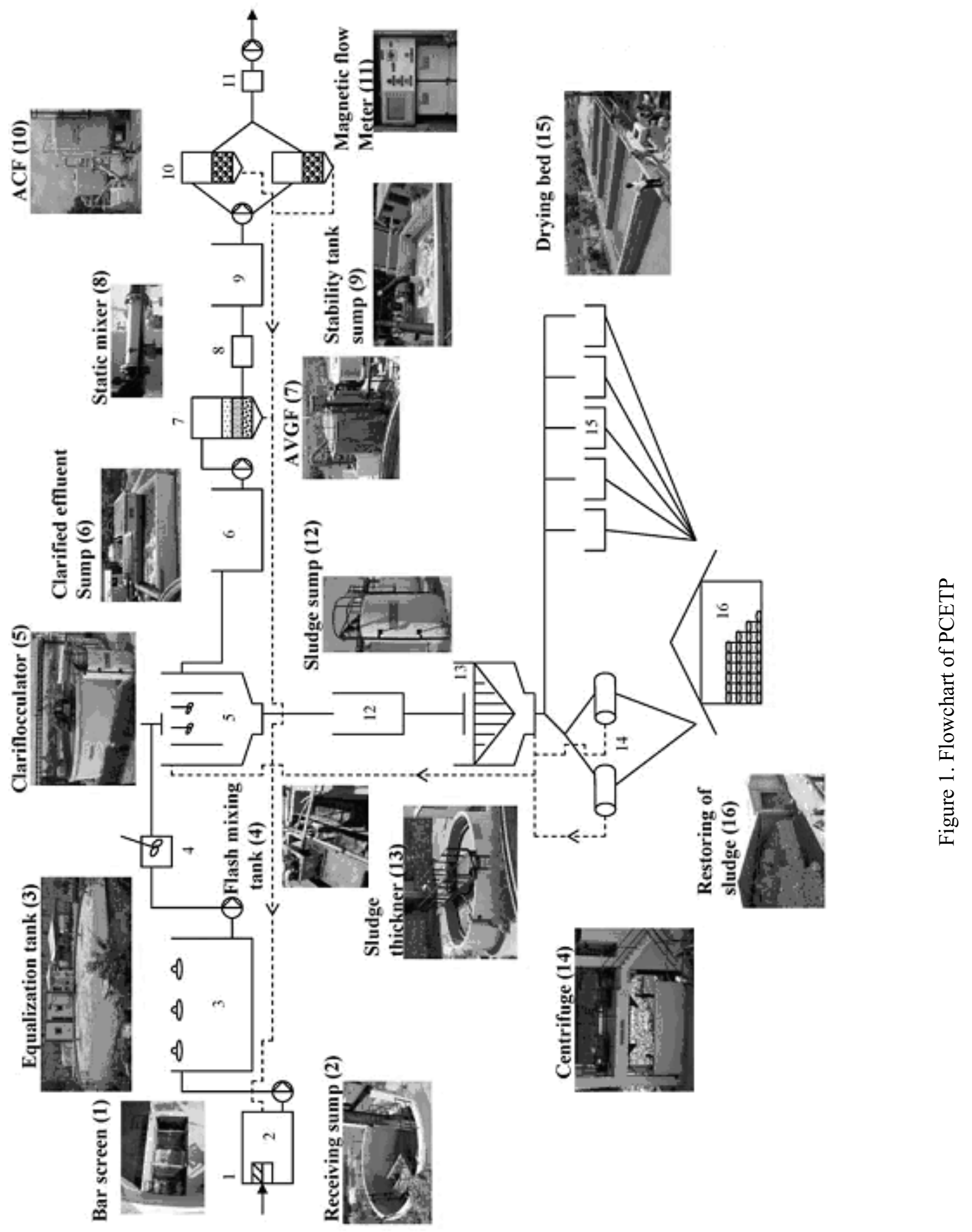




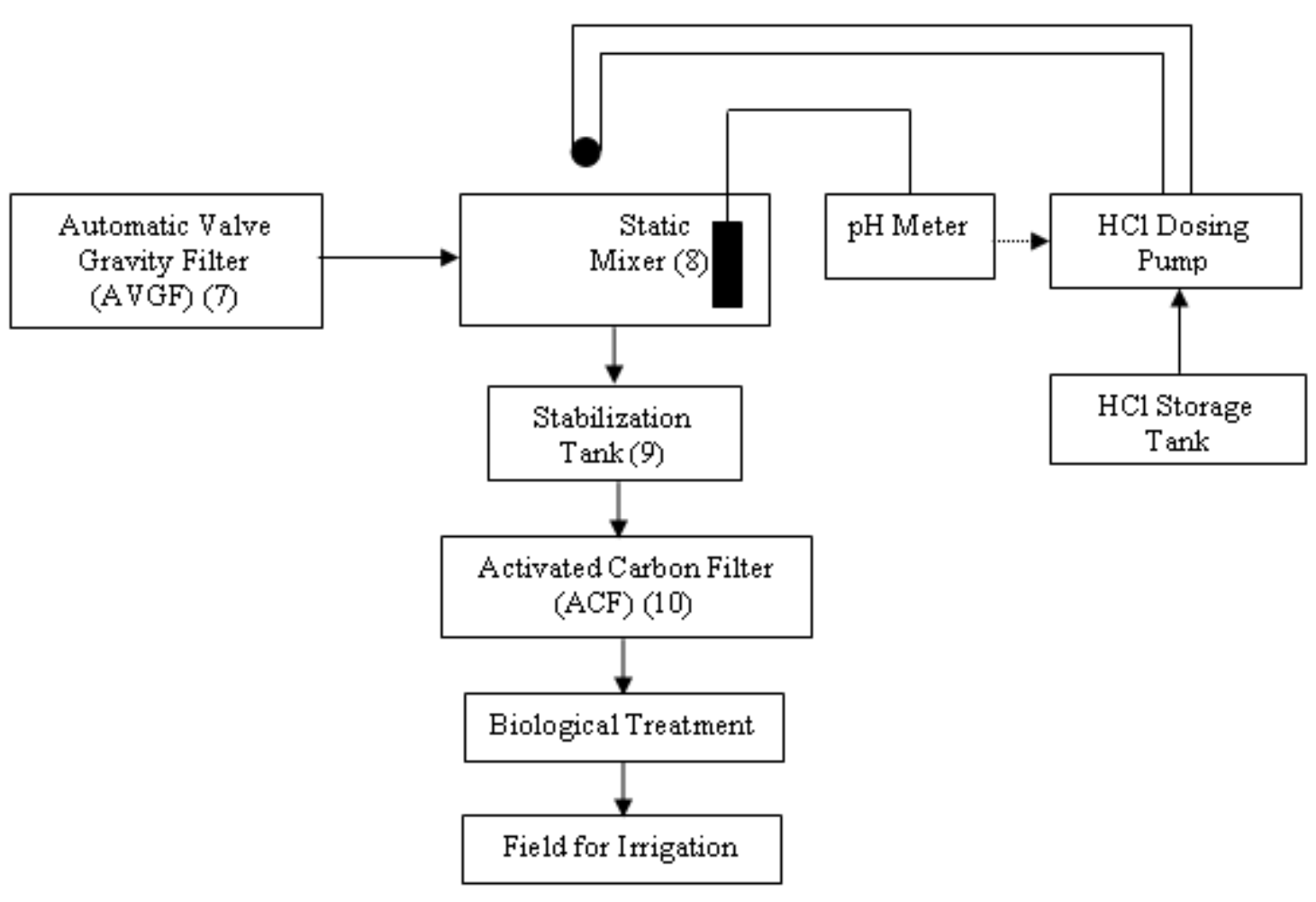

Figure 2. $\mathrm{pH}$ system description in CETP

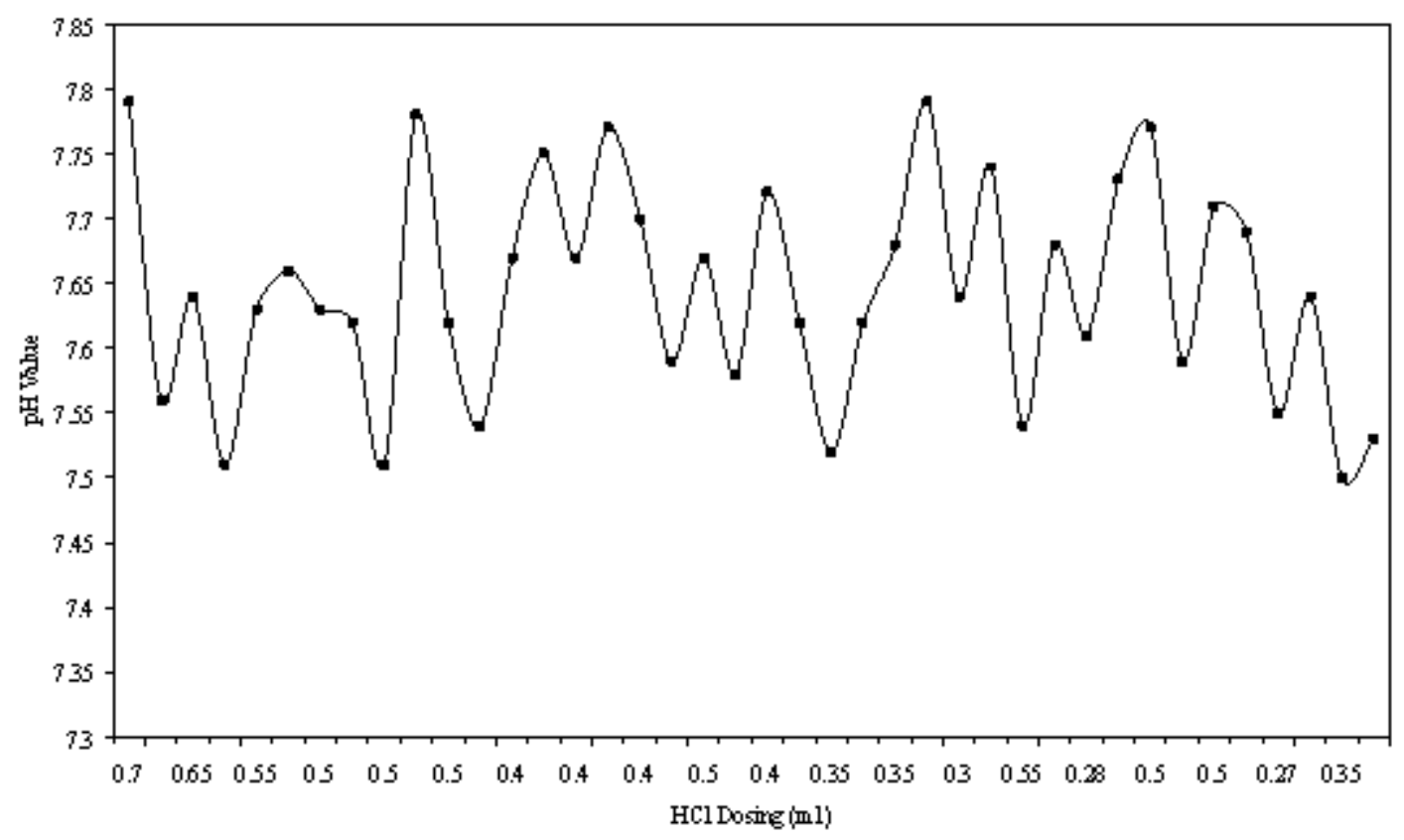

Figure 3. Response of $\mathrm{pH}$ System 


\title{
Analysis and Design of Storage Battery
}

\section{Charge/Discharge Equalization Management}

\author{
Jiaqi Wang \\ College of Computer Technology and Automation, Tianjin Polytechnic University, Tianjin 300160, China \\ E-mail: jiaqi126@126.com
}

\begin{abstract}
This article introduces the design of storage batter charge/discharge equalization system of the electrical cars based on HT46R47. Because it becomes into one difficulty in the development of electrical cars that the characters of the battery decides the equalization of the battery electric quantity, so this system adopts the equalization management to the storage battery charge/discharge, adjusts the unsuited batteries (over charge/over discharge) in the initial adjustment process, and implements equalization in the later charge process. The system makes the use capacity and the cycle life of the storage battery fully enhance. At the same time, this charger adopts the SCM as the main control component, which has many advantages such as simple and credible circuit, short charge time, low power consumption, low use trouble rate and so on.
\end{abstract}

Keywords: Storage battery, Embedded system, Equalization charging

\section{Introduction}

With rapid development of global economy, human living level is changing quickly. Human living is more and more convenient and comfortable, but the follow environment pollution also puzzles human beings. Hundred years history of the flourish develop of auto industry records the brilliant course of human civilization. However, the continual increase of car quantity also put the problem of energy and environment to the increasingly serious situation when it promotes the rapid development of global economy. The electrical car is one important measure to solve the problem of energy and environment in the 21 st century.

At present, the electrical cars mainly include three types, battery electrical vehicle (BEV), hybrid electrical vehicle (HEV), and fuel-cell electrical vehicle (FCEV). Based on various reasons, this system mainly aims at the study of hybrid electrical drive mode. This mode concurrently possesses the advantages of electrical cars and gas engine cars. HEV has two types including series-wound type and shunt-wound type. For the series-wound electrical cars, the gas engine drives the generator, and the generator charges to the battery, and the battery supplies power to the electromotor and the electromotor directly drives the car. The shunt-wound gas engine and electromotor all can directly drive the car. The specific work mode of the electrical car has many special requirements for the power battery, which includes good charge receptivity (regeneration braking, complementary charge), high power density and proportion power, high cycle efficiency and low interior resistance (power equalization), good coherence and so on.

\section{Equalization management of storage battery pile}

The power supply management technology that takes the single battery as the power source such as mobile phone has been very perfect, but in the battery pile, the difference among single battery is always existent. In the cycle charge/discharge process of electrical car, because of the difference of the chemic component of various storage batteries and the difference of running history of the storage battery, the variance of various batteries will be further enlarged, which will induce the difference of charge/discharge final voltage of the storage battery under same charge/discharge condition. If the battery system runs under that situation and without management, the use life and system reliability of the storage battery will be influenced. To extend the use life of the battery pile, we must make all single storage batteries keep same discharge depth and adopt the method of equalization charge to solve this problem.

The battery equalization is to adopt difference current to different batteries (or battery piles) in the series-wound battery group. The current of every battery in the series-wound battery is generally same, so we must add extra components and circuits to realize battery equalization. When all batteries in the battery group fulfill following two conditions, they will realize battery equalization. First, if the capabilities of all batteries are same, they will realize battery equalization when they are in the relative charge state. The state of charge (SOC) is generally represented by the percent of current capability and rating capability, so the open circuit voltage (OCV) can be taken as a measurement standard of SOC. If all batteries in an inequality battery pile can achieve full capability (the equalization point) through difference charge, 
they can be implemented normal charge/discharge and need not any extra adjustment, and this sort of adjustment is one-off generally. Second, if the capabilities of various batteries are different, when SOC is same, they are thought as equalization. But SOC is a relative value, and the absolute value of every battery capability is different. To make SOC of the batteries with different capabilities same, the difference current must be used when implementing charge/discharge to the series-wound batteries every time.

The concrete scheme design includes following aspects.

(1) Shunt: The shunt doesn't cut the work loop of the battery, and it is to add a bypass setting for every battery just like battery partner, and both combined characters is equal to the character of the single battery which has the mean quality in the battery pile.

(2) Feedback: The feedback transfers the warp energy among single batteries to the battery pile or some singe batteries in the pile through the energy convertor. Theoretically speaking, the feedback doesn't consume energy and can realize dynamic equalization. Because the battery pile on the electrical care has large powers and the instantaneous current can achieve hundreds ampere and present double polarities change, so this equalizer adopts the method of shunt feedback under considering many factors such as feasibility, quality-price ratio, practicability and reliability.

(3) Dynamic: The dynamic equalization can realize the equalization of single voltage in the pile and timely keep close load degrees through the method of energy transform under the charge state, discharge state or the float state.

(4) Double directions: The double direction convertor is selected according to the possible current direction of the equalizer treatment energy, which can implement dynamic adjustment of the input and output direction.

(5) Class connection: Several single batteries are spaced between high voltage single battery and low voltage single battery in the pile, and many class connected convertors need working simultaneously when the energy is transferred from high voltage single battery to the low voltage single battery.

(6) Efficiency and safety: For the dynamic equalization, especially in the use discharge process, the heat consumption of the convertor comes from the energy of the battery pile, and because the single battery has low voltage, so the efficiency of the convertor is a design difficulty, which must adopt and refer new design technology of present power supply and circuit, and many general inspection functions such as parameter excessive warning and heat protection are necessary. Because the environment in the car is in the bump and shaking state, so the line matching technology and durance structure must be designed carefully, and the short circuit induced by the lead abrasion may produce hidden fire trouble independent of battery performance.

\section{Design of equalization circuit}

This equipment is composed by a set of four charging series-wound battery pile, four measurement control and equalization modules and Holtek SCM HT47R47.

Figure 1 is the circuit frame of the battery module composed by a battery and its corresponding measurement control and equalization modules.

\subsection{Voltage measurement}

For several series-wound storage batteries (four), in the problems measuring the voltage needed to be solved, the main problem is the voltage sharing the ground. Because the anode of the upper battery connects with the cathode of the lower battery, various batteries don't share the ground when measuring. We can adopt the method of resistance sharing voltage to solve that problem. The principle of the method is seen in Figure 2. The method is to transform the voltage of $\mathrm{B} 1$ to $\mathrm{U} 1$, and transform the voltage of $\mathrm{B} 1+\mathrm{B} 2$ to $\mathrm{U} 2$, and transform the voltage of $\mathrm{B} 1+\mathrm{B} 2+\mathrm{B} 3$ to $\mathrm{U} 3$, and so on. So the $\mathrm{U} 1, \mathrm{U} 2$ and $\mathrm{U} 3$ produced by this method are signals sharing the ground, and the measurement is convenient.

\subsection{Equalization process}

The equalization circuit is composed by one switch pipe $\mathrm{Q}$, one diode $\mathrm{D}$ and one inductance $\mathrm{L}$ (the measurement control and equalization module 4 has not his component). The connection mode is that after Q and D is parallel connected, they are connected with L in series, and then respectively connected with the anode and the cathode of the battery, where, the cathode of $\mathrm{D}$ connects the anode of the battery and L connects the cathode of the battery. In the automatic equalization equipment of series-wound storage battery pile, various equalization circuits are series-wound. When the battery voltage in the $X^{\prime}$ th module is the highest voltage, connect $Q$ and cut other switches, and here, the inductance $L_{x-1}$ and $L_{x}$ charge and $L_{x-1}$ receives the forward voltage $L_{x}$, and $L_{x}$ receives the reverse voltage. When $Q$ is cut, the inductance $L_{x-1}$ charges to the batteries of various modules through $D_{x-1}, D_{x-2} \ldots D_{1}$, and in the same way $L_{x}$ charges to the corresponding batteries though $\mathrm{D}_{\mathrm{x}+1}, \mathrm{D}_{\mathrm{x}+2} \ldots, \mathrm{D}_{4}$. When the difference of single battery voltage is less than certain value, all switch pipes will be cut and the equalization process stops.

The equalization equipment is composed by four lithium batteries in series, and the mean voltage of the battery pile is $4 \mathrm{~V}$, and the maximum voltage of single battery is $4.1 \mathrm{~V}$. Whether the battery pile is in the charge state, discharge state or 
float state, the voltage signals of various single batteries are collected by the voltage inspection circuit in time, and analyzed by the SCM HT46R47. Through the comparison of these voltage signals, we will find one circuit which can fulfill the condition, which voltage is the highest one, and exceeds the mean voltage value to $0.02 \mathrm{~V}$, and we suppose it is the second circuit. So HT46R47 sends instruction to other circuits, orders their corresponding switch pipe Q close and transfer a pulse signal with $20 \mathrm{KHz}$ and $50 \%$ void occupation ratio. But when the circuit with highest voltage is the first circuit or the fourth circuit, i.e. the circuit is in the port of the equalization circuit, so the void occupation ratio is less than $1 / 2$, and under other situations, this value is less than $2 / 3 . Q_{2}$ is connected or cut under the control of the pulse, and the energy is transferred from the battery with higher voltage to other batteries through the inductance. When the difference of the voltage of the second circuit battery with the mean voltage is less than $0.02 \mathrm{~V}, \mathrm{Q}_{2}$ cuts. If other circuit fulfills the condition here, it will control the switch pipe connect or close in this circuit, or else, cut all switch pipes, and the equalization circuit of the storage battery is in the awaiting state. The selection condition of the control switch is the voltage value is the highest voltage and exceeds the mean voltage value $0.02 \mathrm{~V}$, which can avoid energy consumption and low life of switch pipe because of repeated switching actions under the situation that the voltage value difference is very small. Figure 3 is the principle of charge/discharge.

The discharge process is similar with the charge process, and the HT46R47 deals with the collected voltage signals, and finds out the circuit which voltage is the highest one and exceeds the mean voltage $0.02 \mathrm{~V}$, and we suppose it is the third circuit, lead the switch $\mathrm{Q}_{3}$, and charge to $\mathrm{L}_{2}$ and $\mathrm{L}_{1}$, and make various batteries discharge under the situation keeping voltage close, and when the voltage can not fulfill the condition, $\mathrm{Q}_{3}$ cuts.

\subsection{MCU main control module}

The MCU main control module based on HT46R47 microprocessor is the control core. HT46R47 is the SCM with 8 digital high performance simply instruction set, and specially designed for the product which needs implementing A/D transformation. The clock of the system is produced by the crystal oscillator. This clock is divided into four clock cycles without superposition in the interior of the chip. One instruction cycle includes four system clock cycles. The reading and implementation of the instruction is completed through the assembly line mode which can implement instruction operation in one instruction cycle. Therefore, most instructions can be performed completely in one cycle. Figure 4 is the principle of HT46R47 oscillating circuit.

\section{Conclusions}

In this article, we design a sort of equalization manager, which can be used with charge management and discharge management at the same time, and they are independent each other, and the equalization manager can be started in any stage of charge/discharge. The equalization voltage management of charge/discharge enhances the coherence of the single battery, reduces the accumulated influences of disequilibrium factors, and better solves the problem of a great lot of battery discarding induced by hybrid series-wound batteries with differences in the electrical cars.

\section{References}

Blanyer Richard. (1989). Battery Grid Structure Made of Composite Wire. No.12. p.895-913.

Frank Wicks, Kyle Donnelly \& Steinmetz Hall. (1997). Modeling Regenerative Braking and Storage for Vehicles. Proceedings of the Intersociety Energy Conversion Engineering Conference. v 3 -4J ul2 7-Aug1 1997 Sponsored by IEEE. p.2030-2035.

Moseley P.T. (1998). Research Result from the ALABC Point the Way to Long Life and Heighten Specific Energy for Lead-acid Batteries for Electric-vehicle. Journal of Power Source. No.73(5). p.122-126.

M. Shiomi. (1997). Effect of Current on Cycle Life Performance of Valve-regulated Lead-acid Batteries. Journal of Power Source. No.65(1). p.147-152.

Peng, Jinchun, Chen, Quanshi \& Han, Zengjin. (1997). The Modeling of Lead-acid Battery Charge/Discharge Process of Electrical Cars. Automobile Technology. No.6.

Zhuyuan, Han, Xiaodong \& Tian, Guangyu. (2000). Study on the SOC Prediction Technology of Power Battery of Electrical Auto. Chinese Journal of Power Resources. No.3.

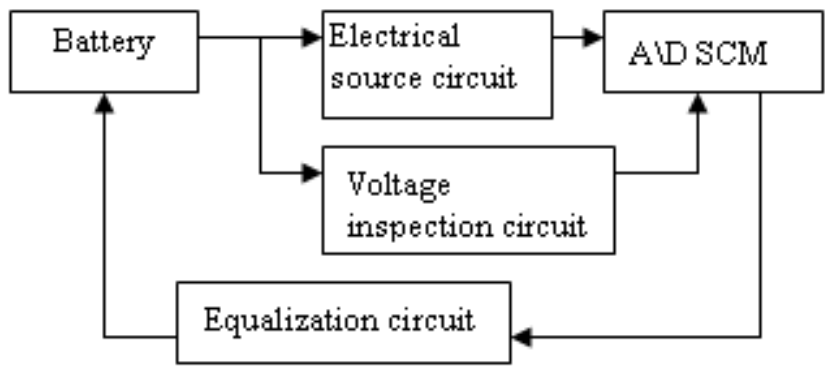




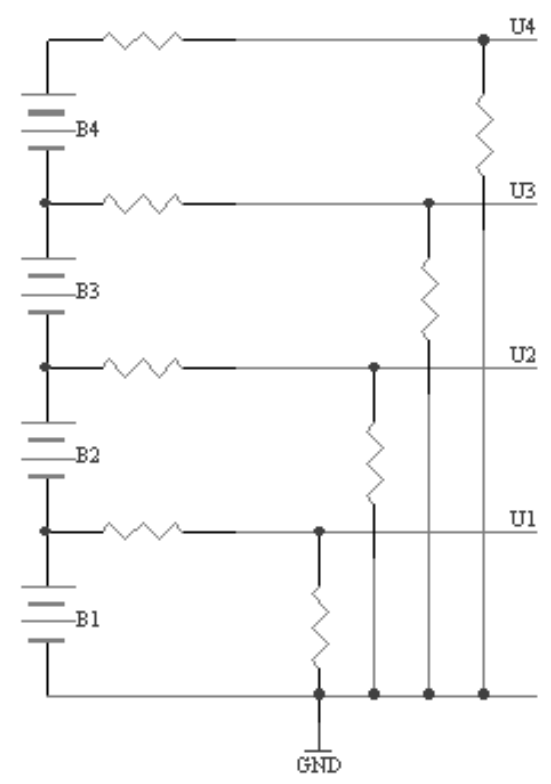

Figure 2. Principle of Voltage Measurement

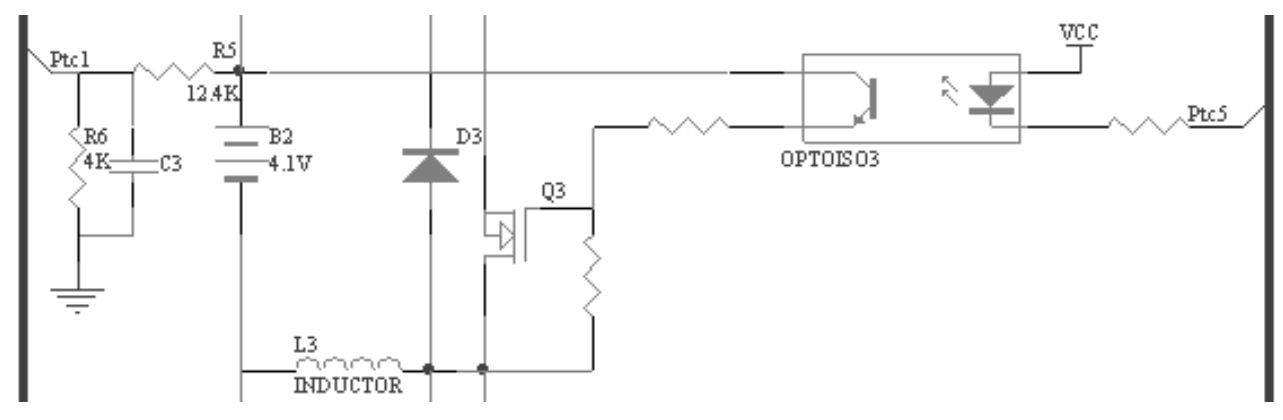

Figure 3. Principle of Charge/Discharge

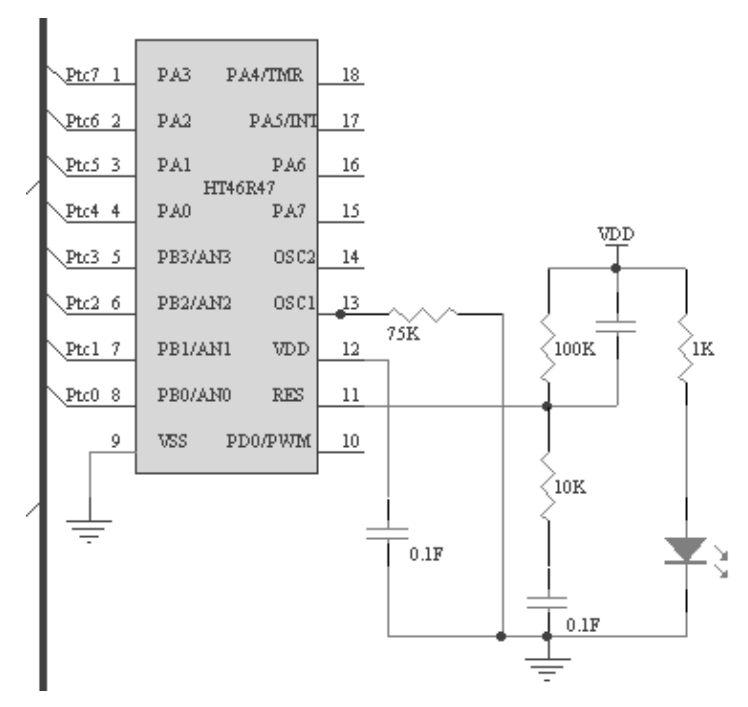

Figure 4. Principle of Oscillating Circuit 


\title{
The Application of MSVC Reactive Power Compensation Device to the High Voltage Power Supply of Coal Mine
}

\author{
Zhenbao Zhu \\ Bureau of Safety Supervision, Xinwen Mining Group Co., Ltd \\ Tai'an 271233, China \\ Rui Tian \\ Xinwen Mining Workers and Staff College \\ Laiwu 271100, China
}

\begin{abstract}
Through the introduction and technical comparative analysis of the SVC reactive power compensation device of the magnetic controlled reactor (MCR) type (it is abbreviated as MSVC), this article measures the working condition of the electrical power distribution system for the Zhaizhen colliery, and confirm the application project of MSVC in the high voltage power supply of Zhaizhen colliery. This device has many obvious advantages such as small output harmonic, low power consumption, maintenance free, simple structure, high reliability, cheap price and small floor area, and it is an ideal dynamic reactive power compensation and voltage regulation device.
\end{abstract}

Keywords: SVC of MCR type, Coal mine, High voltage power supply, Application

The Zhaizhen colliery of Xinwen Mining Group is the modern mine with year output of 2.1 million ton coals, and its dropping station was established in September of 1989, which is the power supply hinge of whole mine. In the coal industry, most loads on the dropping station are inductive loads, and if proper compensation method is not adopted, the system power factor must be too low, and the low side voltage will correspondingly reduce, which will reduce the rotate speed of the motor, increase the current and heat consumption, and if the compensation is not proper, the over compensation and deficient compensation will occur. When over compensation happens, the capacitive reactive power will be transferred reversely to the system, which can not reduce the consumption, but will increase the reactive power consumption of the system. The high voltage load of the mine mainly includes ventilator and lift, and the ventilator is the equipment which can continually run, so the change is partly embodied in the lift which has quick change cycle and large harmonic content. The traditional switching technology can not simultaneously effectively solve the reactive power compensation and harmonic governance, so we can adopt MSVC to fulfill the requirement of quick load change, and this device can smoothly adjust the reactive power, possess high reliability and small harmonic, make the power factor keep in the high level, better improve the power supply quality and enhance the economic benefit of the whole power supply system of the mine.

\section{Introduction of MSVC}

At present, the main devices of reactive power compensation include capacitor, reactor and few dynamic reactive power compensation devices. The regulation mode of the switching capacitor group is discrete, which can not get ideal compensation effect. The flow and over voltage induced by the switching capacitor are very harmful to the system the equipment itself. The present static compensation devices such as the SVC of the phase controlled reactor (TCR) type not only have expensive price, but have large floor area and complex structure, and can not be extended. The MSVC has many obvious advantages such as small output harmonic, low power consumption, maintenance free, simple structure, high reliability, cheap price and small floor area, and it is an ideal dynamic reactive power compensation and voltage regulation device. The MSVC device is composed by compensation (wave filtering) branch and the shunt-wound branch of MCR, and the compensation branch is fixedly connected with the bus bar through the insulation switch, and realizes the soft compensation of the reactive power through regulating the output capacitance (inductive reactive power) of the MCR.

\section{Typical technical comparison of the compensation}

The compensation results are shown in Table 1. 


\section{Characters of MSVC}

(1) The controlled silicon of the control part of MCR generally works on the level of few percent of the system rating voltage, and because it is to control the saturation of the magnetic valve, so it needs not large control power, and the thyristor works on the working condition of low voltage and small current, which can fully enhance the stable operation parameter of the system.

(2) The MCR device likes a transformer, which can adopt different cooling methods. Under the voltages less than $35 \mathrm{kv}$, two natural cooling modes including wind cooling and oil cooling both can be adopted, so there is no assistant cooling equipment, and it can be used combining the change power distribution system without watchers.

(3) Because the controlled part works under the mode of direct current, the harmonic voltage can not happen. The harmonic which is almost equal to half harmonics induced by the TCR type is induced by the magnetized nonlinear process.

(4) The shortcoming of MCR is that its reactive speed is lower that the TCR type's, which is above 0.3 seconds, and reverse proportional with the saturation speed. At present, the product with quicker active speed is developing.

(5) MCR has many advantages such as maintenance free, small floor area and convenient fixing.

\section{Working condition measurement of Zhaizhen colliery power supply}

To better know the power supply reactive power change and harmonic of the mine, we measure the power distribution system of Zhaizhen colliery, and confirm the application project of MSVC in the high voltage power supply system of Zhaizehn colliery based on that.

\subsection{Reactive power}

The change of bus bar reactive power has not obvious time rule, and its fluctuation range is very large. The maximum value can achieve $8200 \mathrm{kvar}$ and the minimum value is $2200 \mathrm{kvar}$. This value is even smaller in the start moment of the lift, and the change cycle is very short. The reactive change curve of the bus bar is seen in Figure 1 . The change is mainly induced by the lift, and when the lift starts, the power factor goes to zero, and this value is only 0.5 when the lift normally runs (seen in Figure 2). The reactive power change of the lift presents periodic changes (seen in Figure 3).

\subsection{Harmonic level}

The main harmonic source of the system is the 12 pulsation direct current motor (lift), and the main harmonic components are divided into 11 times (2.31\%), 13 times (2.26\%), 23 times (0.95\%) and 25 times $(0.98 \%)$, which make the current wave seriously irregular.

The harmonic situation on the bus bar is that because the variator adopts star connection, so the system has quantitive single phase load, which induces the unbalance of three phases and produces three times harmonic (seen in Figure 5).

Therefore, the main harmonics of the bus bar include 3 times, 11 times and 13 times. So when designing the wave filtering equipment, we consider adopting four wave filter branches, i.e. 3 times branch, 5 times branch, 7 times branch, 11 times branch and high pass branch.

\section{Wave filtering project of reactive power compensation}

Based on above analysis, the reactive power compensation capacitance is changed to $5400 \mathrm{kvar}$, the fixing capacitance is 7200kvar, four wave filter branches are set up, where, the 3 times branch, 11 times branches and high pass capacitance are 2400kvar, and adopt fixed switching mode, and the 5 times branch and the 7 times branches adopt vacuum contactor to realize automatic switching. So the continual compensation of 2000kvar- 5400kvar can be realized. In addition, comprehensively considering the wave filtering effect and the cost of equipment, we advise putting the lifts on the same bus bar, which can fix a set of MSVC on the bus bar with lifts, and fix a set of automatic compensation on the other bus bar to fulfill the requirements.

\subsection{Main arrangement}

The capacitor group adopts the tank installation, and it is mainly composed by capacitor, reactor, spurt fuse, vacuum contactor, insulation switch, high voltage fuse, discharge loop, DWK/BR automatic controller and so on.

The MCR branch mainly includes MCR, automatic controller and thyristor valve tank.

\subsection{Merits of the project}

(1) Comparing with pure automatic switching, this project adopts the method of MCR technology combining with the automatic compensation, which completely can achieve continual smooth compensation of reactive power, and avoid over compensation and deficient compensation.

(2) The project can fully reduce the switching times of vacuum contactor, avoid the impact to the system and prolong the use life of the compensation equipment at the same time. 
(3) The project can fully reduce the investment of the equipment when ensuring the compensation effect.

\section{Conclusions}

Since the MSVC reactive power device is fixed and operated in January of 2007, it presents reliable technology and obvious energy saving effect. It effectively enhances the power factor of the high voltage side of the dropping station to above 0.9 , which can not only enhance the using rate of the power supply equipment, but can fully reduce the power loss of the power supply network. Therefore, the device has wide application foreground in the high voltage power supply system of the colliery.

\section{References}

Fangyu. (1997). Over-voltage of Distribution System. Beijing: China Electric Power Press.

Huangjun. (1999). Electric Power and Electric Converter Technology. Beijing: Mechanism Industry Press.

Shang, Guocai. (1997). Electric Power System Automatization. Tianjin: Tianjin University Press.

Wang, Shizheng. (2002). Electrical Engineer Manual in Industrial and Mining Enterprises. Beijing: China Water Power Press.

Wang, Shizheng. (1990). Electric Power System Operation Control and Dispatching Automatization. Nanjing: Hehai University Press.

Wang, Zhao'an \& Liu, Jinjun. (1999). Harmonic Control and Reactive Power Compensation. Beijing: Mechanism Industry Press.

Table 1. Typical technical comparison of the compensation

\begin{tabular}{|c|c|c|c|c|}
\hline $\begin{array}{l}\text { Comparative } \\
\text { item }\end{array}$ & SVC of MCR type & SVC of TCR type & Switching & TSC \\
\hline Investment & Middle size & Large size & Middle size & Large size \\
\hline Running mode & $\begin{array}{l}\text { Stepless regulation } \\
\text { (continual) }\end{array}$ & $\begin{array}{l}\text { Stepless regulation } \\
\text { (continual) }\end{array}$ & $\begin{array}{l}\text { Step switching } \\
\text { (discrete) }\end{array}$ & $\begin{array}{l}\text { Step switching } \\
\text { (discrete) }\end{array}$ \\
\hline Reliability & $\begin{array}{l}\text { Maintenance free, } \\
\text { use life of } 25 \text { years }\end{array}$ & Large maintenances & $\begin{array}{l}\text { Very large } \\
\text { maintenances }\end{array}$ & $\begin{array}{c}\text { Large } \\
\text { maintenances }\end{array}$ \\
\hline Harmonic level & $\begin{array}{c}\text { Less } 50 \% \text { than TCR } \\
\text { type }\end{array}$ & $\begin{array}{l}5 \text { times: } 6.5 \% \text { and } \\
7 \text { times: } 3.7 \%\end{array}$ & null & small \\
\hline Switching flow & null & null & Above 7 times & null \\
\hline $\begin{array}{c}\text { Power } \\
\text { consumption }\end{array}$ & $\begin{array}{c}\text { Less } 50 \% \text { than TCR } \\
\text { type }\end{array}$ & Average $0.5 \%-0.8 \%$ & Very small & small \\
\hline Floor area & $1 / 10$ of TCR type & $\begin{array}{l}\text { Very big, difficult } \\
\text { arrangement }\end{array}$ & big & big \\
\hline Regulation time & $0.3 \mathrm{~s}$ & $40 \mathrm{~ms}$ & $0.8 \mathrm{~s}$ & $40 \mathrm{~ms}$ \\
\hline $\begin{array}{l}\text { Over loading } \\
\text { ability }\end{array}$ & $150 \%$ & null & null & null \\
\hline $\begin{array}{l}\text { Electromagnetic } \\
\text { pollution }\end{array}$ & null & $\begin{array}{l}\text { Eradiating large of power } \\
\text { frequency magnetic field, } \\
\text { harmful to human }\end{array}$ & null & null \\
\hline
\end{tabular}


Three phases reactive power- change curve start time : 03-23 16:31:55 end time: 03-23 18:57:45 interval:5 s

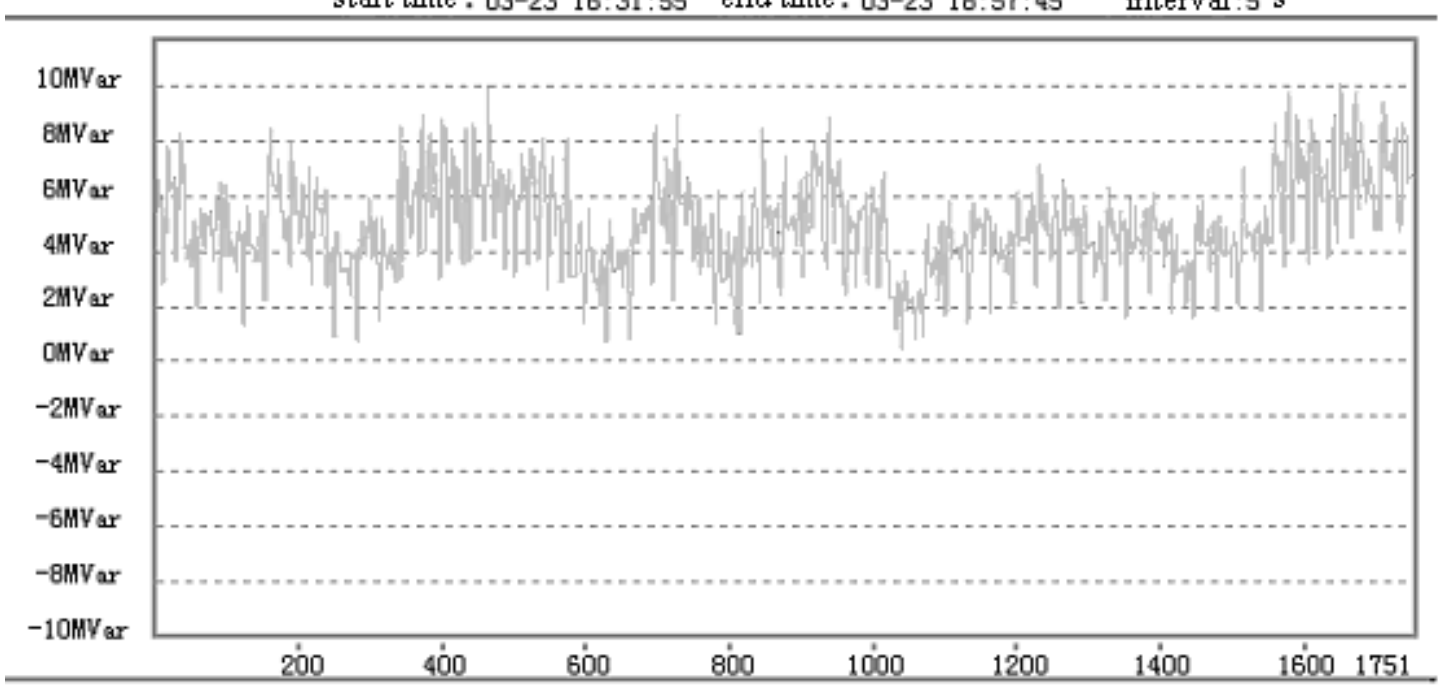

Figure 1. The Reactive Power Change of Bus Bar

Power factor- change curve start time: 03-24 08:35 end time: 03-24 09:13 interval:1 min

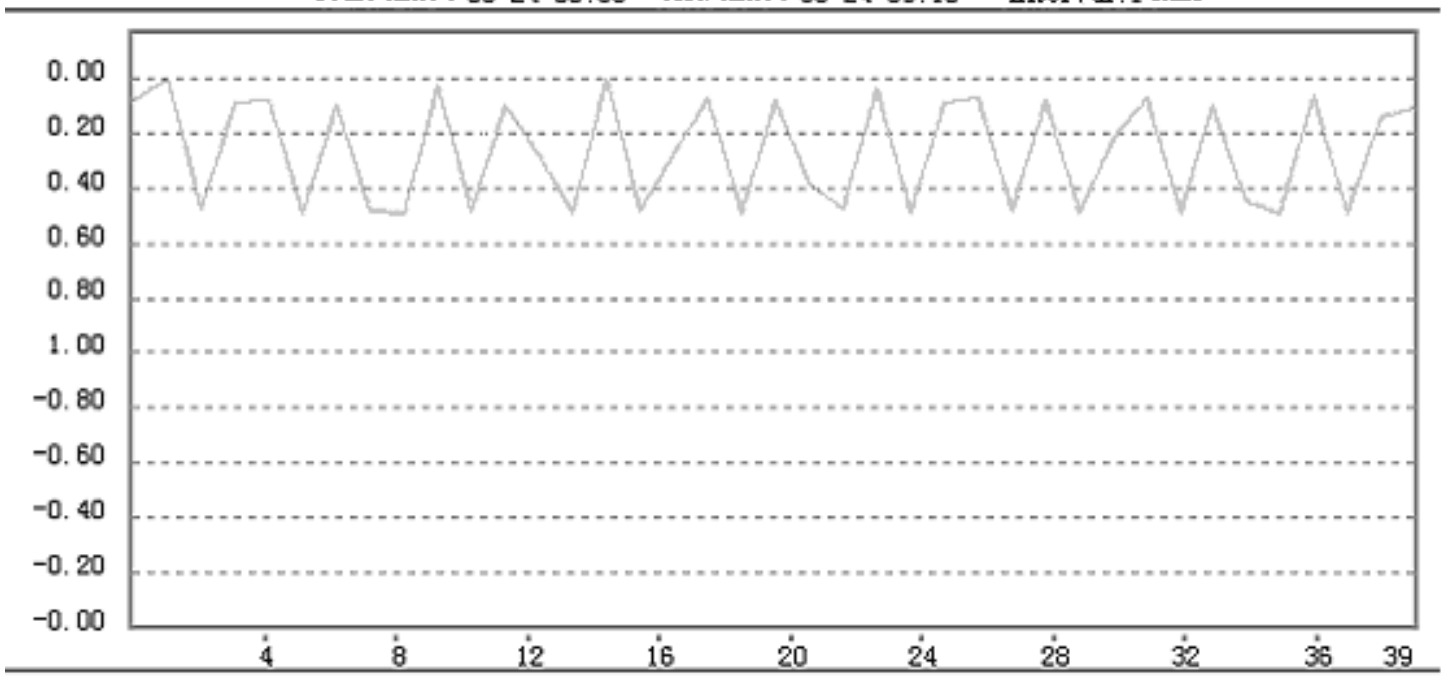

Figure 2. The Power Factor Change Curve of Lift 
Three phases reactive power- change curve

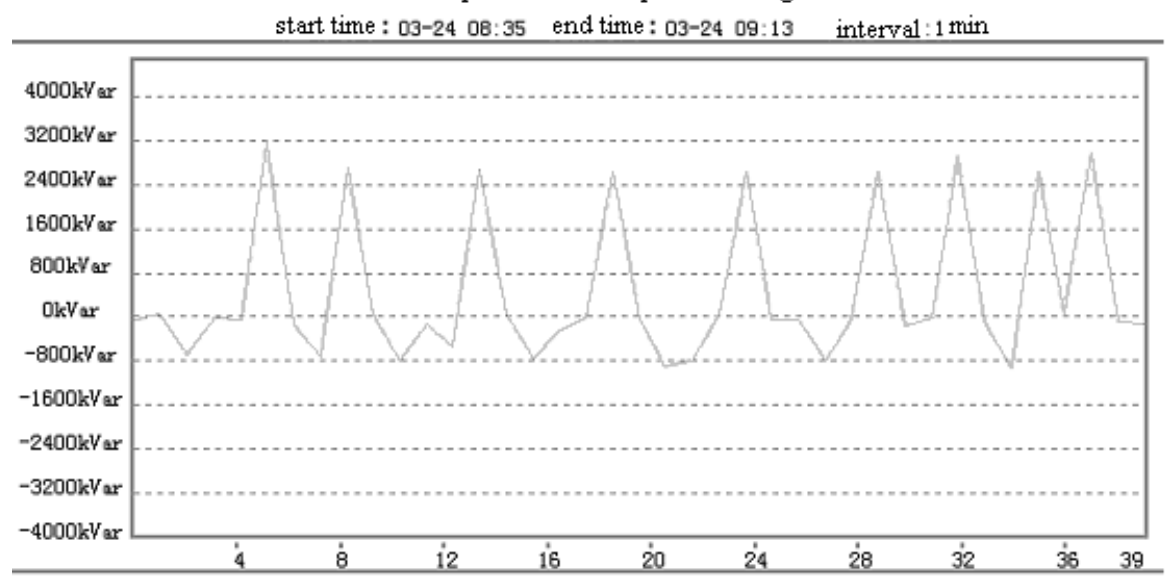

Figure 3. The Reactive Power Change Curve of Lift
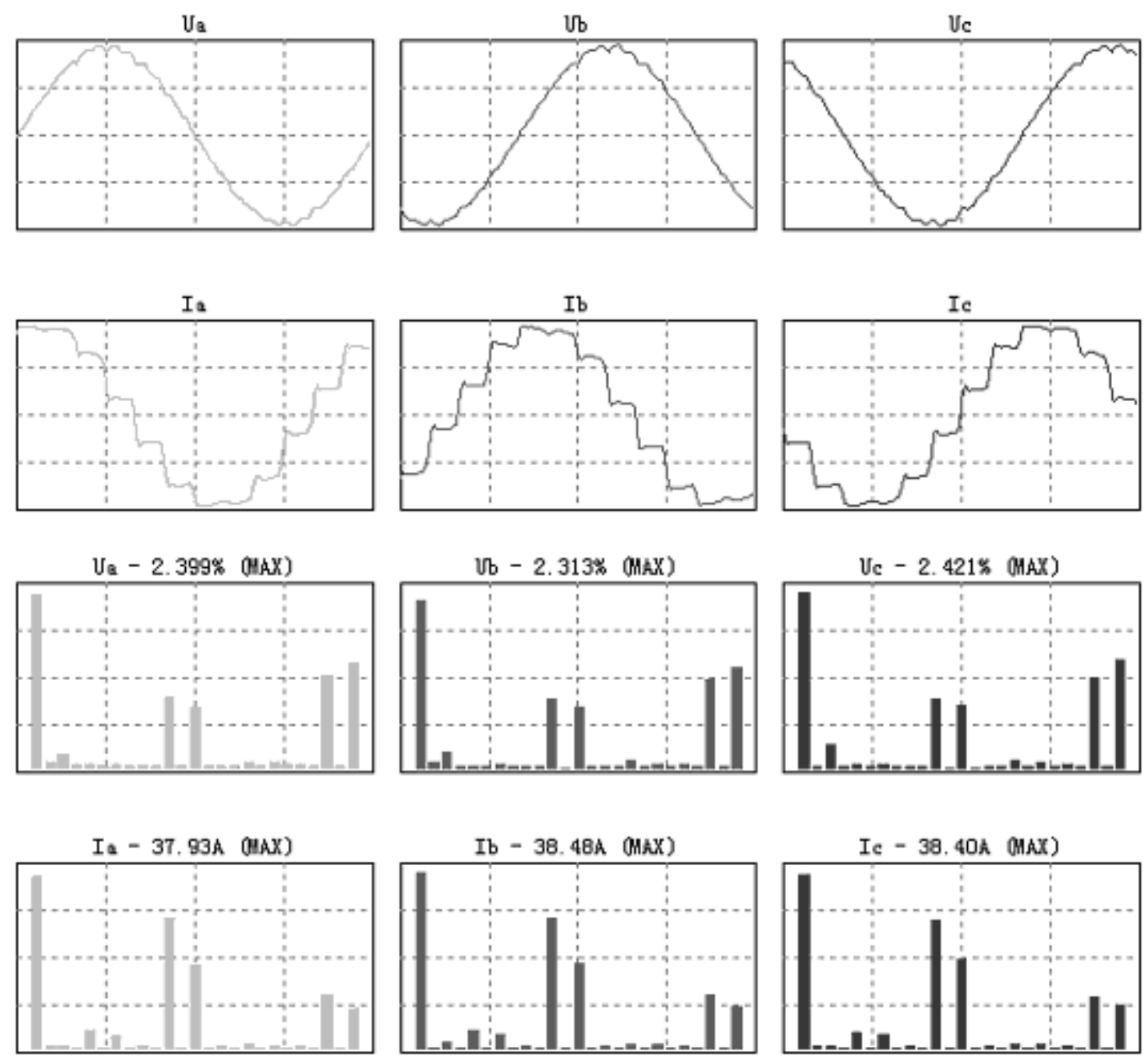

Figure 4. Lift Wave Figure and Frequency Spectrum 


\title{
Statistical Perspective and Pollution Indicator
}

\section{in Mengkabong Mangrove Sediment Sabah}

\author{
Miroslav Radojevic \\ Faculty of Engineering and Computer Science, The University of Nottingham Malaysia Campus \\ Jalan Broga, 43500 Semenyih, Selangor Darul Ehsan, Malaysia \\ Tel: 60-3-8924-8165Ｅ-mail: Miroslav.Radojevic@nottingham.edu.my
}

Sarva Mangala Praveena (Corresponding Author)

School of Science and Technology, Universiti Malaysia Sabah

Locked Bag No. 2073, 88999 Kota Kinabalu, Sabah, Malaysia

Tel: 60-88-325-772 E-mail: smpraveena@gmail.com

Mohd Harun Abdullah

School of Science and Technology, Universiti Malaysia Sabah

Locked Bag No. 2073, 88999 Kota Kinabalu, Sabah, Malaysia

Tel: 60-88-325-875Ｅ-mail: harunabd@ums.edu.my

\begin{abstract}
The role of tidal processes on intertidal surface sediments is frequently stated but rarely investigated due to the methodological restrictions. This study provides a basis for describing the tidal effects on the mangrove sediment. It reports investigations into the chemical composition of mangrove surface sediment in Mengkabong lagoon, Sabah, Malaysia. The levels of 16 parameters were determined in 33 surface sediment samples at high and low tides. The studied parameters showed high values at high tide compared to low tide. The tidal process showed there is a high contribution of seawater that brings additional ions such as $\mathrm{Na}, \mathrm{Mg}$ and $\mathrm{K}$ into the mangrove system at high tide whereas at low tide, lower contribution of seawater was observed. Spearman correlation coefficient was used for the statistical characterizations of mangrove surface sediment at high and low tides. Relationships between physicochemical parameters, metals, granulometric fractions, organic matter and base cations at high and low tides were observed. Geoaccumulation Index calculations showed current sediment quality of Mengkabong mangrove sediments could be classified as having background concentrations of $\mathrm{Al}, \mathrm{Cu}, \mathrm{Fe}$, and $\mathrm{Zn}$, and as unpolluted with regard to $\mathrm{Pb}$. These findings are important for future research which will explain the chemistry that lies in mangrove sediment.
\end{abstract}

Keywords: Mangrove, Mengkabong lagoon, tides, Spearman correlation coefficient, Geoaccumulation Index

\section{Introduction}

Mangrove sediments have been extensively studied around the world (India, Australia, Brazil, Malaysia, Arab, China, Thailand, etc.). Heavy metal cycling is a serious problem addressed in mangrove environments elsewhere (Marchand et al., 2006; Pekey, 2006). High concentrations of heavy metals are derived from anthropogenic inputs such as industrial activities around estuaries as well as discarded automobiles, batteries, tires, waste water disposal, etc. (Shriadah, 1999; Bloom and Ayling, 1977).

Tidal current activity is mainly confined to mangrove channels. Outside the channels, mainly on the upper tidal-flats, tidal current velocities decrease and sediment entrainment is frequently ascribed to wave action. The role of tidal processes on intertidal surface sediments is frequently stated but the differences at these stages have seldom been investigated, apparently because of methodological constraints (Malvarez et al., 2001). The methodological constraints were such as determination of tidally influenced areas, correction of hydraulic gradient error based on tidal fluctuation, data requirements to determine tidal range at one location at coastal sites, definition of problems and development of conceptual model (Zektser and Dzhamalov, 2006). Moreover, one of the most difficult tasks in coastal wetlands 
studies is to use proper spatial scales from regional to habitat levels when selecting site criteria that will promote some specific goal or endpoint (Twilley et al., 1999).

In attempting to determine the extent of pollution in mangrove sediment and better estimate anthropogenic inputs using the heavy metals load in sediment, the Geoaccumulation Index $\left(I_{\text {geo }}\right)$ was employed. $I_{\text {geo }}$ was introduced by Muller (1979) to assess metal pollution in sediments. $I_{\text {geo }}$ includes seven grades describing degrees of enrichment above the background value ranging from unpolluted to very polluted sediment quality. The highest grade (class six) reflects 100-fold enrichment above the background values (Singh et al., 2003).

The Mengkabong lagoon in Tuaran District, where the current research was carried out, has experienced a $15 \%$ decrease in mangrove cover from 1991 to 2000 . In 1991 the mangroves covered $12.6 \mathrm{~km}^{2}$ while in 2000 they covered $10.7 \mathrm{~km}^{2}$. Most of the mangroves have been lost due to the spread of development such as housing, storm water road run-off, agricultural activities, aquaculture projects and the surrounding industrial zone, Kota Kinabalu Industrial Park (KKIP) (Environmental Indicator Report, 2003). One of the problems with further development in the area is very little inflow of water from inland areas. This means very limited flushing of sediment and effluent in the lagoon. The sediment is effectively filling up the bay and it is becoming shallower. The whole lagoon is a sensitive ecosystem and further development should be severely limited when detailing plans for that part of KKIP within Tuaran District (Town and Regional Planning Department, 2003). Due to the proximity at KKIP and the increasing development in the area surrounding the mangrove forest, it was decided to assess the distribution of heavy metals at high and low tides, enrichment and current pollution status of the mangrove sediments.

The objectives of the present study are: (1) to determine the physicochemical characteristics (pH, salinity and electrical conductivity), granulometric fractions (clay, silt and clay), heavy metals ( $\mathrm{Fe}, \mathrm{Cu}, \mathrm{Zn}, \mathrm{Pb}$ and $\mathrm{Al}$ ) and base cations ( $\mathrm{Na}$, $\mathrm{K}, \mathrm{Mg}$ and $\mathrm{Ca}$ ) of Mengkabong Bay surface sediment at high and low tides; (2) to determine the statistical characteristics of Mengkabong lagoon surface sediment using the Spearman correlation coefficient; and (3) to assess the extent of metal pollution using Geoaccumulation Index $\left(I_{\mathrm{geo}}\right)$.

\section{Materials and Methods}

\subsection{Sediment Sampling and Analysis}

The study was conducted in Mengkabong mangrove forest on the west coast of Sabah which is $40 \mathrm{~km}$ from Kota Kinabalu. The study area spreads from latitude $06^{\circ} 06^{\prime} \mathrm{N}$ to $06^{0} 11^{\prime} \mathrm{N}$ and longitude $116^{0} 08^{\prime} \mathrm{E}$ to $116^{0} 13^{\prime} \mathrm{E}$. Mangrove sediments were sampled randomly, based to the accessibility of the mangrove forest, and taken in triplicates with an auger at 33 stations from March 2006 to November 2006 (Figure 1) at low and high tide. The exact position of each sampling site was recorded using Global Positioning System (GPS). Mangrove surface sediments were chosen for this study as this layer controls the exchange of metals between sediments and water (El Nemr et al., 2006).

Figure 1

The sediments were kept cool in an icebox during transportation to the laboratory. The physicochemical parameters $(\mathrm{pH}$, electrical conductivity and salinity) were measured on 1:2 soil to water ratio extracts as soon as the samples reached the laboratory. The $\mathrm{pH}$, electrical conductivity and salinity electrodes were calibrated before the measurements were taken. For other analyses, the surface sediments were air-dried, homogenized using pestle and mortar, passed through a 2-mm mesh screen and stored in polyethylene bags. Methods and references for various analyses are given in Table 1. For the determination of heavy metals, the samples were digested using aqua regia. Approximately $2 \mathrm{~g}$ of each sample was digested with $15 \mathrm{~mL}$ of aqua-regia $\left(1: 3 \mathrm{HCl}: \mathrm{HNO}_{3}\right)$ in a Teflon bomb for $2 \mathrm{~h}$ at $120{ }^{\circ} \mathrm{C}$. After cooling, the digested samples were filtered and kept in plastic bottles before the analysis. Radojevic and Bashkin (1999) stated that aqua regia is adequate for extraction of total metals in soil sample and is widely used in most soil analyses laboratories. Base cations ( $\mathrm{Na}, \mathrm{K}, \mathrm{Ca}$ and $\mathrm{Mg}$ ) were determined by the measurement of exchangeable cations using ammonium acetate. Heavy metals and base cations were analyzed using AAS with air/acetylene $(\mathrm{Cu}, \mathrm{Fe}$, $\mathrm{Pb}, \mathrm{Zn}, \mathrm{Na}, \mathrm{K}, \mathrm{Ca}$ and $\mathrm{Mg}$ ) and nitrous oxide-acetylene (Al) at specific wavelengths (Atomic Absorption Spectrometer Perkin Elmer 4100).

Table 1

\section{Results and Discussion}

\subsection{Descriptive Statistics}

The descriptive statistics of physico-chemical properties ( $\mathrm{pH}$, salinity, electrical conductivity) granulometric fraction, organic matter, heavy metals $(\mathrm{Al}, \mathrm{Cu}, \mathrm{Fe}, \mathrm{Pb}$ and $\mathrm{Zn})$ and base cations $(\mathrm{Ca}, \mathrm{Mg}, \mathrm{Na}$ and $\mathrm{K})$ at low and high tide are given in Table 2.

Table 2

Berner (1981) recorded hundreds of $\mathrm{pH}$ measurements of estuarine sediment in Galician Rias Baixas, NorthWest Spain, within the range from $\mathrm{pH} 6$ to $\mathrm{pH} 8$. Similarly, 90\% of $\mathrm{pH}$ values in the present study fall between $\mathrm{pH} 6$ and $\mathrm{pH} 8$ at 
low and high tide thus reflecting the strongly buffered nature of $\mathrm{pH}$ values in sediment. According to Mitsch and Gosselink (2000) mangrove sediment salinity elsewhere varies with season and type of mangrove. Moreover, salinity is a function of the height and duration of tides. High salinity is found where tidal exchange occurs. With regard to organic matter present in mangrove sediment, a study done by Koop-Jakobsen and Giblin (2002) explained that during low tide, air exposure of the sediment increases the rate of degradation of organic matter. The granulometric fractions of mangrove sediment at high and low tide are quite similar in composition. It is dominated by the high percentage of sand followed by silt and clay. Eisma (1998) explained that in an intertidal estuary, the dominant sediment type is sand. The sediment with high composition of sand and low clay fraction is formed in agitated waters in the subtidal and intertidal zone. Tides are the predominant transport agent that influences the granulometric fractions in the mangrove environment. Coastlines with strong wave activity and tides are characterized by the concentration of sand, silt and clay (Eisma, 1998).

The elevated concentration of metals during high tide compared to low tide (Figure 2) is due to redox conditions in sediment columns (Akpan et al., 2002). According to Marchand et al. (2004) estuarine sediments are usually in reduced condition and have pore water with high concentration of metals. Alloway (1995) explained that metals in interstitial water are the mobile fraction. de Lacerda (2004) showed that the mobile fraction of metals tends to migrate in the sediment through interstitial water until it comes in contact with oxygen. Thus precipitation of hydrous metal oxides will occur. The precipitates of these metals are no longer soluble and are therefore incorporated into the sediment. Wolanski (2006) detailed that when the sediment submerged at high tide, Fe oxides are converted into hydrated forms and provide a large surface area for reactions of metals ion, leading the bioavailability of heavy metals.

The tides control the water-flows that carry the sediments in the mangrove forests, wherein the water from the estuary spills over to inundate the forests at high tide and drains back to the estuary at low tide. During low tide, $\mathrm{H}_{2} \mathrm{~S}$ and nutrients are released into the overlying water (Walpersdorf, 2008). Sulfide formed as the product of bacterial sulphate reduction usually undergoes rapid transformation in coastal sediments. Hydrogen sulfide may readily precipitate with $\mathrm{Fe}^{2+}$ to form iron sulfides. The exact oxidation/reduction transformations involving various reduced sulfur pools in sediments are not yet fully understood. Most sedimentary sulphide is usually recovered as acid volatile sulfur (AVS = $\left.\mathrm{H}_{2} \mathrm{~S}+\mathrm{FeS}\right)$ and chromium reducible sulfur $\left(\mathrm{CRS} .=\mathrm{S}^{\mathrm{o}}+\mathrm{FeS}_{2}\right.$ ) pools (Kristensen et al., 1991).

Bryd et al. (1990) in Guem Estuary, Korea, found that dissolved lead, cadmium, zinc, manganese and copper concentrations are highest at low salinities in the water column. This has been attributed to the flocculation and dissolution of aluminosilicate phases and colloidal iron oxyhydroxides. The increase in the concentrations of these metals at high salinity indicates the possibility that pore waters enriched in remobilized metals are mixed into the water column and sediment. The anaerobic condition allows the sulphate reduction to occur and leads to sulphide precipitation. Important chemical controls on the change of trace metals in the water column are the oxidation and reduction of sulfur and iron in surface sediments. This was shown by Marchand et al. (2006) in French Guiana mangrove forest. Marchand et al. (2006) stated that in estuarine sediments, copper and manganese have been identified as pyrite co-precipitates because of pyrite dissolution. In contrast, cadmium, chromium, lead, and zinc are believed to be attached by other sulfides or oxides because only significant amount of these metals dissolved. This is because these trace metals are involved in sorption or co-precipitation with amorphous FeS (Calloy et al., 2002). Trace metals may be incorporated into sulfide minerals by adsorption, precipitation or ion exchange. The limited studies of metal adsorption on sulfide minerals suggest that the adsorption is dominated by the surface hydroxyl groups. The surface interactions of metals with sulfide minerals are likely to influence the fate and transport of metals in anoxic environments (Morel and Hering, 1993).

The sediment water interface is the zone where the water layer interacts with the sediment. The pore or interstitial water is the water that occupies the free space in the sediment. Its composition reflects the sediment chemistry (Rand, 1995). Bouillon et al. (2007) showed that exchange of pore-water, combined with the physical conditions related to the tidal cycle, were important in explaining the sediment chemistry at high and low tide. Sediment pore-water represents the mediator fluid in the exchange of the components between sediment and water. A steep gradient in ionic strength in sediment pore water destabilizes the colloidal materials causing it to stick together (flocculate) (Andrews, 2004). Tidal flooding can bring additional ions of $\mathrm{Na}, \mathrm{Mg}, \mathrm{Ca}$ and $\mathrm{K}$ into the system and enable ion exchange and alteration of the sediment (Preda and Cox, 2000). The oxic condition during high tide (de Lacerda et al., 2004) makes the mobile fraction of metals tend to migrate to the sediment. According to Hussein and Rabenhorst (2001), dominant cation exchange in soils and sediment involves ions of unequal charge (polymeric $\mathrm{Al}_{1} \mathrm{Al}^{3+}, \mathrm{Na}^{+}$). In coastal environments, impacted by tidal inundation, the selectivity coefficient is no longer constant and becomes a function of ionic strength of the soil solution and surface cations composition. Increasing soil salinity will increase selectivity of the colloidal complex for Al. Clay and silt minerals, the most abundant inorganic colloids in estuarine waters, have surface negative charge that is partly balanced by adsorbed cations. The cations from seawater and heavy metals are attracted to the negative charge on silt and clay surfaces. The cations form a mobile layer in a solution closest to clay minerals. The adjacent particles will approach each other and aggregate. This simple explanation is 
vastly complicated by the presence of hydroxides and oxyhydroxide coating on the particles.

Table 3 shows the comparison with previous studies done elsewhere. A study conducted by Zhou et al. (2004) in the Pearl River Estuary found that the concentration of $\mathrm{Cu}, \mathrm{Zn}$ and $\mathrm{Pb}$ were high. This indicates that heavy metal pollution is serious due probably to the higher degree of industrialization during the last two decades in the Pearl River delta region. Ramanathan et al. (1999) observed high concentration of Fe in mangrove sediments. This might be the result of the textural and mineralogical characteristics of the mangrove sediments. Similar observations were made by Ray et al. (2006), Marchand et al. (2006) and Singh et al. (2003). In Punta Mala Bay (Panama), Izmit Bay (Turkey) and Mai Po (Hong Kong), mangrove areas received high inputs of heavy metals from untreated domestic sewage, storm water road run-off as well as inputs from shipping and agricultural activities. (Defew et al., 2005; Pekey, 2006; Che, 1999). Unlike, studies done by Shriadah (1999) in the Arabian Gulf, Emmerson et al. (1997) in Blackwater estuary (UK), Spencer and Macleod (2002) in Medway Estuary (UK) and Rate et al. (2000) in Swan River Estuary (Australia), showed that the heavy metal in mangrove sediments tend to be low in contamination indicating that the mangrove sediment were in unpolluted condition.

Table 3

\subsection{Spearman Correlation Coefficient Results}

Tables 4 and 5 show the values of Spearman correlation coefficient for the studied mangrove surface sediment. According to Binkley and Fisher (2000), the cations that balance the charge of the anions interact strongly with the solid phase of the soil, principally with the cation exchange complex. Sodium is an important parameter in some soils, particularly the near coastline, where inputs of marine salts are important. An exchange complex of a soil dominated by $\mathrm{H}^{+}$or $\mathrm{Al}^{3+}$ maintains a low soil $\mathrm{pH}$, and progressive replacement of the $\mathrm{H}^{+}$by so-called base cations leads to high $\mathrm{pH}$. According to Hsue and Chen (2000), seawater plays an important role in buffering the pH change. The process of tidal clash occurs in the Mengkabong mangrove forest where the influx of seawater from the high tide results in major inputs of selected cations which are then adsorbed by the sediment (clay, silt and sand). A significant correlation (0.798; $\mathrm{p}<0.01$ ) was observed between salinity and electrical conductivity at high tide, demonstrating the contribution of seawater during high tide compared to low tide in Mengkabong lagoon sediment. According to Church (1989), seawater contains $3.5 \%$ of salinity of which $90 \%$ is fully ionized ions.

Table 4

Table 5

Tidal range and flooding frequency therefore determine direction and quantity of nutrient and organic matter exchange between mangroves and the ocean (Dittmar and Lara, 2001). Sparks (1995) explained that soil organic matter complexes occur with clay minerals and stabilize the soil organic matter. Organic matter acts as a metal carrier and plays an important role in the metal distribution patterns (Lin and Chen 1998; de Groot et al. 1982).

Pekey (2006) and Shriadah (1999) stated that most contaminants are transported as fine-grained suspended matter which has large surface area. Grain size plays a significant role in determining elemental concentrations in sediment (Pekey, 2006). Several authors have studied the relationship between heavy metals and the granulometric fractions. Some studies have found good correlations between heavy metals and granulometric fractions while in some other cases, the relationship was less clear (Pekey, 2006; Shriadah, 1999). Heavy metal ions accumulate in estuarine sediments because of the deposition of metal-enriched allochthonous particles (parents materials; found in a place other than where they and their constituents were formed) or the adsorption of dissolved heavy-metal ions from the water column (Rodrigo, 1989).

It is possible that the differential adsorptive potential is capable of explaining the heavy metals variability. In some cases, the different size fractions of the sediment may differ in their adsorptive potentials because of differences in mineralogy. For instance, quartz is an exceedingly poor scavenger of metal ions. However, some clay minerals have a great affinity for cations because of the presence of iron and manganese oxides. According to Sparks (1995), adsorption potential increased exponentially with a decrease in particle size. The low adsorption potential in finer sediment (as in this study) is a result of the tendency of these particles to flocculate in saline waters. According to Rodrigo (1985) finer sediments will form large particle-aggregates with a correspondingly low total surface-area-to-volume ratio. According to Velde (1995), salt flocculation occurs at salinities of 0.05 to $0.1 \%$. Salt flocculation plays an important role in fine grained materials. The origin of organic matter and binding strength of the organic matter control flocculation and formation of flocs. Milligan and Loring (1997) also mentioned that organic matter is crucial in formation of flocculated suspensions.

A study done by Rodrigo (1985) showed low heavy metals adsorption in the Saltwater Creek estuary sediment compared to the Avon-Heathcote estuary (New Zealand). This decrease was due to the flocculation and adsorption potential. However, it does not affect the overall relationship between heavy metals and granulometric fractions as only a small quantity of very fine sediment is present in the Saltwater Creek, New Zealand (only about $2 \%$ of surface 
sediment consists of very fine silt and clay). The small quantity of silt and clay (4-7\%) in the Mengkabong mangrove forest sediment related to low adsorption potential and flocculation in saline waters is consistent with the study done by Rodrigo (1985). This is supported by correlation coefficient (r) values at high tide and low tide.

Inter-element relationship between metals provides interesting information on metal sources (Manta et al., 2003). In the present study, heavy metals and base cations generally show both positive and negative values among different pairs of variables. According to Ray et al. (2006) and Jonathan et al. (2004), the significant correlation of metals with Fe indicates the adsorption of these metals on to the oxyhydroxides with Fe. Ramanathan et al. (1999) stated that the high concentrations of $\mathrm{Fe}$ in mangrove sediments were the results of textural and mineralogical characteristics. It is important to note that clays and feldspars are essential species present in the sand and silt. Furthermore, the study of Jonathan et al. (2004) in the Gulf of Mannar, India explained the adsorption of these base cations and metals on the aluminophyllosilicate minerals. Firstly, because they are normally present at concentrations higher than the trace metals, they may occupy most of the surface binding sites even though they form less stable surface complexes. Secondly, it may have a significant effect on the amount of natural organics sorbed onto the solid surface (Hart, 1982). Feldspars are the major components and dominate the composition of estuarine sediments of coastal plains (Preda and Cox, 2000). Furthermore, cation forming elements such as $\mathrm{Cu}, \mathrm{Zn}$, etc. are more likely to be involved in oxidation and reduction reactions with each other as part of complex cycle (Kilham, 1990). Anthropogenic enrichment for heavy metals occurs naturally in silt and clay-bearing minerals of terrestrial and marine geological deposits. The natural occurrence of heavy metals complicates the assessment of potentially contaminated estuarine sediments. The measureable concentrations of metals do not automatically indicate anthropogenic enrichment in the lagoon. Therefore, heavy metal enrichment assessment must be conducted in detail (Zhou et al., 2004) using sediment indexes.

\subsection{Geoaccumulation Index $\left(I_{\text {geo }}\right)$}

$I_{\text {geo }}$ proposed by Muller (1979) has been applied to the set of sediment data from the present study to assess the sediment quality in Mengkabong mangrove forest (Table 6). $I_{\text {geo }}$ values can be used more effectively and more meaningfully in explaining the sediment quality (Karbassi et al., 2006). The $I_{\text {geo }}$ index showed that all the heavy metals are in Class 0 and Class 1 (Table 2) at high and low tide. Buccolieri et al. (2006) also reports similar findings in the Gulf of Taranto, Italy. This suggests that the mangrove sediment of Mengkabong is unpolluted. The input of metals into the sediments that are located seawards tends to be low in terms of concentration of most of the elements and this could be due to the mixing of enriched particulate material with relatively clean marine sediments (Soto-Jimenez and Paez-Osuna, 2001).

Table 6

\section{Conclusions}

Physicochemical characteristics of the surface sediment of Mengkabong Bay were determined including: pH, salinity and electrical conductivity, granulometric fractions (clay, silt and clay), heavy metals ( $\mathrm{Fe}, \mathrm{Cu}, \mathrm{Zn}, \mathrm{Pb}$ and $\mathrm{Al}$ ) and base cations ( $\mathrm{Na}, \mathrm{K}, \mathrm{Mg}$ and $\mathrm{Ca}$ ) at high and low tides. The studied parameters showed high values at high tide compared to low tide. The tidal process showed there is a high contribution of seawater that brings additional ions such as Na, $\mathrm{Mg}$ and $\mathrm{K}$ into the mangrove system at high tide whereas at low tide, lower contribution of seawater was observed. The tides control the water-flows that carry the sediments in the mangrove forests, wherein the water from the estuary spills over to inundate the forests at high tide and drains back to the estuary at low tide. This simple explanation of conditions at high and low tides is vastly complicated by the presence of hydroxides and oxyhydroxide coating on the particles. The Spearman correlation rank was used for the statistical characterizations of mangrove surface sediment at high and low tides. The associations between physicochemical parameters, organic matter, granulometric fractions, heavy metals $(\mathrm{Cu}, \mathrm{Fe}, \mathrm{Pb}, \mathrm{Zn}$ and $\mathrm{Al})$ and base cations $(\mathrm{Na}, \mathrm{K}, \mathrm{Mg}$ and $\mathrm{Ca})$ at high and low tide indicates the important contribution of seawater to sediment chemistry. The $I_{\text {geo }}$ value of heavy metals showed that the Mengkabong mangrove sediments have background concentrations of $\mathrm{Al}, \mathrm{Cu}, \mathrm{Fe}$, and $\mathrm{Zn}$ and are unpolluted with respect to $\mathrm{Pb}$. These findings are important for future research which will explain the chemistry that lies in mangrove sediment.

\section{Acknowledgements}

Appreciation is expressed to Universiti Malaysia Sabah Scholarship (YTL Foundation) which made this study possible. Acknowledgment is also given to Mr Asram and Mr Neldin for assisting with the field samplings.

\section{References}

Andrews, J. E. (2004). An Introduction to Environmental Chemistry. Blackwell Publishing. Oxford.

Akpan, E. R., Ekpe, U. J., \& Ibok, U. J. (2002). Heavy Metal Trends in the Calabar River, Nigeria. Environmental Geology, 42, 47-51.

Alloway, B. J. (1995). Heavy Metals in Soil. $2^{\text {nd }}$ Edition. Chapman and Hall, London.

APHA. (1995). Standard Methods for the Examination of Water and Waste Water. American Public Health Association. 
Washington, D.C.

Berner, R. A. (1981). A New Geochemical Classification of Sedimentary Environments. Journal of Sedimentology Petrology, 51, 359-365.

Binkley, D., \& Fisher, R. F. (2000). Ecology and Management of Forest Soils. John Wiley and Sons, New York.

Bouillon, S., Middelburg, J. J., Dehairs, F., Borges, A. V., Abril, G., Flindt, M. R., Ulomi, S., \& Kristensen, E. (2007). Importance of Intertidal Sediment Processes and Porewater Exchange on the Water Column Biogeochemistry in a Pristine Mangrove Creek (Ras Dege, Tanzania). Biogeosciences, 4, 311-322.

Bloom, H., \& Ayling, G.M. (1977). Heavy Metals in the Derwent Estuary. Environmental Geology, 2, 3-22.

Bryd, J. T., Lee, K. W., Lee, D. S., Smith, R. G., \& Windom, H. L. (1990). The Behaviour of Trace Metals in the Geum Estuary, Korea. Estuaries, 13, 8-13.

Buccolieri, A., Buccolieri, G., Cardellicchio, N., Dell'Atti, A., Leo, A. D., \& Maci, A. (2006). Heavy Metals in Marine Sediments of Taranto Gulf (Ionian Sea, Southern Italy). Marine Chemistry, 99, 227-235.

Calloy, S., O’Day, P. A., Esser, B., \& Randall, S. (2002). Speciation and Fate of Trace Metals in Estuarine Sediments under Reduced and Oxidized Conditions, Seaplane Lagoon, Alameda Naval Air Station (USA). U.S. Department of Energy Office of Scientific and Technical Information, P.O. Box 62 Oak Ridge. http://www.llnl.gov/tid/lof.

Che, O. (1999). Concentration of 7 Heavy Metals in Sediments and Mangrove Root Samples from Mai Po, Hong Kong. Marine Pollution Bulletin, 39, 269-279.

Church, A. H. (1989). The Ionic of the Sea. The Phytologist. 68, 239-247.

de Groot, A. J., Zschuppe, K. H., \& Salomons, W. (1982). Standardization of Methods of Analysis for Heavy Metals in Sediments. Hydrobiologia, 92, 689-695.

de Lacerda, L.D., Santelli, R.E., Duursma, E.K., \& Abrao, J.J. (2004). Environmental Geochemistry in Tropical and Subtropical Environments, Springer-Verlag, New York.

Defew, L. H., Mair, J. M., \& Guzman, H. M. (2005). An Assessment of Metal Contamination in Mangrove Sediments and Leaves from Punta Mala Bay, Pacific Panama. Marine Pollution Bulletin, 50, 547-552.

Dittmar, T., \& Lara, R. J. (2001). Driving Forces behind Nutrient and Organic Matter Dynamics in a mangrove tidal creek in North Brazil. Estuarine, Coastal and Shelf Science, 52, 249-259.

Eisma, D. (1998). Intertidal Deposits: River Mouths, Tidal Flats, and Coastal Lagoons. CRC Press, Boca Raton, Florida.

El Nemr, A., Khaled, A., \& Sikaily, A. E. (2006). Distribution and Statistical Analysis of Leachable and Total Heavy Metals in the Sediments of the Suez Gulf. Environmental Monitoring and Assessment, 118, 89-112.

Emmerson, R. H. C., O’Reilly-Wiese, S. B., Macleod, C. L., \& Lester, J. N. (1997). A Multivariate Assessment of Metal Distribution in Inter-tidal Sediments of the Blackwater Estuary, UK. Marine Pollution Bulletin, 34, 960-968.

Environmental Indicator Report. (2003). Environment Protection Department, Sabah, Malaysia. Syarikat Bumi Yakin. Hart, B. T. 1982. Uptake of Trace Metals by Sediments and Suspended Particulates: A Review. Hydrobiologia, 91, 299-313.

Heiri, O., Lotter, A. F. \& Lemcke, G. (2001). Loss on Ignition as a Method for Estimating Organic and Carbonate Content in Sediments: Reproducibility and Comparability of Results. Journal of Paleolimnology, 25, $101-110$.

Hsue, Z., \& Chen, Z. (2000). Monitoring the Change of Redox Potential, pH and Electrical Conductivity of the Mangrove Soils in Northern Taiwan. Proceeding Natural Science Council, 24, 143-150.

Hussein, A. H., \& Rabenhorst, M. C. (2001). Tidal Inundation of Transgressive Coastal Areas: Pedogenesis of Salinization and Alkalinization. Soil Science Society America Journal, 65,536-544.

Jonathan, M. P., Ram-Mohan, V., \& Srinivasalu, S. (2004). Geochemical Variations of Major and Trace Elements in Recent Sediments off the Gulf of Mannar, the Southeast Coast of India. Environmental Geology, 45, 466-480.

Kamaruzzaman, B. Y., Ong, M. C., Norhizam, H. A. G., \& Willison, K. Y. S. (2006). The Pollution Status of the Selected Heavy Metal in Mengabang Telipot River Surrounding Kolej Universiti Sains and Teknologi Malaysia (KUSTEM), Terengganu. International Conference on Coastal Oceanography and Sustainable Marine Aquaculture. 2-4 May 2006, Kota Kinabalu, Sabah, Malaysia.

Karbassi, A. R., \& Shankar, R. (2005). Geochemistry of Two Sediment Cores from the West Coast of India. International Journal Environmental Science and Technology, 1(4), 307-316.

Kilham, P. (1990). Mechanism Controlling the Chemical Composition of Lakes and Rivers. Data from Africa. 
Limnology Oceanography, 35, 80-83.

Koop-Jakobsen, K. \& Giblin, A. (2002). Northeast Tidal Flushing of Ammonium from Intertidal Salt Marsh Sediments: The Relative Importance of Adsorbed Ammonium. The Biological Bulletin, 203, 258-259.

Kristensen, E., Holmer, M., \& Bussarawit, N. (1991). Benthic Metabolism And Sulphate Reduction In A Southeast Asian Mangrove Swamp. Marine Ecology Progress Series, 73, 93-103.

Lin, J., \& Chen, S. (1998). The Relationship between Adsorption of Heavy Metal and Organic Matter in River Sediment. Environment International, 24, 345-352.

Malvarez, G. C., Cooper, J.A.G., \& Jackson, D.W.T. (2001). Relationships between Wave-Induced Currents and Sediment Grain Size on a Sandy Tidal-Flat. Journal of Sedimentary Research. 71, 705-712.

Mantha, D. S., Angelone, M., Belaanca, A., Neri, R., \& Sprovieri, R. (2003). Heavy Metal in Urban Soils: A Case Study from the City of Palermo (Sicily), Italy. Science of Total Environment, 300, 229-243.

Marchand, C., Baltzerb, F., Lallier-Verge`sa, E., \& Albe'rica, P. (2004). Pore Water Chemistry in Mangrove Sediments: Relationship with Species Composition and Developmental Stages (French Guiana). Marine Geology, 208, $361-381$.

Marchand, C., Lalliet Verges, E., Baltzer, F., Alberic, P., Cossa, D., \& Baillif, P. (2006). Heavy Metals Distribution in Mangrove Sediments along the Mobile Coastline of French Guiana. Marine Chemistry, 98, 1-17.

Milligan, T. G., \& Loring, D. H. (1997). The Effect of Flocculation on the Size Distributions of Bottom Sediment in Coastal Inlets: Implications for Contaminant Transport. Water, Air and Soil Pollution, 99, 33-42.

Mitsch, W. J., \& Gosselink, J. G. (2000). Wetlands. $3^{\text {rd }}$ Edition, John Wiley and Sons, New York.

Morel, F. M. M., \& Hering, J. G. (1993). Principles and Applications of Aquatic Chemistry. John Wiley and Sons, New York.

Muller, G. (1979). Schwermetalle in den sedimenten des Rheins-VeraÈnderungenseit. Umschau, 79, $778-783$.

Pekey, H. (2006). Heavy Metals Pollution Assessment in Sediments of the Izmit Bay, Turkey. Environmental Monitoring and Assessment, 123, 219-231.

Preda, M., \& Cox, M. E. (2000). Sediment-Water Interaction, Acidity and Other Water Quality Parameters in a Subtropical Setting, Pimpama River, Southeast Queensland. Environmental Geology, 39, 319-329.

Radojevic, M., \& Bashkin, V. N. (1999). Practical Environmental Analysis. Royal Society of Chemistry, Cambridge.

Ramanathan, A. L., Subramaniam, V., Ramesh, R., Chidambaram, S., \& James, A. (1999). Environmental Geochemistry of the Pichavaram Mangrove Ecosystem (Tropical), Southeast Coast of India. Environmental Geology, 37, 223-233.

Rand, G. M. (1995). Fundamentals of Aquatic Toxicology-Effects, Environmental Fate and Risk Assessmen. Taylor and Francis Publishers, Washingston.

Rate, A. W. W., Robertson, A. E., \& Borg, A. T. (2000). Distribution of Heavy Metals in Near-Shore Sediments of the Swan River Estuary, Western Australia. Water, Air and Soil Pollution, 124, 155-168.

Ray, A. K., Tripathy, S. C., Patra, S., \& Sarma, V. V. (2006). Assessment of Godavari Estuarine Mangrove Ecosystem through Trace Metals Studies. Environment International, 32, 219-223.

Rodrigo, A. G. (1989). Surficial Sediment Heavy Metal Associations in the Avon-Heathcote Estuary, New Zealand. New Zealand Journal of Marine and Freshwater Research, 23, 255-262.

Shriadah, M. M. A. (1999). Heavy Metals in Mangrove Sediments of the United Arab Emirates Shoreline (Arabian Gulf). Water, Air and Soil Pollution, 116, 523-534.

Singh, A. K., Hasnain, S. I., \& Banerjee, D. K. (2003). Grain Size and Geochemical Portioning of Heavy Metals in Sediments of the Damodar River- A Tributary of the Lower Ganga, India. Environmental Geology, 39, 90-98.

Soto-Jimenez, M. F., \& Pacz-Osuna, F. (2001). Distribution and Normalization of Heavy Metal Concentrations in Mangrove and Lagoonal Sediments from Mazatlan Harbour (SE Gulf Of Calfornia). Estuarine, Coastal and Shelf Science, 53, 259-274.

Sparks, D. (1995). Environmental Soil Chemistry. Academic Press Limited, California.

Spencer, K. L., \& Macleod, C. L. (2002). Distribution and Partitioning of Heavy Metals in Estuarine Sediment Cores and Implications for the Use of Sediment Quality Standards. Hydrology and Earth System Sciences, 6, 989-998.

Solomon, W. \& Forstner, U. 1984. Metals in the Hydrocycle. Springer-Verlag, New York. 
Town and Regional Planning Department (TRPD) (2003). Project Sabah, 2003. Environmental Local Planning (ELP), Kota Kinabalu, Sabah.

Twilley, R. R., Rivera-Monroy, V. H., Chen, R., \& Botero, L. (1999). Adapting an Ecological Mangrove Model to Simulate Trajectories in Restoration Ecology. Marine Pollution Bulletin, 37, 404-419.

Vanloon, G. W., \& Duffy, S. J. (2005). Environmental Chemistry: A Global Perspective. $2^{\text {nd }}$ Edition. Oxford University Press Inc.

Velde, B. (1995). Origin and Mineralogy of Clays. Springer, New York.

Walpersdorf, E., Werner, U., Polerecky, L., \& Franke U. (2008). Intertidal and Coral Lagoon Sediments . http://www.mpi-bremen.de/en/Sediments_2.html. 7 February 2008.

Wolanski, E. (2006). The Environment in Asia Pacific Harbours, Springer, Dordrecht.

Zektser, I. S., \& Dzhamalov, R. G. (2006). Submarine Groundwater. CRC Press, Boca Raton, Florida.

Zhou, H., Peng, X., \& Pan, J. (2004). Distribution, Source and Enrichment of Some Chemical Elements in Sediments of the Pearl River Estuary, China. Continental Shelf Research, 24, 1857-1875.

Table 1. Analytical methods used in this study

\begin{tabular}{lll}
\hline \multicolumn{1}{c}{ Parameter } & \multicolumn{1}{c}{ Method } & \multicolumn{1}{c}{ Reference } \\
\hline $\mathrm{pH}$ & Glass electrode & Mettler Toledo Delta 320 Manual \\
$\mathrm{EC}$ & Glass electrode & Eutech/Oakton ECTestr ${ }^{\mathrm{TM}}$ 11 Plus Manual \\
Salinity & Glass electrode & Eutech/Oakton SaltTestr ${ }^{\text {TM }}$ 11 Plus Manual \\
Organic Matter & Loss on Ignition (LOI) & $\begin{array}{l}\text { Heiri et al. (2001), Radojevic and Bashkin } \\
\text { (1999) }\end{array}$ \\
Granulometric analysis & Pipette Method & Radojevic and Bashkin (1999) \\
Total Heavy Metals & AAS & APHA (1995) \\
Base Cations & AAS & APHA (1995) \\
\hline
\end{tabular}


Table 2. Descriptive Statistics for each parameter at high and low tide $(\mathrm{n}=33)$. All elemental concentrations are in $\mathrm{mg}$ $\mathrm{kg}^{-1}$ except for $\mathrm{Na}, \mathrm{K}, \mathrm{Mg}, \mathrm{Ca}, \mathrm{Fe}$ and $\mathrm{Al}$. $(\mathrm{Sa}=$ salinity, $\mathrm{EC}=$ Electrical Conductivity, $\mathrm{OM}=$ Organic matter, HT $=$ High Tide, $\mathrm{LT}=$ Low tide)

\begin{tabular}{|c|c|c|c|c|c|}
\hline Parameter & & Min & Max & Mean & SD \\
\hline \multirow[t]{2}{*}{$\mathrm{pH}$} & HT & 5.4 & 7.6 & 6.5 & 0.4 \\
\hline & LT & 4.5 & 7.2 & 6.1 & 0.6 \\
\hline \multirow[t]{2}{*}{$\mathrm{Sa}(\%)$} & HT & 1.5 & 7.4 & 4.5 & 2.2 \\
\hline & LT & 0.1 & 1.5 & 0.5 & 0.4 \\
\hline \multirow[t]{2}{*}{$\mathrm{EC}\left(\mathrm{mS} \mathrm{cm}^{-1}\right)$} & HT & 2.1 & 11.4 & 6.8 & 2.6 \\
\hline & LT & 0.4 & 4.8 & 2.6 & 1.0 \\
\hline \multirow[t]{2}{*}{ OM (\%) } & HT & 6.4 & 11.7 & 9.0 & 1.3 \\
\hline & LT & 1.4 & 5.2 & 2.5 & 0.8 \\
\hline \multirow[t]{2}{*}{ Sand $(\%)$} & HT & 91.9 & 95.1 & 93.6 & 0.8 \\
\hline & LT & 91.7 & 97.3 & 95 & 1.7 \\
\hline \multirow[t]{2}{*}{ Silt (\%) } & HT & 2.5 & 5.2 & 3.6 & 0.8 \\
\hline & LT & 0.4 & 6.4 & 2.7 & 1.8 \\
\hline \multirow[t]{2}{*}{ Clay (\%) } & HT & 2.2 & 4.2 & 2.8 & 0.4 \\
\hline & LT & 1.3 & 2.9 & 2.4 & 0.4 \\
\hline \multirow[t]{2}{*}{$\mathrm{Na}\left(\mathrm{g} \mathrm{kg}^{-1}\right)$} & HT & 14.2 & 83.5 & 47.5 & 1.0 \\
\hline & LT & 2.5 & 92.7 & 41.6 & 0.4 \\
\hline \multirow[t]{2}{*}{$\mathrm{K}\left(\mathrm{g} \mathrm{kg}^{-1}\right)$} & HT & 5.7 & 16.0 & 9.4 & 2.5 \\
\hline & LT & 2.4 & 10.6 & 7.8 & 1.8 \\
\hline \multirow[t]{2}{*}{$\operatorname{Mg}\left(\mathrm{g} \mathrm{kg}^{-1}\right)$} & HT & 2.0 & 9.2 & 5.3 & 1.8 \\
\hline & LT & 1.0 & 7.6 & 3.8 & 1.9 \\
\hline \multirow[t]{2}{*}{$\mathrm{Ca}\left(\mathrm{g} \mathrm{kg}^{-1}\right)$} & HT & 2.6 & 52.9 & 21.3 & 41.7 \\
\hline & LT & 1.5 & 47.7 & 16.2 & 15.1 \\
\hline \multirow[t]{2}{*}{$\mathrm{Fe}\left(\mathrm{g} \mathrm{kg}^{-1}\right)$} & HT & 3.4 & 14.2 & 7.7 & 2.7 \\
\hline & LT & 1.4 & 18.4 & 6.8 & 4.0 \\
\hline \multirow[t]{2}{*}{$\mathrm{Cu}\left(\mathrm{mg} \mathrm{kg}^{-1}\right)$} & HT & 4.1 & 49.0 & 28.0 & 14.0 \\
\hline & LT & 2.1 & 44.0 & 19.0 & 13.0 \\
\hline \multirow[t]{2}{*}{$\mathrm{Zn}\left(\mathrm{mg} \mathrm{kg}^{-1}\right)$} & HT & 24.0 & 93.0 & 57.0 & 17.0 \\
\hline & LT & 12.0 & 73.0 & 41.0 & 17.0 \\
\hline \multirow[t]{2}{*}{$\mathrm{Pb}\left(\mathrm{mg} \mathrm{kg}^{-1}\right)$} & HT & 24.0 & 69.0 & 52.0 & 11.0 \\
\hline & LT & 34.0 & 47.0 & 41.0 & 3.0 \\
\hline \multirow[t]{2}{*}{$\mathrm{Al}\left(\mathrm{g} \mathrm{kg}^{-1}\right)$} & HT & 4.4 & 3.5 & 14.8 & 8.2 \\
\hline & LT & 2.4 & 2.4 & 9.5 & 6.0 \\
\hline
\end{tabular}


Table 3. Comparison of metal levels $\left(\mathrm{mg} \mathrm{kg}^{-1}\right)$ in various mangrove environments

\begin{tabular}{|c|c|c|c|c|c|}
\hline LOCATION & Al & $\mathbf{C u}$ & $\mathbf{F e}$ & $\mathbf{P b}$ & Zn \\
\hline Present Study & $\begin{array}{c}2411-3539 \\
3\end{array}$ & $2-49$ & $\begin{array}{l}1434-183 \\
60\end{array}$ & $24-69$ & $12-93$ \\
\hline $\begin{array}{l}\text { Telipot mangrove, Terengganu, } \\
\text { Malaysia }^{1}\end{array}$ & - & 3.53 & - & 8.60 & 27.15 \\
\hline Pearl River Estuary, China $^{2}$ & - & 46.5 & - & 59.26 & 150.06 \\
\hline Pichavaram, India $^{3}$ & 46100 & 43.4 & 8080 & 10.4 & 62.2 \\
\hline Izmit Bay, Turkey $^{4}$ & - & 39.2 & - & 77.1 & 345 \\
\hline Punta Mala Bay, Panama ${ }^{5}$ & - & 56.3 & 9827 & 78.2 & 105 \\
\hline Mai Po, Hong Kong ${ }^{6}$ & - & $20-75$ & - & 58.2 & 53.3 \\
\hline Arabian Gulf, United Arab Emirates ${ }^{7}$ & & 8.32 & & 37.3 & 9.05 \\
\hline Kaw River, French Guiana ${ }^{8}$ & & 2.8 & 7890 & 1.3 & 25.1 \\
\hline Ganges River, India ${ }^{9}$ & - & 55 & 40456 & 22 & 102 \\
\hline Beeleigh, Blackwater Estuary, $\mathrm{UK}^{10}$ & 19643 & 77 & 33302 & 60 & 190 \\
\hline Medway Estuary, $\mathrm{UK}^{11}$ & - & 42 & 30282 & 67 & 138 \\
\hline Mean sediment $^{12}$ & 72,000 & 50 & 41,000 & 19 & 95 \\
\hline
\end{tabular}

${ }^{1}$ Kamaruzzaman et al. (2006); ${ }^{2}$ Zhou et al. (2004); ${ }^{3}$ Ramanathan et al. (1999); ${ }^{4}$ Pekey (2006);

${ }^{5}$ Defew et al. (2005); ${ }^{6}$ Che (1999); ${ }^{7}$ Shriadah (1999); ${ }^{8}$ Marchand et al. (2006); ${ }^{9}$ Singh et al. (2003)

${ }^{10}$ Emmerson et al. (1997); ${ }^{11}$ Spencer and Macleod (2002); ${ }^{12}$ Solomon \& Forstner (1984) 


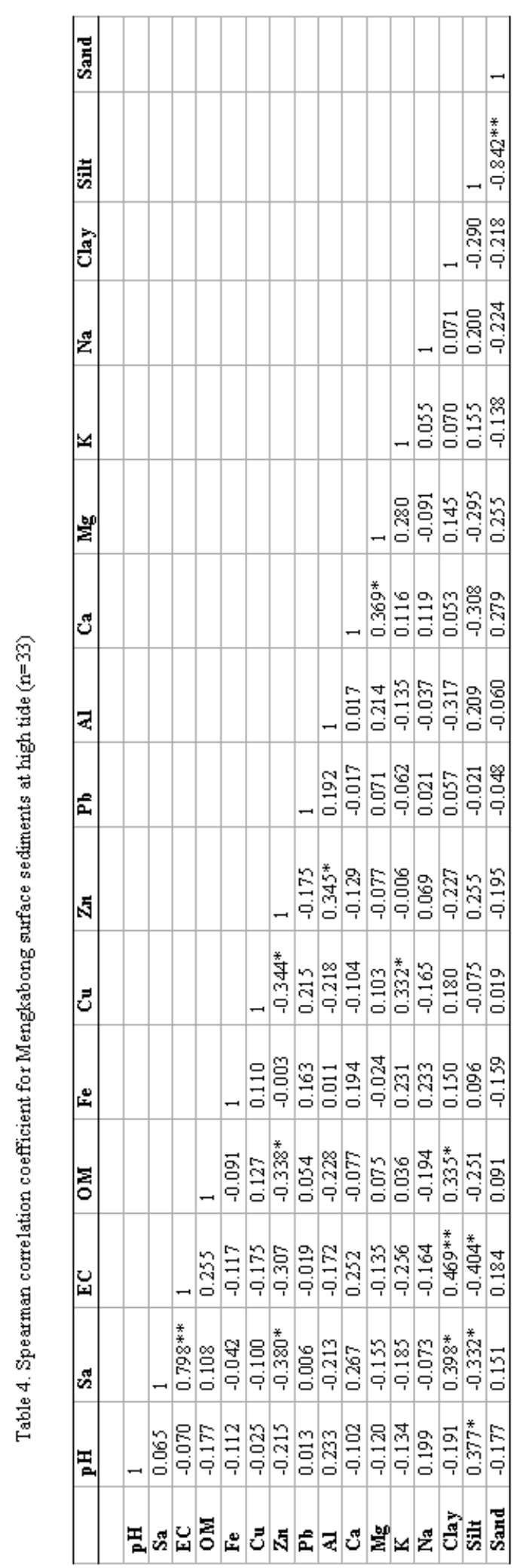

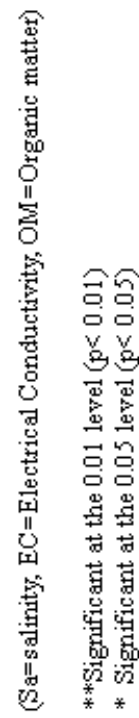




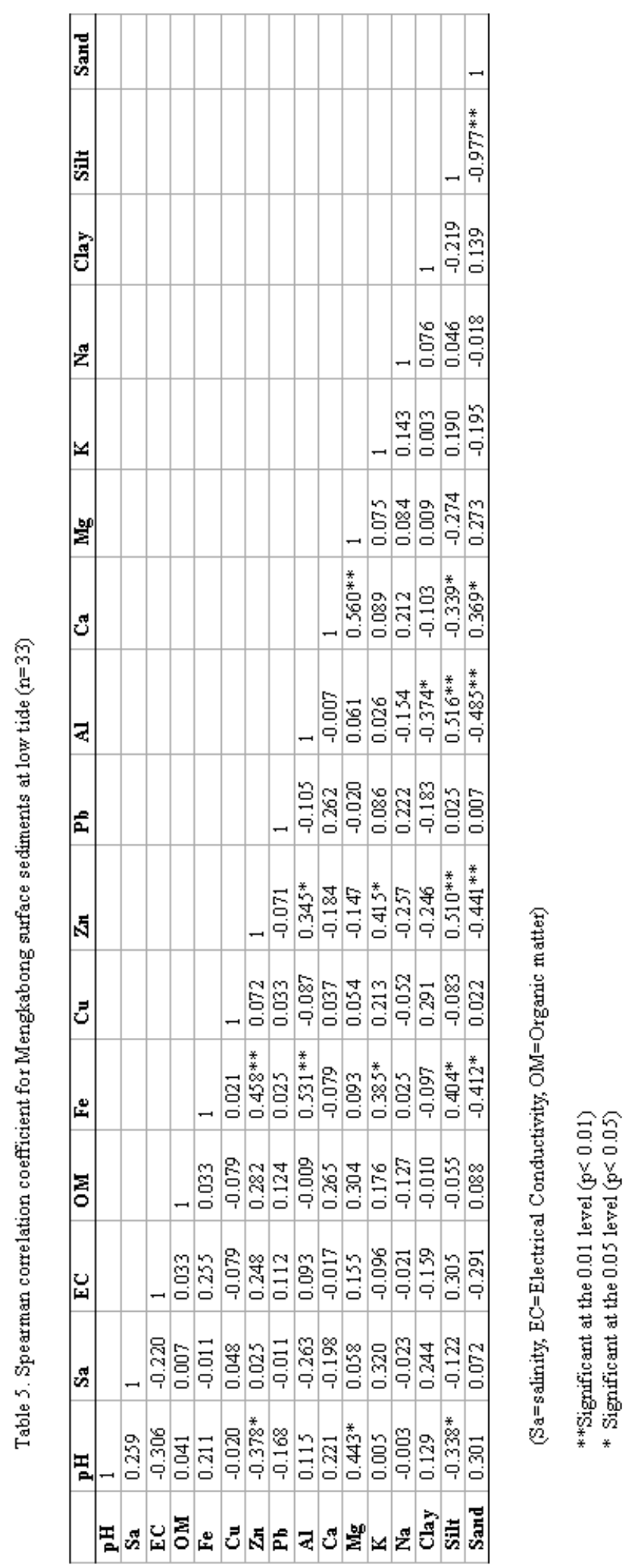


Table 6. Index of Geoaccumulation $\left(I_{\mathrm{geo}}\right)$ for heavy metals in sediment of Mengkabong mangrove forest

\begin{tabular}{ccc}
\hline $\begin{array}{l}\text { Heavy Metals } \\
\text { ( } \text { Igeo }_{\text {class for }} \text { Mengkabong lagoon } \\
\text { sediment) }\end{array}$ & Pollution Intensity & $\begin{array}{c}\text { Geoaccumulation } \\
\text { index }\end{array}$ \\
\hline $\mathrm{Al}, \mathrm{Cu}, \mathrm{Fe}, \mathrm{Zn}$ & Background concentration & 0 \\
$\mathrm{~Pb}$ & Unpolluted & $0-1$ \\
& Moderately to unpolluted & $1-2$ \\
& Moderately polluted & $2-3$ \\
& Moderately to highly polluted & $3-4$ \\
& Highly polluted & $4-5$ \\
\end{tabular}

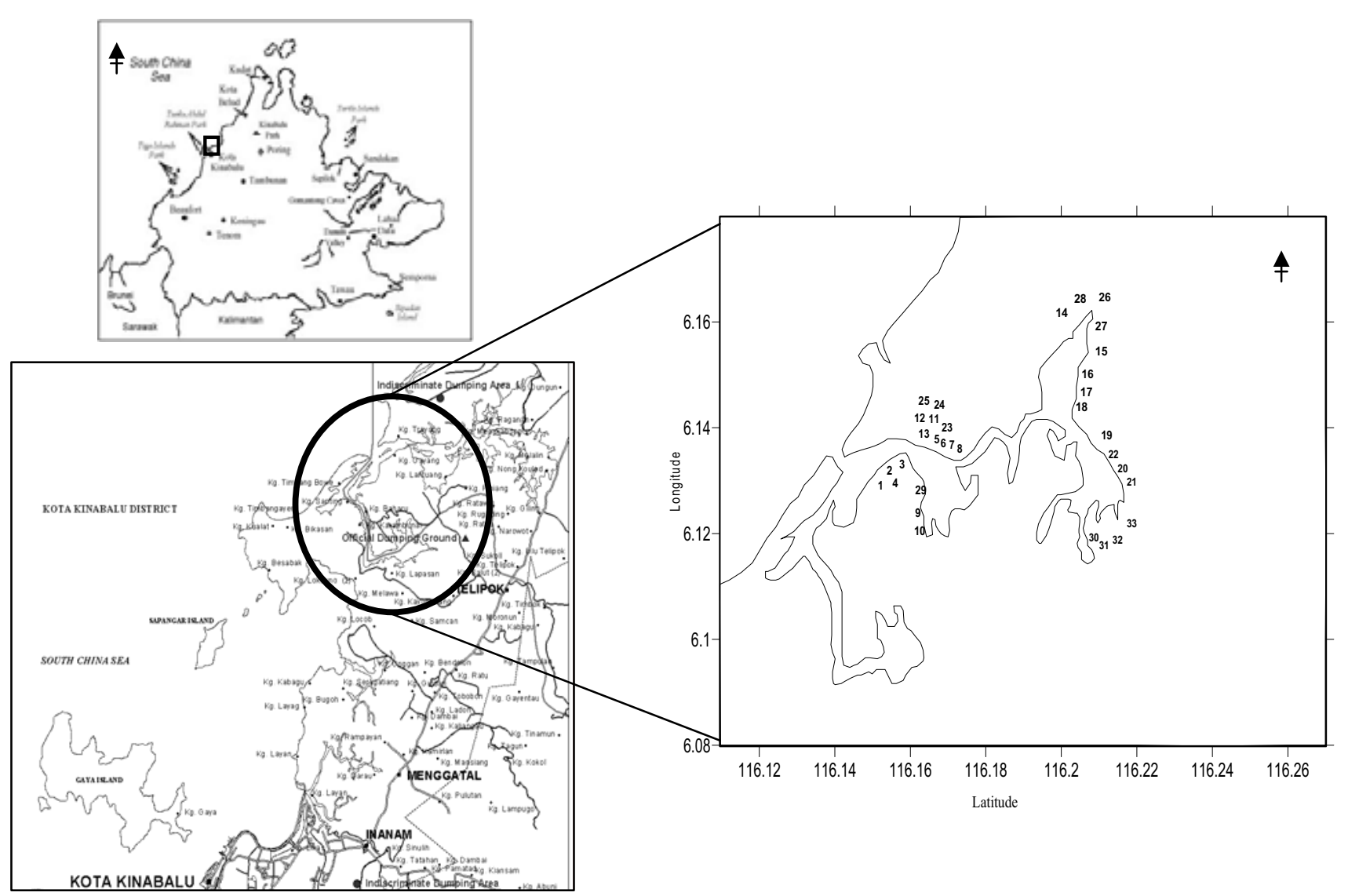

Figure 1. Location of 33 surface sediments taken in Mengkabong Bay 


\title{
Logarithmic Barrier Function Method \\ for Convex Quadratic Programming Problem
}

\author{
Xinghua Wang (Corresponding author) \\ college of Science, Yanshan University \\ Qinhuangdao 066004, China \\ E-mail: wxh811129@163.com \\ Wen Liu \\ college of Science, Yanshan University \\ Qinhuangdao 066004, China \\ Pingping Qin \& Lifeng Sun \\ college of Science, Yanshan University \\ Qinhuangdao 066004, China
}

\begin{abstract}
In this paper, we present a kind of interior point algorithm for solving Convex Quadratic Programming problem using Logarithmic Barrier Function. In which Newton Method and Interior Penalty Function Method are combined to obtain a simple construct and easily calculating algorithm. In each iterate it needs only to solve an equality constrained Quadratic Programming problem.
\end{abstract}

Keywords: Quadratic Programming, Logarithmic Barrier Function, Newton Method, Convergence

\section{Introduction}

Solution of Quadratic Programming problem is an important subject in Mathematical Programming and Industry domain, which has wide practice background. There are many algorithms for Quadratic Programming problem, such as Potential Function Projection Method; Affine Scaling Method; Primal-dual Interior Point Algorithm and so on. In this paper, we improved the Methods of document, we obtain the search direction of $d_{k}$ by Newton Method and then solve the optimal solution of equality constrained problem.

\section{Convergence}

To Nonlinear Programming problem: $(P) \min \{f(x) \mid A x=b, x \geq 0\}$

In which $f(x)=\frac{1}{2} x^{T} Q x+c^{T} x \quad c \in R^{n}, b \in R^{m}, A \in R^{n \times m}, Q \in R^{n \times m}, x \in R^{n}$

Let $\Omega_{\text {int }}=\left\{x \in R^{n} \mid A x=b, x>0\right\}, \operatorname{Rank}(A)=m, Q$ is a symmetric positive matrix.

Considering corresponding Logarithmic Barrier Function problem $\quad:\left(P_{u_{k}}\right) \min \left\{f(x)-u_{k} \sum_{i=1}^{n} \ln x_{i} \mid A x=b, x>0\right\}$

In which $u_{k}>0$ is a penalty factor.

So to the optimal solution of $(P)$ and $\left(P_{u_{k}}\right)$,we give such theorem:

Theorem 1:If $f(x)$ is an Convex Function, $\Omega_{\text {int }}=\{x \mid A x=b, x>0\} \neq \phi,\left\{u_{k}\right\}$ is a strict monotone decreasing Sequence of positive numbers which goes to zero,If we let $x^{*}$ is the optimal solution of $(P)$, 
$x\left(u_{k}\right)$ is the optimal solution of $\left(P_{u_{k}}\right)$, Then $x\left(u_{k}\right)$ is the optimal solution of $(P)$, too.

Proof:First proof $\left\{P\left(x_{u_{k}}, u_{k}\right)\right\}$ is a strict monotone decreasing Sequence with lower-bound.

Because $\quad x_{u_{k}} \in \Omega_{\text {int }}$

So

$P\left(x_{u_{k+1}}, u_{k+1}\right) \leq P\left(x_{u_{k}}, u_{k+1}\right)=f\left(x_{u_{k}}\right)+u_{k+1} B\left(x_{u_{k}}\right) \leq f\left(x_{u_{k}}\right)+u_{k} B\left(x_{u_{k}}\right)=P\left(x_{u_{k}}, u_{k}\right)$

$P\left(x_{u_{k}}, u_{k}\right)=f\left(x_{u_{k}}\right)+u_{k} B\left(x_{u_{k}}\right) \geq f\left(x_{u_{k}}\right) \geq f\left(x^{*}\right)$

and

that $\left\{P\left(x_{u_{k}}, u_{k}\right)\right\}$ is strict monotone decreasing and has a lower-bound,

So there exists limiting $\left(P_{0}\right)$, Next Proof

$P_{0}=f\left(x^{*}\right)$

We use evidence to the contrary

If $P_{0}>f\left(x^{*}\right)$, Then there must exists

$\varepsilon>0$

Such that $P_{0}>f\left(x^{*}\right)+2 \varepsilon$

We can see from the continuity of $f(x)$, there exists

$\bar{x} \in \Omega_{\text {int }}$ let $f(-\bar{x})<f\left(x^{*}\right)+\varepsilon$

Because

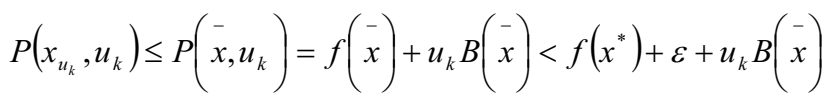

Also when $k$ is sufficiently large, there has $u_{k} B\left(\begin{array}{l}- \\ x\end{array}\right)<\varepsilon$, So we have

$\lim _{k \rightarrow \infty} P\left(x_{u_{k}}, u_{k}\right) \leq f\left(x^{*}\right)+2 \varepsilon$

That $P_{0} \leq f\left(x^{*}\right)+2 \varepsilon \quad$ it is contrary to (2)

Then proof $\forall$ limiting point $\left(x_{0}\right)$ of $x\left(u_{k}\right)$ is the optimal solution of $(P)$

Let $\lim _{k \rightarrow \infty} x_{u_{k}}=x_{0}$

Because $x_{u_{k}} \in \Omega$ int

So $x_{0} \in \Omega_{\text {int }}$

$f\left(x_{0}\right) \geq f\left(x^{*}\right)$ if $f\left(x_{0}\right)>f\left(x^{*}\right)$ and $\lim _{k \rightarrow \infty}\left[f\left(x_{u_{k}}\right)-f\left(x^{*}\right)\right]=f\left(x_{0}\right)-f\left(x^{*}\right)>0$

$P\left(x_{u_{k}}, u_{k}\right)-f\left(x^{*}\right)=f\left(x_{u_{k}}\right)-f\left(x^{*}\right)+u_{k} B\left(x_{u_{k}}\right) \geq f\left(x_{u_{k}}\right)-f\left(x^{*}\right)$

So $\lim _{k \rightarrow \infty}\left[P\left(x_{u_{k}}, u_{k}\right)-f\left(x^{*}\right) \neq 0\right] \quad P_{0} \neq f\left(x^{*}\right)$

It is contrary to (1)

So $f\left(x_{0}\right)=f\left(x^{*}\right)$

$x_{0}$ is the optimal solution of $(P)$

To the given initial inner point $x_{1}$, when the iteration step get to $k$, $x=x_{k} \in \Omega_{\text {int }}$

the search direction of problem $\left(P_{u_{k}}\right)$ can obtain by such that solution way: 
We can consider using proper Quadratic Function to approach target function $f$ in every iteration and then we construct the search direction by the direction which the iteration point points to the minimal point of Quadratic Function, let $x_{k}$ is the approximate minimal point of $f$,we take $f$ Taylor expansion at point $x_{k}$ and use its second-order approximate.

We have

$f(x) \approx f\left(x_{k}\right)+\nabla f\left(x_{k}\right)^{T}\left(x-x_{k}\right)+\frac{1}{2}\left(x-x_{k}\right)^{T} \nabla^{2} f\left(x_{k}\right)\left(x-x_{k}\right)$

Because $\nabla^{2} f\left(x_{k}\right)$ is a symmetric matrix, if we want to solve the minimal point of $f(x)$, we may let

$\nabla f(x)=0 \quad$ that $\quad$ is

$\nabla f\left(x^{*}\right)+\nabla^{2} f\left(x_{k}\right)\left(x-x_{k}\right)=0$

We take $x_{k+1}$ as the $k+1$ times of approximate of the minimal point of $f(x)$,

$x_{k+1}=x_{k}-\left[\nabla^{2} f\left(x_{k}\right)\right]^{-1} \nabla f\left(x_{k}\right)$

$d_{k}=-\left[\nabla^{2} f\left(x_{k}\right)\right]^{-1} \nabla f\left(x_{k}\right)$

\section{Related theorem}

Theorem 2 :If $d \neq 0$, then $d$ is the reduction direction of problem $\left(P_{u_{k}}\right)$

Proof: Because $\nabla^{2} f\left(x_{k}\right)$ is positive, $\left[\nabla^{2} f\left(x_{k}\right)\right]^{-1}$ is positive,

So $\nabla f\left(x_{k}\right)^{T} d_{k}=-\nabla f\left(x_{k}\right)^{T}\left[\nabla^{2} f\left(x_{k}\right)\right]^{-1} \nabla f\left(x_{k}\right)<0$

$d_{k}$ is the reduction direction of $f$ at point $x_{k}$

Now if we want to ensure the strict feasibility of iteration solution $x_{k+1}$, we must choose proper step size $\lambda_{k}$

Because $x_{k} \in \Omega_{\text {int }} \quad x_{k+1}=x_{k}+\lambda_{k} d_{k}$

$\mathrm{A}_{x_{k}}=A x_{k}+\lambda_{k} A d_{k}=A x_{k}=b$

And $x_{k+1}=x_{k}+\lambda_{k} d_{k}>0$

Let $\lambda_{k}=r \min \left\{1,-\frac{x_{k}^{i}}{d_{k}^{i}} \mid d_{k}^{i}<0\right\} r \in(0,1)$

Generally we let $r=0.995$

\section{Logarithmic Description}

Step0: give the strict initial inner point $x_{1} \in \Omega_{\text {int }}$ and tolerance $\varepsilon>0$

$u_{1} \in(0,1), \delta \in\left(0, \frac{1}{2}\right), \beta \in(0,1)$, set $k:=1$

Step1: Compute the solution $d_{k}$ of $(3)$, if $\left\|d_{k}\right\|<\varepsilon$ terminate, $x_{k}$ is the optimal solution of problem $(P)$, otherwise, go to Step2.

Step2: Compute the solution step size $\lambda_{k}$ of (4), check if it satisfies :

$P\left(x_{u_{k}}, u_{k}\right)-P\left(x_{k}+\lambda_{k} d_{k}, u_{k}\right) \geq-\delta \lambda_{k} d_{k}{ }^{T} \nabla P\left(x_{u_{k}}, u_{k}\right)$, if it satisfies, go to

Step3,otherwise, let $\lambda_{k}:=\frac{\lambda_{k}}{2}$, go to Step2.

Step3: let $x_{k+1}=x_{k}+\lambda_{k} d_{k}, u_{k+1}=\beta u_{k}$.

Step4:set $k:=k+1$, go to Step1.

\section{References}

Bai, Fusheng. \& Zhang, Liansheng. (2000). "Approximate Global Exact Barrier Method for Logarithmic Barrier Function”. OR TRANSACTIONS. 2000(3):13-18. 
Fletcher. R. “An exact penalty function for nonlinear programming with inequality”. Math Prog.5(1973). 129-150.

Pillo. G. D. \& Grippo. L. (1989). "Exact penalty function constrained optimization.SIAM.J". Control and Optimization. 27. 1333-1360.

Ruan, Xizhen. (2003). “interior point algorithm for Convex Quadratic Programming problem”. journal south-central university for nationalities..(3):72-74.

Yuan, Yaxiang. \& Sun, Wenyu. (1999).Optimization Theory and Method. Beijing: Science Press.

Zhang, Guangcheng. (2005).Computational Method for Nonlinear Optimization Beijing: CHEP. 


\title{
The Properties of Relative Regularity and Compactness
}

\author{
Genglei Li \\ College of Science, Tianjin Polytechnic University \\ Tianjin , 300160, China \\ E-mail:lglxt@126.com \\ Huidong $\mathrm{Wu}$ \\ College of Business, Hebei Normal University \\ Shijiazhuang, 050000, China \\ E-mail:xtlqjz@sohu.com
}

\begin{abstract}
In this paper, some topological properties were studied, especially including relative Hausdorff, relative regular and relative strongly regular and the property of nearly-paracompact under the perfect mapping was also discussed .
\end{abstract}

Keywords: $\mathrm{Y}$ is Hausdorff in $\mathrm{X}, \mathrm{Y}$ is regular in $\mathrm{X}, \mathrm{Y}$ is strongly regular in $\mathrm{X}, \mathrm{Y}$ is nearly-paracompact in $\mathrm{X}$.

\section{Introduction}

Relative topological properties are extension of classic topological invariants.In 1989, the relative topological properties were discussed by A.V.Archangel'skii and H.M.M.Genecli in Note 1, and A.V.Arhangel'skii gave the first systematic text on relative topological properties in 1996. In recent years, some further new results of the relative topology were obtained respective by A.V.Arhangel'skii, J.Tartir and W.Just, O.Pavlov and M.Matveer, I.Yaschenko, V.V.Tkachuk, M.G.Tkachenko and R.G.Wilson, etc.

In my paper, some relative topological properties were studied and some results were given.

\section{The Properties of Relative Regularity}

$\mathrm{X}$ is a space, $\mathrm{Y} \subset \mathrm{X}$, the concept of $\mathrm{Y}$ is Hausdorff, regular, superregular and strongly regular in $\mathrm{X}$ were introduced in Note 1. In this part, some properties of them were discussed, and I gave there results.

Definition 2.1 $\mathrm{Y}$ is Hausdorff in $\mathrm{X}$ : If for every two distinct points $\mathrm{x}$ and $\mathrm{y}$ of $\mathrm{Y}$, there are disjoint open subsets $\mathrm{u}$ and $\mathrm{v}$ of $X$, such that: $\mathrm{x} \in \mathrm{u}$ and $\mathrm{y} \in \mathrm{v}$.

Definition 2.2 $\mathrm{Y}$ is regular in $\mathrm{X}$ : If for each $\mathrm{y}$ of $\mathrm{Y}$ and each closed subset $\mathrm{p}$ of $\mathrm{X}$, such that $\mathrm{y} \notin \mathrm{p}$, there are disjoint open subsets $\mathrm{u}$ and $\mathrm{v}$ of $\mathrm{X}$, such that: $\mathrm{y} \in \mathrm{u}$ and $\mathrm{p} p \cap Y \subset \mathrm{v}$.

Definition 2.3 $\mathrm{Y}$ is superregular in $\mathrm{X}$ : If for each $\mathrm{y}$ of $\mathrm{Y}$ and each closed subset $\mathrm{p}$ of $\mathrm{X}$, such that $\mathrm{y} \notin \mathrm{p}$, there are disjoint open subsets $\mathrm{u}$ and $\mathrm{v}$ of $\mathrm{X}$, such that: $\mathrm{y} \in \mathrm{u}$ and $p \subset v$.

Definition 2.4 $\mathrm{Y}$ is strongly regular in $\mathrm{X}$ : If for each $\mathrm{x}$ of $\mathrm{X}$ and each closed subset $\mathrm{p}$ of $\mathrm{X}$, such that $\mathrm{y} \notin \mathrm{p}$, there are disjoint open subsets $\mathrm{u}$ and $\mathrm{v}$ of $\mathrm{X}$, such that: $\mathrm{x} \in \mathrm{u}$ and $p \cap Y \subset \mathrm{v}$.

Theory 2.5 If $\mathrm{Y}$ is a dense subspace of a space $\mathrm{X}$. Then, $\mathrm{Y}$ is Hausdorff in $\mathrm{X}$ if and only if $\mathrm{Y}$ is Hausdorff.

Proof. “ $\Rightarrow$ " Let $y_{1}, y_{2}$ are arbitrary points of $\mathrm{Y}$. Since $\mathrm{Y}$ is Hausdorff in $\mathrm{X}$, so there exist two disjoint open subsets $u_{1}$ and $v_{1}$ in $\mathrm{X}$, such that: $y_{1} \in u_{1}$ and $y_{2} \in v_{1}$. We may assume that: $u=u_{1} \cap Y$ and $v=v_{1} \cap Y$. Then, $\mathrm{u}$ and $\mathrm{v}$ are two open sets in $\mathrm{Y}$ and such that: $u \cap v=\varnothing, y_{1} \in u$ and $y_{2} \in v$. That is $\mathrm{Y}$ is Hausdorff.

" $\Leftarrow$ " Let $y_{1}, y_{2}$ are arbitrary points of $\mathrm{Y}$. Since $\mathrm{Y}$ is Hausdorff, so there exist two disjoint open subsets $u_{1}$ and $v_{1}$ in $\mathrm{Y}$, such that: $y_{1} \in u_{1}$ and $y_{2} \in v_{1}$. So there exist two open sets $\mathrm{u}$ and $\mathrm{v}$ in $\mathrm{X}$, such that: $u_{1}=u \cap Y, v_{1}=v \cap Y$. As follow we will prove $u \cap v=\varnothing$. We may also assume that $u \cap v \neq \varnothing$. Then $u \cap v$ is open in $\mathrm{X}$ since $\mathrm{u}$ and $\mathrm{v}$ are 
open in $\mathrm{X}$, and $\mathrm{Y}$ is a dense subspace of $\mathrm{X}$, so $(u \cap v) \cap Y \neq \varnothing$, therefore $u_{1} \cap v_{1} \neq \varnothing$. This is contradict with $u_{1} \cap v_{1}=\varnothing$. So, $u \cap v=\varnothing$. That is $\mathrm{Y}$ is Hausdorff in $\mathrm{X}$.

Theory 2.6 If $\mathrm{Y}$ is closed-open subspace of $\mathrm{X}$. Then, $\mathrm{Y}$ is regular in $\mathrm{X}$ if and only if $\mathrm{Y}$ is superregular in $\mathrm{X}$.

Proof. " $\Rightarrow$ Let $\mathrm{y}$ is an arbitrary point of $\mathrm{Y}$ and an arbitrary closed subset $\mathrm{p}$ of $\mathrm{X}$, such that $\mathrm{y} \notin \mathrm{p}, \quad$ since $\mathrm{Y}$ is regular in $\mathrm{X}$, there are disjoint open subsets $u_{1}$ and $v_{1}$ of $\mathrm{X}$, such that: $\mathrm{y} \in u_{1}$ and $p \cap Y \subset v_{1}$. We may assume that $u=Y \cap u_{1}$, then Since $\mathrm{y}$ is a point of $\mathrm{Y}$ and $\mathrm{Y}$ is open in $\mathrm{X}$, so $\mathrm{u}$ is an open set of $\mathrm{X}$, and such that: $y \in u$. Since $\mathrm{Y}$ is closed in $\mathrm{X}$, so $X / Y$ is an open set of $\mathrm{X}$. We may also assume that: $v=v_{1} \cup(X / Y)$, then we can get: $p \subset v$ and $u \cap v=\varnothing$. That is $\mathrm{Y}$ is superregular in $\mathrm{X}$.

" $\Leftarrow$ " Let $\mathrm{y}$ is an arbitrary point of $\mathrm{Y}$ and an arbitrary closed subset $\mathrm{p}$ of $\mathrm{X}$, such that $\mathrm{y} \notin \mathrm{p}$, there are disjoint open subsets $u$ and $v$ of X, such that: $y \in u$ and $p \subset v$. Obviously, $p \cap Y \subset v$. That is $\mathrm{Y}$ is regular in $\mathrm{X}$.

Theory $2.7 \mathrm{Y}$ is strongly regular in $\mathrm{X}$ if and only if for each point $\mathrm{x}$ of $\mathrm{X}$ and arbitrary open set $u$ of $\mathrm{X}$, such that $x \in X$, there exist an open $u_{x}$ of $\mathrm{X}$, such that $\mathrm{y} x \in u_{x} \subset u$ and $\overline{u_{x}} \cap(Y \backslash u)=\varnothing$.

Proof. " $\Rightarrow$ Let $\mathrm{x}$ is an arbitrary point of $\mathrm{Y}$ and an arbitrary open subset $\mathrm{u}$ of $\mathrm{X}$, such that $\mathrm{x} \in \mathrm{p}$. Let $\mathrm{p}=\mathrm{X} \backslash \mathrm{u}$, then $\mathrm{p}$ is closed in $\mathrm{X}$ and $y \notin p$. Since $\mathrm{Y}$ is strongly regular in $\mathrm{X}$, so there are disjoint open subsets $u_{1}$ and $v_{1}$ of $\mathrm{X}$, such that: $\mathrm{x} \in u_{1}$ and $p \cap Y=Y \backslash u \subset v_{1}$. We may let $u_{x}=u_{1} \cap u$, therefore, $x \in u_{x} \subset u$ and $\overline{u_{x}} \cap(Y \backslash u)=\varnothing$.

" $\Leftarrow$ " Let $\mathrm{x}$ is an arbitrary point of $\mathrm{X}$ and $\mathrm{p}$ is an arbitrary closed subset of $\mathrm{X}$, such that $\mathrm{x} \notin \mathrm{p}$. Let $\mathrm{u}=\mathrm{X} \backslash \mathrm{p}$. Then $x \in u$. So there is an open set $u_{x}$ of $\mathrm{X}$, such that: $x \in u_{x} \subset u$ and $\overline{u_{x}} \cap(Y \backslash u)=\varnothing$. Since $\mathrm{Y} \backslash \mathrm{u}=p \cap Y$, So we can assume: $u_{1}=u_{x}$ and $u_{2}=X \backslash \bar{u}_{x}$. Obviously, $x \in u_{1}, p \cap Y \subset u_{2}$ and $u_{1} \cap u_{2}=\varnothing$. That is $\mathrm{Y}$ is strongly regular in $\mathrm{X}$.

\section{The Property of Relative Compactness under the Perfect Mapping.}

The definition of nearly-paracompact was introduced in Note 3. Some properties of topological spaces under the perfect mapping were given in Note 6 . In this part, I studied the property of nearly-paracompact under the perfect mapping, and gave a result about it.

Definition $3.1 \mathrm{Y}$ is nearly-paracompact in $\mathrm{X}$ : If for each open covering $\mathrm{A}$ of $\mathrm{X}$, there exists an open family covering $\mathfrak{R}$ of $\mathrm{Y}$, such that: $\mathfrak{R}$ refines $\mathrm{A}$, and $\mathfrak{R}$ is locally finite at each $\mathrm{y}$ of $\mathrm{Y}$.

Theorem 3.2 Let $\mathrm{f}: \mathrm{X} \rightarrow \mathrm{Y}$ is a perfect mapping. If $Y_{1}$ is nearly-paracompact in Y.Then $f^{-1}\left(Y_{1}\right)$ is nearly-paracompact in $\mathrm{X}$.

Proof. Let $\mathrm{A}=\left\{u_{s}: s \in S\right\}$ is an open covering of $\mathrm{X}$. Since $\mathrm{f}$ is a perfect mapping, so for each $\mathrm{y} \in \mathrm{Y}$, the fiber $f^{-1}(y)$ is a compact subset of $\mathrm{X}$. Thus, there exists a finite subset $s(y)$ of $\mathrm{S}$, such that: $f^{-1}(y) \subset \bigcup_{s \in S(y)} u_{s}=u_{y(s)}$. Since $\mathrm{f}$ is a perfect mapping, by the TH1.4.13 in Note 6, there exists an open neighborhood $w_{y(s)}$ of $\mathrm{y}$, such that $: f^{-1}(y) \subset f^{-1}\left(w_{y(s)}\right) \subset u_{y(s)}$. We may also assume that: $f^{-1}\left(w_{y(s)}\right)$ is $v_{y(s)}$. That is $v_{y(s)}=f^{-1}\left(w_{y(s)}\right)$. Then, it is obvious that: $v_{y(s)}$ is open in $\mathrm{X}$ and such that: $f^{-1}(y) \subset v_{y(s)}=f^{-1}\left(f\left(v_{y(s)}\right)\right) \subset u_{y(s)}$ and $f\left(v_{y(s)}\right)$ is an open subset of $\mathrm{Y}$. Obviously, $\mathfrak{R}_{1}=\left\{f\left(v_{y(s)}\right): y \in Y\right\}$ is an open covering of $\mathrm{Y}$. Since $Y_{1}$ is nearly-paracompact in $\mathrm{Y}$, so there exists an open family covering $\mathfrak{R}_{2}=\left\{v_{a}: a \in A\right\}$ of $\mathrm{Y}$ by open subsets of $Y_{1}$, such that: $\mathfrak{R}_{2}$ refines $\mathfrak{R}_{1}$, and $\mathfrak{R}_{2}$ is locally finite at each $\mathrm{y} \in \mathrm{Y}$. We may also assume that $f\left(v_{y(s)}\right)$ which contains $v_{a}$ is $f\left(y_{a}(s)\right)$. Since $\mathrm{f}$ is perfect mapping ,thus, $\mathfrak{R}_{3}=\left\{f^{-1}\left(v_{a}\right) ; a \in A\right\}$ is an open family of $\mathrm{X}$ and locally Finite each $x \in f^{-1}\left(Y_{1}\right)$. Obviously, $f^{-1}\left(v_{a}\right) \subset f^{-1}\left(f\left(v_{y(s)}\right)\right) \quad=v_{y_{a}(s)}=u_{y_{a}(s)}$. Let $\mathfrak{R}=\left\{f^{-1}\left(v_{a}\right) \cap u_{s} \cap Y: a \in A, s \in S_{a}(y)\right\}$. Then , $\mathfrak{R}$ is an open family covering of $\mathrm{Y}$ and such that $\mathfrak{R}$ refines $\mathrm{A}$, and $\mathfrak{R}$ is locally finite at each $\mathrm{x} \in f^{-1}\left(Y_{1}\right)$. That is $f^{-1}\left(Y_{S}\right)$ is nearly-paracompact in $\mathrm{X}$. 


\section{References}

A.V.Arhangel'skii. (1996). Relative topological properties and relative topological spaces. Topology and Appl.20, 1-13.

A.V.Arhangel'skii and T.Nogura. (1998). Relative sequentiality. Topology and Appl. 82, 49-58.

A.V.Arhangrl'skii.(2002). From classic topological invariants to relative topological properties. Scientiae mathematicae japonicae,55, No. 1 153-201.

A.V.Arhangel'skiiandI.Ju.Gordienko.(1994). Locally Finite Topological Spaces. Questions and Answers in General Topology. 12:1.

Baturov D.P.(1990). Normality in dense subspaces of products. Topology and Appl.36, 111-116.

R.Engelking.(1997). General topology. Warszawa.(Chapter 1 ). 


\title{
Determination of Glucose and Fructose from Glucose Isomerization Process by High-performance Liquid Chromatography with UV Detection
}

\author{
N A.Rahman \\ Department of Chemical Engineering \& Process \\ Faculty of Engineering, Universiti Kebangsaan Malaysia \\ 43650 Bangi, Selangor, Malaysia. \\ E-mail:liza@vlsi.eng.ukm.my \\ M.Hasan \& M.A.Hussain \\ Department of Chemical Engineering, Faculty of Engineering, Universiti Malaya \\ 50603K.Lumpur, Malaysia \\ E-mail:masitahhasan@um.edu.my \\ J Jahim \\ Department of Chemical Engineering \& Process \\ Faculty of Engineering, Universiti Kebangsaan Malaysia \\ 43650 Bangi, Selangor, Malaysia. \\ E-mail:liza@vlsi.eng.ukm.my
}

\begin{abstract}
Analysis of fructose and glucose from glucose isomerization process using immobilised glucose isomerase (IGI), \{Sweetzyme from Novozymes\} are often performed by HPLC methods with refractive index (RI) detector. This study is focused on developing new methods of measuring glucose and fructose using a specific carbohydrate column. The importance of this research, primarily based on the performance of the HPLC with ultra-violet (UV) detection as another alternative of detector rather than using RI . The method was carried out under the following condition; UV detection was made at $195 \mathrm{~nm}$ with column temperature of $30^{\circ} \mathrm{C}$, flow rate of $0.6 \mathrm{ml} / \mathrm{min}$ and injections of $20 \mu \mathrm{L}$. The ratio of acetonitrile and the deionised water used was $80 \%$ to $20 \%$. From the results, the detection of fructose and glucose by HPLC with acetonitrile and water as solvents can be obtained using UV detection (195nm) instead of the commonly used detector of RI.
\end{abstract}

Keywords: Isomerization, HPLC, Glucose, Fructose ,UV detection

\section{Introduction}

Enzymatic reaction is a chemical reaction with enzymes acting as biological catalysts. According to Shuler \& Kargi(1992), under ambient conditions, the presence of enzymes result in much higher reactions rates as compared to chemically reactions. The role of enzyme catalysis in organic chemistry and bioprocess technology has increased tremendously in the last decade. According to Harmand et al (2004), two types of biological processes exist, microbiological and enzymatic reactions.

Isomerization of D-glucose to D- fructose by immobilized glucose isomerase is one example of enzymatic reaction. This reaction is a reversible reaction and important industrial process to produce high fructose syrup (HFS) with at least $50 \%$ conversion of glucose to fructose. The discovery of glucose isomerase started in 1957 by Marshall \& Kooi (1957) who carried out enzymatic isomerization in batch reactors with soluble enzymes of immobilized glucose isomerase (IGI).

Detection of fructose and glucose in this process have widely used HPLC column using RI detector such as by Gram \& Bang (1990) followed by several researchers (Crabb \& Shetty, Bhosale.; Rao.\& Deshpande, Salehi, Sohrabi , Kaghazchi.\& Bonakdarpour, Lee. \&Hong ). Another paper (Rački et al..(1991) reported a Dische-Borenfreund method for determination of fructose concentration.

In the present work, we demonstrate the use of HPLC column by UV detection to measure glucose and fructose using a carbohydrate column, instead of using RI detector. This research differ from the work done by Slimestad \& 
Vảgen. [10] in terms of range of detector and procedure of HPLC. In their study, Slimestad \& Vảgen (2006) used evaporative light scattering (ELSD) detection of $230 \pm 4 \mathrm{~nm}$ and the solvent gradient consisted of a linear increase in the amount of water in acetonitrile. The ability of the method proposed to analyze fructose and glucose is demonstrated under various operating conditions of the reaction.

\section{Materials and methods}

The materials for this study are: D-glucose(G), D-fructose(F) and $\mathrm{MgSO}_{4} .7 \mathrm{H}_{2} \mathrm{O}$, obtained from R\&M Chemical,UK; $12 \mathrm{~g}$ of Immmobilised Glucose Isomerase (IGI) of S.murinus, (brown cylindrical shape granules, diameter $0.3-1.0 \mathrm{~mm}$, length 1.0- $1.5 \mathrm{~mm}$ activity $350 \mathrm{IGIU} / \mathrm{g}$ ) from Sweetzyme, Novozymes; deionised water and acetonitrile (HPLC grade). The standard solutions were prepared in the following ways ; with $2 \mathrm{~g} / 100 \mathrm{~mL}$ each of $\mathrm{G}$ and $\mathrm{F}$ and diluted with distilled water. All analytical samples were diluted with distilled water and filtered through $0.2 \mu \mathrm{m}$ Nylon filters prior to HPLC-analysis.

The HPLC system in this study is an Agilent 1100 with diode array detector. UV detection was made at $195 \mathrm{~nm}$ with column temperature of $30^{\circ} \mathrm{C}$. The flow rate was set to $0.6 \mathrm{~mL} / \mathrm{min}$ and injections of $20 \mu \mathrm{L}$ were made. The column used was Supelco Kromasil $\mathrm{NH}_{2}$ column $(250 \mathrm{~mm} \times 4.5 \mathrm{~mm}, 5 \mu \mathrm{m})$. The ratio of acetonitrile and the deionised water used was $80 \%$ to $20 \%$. A guard column was attached to the inlet of the Kromasil column to prevent clogging.

\section{Results and discussion}

Table 1 shows the retention time $t_{R}(\mathrm{~min})$ and the area (mAUs) of glucose and fructose by HPLC-UV at different concentrations on a Kromasil $\mathrm{NH}_{2}$ column.

From Table 1 it can be confirmed that fructose (mainly) and glucose can be determined using UV detector instead of the commonly used RI detector. The average retention time of fructose was $14.2 \mathrm{~min}$, and 16.25 min for glucose. Figure 1 shows the standard curve for fructose and glucose at a specific concentration range. The values of $\mathrm{R}^{2}$ for both of fructose and glucose confirmed that the results were statistically reliable. Figure 3 shows the HPLC result in this study for detection of fructose and glucose using the Kromasil column at a $0.5 \%$ concentration of fructose and glucose. The detection of fructose was faster compared to the glucose which was similar in trends to given by the supplier (Kromasil) who suggested using RI as the detector, as seen in Figure 2 and the research by Slimestad and Vảgen (2006). This occurs because fructose has been described as the first step in the hydrothermal degradation of glucose. Fructose and glucose are isomers which have similar molecular weight but different in terms of the arrangement or configuration of the atoms (Hawley,2001).

Comparable analyses with other method for detection of glucose was made by the DNS method (Miller,1959) for reducing sugar, and using a UV spectrophotometer (Shimadzu) at wavelength of 550nm for a sample obtained from the same operating reaction conditions. The result show that the glucose concentration using HPLC - UV was $12.8 \mathrm{~g} / \mathrm{L}$ whereas for UV spectrophotometer (Shimadzu) was at $14.96 \mathrm{~g} / \mathrm{L}$. However the spectrophotometer measurement could not distinguish glucose from fructose, as they exist as isomers in the mixture. Hence resulting in the higher value.

\section{Conclusion}

The results imply that the detection of fructose and glucose by UV (195nm) with acetonitrile and water as solvents can be obtained using HPLC instead of commonly used detector of RI.

\section{Acknowledgment}

The authors would like to thank the Ministry of Science, Technology and Innovation (MOSTI) for the grants through IRPA Project 09-02-02-0110-EA267.

\section{References}

Bhosale H.S.; Rao B.M. \& Deshpande V.V, (1996). Molecular and Industrial Aspects of Glucose Isomerase Microbiol. Rev. 60, 280-300.

Crabb W.D \& Shetty J.K,. (1999). Commodity Scale Production of sugars from starches.. Microbiology. 2, $252-256$.

Gram J \& Bang De.M. (1990). An automated glucose isomerase reactor system with online flow injection analysers for monitoring of $\mathrm{pH}$, glucose and fructose concentrations. Chem.Eng. Sci.45, 1031-1042.

Harmand J, Rapaport A \& Dramé A.K. (2004). Optimal design of two interconnected enzymatic bioreactors.J.P.Control,14,785-794.

Hawley L. R.J. (Ed.) (2001). Condensed Chemical Dictionary. $14^{\text {th }}$ ed.,.Wiley. New York.

Lee H.S. \& Hong J (2000). Kinetic of glucose isomerization to fructose by immobilized glucose isomerase : anomeric reactivity of D-glucose in kinetic model J. Biotechnol. 84, 145- 153.

Marshall R.O, E.R Kooi. (1957). Enzymatic conversion of ${ }_{\mathrm{D}}$-glucose to $\mathrm{D}^{- \text {fructose }}$ Science.125, 648. 
Miller G.L. (1959). Use of dinitrosalicylic acid reagent for determination of reducing sugar. Anal. Chem. 31 ,426.

Rački D.V, Pavlović N., Čižmek S., Dražić M. \& Husadžić B. (1991). Development of reactor model for glucose isomerization catalyzed by whole-cell immobilized glucose isomerase Bioproc. Eng. 7, 183-187.

Salehi Z., Sohrabi M., Kaghazchi T., Bonakdarpour B, (2004). Application of down flow jet loop bioreactors in implementation and kinetic determination of solid-liquid enzyme reactions Proc. Biochem. 40, 2455-2460.

Slimestad R, \& Vảgen I.M. (2006). Thermal stability of glucose and other sugar aldoses in normal phase high performance liquid chromatography J. Chromatogr. A. 1118, 281-284.

Shuler L M \& Kargi F. (1992). Bioprocess Engineering; Basic Concepts, Prentice Hall, Englewood Cliffs ,New Jersey.

www.kromasil.com online 29/11/2007.

Table 1. The retention time $t_{R}(\mathrm{~min})$ and the area (mAUs) of glucose and fructose by HPLC-UV at different concentrations on a Kromasil $\mathrm{NH}_{2}$ column

\begin{tabular}{|l|l|l|}
\hline Conc. & \multicolumn{2}{|l|}{ Area [mAU.s $]$} \\
\hline$[\mathrm{g} / 100 \mathrm{ml}]$ & Fru & Glu \\
\hline 0 & 0 & 0 \\
\hline 0.5 & 2101 & 721 \\
\hline 1 & 5329 & 1939 \\
\hline 1.5 & 8532 & 3080 \\
\hline 2 & 12019 & 4410 \\
\hline R.time & 14.2 & 16.3 \\
\hline
\end{tabular}

Fructose + Glucose Standard Curve

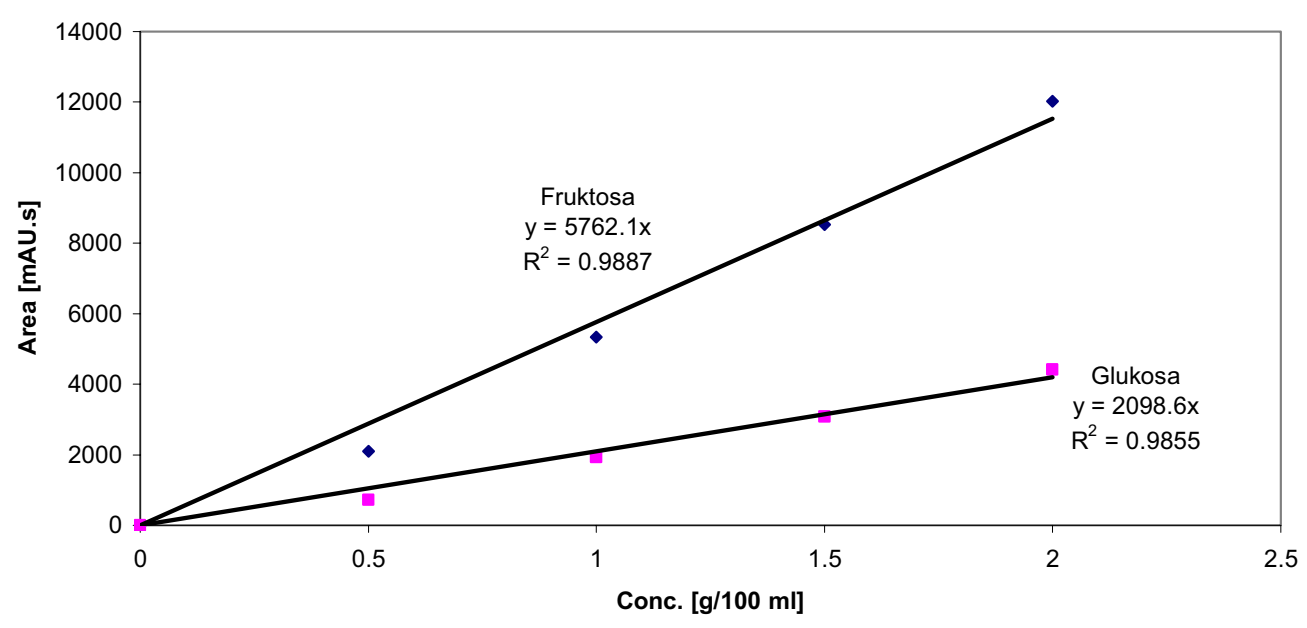

Figure 1. Standard curve for HPLC result for detection of fructose and glucose using Kromasil column by UV detector. 


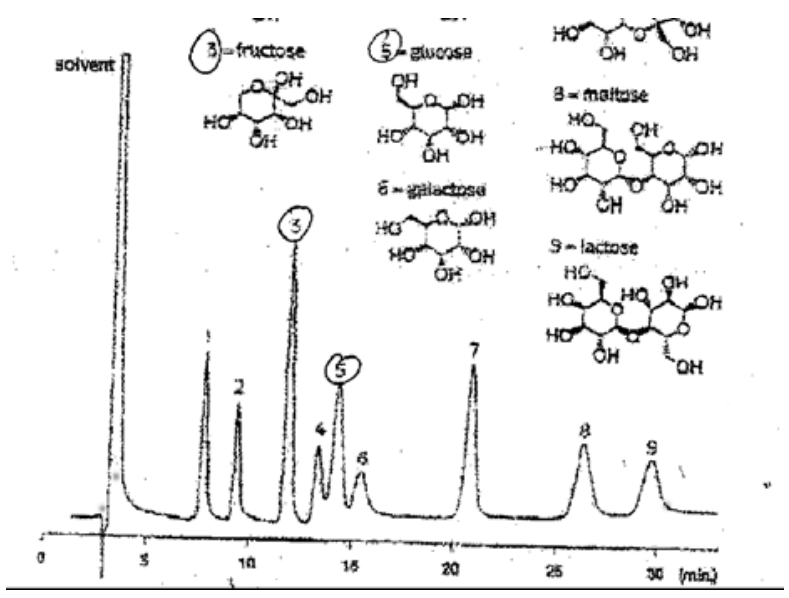

Figure 2. HPLC result for detection of fructose and glucose using Kromasil column by RI detector

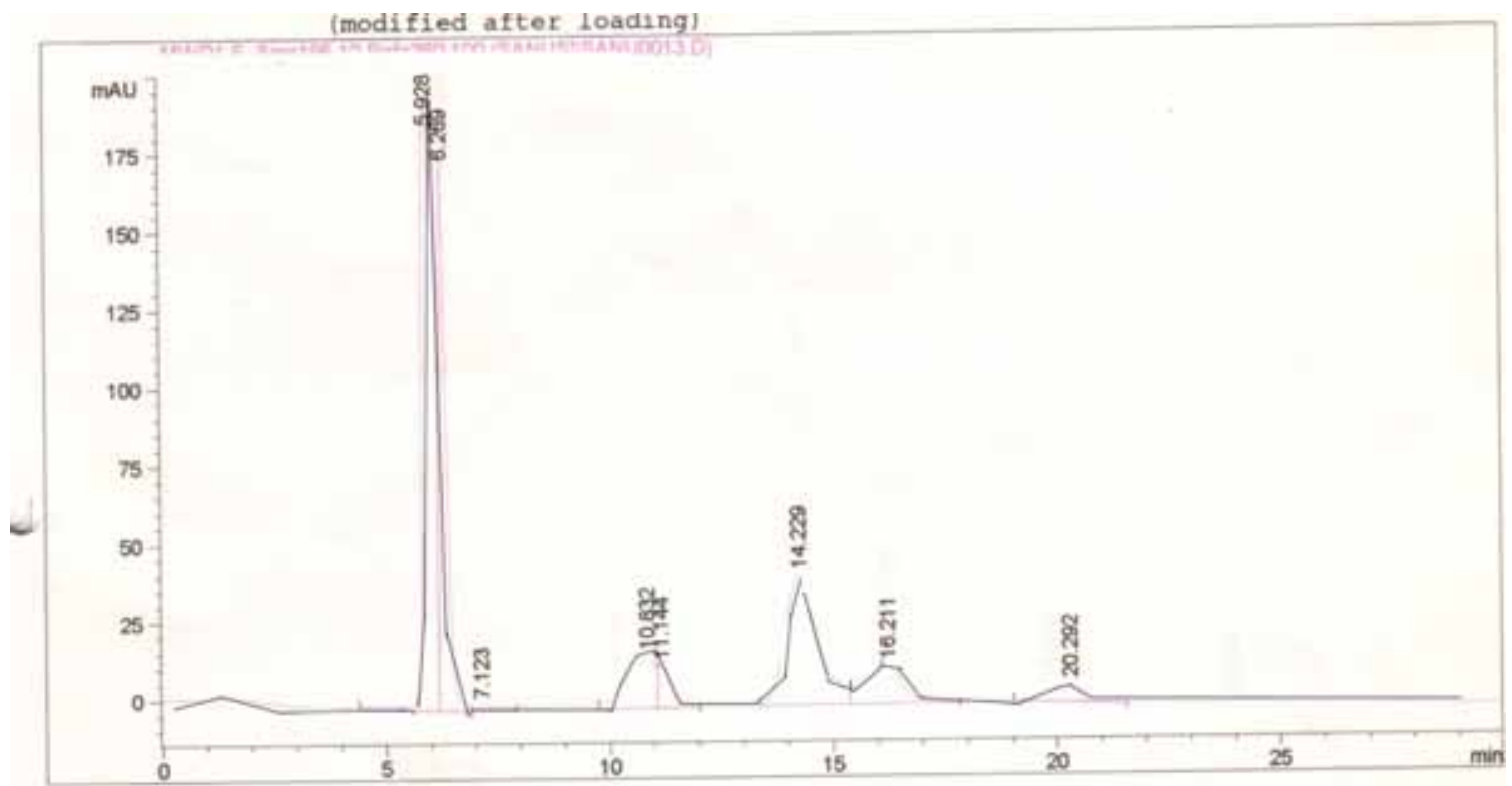

Figure 3. HPLC result for detection of fructose and glucose at a $0.5 \%$ concentration of fructose and glucose using Kromasil with UV detector. 


\title{
The Design and Implement of Improvement for Pointer MV-meter Display Mode
}

\author{
Yani Gao \& Ping Wang \\ Institute of Computer Technology\&Automatization \\ Tianjin Polytechnic University \\ Tianjin 300160, China \\ E-mail:gaoyani1984@163.com
}

\begin{abstract}
Based on relative fresh foreign and domestic scientific research results about intelligent apparatus and instruments, we adopt SCM to be the main controller of the meter, utilize former DA-16 low frequency MV-meter, realize the improvement of the DA-16 low frequency MV-meter under the premise that doesn't change its work principle, and transforms the needle output of the MV-meter to digital display. The improvement of MV-meter acquires large advancements in many aspects such as the automatization of measurement process, the data processing of measurement result and the display precision, and the improved MV-meter can not only enhance the reading precision, but fully reduce the reading time, and its use is more convenient and simple in the experiment.
\end{abstract}

Keywords: Low frequency MV-meter, SCM, ADC0809, LED display

\section{Introduction}

At present, more digital experiment instruments are selected in academies when they select lab MV-meter. The needle MV-meter facing disuse can be as the experiment teaching material that students study the lesson of SCM, which can enrich students' experiment lesson, exercise their hand abilities, and exert the function of waste using. The digital MV-meter completed by the experiment can replace the traditional needle display, which makes the reading more visual and exactly, fully reduces the reading time, enhances the display performance of the MV-meter, and possesses good actual values to be as later experiment instrument.

\section{Design and implementation}

The circuit of the hardware is seen in Figure 1. The output voltage of DA-16 low frequency MV-meter in the figure is adopted from the demodulation output of the meter, i.e. the voltage that the circuit part of DA-16 low frequency MV-meter export to the two ports of the needle meter. Through actual measurement, when the needle meter is in full scale, the voltage is $150 \mathrm{mV}$.

Generally, most full scale voltage of the A/D converter is $2.5 \mathrm{~V}$ or $5 \mathrm{~V}$. Because the full scale voltage exported by the DA-16 low frequency MV-meter is only $150 \mathrm{mV}$, so the reading needs to be amplified and transfer to the A/D converter. The requirements to the amplified circuit are small temperature excursion and small time excursion of the circuit.

The digital quantity obtained by the A/D converter is transmitted to the SCM which can confirm the position of the decimal according the classification information, implement digital scale transformation according to 100 or 300 full scale, and select the unit of the voltage.

In the process of the research, we take the usual DA-16 low frequency MV-meter as the research object, start from the changeless circuit and classification form of the former MV-meter, and mainly implement following works.

\subsection{DA-16 low frequency $M V$-meter}

The DA-16 low frequency MV-meter is a sort of low frequency electrical voltage meter in common use. Its voltage measurement scale is $1 \mathrm{mV} \sim 300 \mathrm{~V}$ and it has 11 shifts. Various shifts can display db number and it can measure the level, and the frequency scale of the measured voltage is $20 \mathrm{~Hz} \sim 1 \mathrm{MHz}$, and the input impedance exceeds $1 \mathrm{M} \Omega$.

\subsection{Direct current amplified circuit}

The full scale simulated output signal of DA-16 low frequency MV-meter is $150 \mathrm{mV}$, the full scale voltage of A/D 
converter is $5 \mathrm{~V}$, and we can compute the closed loop amplified multiple Av of the amplifier, and the circuit selects the high precision chopper-stabilized operational amplifier ICL7650 as the amplified component. ICL7650 has very small input deflection current and input maladjustment current, and it possesses very high open loop voltage gain and common-mode rejection ratio, and eliminates intrinsic maladjustment and excursion of the CMOS through the dynamic correcting null, so it is usually used in the circuit measuring the feeble signal, for example the occasion of direct current and low frequency. In this circuit, the amplified signal is the direct current signal which has no the problem of transmission bands. And the first class amplification can obtain stable amplified effect.

\subsection{ADC0809A/D converter chip}

The interior of the SCM 89S52 has no A/D converter, and the full span error of the DA-16 low frequency MV-meter is \pm 2 , and the needle meter itself is the 1.5 class meter. The differentiation rate of ADC0809 is 8 bits, its precision is 7 bits, and the maximum unadjusted error is less than $\pm 1 \mathrm{LSB}$, i.e. $4 \%$. Adding the error of $1 \%$ in the circuit part of DA-16 low frequency MV-meter, the total error can be controlled in $\pm 1.5 \% \sim \pm 1$, so the ADC0809 converter connected with it outside is well situated in precision, speed and price. The part circuit of A/D converter is seen in Figure 3 .

In Figure 3, the IN0 IN7 is the input port of the simulated signal, and this design only uses one input, i.e. IN0. Because there are not extended memorizer and I/O interface, so the address flip-latch is not needed, and P2.4 is the selection line. D0 D7 is the output port with 8 bits after transformation, which should connect with the port of P0 in 89S52. The ALE signal locks the channel address, and when the start is effective, the A/D converter is started. To enhance the precision, a measured signal is collected ten times in the design, and the mean value is the measured voltage value after getting rid of one maximum value and one minimum value. When A/D conversion is completed, EOC port emits a plus impulse and applies for intermitting. The exterior intermitting null is used in the design, and the low level is effective, so the INT0 of 89S52 needs to be transformed to low level and started through reverse phase of 74HC02.

The sampling veracity of ADC0809 is closely correlative with the stability of the reference voltage, and the exact reference source 2DW232 offers the reference voltage in the design. The 2DW232 has stable work performance and its temperature parameter is $100 \mathrm{PPM} /{ }^{\circ} \mathrm{C}$.

\subsection{Frequency division circuit}

When the frequency of the exterior clock connected with ADC0809 is $640 \mathrm{KHz}$, the ADC0809 has the most stable work situation. To simplify the circuit, we don't set up another clock circuit. 89S52 adopts the crystal vibration of $12 \mathrm{Mz}$, and the plus impulse signal frequency exported by the foot of ALE is one sixth of the oscillator, i.e. $2 \mathrm{MHz}$, so it needs two times half frequency division through $74 \mathrm{HC} 163$, and the obtained frequency of $500 \mathrm{KHz}$ is the clock signal of ADC0809. Every time transformation generally needs 64 clock cycles, and the transformation time is about $100 \mu$ s. The circuit is shown in Figure 4.

\subsection{Shift switch}

In the process of digital display, the position of the decimal, the selection of the transformation formula and the display of the unit should be considered, which needs to be controlled by the shift switch. So we add the input circuit of 11 shifts of MV-meter, which is seen in Figure 5. The shift position can control the scale. When the shift is used, the signal input in the SCM 89S52 is low, and the circulation inquiring mode is used in the SCM, and when the transformation of ADC0809 and the intermitting application are completed, the SCM compute the voltage through amplification of the measured signal by the amplifier according to the shift information input by the shift switch circuit.

As viewed from the unit of the measured voltage, 11 shifts can be divided into two parts, and P1.0 P1.5 is the shift of $\mathrm{mV}$, and P1.6, P1.7, P3.3, P3.4 and P3.5 are the shift of V. Inquiring by 89S52, when the signal of certain port is low, 89S52 first will judge whether it is the " $\mathrm{mV}$ " shift or the "V" shift and lighten the corresponding LBD. At the same time, different selective scales correspond with different formulas. The reference voltage of ADC0809 is 5V, the data scale of 8 bits $\mathrm{A} / \mathrm{D}$ converter is $0 \sim 255$, so the voltage value represented by every step is $19.6 \mathrm{mV}$ (the differentiated rate of the converter). Considering the situation of exceeded scale, we use 250 steps to correspond with the voltage of full scale. The formulas are respectively as follows:

Formula 1: the corresponding number of the measured voltage $=$ the measured voltage value $/ 19.6 \mathrm{mV}$

Formula 2: the measured voltage value $=$ the number $\times$ (the voltage value of full scale/250) (the scale is seen in Table 1)

The formula 1 reflects the process of ADC0809 transformation, and the formula 2 is completed in the exertion program of 89S52.

The position of the decimal is controlled by the shift. The "V" shift and the "mV" shift have same principle which is seen in Table 1. The SCM drives the corresponding LBD through the input shift signal.

\section{6 $89 S 52$ SCM}

The function of 89S52 SCM is basically same with traditional 80C51. Because this design doesn't use the added 
function of $89 \mathrm{~S} 52$, so it can be took as 8051 to a certain extent.

27 ports of 89S52 are used in this design. And the port XYAL1 and XYAL2 connected with $12 \mathrm{MHz}$ quartz crystal compose a stable self-oscillator with two 33PF capacitances.

The port of P0 is connected with D0 D7 of ADC0809, which receives the data after the conversion of ADC0809.

The ports of P1, P3.3, P3.4, P3.5 and total 11 ports are the input ports of the shift selection.

The port of P2.0 and the port of P2.1 are the unit display ports. The P2.0 connects with green LED and displays $\mathrm{mV}$, and the P2.1 connects with red LED and displays V.

The port of P2.4 respectively connects with the control ports of START, ALE and OE of ADC0809 which P3.7 (/RD) and P3.8 (/WR) pass 74HC02 or NOR-gate.

The port of P3.0 (RXD) and the port of P3.1 (TXD) connect with 74HC164 and export the value display data. The P3.2 (/INT0) connects with the port of EOC of ADC0809 and the low level of /INT0 is effective, and when the EOC applies for intermitting, it emits the high level, so one phase reverser is needed to be added. Utilizing the Nor-gate of 74HC02, when the level and constant low level is NOR, the output is the effective low level.

\subsection{Work principle of LED}

As Figure 6, the display circuit adopts the static display of common cathode eight segments digital tube.

In the process of TXD, when the first frame data are transmitted, the first $74 \mathrm{HC} 164$ exporting the data and the LED1 displays the data. When the second frame data are transmitted, LED1 displays the second frame data, and the first frame data are input to the second 74HC164, and LED2 displays the first frame data. In this turn, all 4 bits data are transmitted. When all data are transmitted, the first frame data are displayed in the last LED.

To protect various LED, the current limitation resistance should be added. The work current of LBD is 5mA, the work voltage is $1.5 \mathrm{~V}$ which ignores the wasting voltage when $74 \mathrm{HC} 164$ exports, and the obtained current limitation resistance value is $700 \Omega$. If the resistance with large resistance value is used, it will influence the brightness of the LED, and if the resistance with too small resistance value is used, it will burn the LED. In the design, we use the resistance of $1 \mathrm{~K} \Omega$. The eight segments digital tube used in this design is in common cathode, so the common cathode connects with the earth. The segment selection line of every bit respectively connects with the output port of $74 \mathrm{HC} 164$, and various bits in the display are independent each other, and once the display character of various bits is confirmed, the output of corresponding flip-latch will keep constant. So the static display has higher brightness than the dynamic display.

Comparing with dynamic scanning, CPU needs not continually scan and frequently serve for the display, which can save the time of CPU and enhance the work efficiency. And the hardware of static display has simple structure and easy software programming, so the price of the chip is cheap. When the output display is not complex, the static display is generally adopted.

\subsection{The design process of the software}

The design process of the software is seen in Figure 7 and the program is omitted.

\section{Conclusions}

In this design, we adopt the SCM control and basically realize the digital display of DA-16 low frequency MV-meter, and fully enhance its display precision. The measured voltage of the improved MV-meter displays by four bits LED, which avoids the error produced by man-made reading angle in the former experiment. The improved MV-meter can not only enhance the reading precision, but fully reduce the reading time, and its use is more convenient and simple in the experiment.

\section{References}

Hu, Hancai. (1996). SCM Principle and Interface Technology. Beijing: Tsinghua University Press. p.85-113.

Li, Chaoqing. (1998). SCM Principle and Interface Technology. Beijing: Beijing Aviation and Spaceflight University Press. p.89-93.

Ma, Zhongmei. (2003). C Language Application Design of SCM. Beijing: Beijing Aviation and Spaceflight University Press. p.46-98.

Tong, Shibai \& Hua, Chengying. (2000). Analog Electronic Technology. Beijing: Higher Education Press. p.171-296. 
Table 1. The scale table of the shift

\begin{tabular}{|c|c|c|c|}
\hline No. & Port & Scale & Poison of decimal \\
\hline K1 & P1.0 & $1 \mathrm{mV}$ & After the 1st digit \\
\hline K2 & P1.1 & $3 \mathrm{mV}$ & After the 1st digit \\
\hline K3 & P1.2 & $10 \mathrm{mV}$ & After the 2nd digit \\
\hline K4 & P1.3 & $30 \mathrm{mV}$ & After the 2nd digit \\
\hline K5 & P1.4 & $100 \mathrm{mV}$ & After the 3rd digit \\
\hline K6 & P1.5 & $300 \mathrm{mV}$ & After the 3rd digit \\
\hline K7 & P1.6 & $1 \mathrm{~V}$ & After the 1st digit \\
\hline K8 & P1.7 & $3 \mathrm{~V}$ & After the 1st digit \\
\hline K9 & P3.3 & $10 \mathrm{~V}$ & After the 2nd digit \\
\hline K10 & P3.4 & $30 \mathrm{~V}$ & After the 2nd digit \\
\hline K11 & P3.5 & $300 \mathrm{~V}$ & After the 3rd digit \\
\hline
\end{tabular}

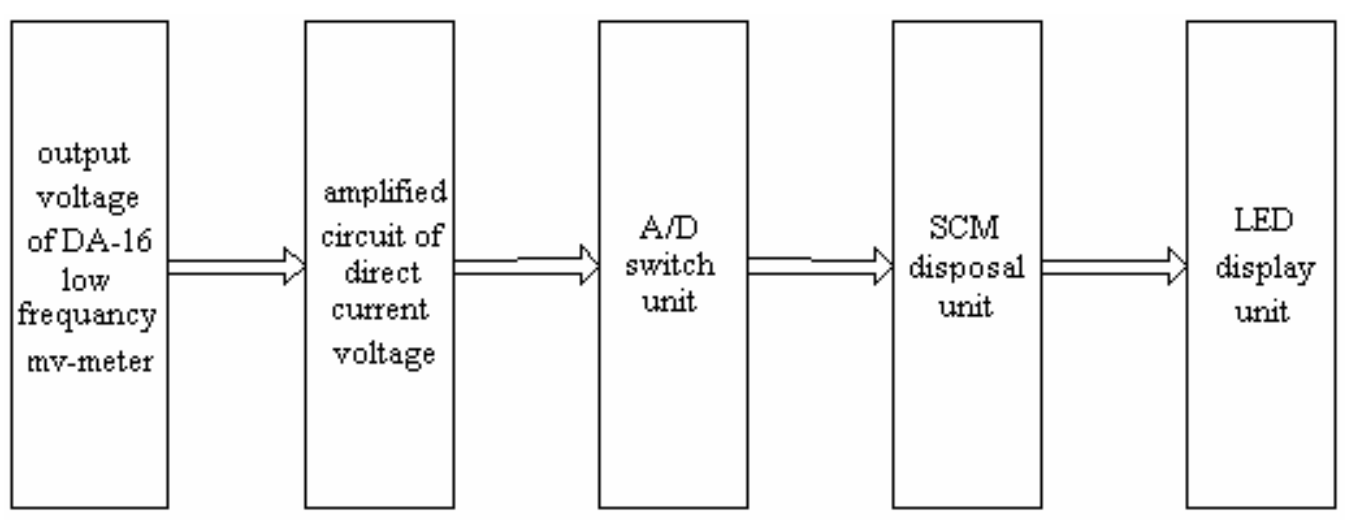

Figure 1. The Circuit of the Hardware

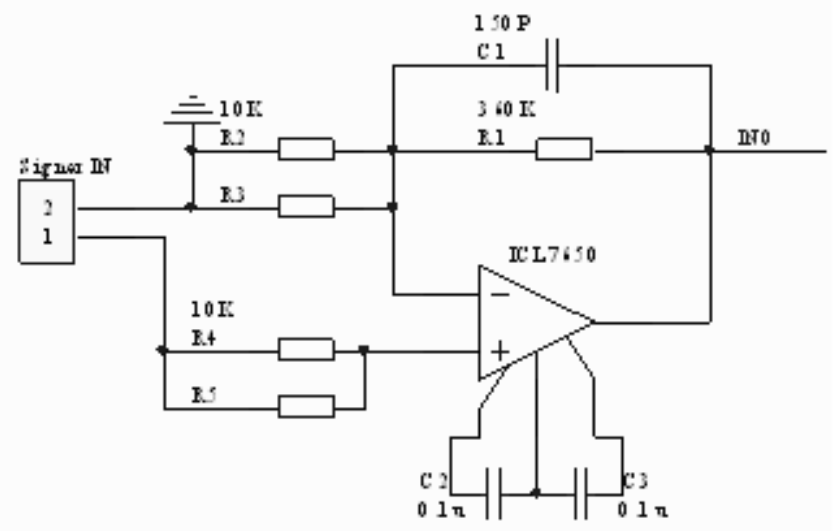

Figure 2. The A mplified Circuit 


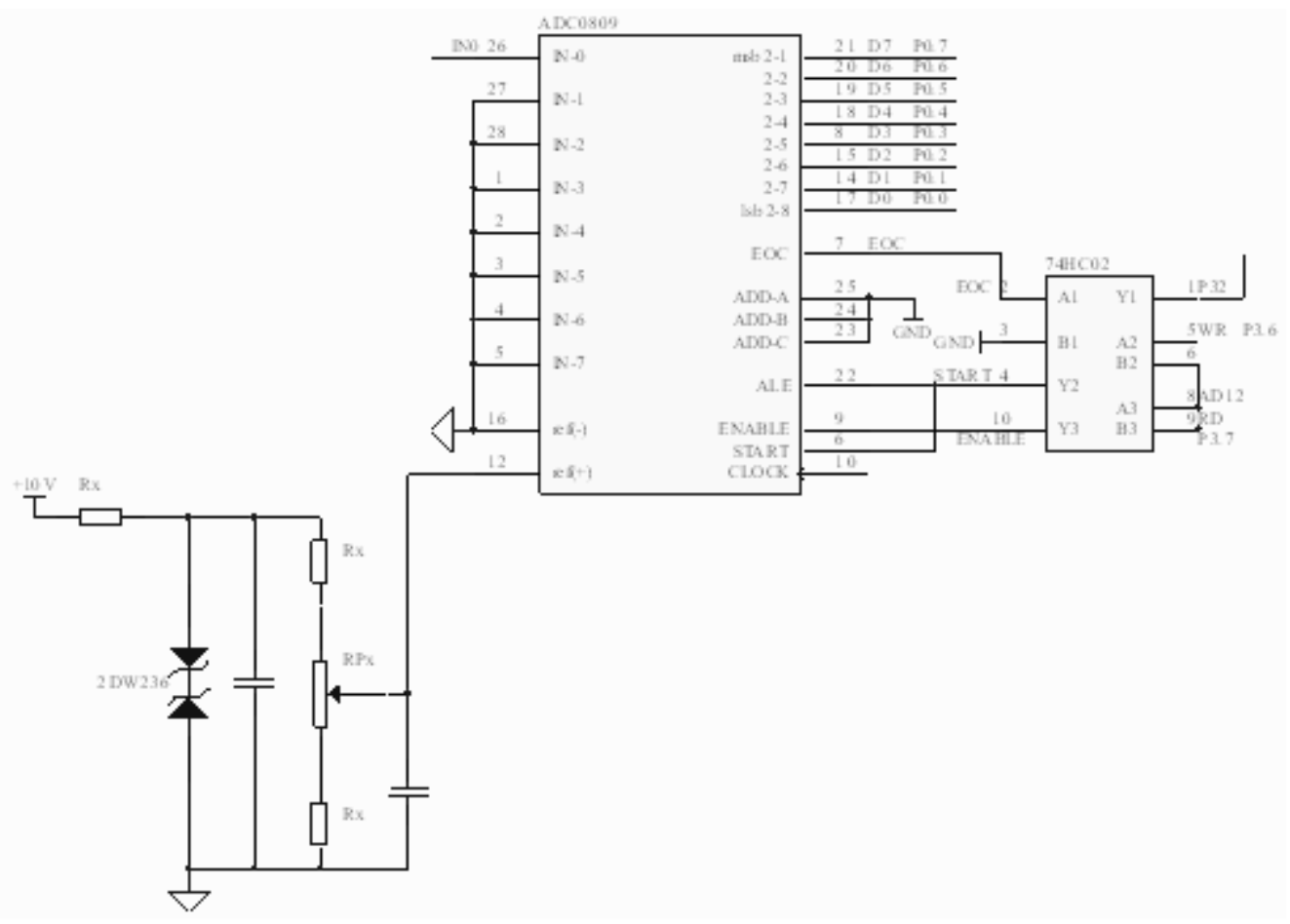

Figure 3. The Local Circuit of ADC

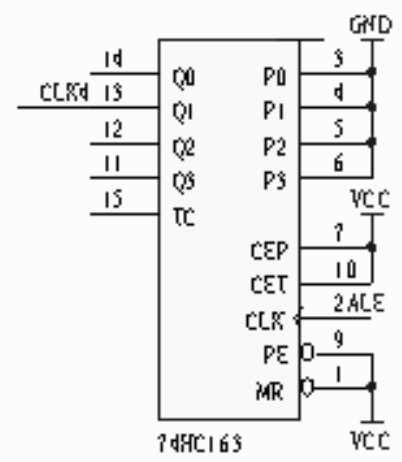

Figure 4. The Frequency Division Circuit

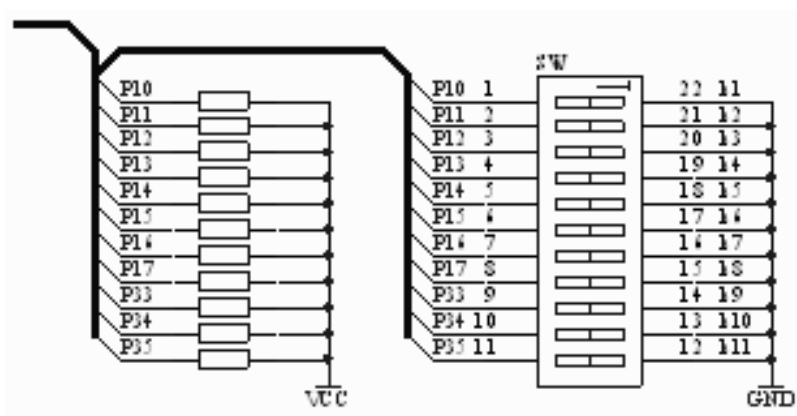

Figure 5. The Circuit of Shift Switch 


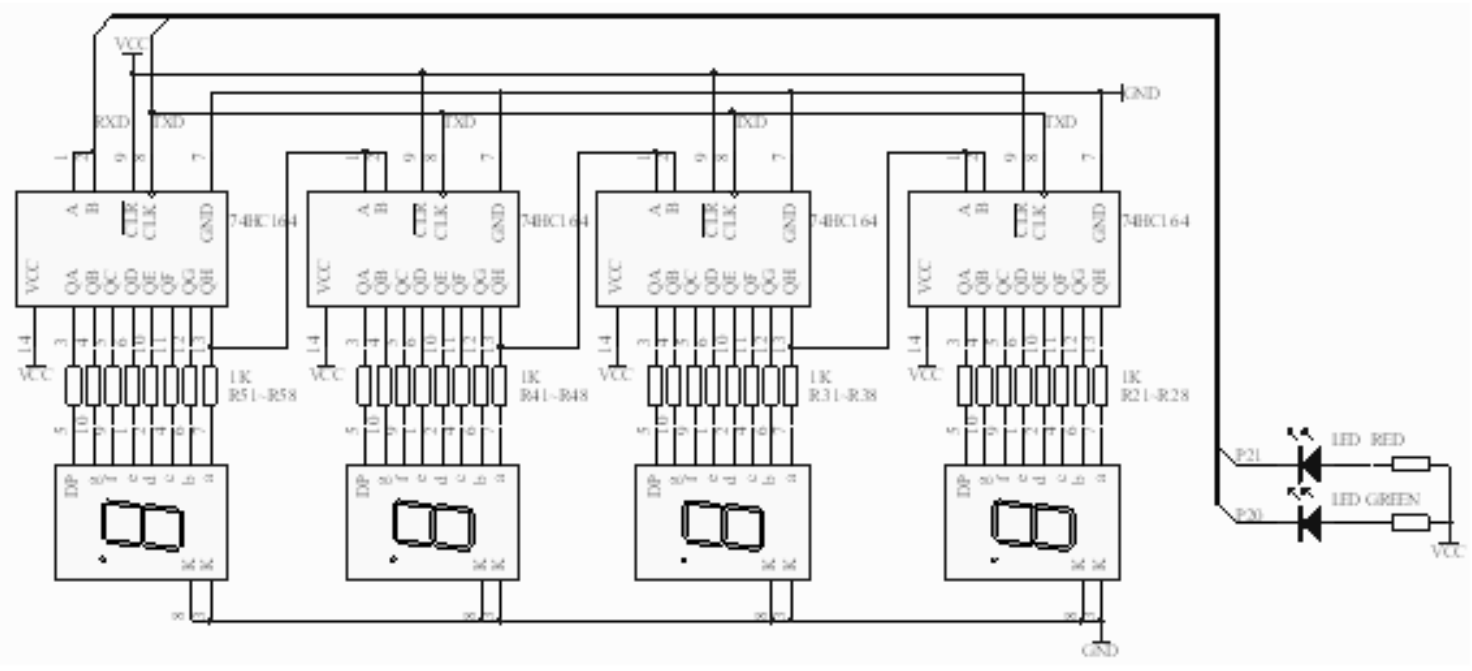

Figure 6. The LED Display Circuit
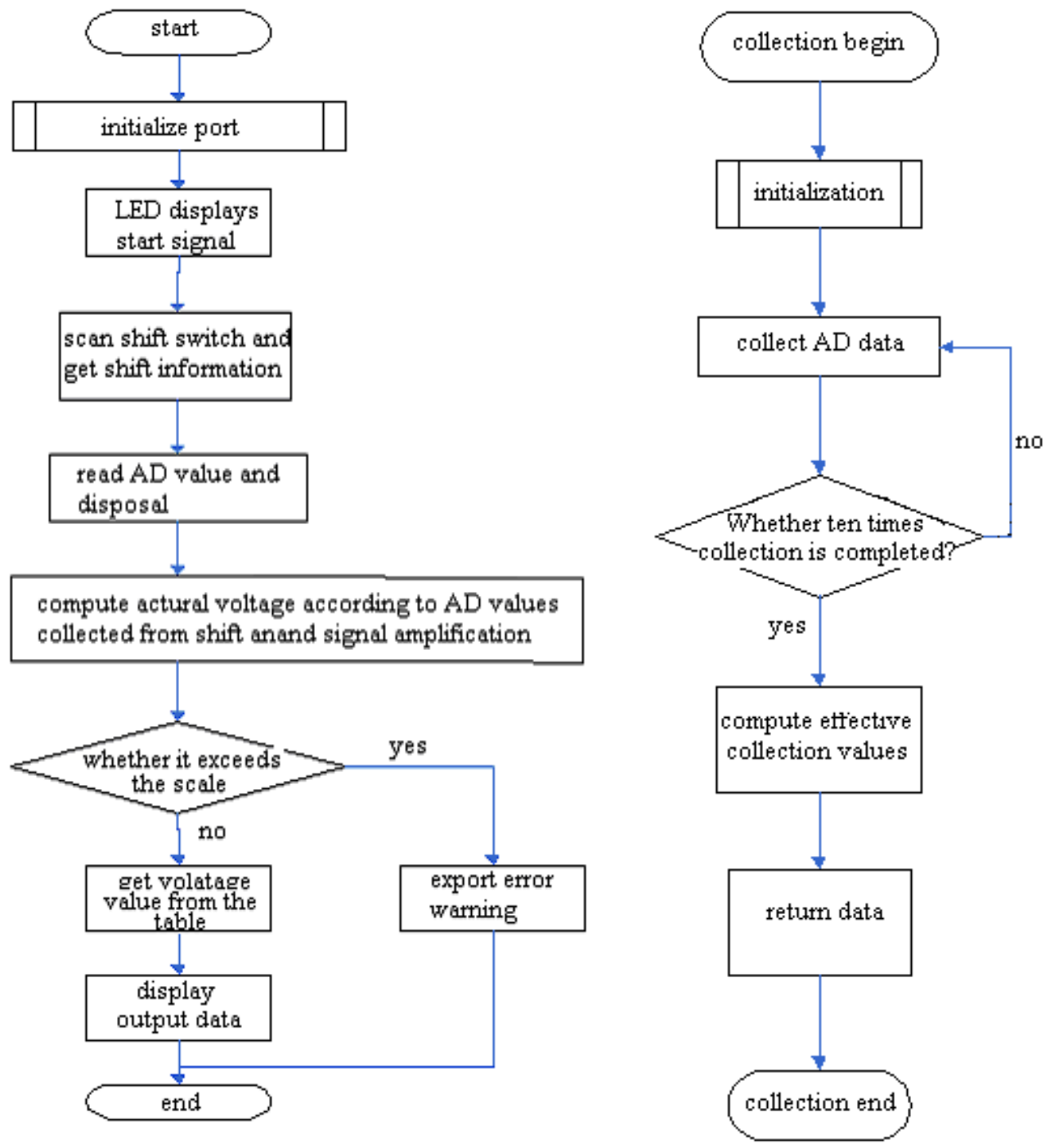

Figure 7. The Design Process of the Software 


\title{
Fuzzy Reliability of Two Units of the Cold Storing System
}

\author{
Taotao Wang \\ Department of Science, Yanshan University \\ Qinhuangdao 066004, China \\ Xianyun Meng (Corresponding author) \\ Department of Science, Yanshan University \\ Qinhuangdao 066004, China E-mail:wangtaoqhd@163.com \\ Yanqin Guan \\ Department of Science, Yanshan University \\ Qinhuangdao 066004, China \\ Jianying Yang \\ Department of Science, Yanshan University \\ Qinhuangdao 066004, China
}

Supported by the Plan Projects of He Bei Education Office (No.2007323)

Supported by the Foundation for the natural science of He Bei province of China (A2005000301)

\begin{abstract}
This paper which adopts Probability statistics fuzzy mathematical principles and methods gives the Fuzzy reliability index of the cold storing system with two different units when the switch is completely reliable and the switch is not completely reliable (Switch life 0-1and Exponential distribution). And this paper gives a new kind of Failure mode, that is: system will be immediately failure if the switch is failure, meanwhile, it gives the new mode's Fuzzy reliability index.
\end{abstract}

Keywords: Cold storing system, Reliability, Fuzzy reliability

\section{Prior knowledge}

Knows $\mathrm{C}$ by literature [1] to express in the classical reliable definition "the product in...maintains its stipulation function" this clear event, $C_{1}, C_{2} \cdots C_{n}$ expressed separately each fuzzy function represent fuzzy event. Obviously $\mathrm{C}$ separately belongs to $C_{1}, C_{2} \cdots C_{n}^{\sim}$ in varying degrees. $C$ expresses the system breakdown, $C_{i}$ expressed "the ist unit is working", $C_{i}$ expressed the fuzzy function subset which we discussed.

By fuzzy conditional probability definition we obtain:

$$
\begin{aligned}
& P\left(C \Delta C_{j}\right)=P\left(C_{j} / C\right) \cdot P(C) \\
& P\left(C_{i} \Delta C_{j}\right)=p\left(C_{j} / C_{i}\right) \cdot P\left(C_{i}\right)
\end{aligned}
$$

According to the fuzzy reliable theory and the ordinary reliable theory we have:

$$
\begin{array}{lc}
P\left(C \Delta C_{j}\right)=R_{s} & P\left(C_{i} \Delta C_{j}\right)=R_{i} \\
P\left(C_{j} / C\right)=u c_{j}\left(R_{s}\right) & P\left(C_{j} / C_{i}\right)=u c_{j}\left(R_{i}\right)
\end{array}
$$

Substitutes (3) into (1) (2) we have:

$R_{s}=u c_{j}\left(R_{s}\right) \cdot R_{s}$ 


$$
R_{i}=u c_{j}\left(R_{i}\right) \cdot R_{i}
$$

Based on the literature [1], [4] knowledge, the relations between every unit fuzzy failure rate $\lambda_{i}$ and the ordinary failure rate $\lambda_{i}$ is:

$$
\underset{\sim}{\lambda_{i}}=\lambda_{i}-\frac{d u c_{j}\left(R_{i}\right) \cdot d t}{u c_{j}\left(R_{i}\right) d t}=\lambda_{i}-\overline{u^{\prime} c_{j}\left(R_{i}\right)}
$$

Where $\overline{u^{\prime} c_{j}\left(R_{i}\right)}$ is the relative rate of $u^{\prime} c_{j}\left(R_{i}\right)$.

\section{Fuzzy Reliability analysis}

Theorem 1 Suppose the system is the cold storing system with two different units and the switch is completely reliable, Its life respectively is $x_{1}, x_{2}$, also obeys separately exponential distribution $\lambda_{1}, \lambda_{2}$, mutually independent, so the fuzzy reliability and fuzzy mean lifetime are:

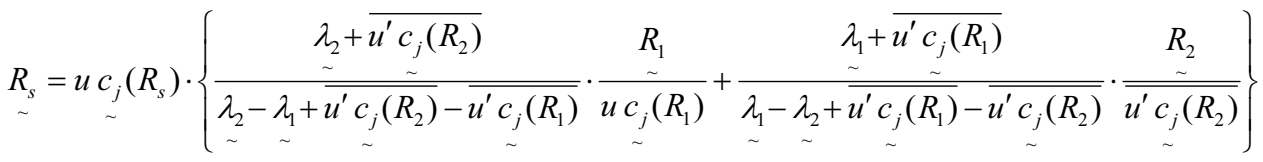

$$
\begin{aligned}
& \lambda_{1}+\lambda_{2}+\overline{u^{\prime} c_{j}\left(R_{1}\right)}+\overline{u^{\prime} c_{j}\left(R_{2}\right)}
\end{aligned}
$$

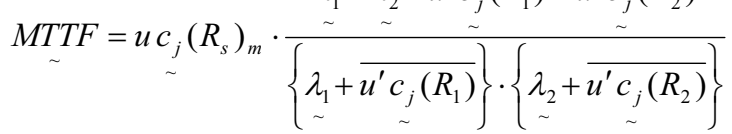

Proof: Known two unit life distributions respectively are $F_{1}=1-e^{-\lambda_{1} t}, F_{2}=1-e^{-\lambda_{2} t}$, also knows the system by literature [2] the reliability is:

$$
R_{s}=\frac{\lambda_{2}}{\lambda_{2}-\lambda_{1}} \cdot R_{1}+\frac{\lambda_{1}}{\lambda_{1}-\lambda_{2}} \cdot R_{2}
$$

So substitutes (5) (6) (7) into (4) we obtain the fuzzy reliability

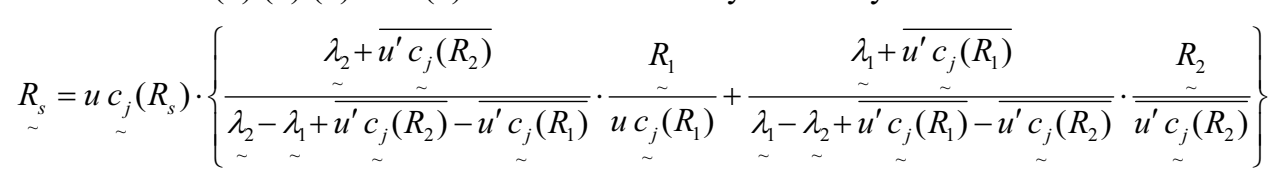

Result of $R_{s}=\frac{\lambda_{2}}{\lambda_{2}-\lambda_{1}} \cdot R_{1}+\frac{\lambda_{1}}{\lambda_{1}-\lambda_{2}} \cdot R_{2}$, obtain easily:

$$
\underset{\sim}{M T T F}=\int_{0}^{\infty} R_{s} d t=\int_{0}^{\infty} u c_{\sim}\left(R_{s}\right) \cdot R_{s} \cdot d t=u c_{\sim}^{c_{j}}\left(R_{s}\right)_{m} \cdot \int_{0}^{\infty} R_{s} \cdot d t
$$

$={ }_{u c_{j}}\left(R_{s}\right)_{m} \cdot \int_{0}^{\infty}\left[\frac{\lambda_{2}}{\lambda_{2}-\lambda_{1}} \cdot e^{-\lambda_{1} t}+\frac{\lambda_{1}}{\lambda_{1}-\lambda_{2}} \cdot e^{-\lambda_{2} t}\right] \cdot d t$

$=u c_{j}\left(R_{s}\right)_{m} \cdot\left[\frac{1}{\lambda_{1}}+\frac{1}{\lambda_{2}}\right]$

Therefore substitute (6) into equation (8), we have:

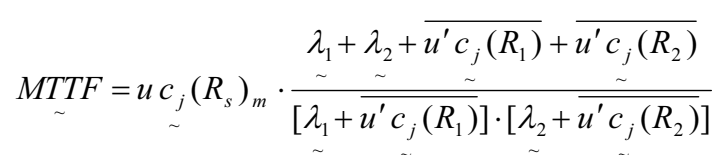

Where, $u c_{j}\left(R_{s}\right)_{m}-u c_{j}\left(R_{s}\right)$ is an average value which is in operating time sector

$[0, \infty)$, and it is a constant. 
Theorem 2 suppose the system is the cold storing system with two different units and the switch is not completely reliable, Its life respectively is $x_{1}, x_{2}$, Also obeys separately exponential distribution $\lambda_{1}, \lambda_{2}$, mutually independent, so the fuzzy reliability and fuzzy mean lifetime are:

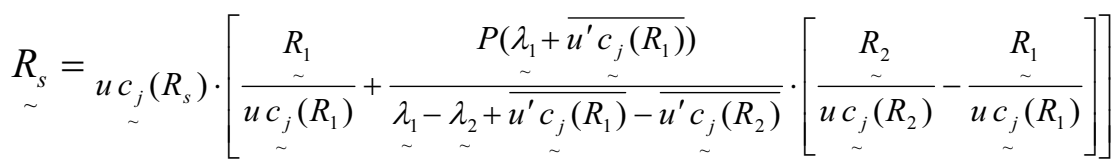

$$
\begin{aligned}
& \underset{\sim}{\operatorname{MTF}}=u c_{\sim}\left(R_{s}\right)_{m} \cdot\left[\frac{1}{\lambda_{\sim}+\overline{u^{\prime} c_{j}\left(R_{1}\right)}}+p \cdot \frac{1}{{\underset{\sim}{\sim}}_{\sim}+\overline{u^{\prime} c_{j}\left(R_{2}\right)}}\right]
\end{aligned}
$$

Proof: Introduces a random variable v, we have:

$$
p\{v=j\}=\left\{\begin{array}{l}
\mathrm{q}(\text { 当 } j=1) \\
p(\text { 当 } j=2)
\end{array}\right.
$$

The reliability of system is

$$
\begin{aligned}
R= & P\left\{\sum_{J=1}^{V} x_{j}>t\right\}=q \cdot p\left\{x_{1}>t\right\}+p \cdot p\left\{x_{1}+x_{2}>t\right\} \\
& =e^{-\lambda_{1} t}+\frac{p \lambda_{1}}{\lambda_{1}-\lambda_{2}}\left(e^{-\lambda_{2} t}-e^{-\lambda_{1} t}\right)=R_{1}+\frac{p \lambda_{1}}{\lambda_{1}-\lambda_{2}} \cdot\left(R_{2}-R_{1}\right)
\end{aligned}
$$

Substituting (10) (5) (6) into (4) entails that:

$$
\begin{aligned}
& R_{\sim}=u c_{\sim}\left(R_{s}\right) \cdot R_{s} \\
& =u c_{\sim}\left(R_{s}\right) \cdot\left[\frac{R_{1}}{\sim \underset{\sim}{u c_{j}\left(R_{1}\right)}}+\frac{P\left(\lambda_{1}+\overline{u^{\prime} c_{j}\left(R_{1}\right)}\right)}{\sim_{\sim}-\underset{\sim}{\sim} \lambda_{2}+\overline{u^{\prime} c_{j}\left(R_{1}\right)}-\overline{u^{\prime} c_{j}\left(R_{2}\right)}} \cdot\left[\begin{array}{c}
R_{\sim} \\
\frac{\sim}{u c_{j}\left(R_{2}\right)}-\frac{R_{1}}{u c_{j}\left(R_{1}\right)}
\end{array}\right]\right]
\end{aligned}
$$

Because the mean life of system is:

$$
M T T F=\int_{0}^{\infty} R_{s} d t=\int_{0}^{\infty} e^{-\lambda_{1} t}+\frac{p \lambda_{1}}{\lambda_{1}-\lambda_{2}}\left(e^{-\lambda_{2} t}-e^{-\lambda_{1} t}\right) d t=\frac{1}{\lambda_{1}}+p \frac{1}{\lambda_{2}}
$$

So the MTTF is:

$$
\begin{aligned}
\underset{\sim}{\operatorname{MTTF}}= & \int_{0}^{\infty} R_{s} d t=\int_{0}^{\infty} u c_{\sim}\left(R_{s}\right) \cdot R_{s} \cdot d t=u c_{j}\left(R_{s}\right)_{m} \cdot\left[\frac{1}{\lambda_{1}}+p \frac{1}{\lambda_{2}}\right] \\
& =\underset{\sim}{u c_{j}}\left(R_{s}\right)_{m} \cdot\left[\frac{1}{\lambda_{\sim}+\overline{u^{\prime} c_{j}\left(R_{1}\right)}}+p \cdot \frac{1}{\lambda_{\sim}+\overline{u^{\prime} c_{j}\left(R_{2}\right)}}\right]
\end{aligned}
$$

Theorem 3 The system not immediately expires when the switch is not working, the life of two different units is $x_{1}, x_{2}$, he life of switch is $x_{K}$, Obeys the exponential distribution separately and the parameter is $\lambda_{1}, \lambda_{2}$ and $\lambda_{K}$, mutually independent, so the fuzzy reliability and fuzzy mean lifetime are:

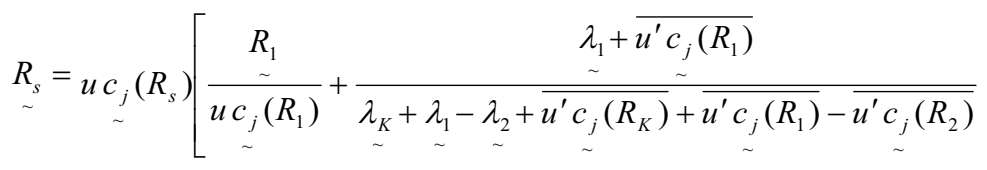

$$
\begin{aligned}
& \left.\cdot\left[\frac{R_{2}}{u c_{j}\left(R_{2}\right)}-\frac{R_{1}}{u c_{j}\left(R_{1}\right)} \cdot \frac{R_{K}}{u c_{j}\left(R_{K}\right)}\right]\right] \\
& M T T F=u c_{j}\left(R_{s}\right)_{m}
\end{aligned}
$$




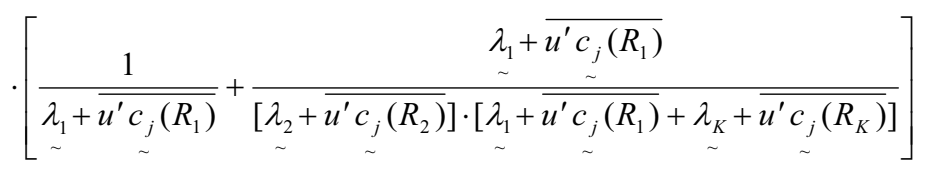

Proof: From literature [2] we know

$R=e^{-\lambda_{1} t}+\frac{\lambda_{1}}{\lambda_{K}+\lambda_{1}-\lambda_{2}}\left[e^{-\lambda_{2} t}-e^{-\left(\lambda_{1}+\lambda_{K}\right) t}\right]$

$$
\text { MTTF }=\frac{1}{\lambda_{1}}+\frac{\lambda_{1}}{\lambda_{2}\left(\lambda_{1}+\lambda_{K}\right)}
$$

Substituting (12) (5) (6) into (4) entails that

$$
R_{s}=u c_{j}\left(R_{s}\right) \cdot R_{s}
$$

$$
\begin{aligned}
& =u c_{j}\left(R_{s}\right)\left[\frac{R_{1}}{\frac{\sim}{u c_{j}\left(R_{1}\right)}}+\frac{\lambda_{1}+\overline{u^{\prime} c_{j}\left(R_{1}\right)}}{\underset{\sim}{\lambda_{K}+\lambda_{1}-\underset{\sim}{\lambda_{2}}+\overline{u^{\prime} c_{j}\left(R_{K}\right)}+\bar{\sim}} \overline{u^{\prime} c_{j}\left(R_{1}\right)}-\overline{u^{\prime} c_{j}\left(R_{2}\right)}}\right. \\
& \left.\cdot\left[\frac{R_{2}}{u c_{j}\left(R_{2}\right)}-\frac{R_{1}}{u c_{j}\left(R_{1}\right)} \cdot \frac{R_{K}}{u c_{j}\left(R_{K}\right)}\right]\right]
\end{aligned}
$$

Because also

$$
\begin{aligned}
\underset{\sim}{M T T F}= & \int_{0}^{\infty} R_{s} d t=\int_{0}^{\infty} u c_{\sim}\left(R_{s}\right) \cdot R_{s} \cdot d t \\
& =u c_{\sim}\left(R_{s}\right)_{m} \cdot \int_{0}^{\infty} R_{s} \cdot d t=u \underset{\sim}{c_{j}}\left(R_{s}\right)_{m} \cdot\left[\frac{1}{\lambda_{1}}+\frac{\lambda_{1}}{\lambda_{2}\left(\lambda_{1}+\lambda_{K}\right)}\right]
\end{aligned}
$$

Substituting (6) into (14) entails that

$$
M T T F=u c_{j}\left(R_{s}\right)_{m}
$$

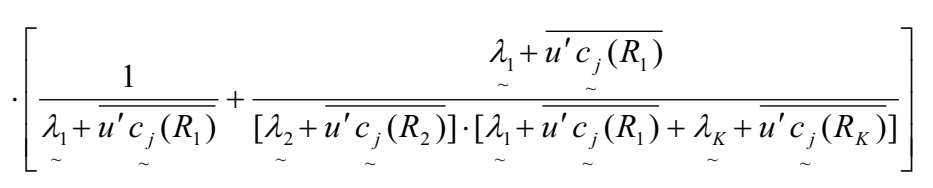

Theorem 4 The system immediately expires when the switch is not working, the life of two different units is $x_{1}, x_{2}$, the life of switch is $x_{K}$, Obeys the exponential distribution separately and the parameter is $\lambda_{1}, \lambda_{2}$ and $\lambda_{K}$, mutually independent, so the fuzzy reliability is:

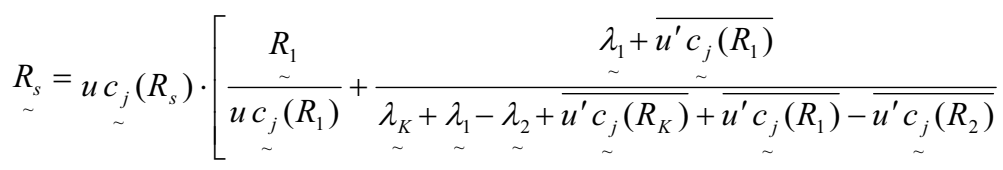

$$
\begin{aligned}
& \cdot\left[\frac{R_{2}}{u c_{j}\left(R_{2}\right)}-\frac{R_{1}}{u c_{j}\left(R_{1}\right)} \cdot \frac{R_{K}}{u c_{j}\left(R_{K}\right)}\right] \\
& {\left[\lambda_{K}+\overline{u^{\prime} c_{j}\left(R_{K}\right)}\right] \cdot\left[\lambda_{1}+\overline{u^{\prime} c_{j}\left(R_{1}\right)}\right]}
\end{aligned}
$$

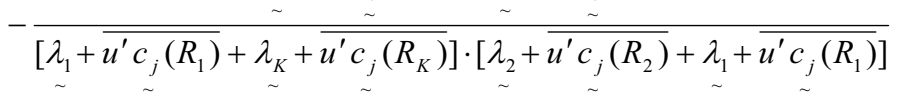

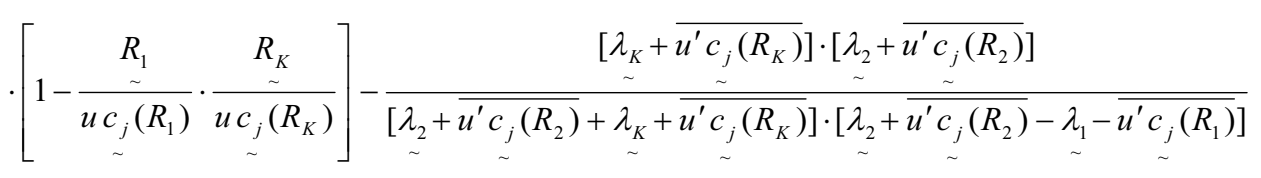




$$
\left.\cdot\left[1-\frac{R_{2}}{u c_{j}\left(R_{2}\right)} \cdot \frac{R_{K}}{u c_{j}\left(R_{K}\right)}\right]\right]
$$

Proof: the switch is not expire when the unit $x_{1}$ is not working, $x_{K}>x_{1}$, unit $x_{1}$ is replaced by storing unit $x_{2}$, the life of system is $x_{K}$ when unit $x_{2}$ is not expire.

Because the life distribution of system is:

$$
\begin{aligned}
1-R_{s}= & \iint_{t_{1} \leq t, t_{K} \leq t_{1}} \lambda_{1} \lambda_{K} e^{-\lambda_{1} t_{1}} e^{-\lambda_{K} t_{K}} d t_{1} d t_{K}+ \\
& \iiint_{t_{1}+t_{2} \leq t, t_{K}>t_{1}} \lambda_{1} \lambda_{2} \lambda_{K} e^{-\lambda_{1} t_{1}} e^{-\lambda_{2} t_{2}} e^{-\lambda_{K} t_{K}} d t_{1} d t_{2} d t_{K}+ \\
& \iiint_{t_{1}+t_{2} \geq t_{K}, t_{1} \leq t_{K} \leq t} \lambda_{1} \lambda_{2} \lambda_{K} e^{-\lambda_{1} t_{1}} e^{-\lambda_{2} t_{2}} e^{-\lambda_{K} t_{K}} d t_{1} d t_{2} d t_{K} \\
= & 1-e^{-\lambda_{1} t}-\frac{\lambda_{1}}{\lambda_{K}+\lambda_{1}-\lambda_{2}}\left[e^{-\lambda_{2} t}-e^{-\left(\lambda_{1}+\lambda_{K}\right) t}\right]+ \\
& \frac{\lambda_{K} \lambda_{1}}{\left(\lambda_{K}+\lambda_{1}\right)\left(\lambda_{2}-\lambda_{1}\right)}\left[1-e^{-\left(\lambda_{K}+\lambda_{1}\right) t}\right]+\frac{\lambda_{K} \lambda_{2}}{\left(\lambda_{K}+\lambda_{2}\right)\left(\lambda_{2}-\lambda_{1}\right)}\left[1-e^{-\left(\lambda_{K}+\lambda_{2}\right) t}\right]
\end{aligned}
$$

So the reliability of system is:

$$
\begin{aligned}
R_{s}= & e^{-\lambda_{1} t}+\frac{\lambda_{1}}{\lambda_{K}+\lambda_{1}-\lambda_{2}}\left[e^{-\lambda_{2} t}-e^{-\left(\lambda_{1}+\lambda_{K}\right) t}\right]- \\
& \frac{\lambda_{K} \lambda_{1}}{\left(\lambda_{K}+\lambda_{1}\right)\left(\lambda_{2}-\lambda_{1}\right)}\left[1-e^{-\left(\lambda_{K}+\lambda_{1}\right) t}\right]-\frac{\lambda_{K} \lambda_{2}}{\left(\lambda_{K}+\lambda_{2}\right)\left(\lambda_{2}-\lambda_{1}\right)}\left[1-e^{-\left(\lambda_{K}+\lambda_{2}\right) t}\right]
\end{aligned}
$$

Substituting (15) (5) (6) into (4) we obtain:

$$
\begin{aligned}
& R_{s}=u c_{j}\left(R_{s}\right) \cdot R_{s}
\end{aligned}
$$

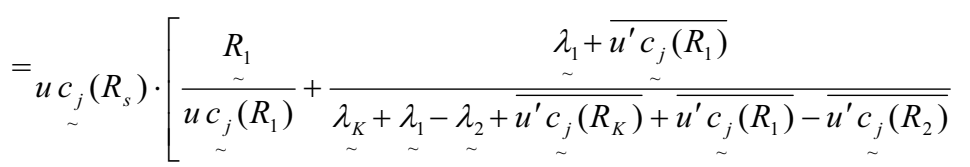

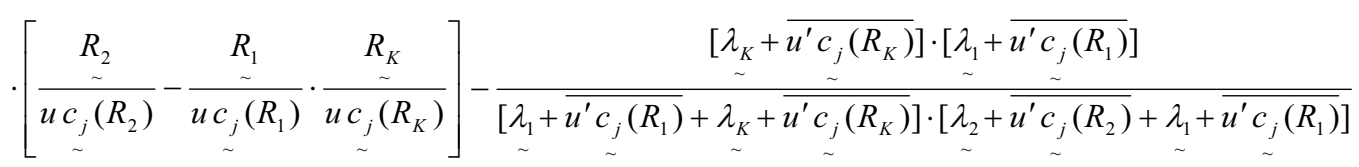

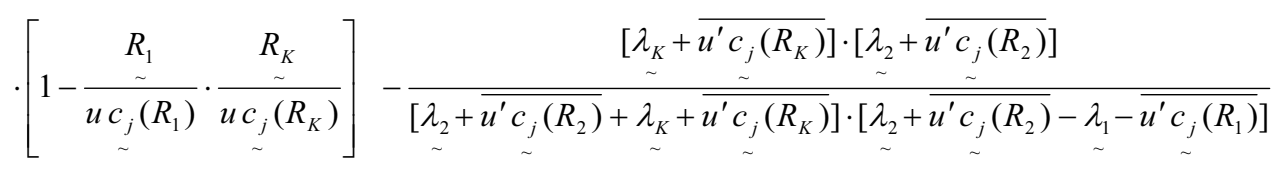

$$
\begin{aligned}
& \left.\cdot\left[1-\frac{R_{2}}{u c_{j}\left(R_{2}\right)} \cdot \frac{R_{K}}{u c_{j}\left(R_{K}\right)}\right]\right]
\end{aligned}
$$

\section{References}

Li, Tingjie\&Gao, He. Fuzzy Reliability. BUSEFAL. issue 35,1988.7.pp.12-25.

Cao, Jinhua \& Cheng, Kan. (2005). Introduction to Reliability Mathematics. Beijing: Science Press.pp. 45-52.

Huang, XiShi \&Leng, HuJi. Fuzzy Reliability of n Units of the Same Distribution Cool Storing System Mechanical Science and Technology for Aerospace Engineering, 1997.26(3). 25-27.

Miao, EnMing, Complementarity of cool reserve system reliability's mathematics model, Journal of Heilongjiang Institute of Science and Technology, 2003.13(4). 36-44. 
Meng, Xianyun, Yuan, Li \& Yin, Ruiling. The Reliability Analysis of a Two-unit Cold Standby System with failed Switch and Maintenance Equipment[A].Proceedings of the International Conference on Computational Intelligence and Security[C]. 2006. 941-944.

Meng, Xianyun, Li, Hongxia \&Li, Ning. Reliability Analysis of an n-unit Standby Repairable System with k Repair Facilities. Modern Applied Science.1(4). 55-59. 


\title{
Mandible Swing Approach for Excision of Tumors from Parapharyngeal Space
}

\author{
Yiwen Ma \\ Hospital of Qingdao Technological University \\ Qingdao 266033, China \\ Liying $\mathrm{Li}$ \\ Department of Stomatology, Qingdao Eighth People's Hospital \\ Qingdao 266100, China \\ Chuanliang Du \\ Department of Stomatology, Qingdao Eighth People's Hospital \\ Qingdao 266100, China
}

\begin{abstract}
Five cases of resection of pharyngeal and parapharyngeal space (pps) tumors show that mandible swing approach is an optimal option for thoroughly removing retromandibular tumors of the parotid. The excisions do not injure the seventh nerve or cause any complications. In all the five cases, tumors are located at parapharyngeal space, while in one of the five cases, the tumor protrudes to the palate.

Keywords: Mandible swing, Parapharyngeal space (pps), Tumor resection, Surgery approach

Incidence of tumor in parapharyngeal space is low, accounting for less than $0.5 \%$ of head and neck neoplasms (Cai, et al., 1998). Various approaches have been employed in the world to thoroughly resect the pharyngeal and parapharyngeal space tumors. The mandible is the major barrier for surgeons to have full access to the pharyngeal and parapharyngeal space. Many scholars applied mandible swing approach to resect the parapharyngeal space tumors and cranial base tumors (Cai, et al., 1998; Wang, et al., 1998; Han, et al., 2002), using the same method, we successfully resected five cases of parapharyngeal space tumors from 2000 to 2006.
\end{abstract}

\section{Clinic information and method}

\subsection{Clinic information}

Using the mandible swing approach, researchers resected the parapharyngeal space tumors of five patients (three men and two women) who were aged 27 to 55 years old. Three tumors were on the left and two on the right. The largest tumor was $8 \mathrm{~cm} \times 6 \mathrm{~cm} \times 5 \mathrm{~cm}$, and the smallest one was $3 \mathrm{~cm} \times 3 \mathrm{~cm} \times 1.5 \mathrm{~cm}$. There were one sponge-like angioma, three pleomorphic adenomas and one basal cell adenoma. The largest one protruded to the palate and influenced breath and deglutition of the patient, and other tumors gave rise to a feeling of eyewinker, deglutition disorder, and snoring.

\subsection{Therapy method}

Five patients received a standard preoperative examination and preoperative three-dimensional imaging of spiral CT. The pathological position was located and the operation plan and approach were determined.

General anesthesia was done by endotracheal intubation via nose. Patient lay in a supine position, with the head turning to the other side. "S" shape incision of standard parotid gland operation was performed, from the position two centimeters down the mandible to the surface of hyoid. The dermis, platysma were separated to expose the submandibular triangle. The hypoglossal nerve and facial artery was protected, the upward external carotid artery were separated and exposed, and the external carotid artery between glossal artery and the start of superior thyroid artery was ligated. Full lower lip was longitudinally cut from the middle, and the incision was joined with the former incision like an arch. Two and a half centimeters chin periosteum was turned toward the affected side, the mental nerve was carefully protected, after boring on the two sides of cut for the following fixation of splint, the mandible was sawed between incisor and canine tooth on the affected side. The tongue was drawn to the intact side; the mouth floor mucosa was cut along the inner side of mandible until the glossal palatine arch and the glossal nerve was protected. Mylohyoid muscle 
was cut from the posterior to the anterior until the midline, and then the mandible was swung outside to thoroughly expose the pharyngeal and parapharyngeal space (Figure 1, Figure 2, Figure 3, and Figure 4). The tumor was separated via blunt dissection along the envelope, and extirpated completely. The blood was thoroughly stanched and the mandible was reposited and fixed with titanium mini-plate. The mouth floor mucosa, mylohyoid muscle and lower lip were sewed up; negative pressure drainage was used and the cut was sewed up step by step.

\section{Results}

All the mandibles were sawed between tooth 2 and tooth 3, and tumors were completely extirpated with naked eye by mandible swing approach. Nose feeding was done for ten days, and the cut healed by first intention. Within one to three years after the operation, patients had short-term mouth opening and closing disorders and speaking problems. But patients' lives were brought to normal by sufficient focused training and no complications appeared. In none of the five cases was trachea incision was performed or breathing disorder was found.

\section{Discussion}

\subsection{The anatomical characteristic of pharyngeal and parapharyngeal space}

Pharyngeal is a crateriform muscle pipeline from the bottom of skull to the sixth neck vertebrae, and the back and exterior side of pharyngeal is called parapharyngeal space, which looks like a filler and is also named as danger space. Parapharyngeal space lies adjacent to the lateral wall of pharyngeal, medial pterygoid muscle and parotid gland envelope, the back side is pre-vertebral fascia, and the upside is pterygopalatine space, it indirectly connects to skull base, and its exterior side connects to parotid gland recess. Tumors of parotid gland can directly get to the space and transfer to the lymph node, so when incising the tumor and lymph node in the space, one should pay attention to the misshapen blood vessel and neural tissue. It is reported that the incidence of tumor in parapharyngeal space is low, but it shows a trend of increase in recent years. Mixed tumor in parotid deep lobe and minor salivary gland is common, and tumors in nose and pharyngeal often affect the parapharyngeal space (Han, et al., 2002; Yu and Ma, 1988).

\subsection{The clinic characteristic of tumor in parapharyngeal space}

It is reported that tumor in parotid deep lobe accounts for $12.8 \%$ of the parotid gland tumor (Yu and Ma, 1988) and $2.6 \%$ of the parotid gland tumors will transfer to the pharyngeal, parapharyngeal, palate and skull base (Sun, et al., 2006). In this report, the adenoma in the parapharyngeal space accounted for $3.7 \%$ of parotid gland tumor. Generally, there was no obvious symptom in the beginning, the patients usually felt uncomfortable in their pharynxes and had a feeling of eyewinker, they would snore when lying, and their voice was obscure, it was uncomfortable to swallow, but it didn't hurt much. One patient felt pain because of infection, but the hurt disappeared after receiving anti-inflammation treatment. After operation, it was indicated that there was three pleomorphic adenomas, one sponge-like angioma and one basal cell adenoma.

\subsection{A comparison of different approaches to resect the pharyngeal and parapharyngeal tumors}

Operation is an effective method to cure pharyngeal and parapharyngeal tumors, and there are various operative approaches as follows (Cai, et al., 1998; Wang, et al., 1998; Han, et al., 2002; Yu and Ma, 1988; Sun, et al., 2006). The first is the oral approach. Its weaknesses are that the operative space is small and that the important blood vessel and tumor can not be clearly exposed. Plus, the tumor can be broken easily and the large blood vessel might be accidentally injured. The second is lateral neck dissection approach which could injure important structures due to insufficient exposure of the parapharyngeal space. The third is the neck-parotid approach, which will lead to peripheral facial paralysis and facial malformation. The fourth is lateral-neck-postotic approach. It is appropriate for large tumor that intrudes to the skull base, but it can not completely expose the structure of skull base. Comparatively speaking, the mandible swing approach in question can thoroughly expose the important blood vessels in the upper neck and the structure of skull base. It can also clearly exhibit the tumor in the pharyngeal and parapharyngeal space, so that operation could be performed in an open visual field. It becomes easier to resect the tumor thoroughly and clear the lympha node behind the pharyngeal; in addition, it is easier to thoroughly resect the glomangioma. Our conclusion is that mandible swing approach is ideal for the resection of pharyngeal and parapharyngeal tumors (Han, et al., 2002; Sun, et al., 2006). In our case report, all the five patients received spiral CT and other standard preoperative examinations. General anesthesia was given by endotracheal intubation via nose, so the trachea was not incised. After wakeup, patient received aerosol inhalation two to three times every day. And no complication such as dyspnea was found. It should be noticed that mandible swing approach could lead to incomplete concrescence of mandible, and patient might have the following complications: inarticulacy, deglutition obstacle, middle ear effusion and bleeding, and cranial nerve palsy (Wang, et al., 1998). The mandible swing approach could make successful operations. Blind and unnecessary injuries could be avoided. But it requires that the operators be familiar with the anatomical structure and try to preserve the parenchyma around the chin so as to reduce complications. 


\section{References}

Cai, Xiaolan. Shi, Li. Dong, Pin et al. (1998). Parapharyngeal space tumors. Chinese Journal of Otorhinolaryngology. 33: 178-180.

Han, Yuefeng and Zhang, Kunling. (2002). Mandible swing approach for excision of the pharyngeal and parapharyngeal tumors. Anatomy and Clinics. 7(3): 89-91.

Sun, Lianfen. Wang, Hongtao and Zhang, Zubin. (2006). Mandible swing approach for excision of tumors from parotid deep lobe. Journal of Oral and Maxillofacial Surgery. 16 (2): 142-144.

Wang, Tianduo. Li, Mei and $\mathrm{Xu}$, anting. (1998). Mandible swing approach to resect the pharyngeal and skull basetumors. Chinese Journal of Otorhinolaryngology. 33: 371-374.

Yu, Guangyan and Ma, Daquan. (1988). Diagnosis and treatment of tumors from parotid deep lobe. Chinese Journal of Stomatology. 23 (2): 108-110.

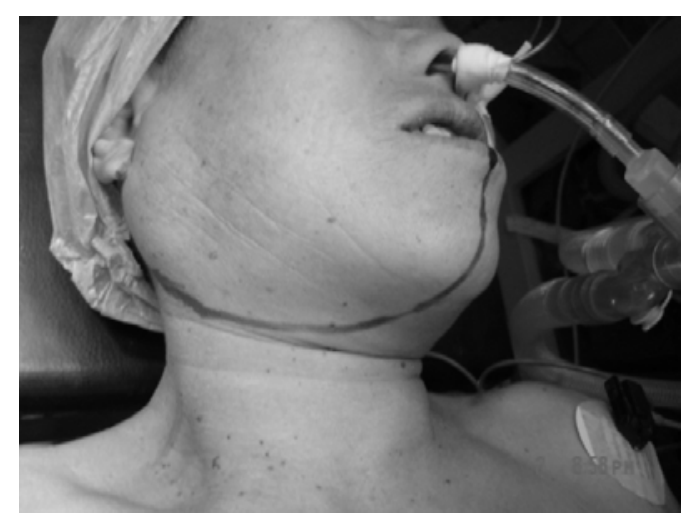

Figure 1. Design of incision

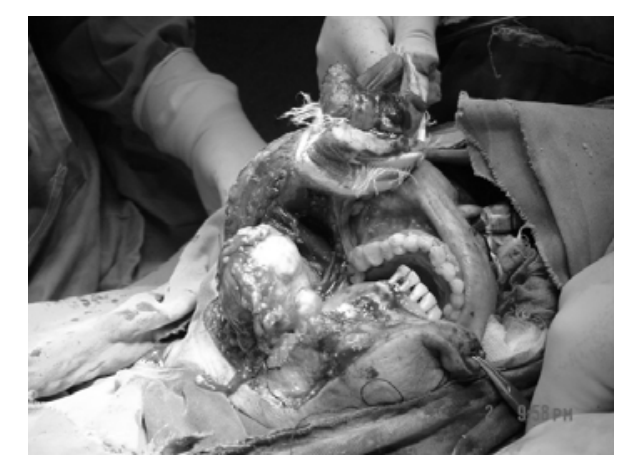

Figure 2. Mandible swing 


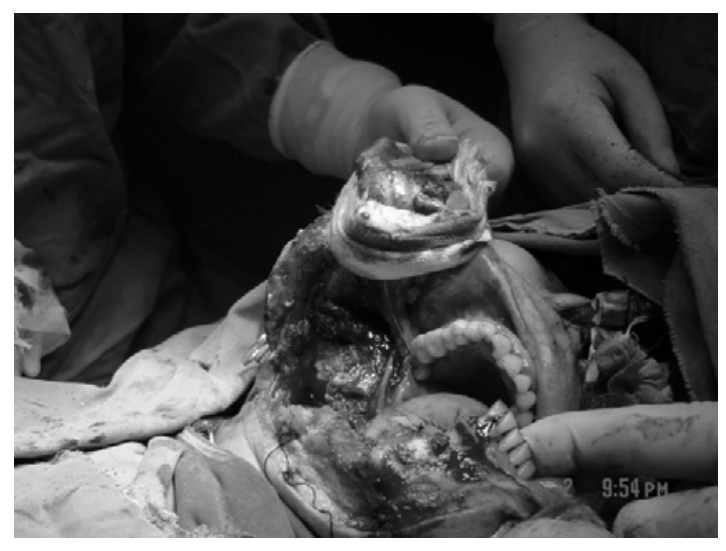

Figure 3. Resection of tumor

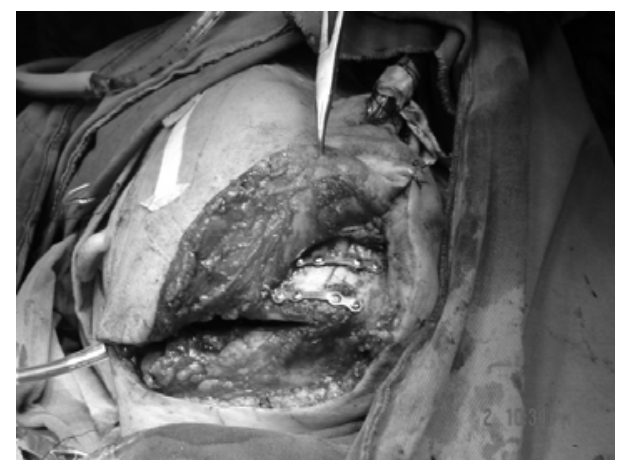

Figure 4. Fixed mandible by mini-plate 


\title{
A Study on the Alteration Tendency of Physical Ability Index and Stress Feature Index of Elite Female Judoists in Intensity Training
}

\author{
Ming Chen \\ Physical Education College, Inner Mongolia Normal University \\ Hohhot 010020, China \\ E-mail: chen_mingtiyu@126.com
}

\begin{abstract}
A cluster analysis was conducted to preliminarily screen the physical ability index and stress feature index from the hormones measured in this study, and the alterations of the indexes in intensity training of elite female judoists were discussed. Results showed that the intensity training affected alterations of physical ability indexes, including LH, TT, T/C and PRL, and the stress feature indexes, including EN, ACTH, $\beta$-END and C. The results suggested that in intensity training, alterations of physical capacity were affected by several factors, such as endocrine indexes.
\end{abstract}

Keywords: Elite female judoists, Intensity training, Physical ability index, Stress feature index, Hormone

Intensity training will accelerate the production of catecholamine in the nerve centre and its downstream function, and accordingly regulate the material and oxygenic supply in the motorial muscle. As a stressor, tumbling is an important factor that influences the activities of autonomic nerve, because movement can increase the level of adrenalin and noradrenalin in the blood, and then influence the level of other hormones. Gonadotropin-gonadal axis is of great significance for the strength based movement. This paper discussed the variation of endocrine indexes of female judoists in intensity training and made a classification about the indexes, it will be a reference for the evaluation of body quality.

\section{Methods}

\subsection{Research object}

Ten judoists (age, $20.30 \pm 1.42$ year; stature, $167.50 \pm 4.92 \mathrm{~cm}$; weight, $65.10 \pm 7.96 \mathrm{Kg}$; training life, $4.60 \pm 1.26$ year; percentage body fat, $16.88 \pm 6.44 \%$; hemoglobin, $13.60 \pm 1.26 \mathrm{~g} / \mathrm{dL}$; systolic pressure, $119.50 \pm 10.12 \mathrm{mmHg}$; diastolic pressure, $77.00 \pm 6.32 \mathrm{mmHg}$ ) who were first class athletes or master sportsman were the research objects, they were not overtrained, had no cardiovascular disease and didn't eat any drugs that contain hormones.

\subsection{Training arrangement}

Training cycle was one week, specifically, 11 large intensity trainings would be done in one week, i.e. large intensity training on Thursday and Friday, less intensity training on Monday, Wednesday and Saturday and agilely arranged training on Tuesday according to athletes' situation. One class lasts 2 hours, and the intensity was controlled by observational method and the Rating of Perceived Exertion (RPE) recommended by Borg (Borg, 1962; Borg and Linderholm, 1970).

\subsection{Sampling}

Blood sample was taken every two weeks, totally four times, and blood sample was taken at three time points, i.e. before training, just after training and the next day morning. Venous blood was taken at 7:00-8:00 am; athletes were hollow and just after intensity training. Blood serum and blood plasma were separated according to the guideline of kit, and kept at low temperature. RPE and anxiety investigation were done at the same time with blood sampling.

\subsection{Tested indexes}

\subsubsection{Recorded athletes' rating of perceived exertion using the RPE table recommended by Borg}

1.4.2 Investigated athletes' anxiety according to the sport anxiety questionnaire revised by Zhu, Peili, et al.

1.4.3 The method of ${ }^{125}$ I radioimmunoassay gamma counting was used to detect adrenocorticotrophic hormone (ACTH), cortisol (C), total testosterone (T), follicle stimulating hormone (FSH), luteinizing hormone (LH), and prolactin (PRL), the kit was provided by DPC (Tianjin) Co., Ltd., $\beta$-endorphin ( $\beta$-END) was provided by Department of Neurobiology, The Second Military Medical University. For ECTH, the coefficient of variation within a single assay was $8.1 \%$, and the 
coefficient of variation between assays was $9.0 \%$, for $\mathrm{C}$, they were $5.0 \%$ and $10.0 \%$ respectively, for $\mathrm{T}$, they were $5.9 \%$ and $6.4 \%$ respectively, for FSH, they were $7.0 \%$ and $9.6 \%$ respectively, for, $\mathrm{LH}$, they were $6.0 \%$ and $9.8 \%$ respectively, for PRL, they were $6.0 \%$ and $10.0 \%$ respectively, and for $\beta$-END, they were $7.8 \%$ and $9.6 \%$ respectively. Epinephrine (E) and norepinephrine (NE) were detected by high performance liquid chromatography (HPLC).

\subsection{Index classification and evaluation}

After analyzing the data, the endocrine indexes were classified into physical ability indexes and stress feature indexes. The various indexes during the training were detected and evaluated according to the classification standard.

\subsection{Statistical analysis}

The data was analyzed by cluster analysis, Pearson correlation analysis and repeated measurement variance analysis, if there are unequal variances, data will firstly be revised then analyzed, $\mathrm{P}<0.05$.

\section{Results}

\subsection{Index classification}

The data about the indexes, including T, T/C, LH, FSH, PRL, ACTH, $\beta$-END, NE, E and C, were aggregated into one cluster after nine times of aggregation. The indexes were classified into two kinds, i.e. the indexes relating to physical ability (T, T/C, LH, FSH, PRL) and the indexes relating to stress feature (ACTH, $\beta$-END, NE, E and C). Pearson correlation analysis was conducted in the two kinds of indexes, it was indicated that indexes relating to anabolism were LH and $\mathrm{T}$, and there was a significant difference between $\mathrm{T}$ and $\mathrm{T} / \mathrm{C}(\mathrm{P}<0.01)$. The average of correlated index of each index compared with other indexes was used to calculate the typical index; it was shown that T, T/C and LH could be used as typical indexes to analyze the physical ability. Using the same calculating method, it was indicated that there was significant correlation between $\mathrm{E}$ and $\mathrm{NE}, \mathrm{ACTH}(\mathrm{P}<0.01, \mathrm{P}<0.05), \mathrm{C}$ and $\mathrm{NE}(\mathrm{P}<0.05), \beta$-END and ACTH, RPE $(\mathrm{P}<0.01, \mathrm{P}<0.05)$, RPE and $\mathrm{C}(\mathrm{P}<0.05)$, further analysis revealed that $\mathrm{E}, \mathrm{NE}, \beta-\mathrm{END}, \mathrm{C}, \mathrm{ACTH}$ and RPE could be used as the indexes to analyze the physical and psychological stress.

\subsection{The test of various indexes during the intensity training}

\subsubsection{The variation of indexes relating to physical ability}

As shown in table 1 that, in the first sampling, there was no significant difference between the LH level before training and just after training $(\mathrm{P}>0.05)$, but the LH level in the next day morning was higher than that before training $(\mathrm{P}<0.05)$ and just after training $(\mathrm{P}<0.05)$, no significant variation was shown in other sampling point. Total testosterone before training and in the next day morning in the second sampling was significantly lower than that in the first sampling $(\mathrm{P}<0.01)$, but no difference was found in total testosterone level just after training $(\mathrm{P}>0.05)$. As the going of training, the testosterone level in the next day morning in the fourth sampling was significantly lower than that in the first sampling $(\mathrm{P}<0.05)$. The variation of $\mathrm{T} / \mathrm{C}$ was similar to testosterone, $\mathrm{T} / \mathrm{C}$ in the second sampling was significantly lower than that in the first sampling $(\mathrm{P}<0.01)$, but $\mathrm{T} / \mathrm{C}$ just after training showed no significant difference $(\mathrm{P}>0.05)$. $\mathrm{T} / \mathrm{C}$ in the fourth sampling was significantly lower than that in the first sampling $(\mathrm{P}<0.05)$. In the fourth sampling, PRL just after training was significantly higher than that before training $(\mathrm{P}<0.01)$.

\subsubsection{The variation of indexes relating to stress feature}

In the beginning of intensity training, adrenalin just after training was significantly higher than that before training $(\mathrm{P}<0.05)$, with the further going of intensity training, in the fourth sampling, the adrenalin just after training was significantly lower than that before training $(\mathrm{P}<0.05)$. ACTH concentration in the third sampling was higher than that in other samplings $(\mathrm{P}<0.01)$, but ACTH in the next day morning was low $(\mathrm{P}<0.05)$. In the third sampling, $\beta$-END just after training was significantly higher than that in the first sampling and the second sampling $(\mathrm{P}<0.01, \mathrm{P}<0.05)$. In the fourth sampling, cortisol level before training was significantly lower than that in the third sampling $(\mathrm{P}<0.05)$, and cortisol level just after training and in the morning were higher than that before training $(\mathrm{P}<0.01, \mathrm{P}<0.01)$ (Table 2$)$.

\subsubsection{The variation of psychological indexes}

As shown in table 3 that athletes' score of rating of perceived exertion just after training and in the next day morning was significantly higher than that before training $(\mathrm{P}<0.01, \mathrm{P}<0.01)$.

\section{Discussion}

\subsection{Classification of indexes}

In intensity training, the variation of multiple body functions is represented by the interaction of various factors; it is mechanical to try to reflect the interaction process of various factors with one way or one direction in the job of body function evaluation. As the subject and object of training, athletes are greatly stimulated physically and psychologically, especially in the training of judo. Judo is a sport that has strong counterwork, and has high demand on athletes' physical ability and psychological reaction. In order to meet the physical and psychological need, human body will mobilize its 
potential; hence the activity of endocrine system is very important. During the sports, the dynamic equilibrium of the material and energy requires the hormones that are involved in assimilation and dissimilation. Usually, assimilation hormones are of significance for the physical ability of body and stress hormones is good for the body in intensity sport. The level of hormones during the intensity training of female judoists, were analyzed, it was indicated that the hormones could be classified into two kinds, in the first kind, LH, T and T/C of Gonadotropin-gonadal axis were dominant in response, in the second kind, ACTH, C, E, $\beta$-END and NE were sensitive to intensity training. Hence, the above two kinds of index system were named as indexes relating to physical ability and indexes relating to stress, the two index systems were used in the evaluation of athletes' body function in intensity training.

\subsection{The variation of indexes relating to physical ability}

The synthesis of testosterone is regulated by LH, normally, LH binds to the receptor on the Leydig cell membrane and activates adenyl cyclase, the concentration of cAMP will be increased, and accordingly the protein kinases that are dependent on cAMP will be activated, in that way, cholesterin will be transformed into $20 \alpha$-hydroxyl-cholesterin, and the synthesis of progesterone will be increased, finally testosterone will be synthesized. The secretion of testosterone has day and night rhythm, usually the highest level is at 8:00 in the morning and the lowest level is at twelve at night, but it is also influenced by wake time (Zhang, et al., 1996). The variation of LH, T and T/C can basically represent the characteristic of intensity training, i.e. with the going of training, the level of indexes relating to synthesis metabolism decreased. As the hormone that regulate the synthesis and secretion of testosterone, LH changed significantly in the beginning of this study, but later, testosterone changed significantly.

It was put forward by Hackney et al. (Hackney, et al., 1997; Hackney, et al., 1988) that the great changes of PRL would decrease the level of testosterone, PRL might increase the concentration of testosterone by enhancing the synthesis activity of Leydig cell or increasing the concentration of cholesterin and activating the enzymes needed by testosterone synthesis, or large or excessive amount of PRL could antagonize the function of LH and FSH (Wheeler et al., 1991; Wheeler et al., 1984). But there are other factors that might affect the variation of the testosterone.

As far as the T/C concerned, Vervoorn et al. reported that the T/C value of 6 rowing athletes who were elected to take part in the Olympic Games in 1988 in intensity training was 5-50\% lower than the T/C value when they stayed still (Vervoorn et al., 1991). In normal training, T/C value is a little different from the situation mentioned above, i.e. T/C value is not lower than $0.35 \times 10^{-3}$ as reported by the previous scholars, but when they are working, $\mathrm{T} / \mathrm{C}$ value is always about $30 \%$ lower than $\mathrm{T} / \mathrm{C}$ value when they stay still. The variation indicates that the trainees haven't get back to normal, even they are not in the state of overtraining. But the scholars still think that the decrease of $\mathrm{T} / \mathrm{C}$ value in several months will eventually lead to overtraining of the body. At $4.0 \mathrm{mmol}$, lactic acid has no relevant relationship with the variation of hormones. Lutoslawska observed the testosterone and cortisol level of five excellent canoeing athletes in $19 \mathrm{~km}$ and $42 \mathrm{~km}$ race (Lutoslawska, 1991), it was shown that the race would increase the cortisol level, and the increase was dependent on the time of race, i.e. the cortisol level in the $42 \mathrm{~km}$ race was higher than that in the $19 \mathrm{~km}$ race. Later, they found that the testosterone level significantly decreased in both games, and there was no significant difference between the testosterone levels induced by the two games, but the decrease of T/C value in $42 \mathrm{~km}$ race was larger than that in 19 $\mathrm{km}$ race. 18 hours after the game, testosterone, cortisol and $\mathrm{T} / \mathrm{C}$ value could get back to normal level. It can be seen that the $\mathrm{T} / \mathrm{C}$ value of female judoists showed a trend of getting back, whether it was induced by training needs further discussion.

\subsection{The alteration of indexes relating to stress}

In the practical training, stress reaction and emergency reaction are of equal importance. Stress reaction mainly means the basic endurance of body to the damage and stimulation, emergency reaction mainly means the watchful ability of body to emergency. The latter has close relationship with $\mathrm{E}$ and NE, which are mainly secreted by adrenal medulla. In vivo, after binding to their receptor, $\mathrm{E}$ and $\mathrm{NE}$ will activate phosphorylase, accelerate the glycogenolysis and improve the blood sugar, which will be propitious to the oxidation of lactic acid and the gluconeogenesis in the muscle. Besides, in intensity training, the environment, training task and the antagonists will stimulate the athletes' to response to the stress and emergency, the sympathetic-adrenergic-system will be strongly activated. Hence, the E level just after training showed a trend of increase, with the progress of training, E level just after training showed a trend of decrease, maybe athletes' response was lessened after they were familiar with the training plan and the environment.

$\beta$-END and ACTH come from a common precursor, i.e. POMC, when in stress, $\beta$-END and ACTH will be released to the blood together. The END can get to the brain and act on the neurons that are involved in the cardiovascular activity and reduce the activity of sympathetic nerve and enhance the activity of heart pneumogastric nerve. Stress can lead to the secretion of anterior pituitary hormone, such as ACTH, PRL and $\beta$-END. Study has shown that intensity training will lead to the increase of $\beta$-END level (Farrell, 1985; Elias, et al., 1986). Endogenous opioid peptide and its ramifications can repress $\mathrm{LH}$ and FSH, while opioid peptide's antagonist can promote the secretion of gonadotropin-gonadal axis hormones, the above situation is reasonable at least for women. In this study, it was indicated that $\beta$-END and ACTH after training showed a trend of increase, and after rest, they showed a trend of getting 
back, it was obvious that the activity of gonadotropin-gonadal axis was influenced.

Buono et al. showed in their study on the response of hypothalamic-pituitary-gonadal axis to short time training that short time training could lead to the increase of ACTH and $\mathrm{C}$, and the increase of $\mathrm{C}$ level was caused by the enhancement of adrenal cortex's activity (Buono, 1986). As an important stress hormone, C plays an important role in the material metabolism in intensity training, $\mathrm{C}$ can promote the proteolysis of extrahepatic tissue, especially the muscle, and accelerate the gluconeogenesis in the liver; in addition, $\mathrm{C}$ can promote the fat metabolism and the gluconeogenesis using fatty acid, which will be propitious to the continuous progress of movement; $\mathrm{C}$ is one of the most important hormones that increase the blood sugar, it can active the enzymes that are involved in gluconeogenesis in the liver, antagonize the activity of insulin, reduce muscle and fat tissue's sensitivity to insulin, and reduce the utilization of glucose in the peripheral tissue, so that increase the level of blood sugar for muscle movement. Hence, when there is high concentration recycled $\mathrm{C}$, blood sugar will be of high level, and the large consumption of blood sugar will influence the behavior of $\mathrm{C}$. Tabata et al. investigated the function of low intensity continuous movement on the hormones of serum, trainees were on fasting for 12 hours, and pedaled with the $50 \%$ intensity of maximal oxygen intake before training, there was no significant change in the indexes mentioned above, no matter it was exhausted training, training for 3 hours or systematic training (7W, average energy consumption every day is 531 kcal, i.e. $230 \mathrm{~J}$ ) (Tabata , et al., 1990); but in the later stage of training, the level of ACTH and C decreased with the reduction of blood sugar (Terada, et al., 2004). In this study, the variation of ACTH and C was inconsistent, and the reasons for that need further investigation.

If normal testees take hydrocortisone and insulin orally, serum cortisol will sharply increase, and the testosterone will decrease, while the LH and FSH don't change, it is indicated that endogenous and extrinsic increase of cortisol level will quantificationally lead to the decrease of recycling testosterone (Cumming, et al., 1983). Glucocorticoid can restrict the function of testicle through hypothalamic-pituitary-gonadal axis, 95\% recycling testosterone comes from Leydig cell, glucocorticoid can restrict the activity of LH receptor of Leydig cell and accordingly restrict the secretion of testosterone (Wheeler, et al., 1994).

RPE is a simple and effective medical supervision method to evaluate the intensity of training; it is an index between physiology and psychology. In 1962, Borg firstly put forward the table of 21 point to determine the rating of perceived exertion, and in 1970, he put forward the table of 15 point to evaluate the variation of body function relating to intensity of training. The table was used to detect the RPE of healthy adults and trainees, accordingly got the relevant degree of physiological indexes and psychological indexes. After that, the table was widely used in swimming, running and patients (Borg and Linderholm, 1970). As a matter of fact, the psychological exhibition of RPE reflects the variation of physiological function, that is why the RPE indexes and physiological indexes are detected and analyzed at the same time; human has strong ability to sense the consumption of physical power, i.e. perceiving exertion. The sense of physical power will provide people with the information about the body's endurance degree and suffering degree for the intensity of training. In the beginning of sport, if the intensity of training is appropriate, even it is a little hard, sport will become a pleasant feeling. So psychologist, physiologist and doctor show great zest in studying the relationship between physical ability perceiving and intensity, and in studying the relationship between physical ability perceiving and the symptom of disease as well as body function of athletes. Basing on the situation mentioned above, many scholars think that the subjective feeling should be taken as a meaningful index, and be quantified, so that the method will be used by most people without regard to sex, age and race. Borg firstly put forward "rating of perceived exertion" according to the concept mentioned above.

\subsection{Further discussion}

As far as the evaluation of body function of athletes concerned, the variation of index should be consistent with the exterior representation of body function. However, judo is special compared with the other periodical sports item, it is difficult to evaluate the body function of judoists by achievement. Hence, we introduce some indexes, such as rating of perceived exertion, into the evaluation of body function, and we think that comprehensive evaluation is better than single index evaluation.

\section{References}

Borg G. (1962). Physical Performance and perceived exertion. [J]. Lund: Gleerup. 1-63.

Borg G and Linderholm H. (1970). Exercise performance and perceived exertion in patients with coronary insufficiency, arterial hypertension and vasoregulatory asthenia. [J]. Acta Med Scand. 187(1-2):17-26.

Buono MJ. Yeager JE and Hodgdon JA. (1986). Plasma adrenocorticotropin and cortisol responses to brief high-intensity exercise in humans [J]. J Appl Physiol. 61(4):1337-9.

Cumming DC. Quigley ME and Yen SS. (1983). Acute suppression of circulating testosterone levels by cortisol in men [J]. J Clin Endocrinol Metab, 57 (3):671-3. 
Elias AN. Iyer K. Pandian MR, et al. (1986). Beta-endorphin/beta-lipotropin release and gonadotropin secretion after acute exercise in normal males. [J]. J Appl Physiol. 61(6):2045-9.

Farrell PA. (1985). Exercise and endorphins--male responses [J]. Med Sci Sports Exerc. 17(1): 89-93.

Hackney AC. Fahrner CL and Stupnicki R. (1997). Reproductive hormonal responses to maximal exercise in endurance-trained men with low resting testosterone levels. [J]. Exp Clin Endocrinol Diabetes, 105 (5): 291-5.

Hackney AC. Sinning WE and Bruot BC. (1988). Reproductive hormonal profiles of endurance-trained and untrained males. [J]. Med Sci Sports Exerc. 20 (1): 60-5.

Lutoslawska G. Obminski Z. Krogulski A. et al. (1991). Plasma cortisol and testosterone following 19-km and 42-km kayak races [J]. J Sports Med Phys Fitness. 31(4): 538-42.

Tabata I. Atomi Y. Kanehisa H, et al. (1990). Effect of high-intensity endurance training on isokinetic muscle power[J]. Eur J Appl Physiol Occup Physiol. 60(4): 254-8.

Terada S. Tabata I and Higuchi M. (2004). Effect of high-intensity intermittent swimming training on fatty acid oxidation enzyme activity in rat skeletal muscle [J]. Jpn J Physiol. 54(1): 47-52.

Vervoorn C. Quist AM. Vermulst LJ. et al. (1991). The behaviour of the plasma free testosterone/cortisol ratio during a season of elite rowing training. [J]. Int J Sports Med, 12 (3): 257-63.

Wheeler G. Cumming D. Burnham R, et al. (1994). Testosterone, cortisol and catecholamine responses to exercise stress and autonomic dysreflexia in elite quadriplegic athletes. [J]. Paraplegia. 32(5): 292-9.

Wheeler GD. Singh M. Pierce WD. et al. (1991). Endurance training decreases serum testosterone levels in men without change in luteinizing hormone pulsatile release [J]. J Clin Endocrinol Metab. 72 (2): 422-5.

Wheeler GD. Wall SR. Belcastro AN. et al. (1984). Reduced serum testosterone and prolactin levels in male distance runners. [J]. JAMA. 252(4): 514-6.

Zhang, Jingru and Qiao, Jiantian. (1996). Physiology. The fourth edition. [M]. Beijing. People's Medical Publishing House. 370-413. 
Table 1. Variation of indexes relating to physical ability

\begin{tabular}{|c|c|c|c|c|c|}
\hline & $\mathrm{FSH}$ & $\mathrm{LH}$ & $\mathrm{T}$ & $\mathrm{T} / \mathrm{C}$ & PRL \\
\hline \multicolumn{6}{|l|}{ The first test } \\
\hline $\begin{array}{l}\text { Before } \\
\text { training }\end{array}$ & $40.89 \pm 8.93$ & $4.96 \pm 0.76$ & $0.32 \pm 0.08$ & $0.0025 \pm 0.0006$ & $11.54 \pm 4.02$ \\
\hline $\begin{array}{l}\text { Just after } \\
\text { training }\end{array}$ & $29.18 \pm 8.37$ & $5.16 \pm 0.54$ & $0.29 \pm 0.10$ & $0.0021 \pm 0.0007$ & $14.46 \pm 4.10$ \\
\hline $\begin{array}{c}\text { The next day } \\
\text { morning }\end{array}$ & $29.96 \pm 7.05$ & $5.95 \pm 0.86 \mathrm{ab}$ & $0.37 \pm 0.13$ & $0.0028 \pm 0.0010$ & $13.52 \pm 4.20$ \\
\hline \multicolumn{6}{|l|}{$\begin{array}{c}\text { The second } \\
\text { test }\end{array}$} \\
\hline $\begin{array}{l}\text { Before } \\
\text { training }\end{array}$ & $25.19 \pm 6.05$ & $4.09 \pm 0.86$ & $0.17 \pm 0.07 \mathrm{cc}$ & $0.0013 \pm 0.0005 \mathrm{c}$ & $9.65 \pm 4.54$ \\
\hline $\begin{array}{l}\text { Just after } \\
\text { training }\end{array}$ & $37.02 \pm 10.23$ & $3.79 \pm 0.76$ & $0.18 \pm 0.09$ & $0.0015 \pm 0.0009$ & $10.63 \pm 2.94$ \\
\hline $\begin{array}{c}\text { The next day } \\
\text { morning }\end{array}$ & $28.20 \pm 9.24$ & $3.98 \pm 0.77$ & $0.20 \pm 0.10 \mathrm{dd}$ & $0.0015 \pm 0.0008$ & $13.36 \pm 4.85$ \\
\hline \multicolumn{6}{|l|}{ The third test } \\
\hline $\begin{array}{l}\text { Before } \\
\text { training }\end{array}$ & $29.52 \pm 10.20$ & $4.73 \pm 0.79$ & $0.24 \pm 0.09$ & $0.0019 \pm 0.0008$ & $12.59 \pm 4.72$ \\
\hline $\begin{array}{l}\text { Just after } \\
\text { training }\end{array}$ & $29.16 \pm 5.93$ & $5.06 \pm 0.76$ & $0.18 \pm 0.07$ & $0.0014 \pm 0.0005$ & $12.89 \pm 4.65$ \\
\hline $\begin{array}{c}\text { The next day } \\
\text { morning }\end{array}$ & $30.79 \pm 6.70$ & $4.30 \pm 0.87$ & $0.28 \pm 0.11$ & $0.0022 \pm 0.0009$ & $12.09 \pm 4.20$ \\
\hline \multicolumn{6}{|l|}{ The fourth test } \\
\hline $\begin{array}{l}\text { Before } \\
\text { training }\end{array}$ & $37.87 \pm 10.18$ & $4.16 \pm 0.77$ & $0.23 \pm 0.06$ & $0.0020 \pm 0.0007$ & $8.62 \pm 3.03$ \\
\hline $\begin{array}{l}\text { Just after } \\
\text { training }\end{array}$ & $31.12 \pm 10.83$ & $4.58 \pm 0.93$ & $0.19 \pm 0.10$ & $0.0013 \pm 0.0008$ & $15.08 \pm 3.26 \mathrm{aa}$ \\
\hline $\begin{array}{c}\text { The next day } \\
\text { morning }\end{array}$ & $33.22 \pm 7.37$ & $4.54 \pm 0.59$ & $0.23 \pm 0.09 \mathrm{~d}$ & $0.0017 \pm 0.0007 \mathrm{~d}$ & $12.41 \pm 4.37$ \\
\hline
\end{tabular}
a: $\mathrm{P}<0.05$ aa: $\mathrm{P}<0.01$ compared with the situation before training
b: $\mathrm{P}<0.05$ bb: $\mathrm{P}<0.01$ compared with the situation just after training
c: $\mathrm{P}<0.05$ cc: $\mathrm{P}<0.01$ compared with the situation before training in the first sampling.
$\mathrm{d}: \mathrm{P}<0.05 \mathrm{dd}: \mathrm{P}<0.01$ compared with the situation of the next day morning in the first sampling. 
Table 2. Variation of indexes relating to stress feature

\begin{tabular}{|c|c|c|c|c|c|}
\hline & $\mathrm{E}$ & $\mathrm{NE}$ & $\mathrm{ACTH}$ & $\beta$-END & $\mathrm{C}$ \\
\hline \multicolumn{6}{|l|}{ The first test } \\
\hline $\begin{array}{l}\text { Before } \\
\text { training }\end{array}$ & $59.44 \pm 22.26$ & $271.55 \pm 126.62$ & $16.67 \pm 4.07$ & $6.01 \pm 3.31$ & $127.94 \pm 12.41$ \\
\hline $\begin{array}{l}\text { Just after } \\
\text { training }\end{array}$ & $107.89 \pm 28.23 \mathrm{aa}$ & $474.26 \pm 179.74$ & $17.94 \pm 4.82$ & $8.02 \pm 4.32$ & $141.24 \pm 7.92$ \\
\hline $\begin{array}{l}\text { Next day } \\
\text { morning }\end{array}$ & $64.79 \pm 15.28 b$ & $259.70 \pm 127.09$ & $18.14 \pm 4.32$ & $4.71 \pm 3.23$ & $134.01 \pm 13.14$ \\
\hline \multicolumn{6}{|l|}{$\begin{array}{c}\text { The second } \\
\text { test }\end{array}$} \\
\hline $\begin{array}{l}\text { Before } \\
\text { training }\end{array}$ & $71.15 \pm 21.31$ & $246.95 \pm 146.89$ & $17.89 \pm 4.63$ & $8.71 \pm 4.43$ & $128.47 \pm 12.01$ \\
\hline $\begin{array}{c}\text { Just after } \\
\text { training }\end{array}$ & $98.43 \pm 23.02$ & $375.42 \pm 148.22$ & $20.17 \pm 5.57$ & $10.17 \pm 3.83$ & $126.83 \pm 13.70$ \\
\hline $\begin{array}{l}\text { Next day } \\
\text { morning }\end{array}$ & $63.47 \pm 27.19$ & $271.45 \pm 167.74$ & $19.79 \pm 5.80$ & $8.76 \pm 3.09$ & $133.69 \pm 11.78$ \\
\hline \multicolumn{6}{|c|}{ The third test } \\
\hline $\begin{array}{l}\text { Before } \\
\text { training }\end{array}$ & $72.51 \pm 18.86$ & $311.70 \pm 136.74$ & $17.61 \pm 3.99$ & $7.81 \pm 4.52$ & $127.59 \pm 13.21$ \\
\hline $\begin{array}{l}\text { Just after } \\
\text { training }\end{array}$ & $85.72 \pm 21.12$ & $332.46 \pm 161.28$ & $26.27 \pm 4.60 \mathrm{acd}$ & $15.07 \pm 3.62 \mathrm{ccd}$ & $132.98 \pm 9.12$ \\
\hline $\begin{array}{l}\text { Next day } \\
\text { morning }\end{array}$ & $64.77 \pm 19.10$ & $333.15 \pm 137.67$ & $21.57 \pm 4.22 \mathrm{~b}$ & $9.24 \pm 3.71$ & $131.00 \pm 8.44$ \\
\hline \multicolumn{6}{|c|}{ The fourth test } \\
\hline $\begin{array}{l}\text { Before } \\
\text { training }\end{array}$ & $61.18 \pm 23.24$ & $297.30 \pm 124.43$ & $18.36 \pm 3.36$ & $9.93 \pm 4.56$ & $114.66 \pm 12.32$ \\
\hline $\begin{array}{c}\text { Just after } \\
\text { training }\end{array}$ & $80.30 \pm 20.54 c$ & $387.92 \pm 185.59$ & $19.58 \pm 4.87 \mathrm{e}$ & $12.28 \pm 3.95$ & $140.58 \pm 10.62 \mathrm{ae}$ \\
\hline $\begin{array}{l}\text { Next day } \\
\text { morning }\end{array}$ & $69.65 \pm 20.75$ & $196.25 \pm 122.64$ & $18.78 \pm 3.12$ & $9.06 \pm 4.33$ & $134.99 \pm 8.66 \mathrm{ab}$ \\
\hline
\end{tabular}

a: $\mathrm{P}<0.05$ aa: $\mathrm{P}<0.01$ compared with the situation before training

b: $\mathrm{P}<0.05$ bb: $\mathrm{P}<0.01$ compared with the situation just after training

c: $\mathrm{P}<0.05$ cc: $\mathrm{P}<0.01$ compared with the situation just after training in the first sampling

$\mathrm{d}: \mathrm{P}<0.05 \mathrm{dd}: \mathrm{P}<0.01$ compared with the situation just after training in the second sampling

e: $\mathrm{P}<0.05$ ee: $\mathrm{P}<0.01$ compared with the situation just after training in the third sampling 
Table 3. Variation of psychological indexes

\begin{tabular}{ccc}
\hline & RPE & ANX \\
\hline The first test & $6.00 \pm 0.00$ & $16.30 \pm 1.70$ \\
Before training & $12.00 \pm 1.41$ & $16.90 \pm 3.45$ \\
Just after training & $10.50 \pm 1.84 \mathrm{~b}$ & $16.20 \pm 1.75$ \\
Next day morning & & \\
The second test & $11.25 \pm 1.23$ & $14.90 \pm 1.79$ \\
Before training & $12.50 \pm 1.83$ & $14.60 \pm 1.43$ \\
Just after training & $11.00 \pm 0.94$ & $15.30 \pm 2.06$ \\
Next day morning & & \\
The third test & $10.00 \pm 1.05$ & $16.20 \pm 2.20$ \\
Before training & $12.00 \pm 3.25$ & $15.90 \pm 1.66$ \\
Just after training & $9.65 \pm 2.06$ & $16.30 \pm 1.89$ \\
Next day morning & & \\
The fourth test & $11.05 \pm 2.41$ & $15.80 \pm 2.49$ \\
Before training & $11.90 \pm 2.32$ & $16.30 \pm 2.67$ \\
Just after training & $11.20 \pm 1.48$ & $16.30 \pm 2.58$ \\
Next day morning & & \\
\hline
\end{tabular}

a: $\mathrm{P}<0.05$ aa: $\mathrm{P}<0.01$ compared with the situation before training

b: $\mathrm{P}<0.05$ bb: $\mathrm{P}<0.01$ compared with the situation just after training 
A journal archived in Library and Archives Canada

A journal indexed in CANADIANA (The National Bibliography)

A journal indexed in AMICUS

A leading journal in applied science research

A journal indexed in Zentralblatt MATH

\section{Modern Applied Science}

\section{Bimonthly}

Publisher Canadian Center of Seience and Education

Address 4915 Bathurst St. Unit \# 209-309. Toronto, ON. M2R IX9

Telephone 1-416-208-4027

Fax 1-416-208-4028

E-mail mas@ccsenet.org

Website www.cesenet.org

Printer William Printing Inc.

Price CAD.\$20.00

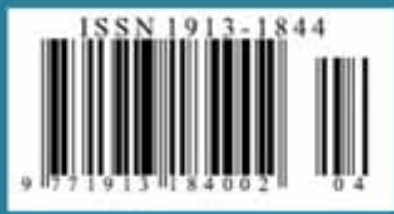

